MARCIA MIDORI TAKAHASHI

Avaliação do envelhecimento e rejuvenescimento de ligantes asfálticos 
MARCIA MIDORI TAKAHASHI

\section{Avaliação do envelhecimento e rejuvenescimento de ligantes} asfálticos

Versão Corrigida

Dissertação apresentada à Escola Politécnica da Universidade de São Paulo para obtenção do título de Mestre em Ciências. 
MARCIA MIDORI TAKAHASHI

\section{Avaliação do envelhecimento e rejuvenescimento de ligantes asfálticos}

Versão Corrigida

Dissertação apresentada à Escola Politécnica da Universidade de São Paulo para obtenção do título de Mestre em Ciências.

Área de Concentração:

Engenharia de Transportes

Orientadora:

Profa. Dra. Kamilla Vasconcelos Savasini

\section{São Paulo}


Autorizo a reprodução e divulgação total ou parcial deste trabalho, por qualquer meio convencional ou eletrônico, para fins de estudo e pesquisa, desde que citada a fonte.

Este exemplar foi revisado e corrigido em relação à versão original, sob responsabilidade única do autor e com a anuência de seu orientador.

São Paulo, de de

Assinatura do autor:

Assinatura do orientador:

\section{Catalogação-na-publicação}

Takahashi, Marcia Midori

Avaliação do envelhecimento e rejuvenescimento de ligantes asfálticos /

M. M. Takahashi -- versão corr. -- São Paulo, 2020.

$151 \mathrm{p}$.

Dissertação (Mestrado) - Escola Politécnica da Universidade de São Paulo. Departamento de Engenharia de Transportes.

1.Pavimentação asfáltica (reciclagem) 2.Asfalto 3.Reologia 4.Análise química 5.Agente rejuvenescedor I.Universidade de São Paulo. Escola Politécnica. Departamento de Engenharia de Transportes II.t. 
Dedico este trabalho aos meus pais,

Akiko e Yoshimitsu (in memorian) 


\section{AGRADECIMENTOS}

Em primeiro lugar, agradeço à Deus por todas as oportunidades e aprendizados que pude vivenciar, por me guiar, me proteger e me dar forças durante esta jornada.

Agradeço aos meus pais, Akiko e Yoshimitsu (in memorian), pelo amor, apoio, confiança e por sempre me proporcionar o melhor. À minha família, em especial aos meus irmãos, Yukio e Na, pelo apoio e por me incentivar a continuar sempre fazendo o meu melhor.

Agradeço à minha orientadora, professora Kamilla Vasconcelos, por ter me incentivado a fazer o mestrado e por ter me guiado por todo o desenvolvimento deste trabalho. Obrigada por todo apoio e carinho, principalmente nos momentos difíceis, pela paciência, confiança e incentivo nos meus momentos de indecisão, pela dedicação, por todos os ensinamentos compartilhados, pelo seu exemplo de pessoa e profissional que busca não somente o melhorpara todos ao seu redor como também se engaja em projetos e ações para uma sociedade e um mundo melhor para todos.

Agradeço também, à professora Liedi Bernucci, por todas as oportunidades que tive desde o início da minha iniciação científica, pela confiança, pelo incentivo para ingressar na pós-graduação e por todos os conselhos e en sin amentos compartilhados que, com certeza, contribuíram para o meu crescimento profissional e pessoal ao longo desses anos que convivemos no laboratório e na Poli.

À equipe querida do Laboratório de Tecnologia de Pavimentação (LTP-POLI-USP) com os quais sempre aprendi muito desde a iniciação científica: à professora Rosângela (Rô) por nos tratar de forma sempre tão carinhosa e por tudo que aprendi durante os projetos que trabalhamos juntas; à querida amiga Diomária (Dio) pelo carinho, amizade e por todo apoio, principalmente nos momentos mais difíceis; ao Edson por todos os ensinamentos passados de forma tão descontraída, pela ajuda imprescindível na ida ao trecho experimental e por sempre buscar nos proporcionar o melhor ambiente de trabalho; ao Robson pelo apoio e por sempre compartilhar suas experiências e conhecimentos; ao Erasmo pela amizade e gentileza com a qual sempre me ajudou durante os ensaios; ao Higor e ao Lucas por todo auxílio no laboratório; e ao Vanderlei (Vandi) pela amizade e apoio. 
À Petrobras pelo financiamento do projeto da Rede Temática de Asfalto no qual foram construídos os trechos experimentais. Agradeço também ao Centro de Pesquisas Leopoldo Américo Miguez de Mello (CENPES) pela realização dos ensaios químicos, especialmente à Dra. Margareth Cravo por viabilizar os ensaios e pela inestimável contribuição nas análises dos resultados.

À Profa. Leni Leite e a Dra. Margareth Cravo pela participação nas bancas de qualificação e defesa e por toda contribuição que deram para o desenvolvimento e aperfeiçoamento deste trabalho.

A todos os amigos do LTP pelo apoio, incentivo, ensinamentos e pelos bons momentos que compartilhamos, especialmente ao Kazuo, Matheus, Deise, luri, Zila, Talita, Rafael, Gabriel, Guilherme Pereira, Camila, Fernanda Carvalho, João Paulo, Guilherme Barbosa, Lucas, Paulo, Fernanda Gadler, Leidy, Laura, Marina, João Paulo Menezes, Gustavo, Raíssa, Júlia, André Rosa, José João, Caio, Andréia, Ingrid, Larissa, Cláudio, Patrícia e aos demais colegas que conheci durante esses anos no LTP.

Aos amigos da secretaria do PTR: Simone, Luciane, Edson e Patrícia, obrigada pelo apoio e por toda ajuda quando precisei.

Aos amigos da Associação Religiosa Oomoto do Brasil, em especial a família Fujimoto (minha segunda família), por sempre me apoiar e incentivar.

À CAPES pela bolsa de mestrado.

Um agradecimento especial às amigas Aline Lima, Pâmela Castro, Laura Fernández, Marylinda de França e Eliane Costa pela amizade, apoio e incentivo. Ao psicólogo Gustavo Crivello Cesar pela imensa contribuição no meu desenvolvimento pessoal durante o último ano, por me ouvir e me ajudar a entender os meus conflitos internos, a enfrentaras dificuldades e a superá-las. E também à coach Andrea Paixão da Costa, pelo carinho, incentivo e por compartilhar comigo seus conhecimentos, contribuindo muito para o meu desenvolvimento pessoal.

E a todos que, direta ou indiretamente, contribuíram para o desenvolvimento deste trabalho, assim como para o meu amadurecimento profissional e pessoal, muito obrigada! 
"Não importa o quão rápido você anda, mas a força de vontade para nunca parar" 


\section{RESUMO}

O envelhecimento e reju venescimento de dois ligantes asfálticos convencionais foram avaliados neste estudo. Os ligantes são provenientes de um trecho experimental construído com mistura asfáltica densa a quente, com $4 \mathrm{~cm}$ de espessura (para ambos os ligantes). Os ligantes foram extraídos e recuperados das amostras coletadas das seções do trecho experimental em diferentes tempos ( $T=0,12,24,36$ e 108 meses após a construção do pavimento). Em laboratório, os ligantes foram envelhecidos por meio dos en saios RTFOT, PAV 20h, PAV 60h e SUNTEST. Foram realizados ensaios reológicos de varredura de frequência e temperatura, bem como a análise dos parâmetros $G^{*} c, \omega_{c}, R$ e GR. Além disso, foram realizados os ensaios MSCR e LAS para avaliar a resistência à deformação permanente e à fadiga dos ligantes, respectivamente, nos diferentes níveis de envelhecimento e rejuvenescimento. Os ensaios de fracionamento SARA, GPC, FTIR e RMN foram realizados para avaliar as alterações químicas decorrentes do envelhecimento em laboratório e em campo. Os resultados mostraram que o envelhecimento pelo SUNTEST foi o mais severo, mostrando a importância da radiação UV no processo de degradação dos ligantes asfálticos. Além disso, o envelhecimento fotoquímico provocou reações químicas diferentes nos ligantes asfálticos quando comparado ao envelhecimento termo oxidativo, tendo impacto diferente nas frações químicas dos dois ligantes avaliados. Em campo, os ligantes continuaram envelhecendo ao longo do tempo, provocando alterações químicas e de desempenho nos ligantes asfálticos. A comparação entre os envelhecimentos em laboratório e em campo mostrou que o envelhecimento em campo (após 36 meses) foi mais severo que o ensaio PAV 20h, apresentando resultados mais próximos do PAV 60h, para ambos os ligantes. A utilização de AR a base de óleo vegetal de pinho, nos teores de $2 \%, 4 \%$ e $6 \%$, mostrou que o AR permite recuperar a maioria das propriedades do ligante envelhecido com teor de $4 \%$ de AR. No entanto, o rejuvenescimento segue uma tendência diferente do envelhecimento, mostrando que o AR atua de forma diferente sobre as propriedades viscoelásticas dos ligantes envelhecidos. Além disso, a avaliação da dosagem de AR com diferentes parâmetros mostrou que a dosagem apenas pelas propriedades viscoelásticas 
lineares do ligante asfáltico pode não ser suficiente para garantir o desempenho final das misturas recicladas.

Palavras-chave: Pavimentação asfáltica (reciclagem), Asfalto, Reologia, Análise química, Agente rejuvenescedor 


\begin{abstract}
The aging and rejuvenation of two neat asphalt binders were evaluated in this study. Both binders are from an experimental section that was built with dense hot asphalt mixtures of the two binders, with $4 \mathrm{~cm}$ thick. The binders were extracted and recovered from the samples collected from the experimental section sat different times $(T=0,12$, 24, 36 and 108 months after the pavement construction). In the laboratory, the virgin binders were aged using RTFOT, PAV 20h, PAV 60h and SUNTEST. Rheological frequency sweep tests were carried out, as well as the analysis of the parameters $\mathrm{G}^{*}$, $\omega_{c}, R$ and GR. In addition, MSCR and LAS tests were carried out to evaluated the resistance to permanent deformation and to fatigue, respectively, of both binders at different levels of aging and rejuvenation. The SARA fraction, GPC, FTIR and NMR tests were performed to evaluate the chemical changes resulting from laboratory and field aging. The results show that the SUNTEST aging was the most severe, showing the importance of UV radiation in the aging process of asphalt binders. In addition, photochemical aging causes different chemical reactions in the asphalt binders when compared to thermo oxidative aging, with different impact on chemical fractions of the two binders evaluated. In the field, binders continued to age over time, resulting in chemical and performance changes in asphalt binders. The comparison between laboratory and field aging showed that aging in the field (after 36 months) was more severe than the PAV 20h, and the results were closer to PAV 60h, for both binders. The use of pine-based rejuvenating agent with $2 \%, 4 \%$ and $6 \%$ content, showed that the AR allowed to recover most of the properties of the aged binders with $4 \%$ of $A R$. However, rejuvenation follows a different trend from aging, showing that AR acts differently on the viscoelastic properties of aged binders. In addition, the AR dosage evaluation using different parameters showed that the dosage only through binder's linear viscoelastic properties may not be sufficient to guarantee the final performance of the recycled mixtures.
\end{abstract}

Keywords: Asphalt pavement (recycling), Asphalt, Rheology, Chemical analysis, Rejuvenating agent 


\section{LISTA DE ILUSTRAÇÕES}

Figura 1 - Comparação dos custos de produção entre misturas asfáltica nova e mistura asfáltica reciclada a quente.

Figura 2 - Organização e etapas da dissertação

Figura 3 - Módulo de cisalhamento dinâmico e ângulo de fase a $25^{\circ} \mathrm{C}$ (a) PG 64-22 S e em (b) PG 70-22 S.

Figura 4 - Black espace dos ligantes envelhecidos por radiação UV.

Figura 5 - llustração dos parâmetros crossover modulus, crossover frequency e índice $\mathrm{R}$ do modelo $\mathrm{CA}$. 35

Figura 6 - Parâmetro $\Delta T c$ de ligantes asfálticos modificados em diferentes níveis de envelhecimento. 36

Figura 7 - Representação de possíveis tipos de reações em uma estrutura hipotética de ligante asfáltico durante o envelhecimento.

Figura 8 - Fracionamento desenvolvido por Corbett. .38

Figura 9 - Efeito do envelhecimento em análise de cromatografia TLC-FID 39

Figura 10 - Espectro de infravermelho de ligantes virgem e após envelhecimento em laboratório e em campo 40

Figura 11 - Curva GPC do ligante virgem e após envelhecimento TFOT .41

Figura 12 - Espectros de RMN obtidos para uma fração de asfaltenos. Em (a) RMN ${ }^{1} \mathrm{H}$ e (b) RMN ${ }^{13} \mathrm{C}$

Figura 13 - Molécula hipotética de asfalteno contendo os parâmetros moleculares obtidos por (a) RMN ${ }^{1} \mathrm{He}$ e (b) $\mathrm{RMN}{ }^{13} \mathrm{C}$.

Figura 14 - Imagens captadas pelo AFM do ligante CAP 30/45. Em (a) virgem e (b) envelhecido 
Figura 15 - Etapas de estudo do envelhecimento em laboratório

Figura 16 - Equipamentos utilizados na análise química. Em (a) SARA (latroscan MK3), em (b) GPC (Agilent 1200), em (c) RMN (INOVA 300) e em (d) FTIR-ATR (Nicolet Avatar 360). 50

Figura 17 - Curvas mestras do ligante CAP 50/70 envelhecido em laboratório, na temperatura de referência de $15^{\circ} \mathrm{C}$. Em (a) $\left|\mathrm{G}^{*}\right|$ e em (b) $\delta$. 52

Figura 18 - Curvas mestras do ligante CAP 30/45 envelhecido em laboratório, na temperatura de referência de $15^{\circ} \mathrm{C}$. Em (a) $\left|G^{*}\right|$ e em (b) $\delta$. 53

Figura 19 - Comparação do crossover frequency $\left(\omega_{c}\right)$ e do parâmetro $R$ para os ligantes envelhecidos em laboratório. 55

Figura 20 - Diagrama de Espaço Black dos ligantes nos diferentes níveis de envelhecimento em laboratório. Em (a) CAP 50/70 e em (b) CAP 30/45. 56

Figura 21 - Resultados de Jnr para cada ligantes nos diferentes níveis de envelhecimento em laboratório. Em (a) tensão de 100Pa e em (b) tensão de $3200 \mathrm{~Pa}$.

Figura 22 - Curvas característica de dano em (a) e curvas de fadiga em (b) para o CAP 50/70 envelhecido em laboratório 60

Figura 23 - Curvas característica de dano em (a) e curvas de fadiga em (b) para o CAP 30/45 envelhecido em laboratório 61

Figura 24 - Resultado fracionamento SARA para os ligantes envelhecidos em laboratório. Em (a) CAP 50/70 e em (b) CAP 30/45.

Figura 25 - Resultados ensaio GPC para os ligantes envelhecidos em laboratório. Em (a) CAP 50/70 e em (b) CAP 30/45. 64

Figura 26 - Índice de carbonila dos ligantes em diferentes níveis de envelhecimento em laboratório. 
Figura 27 - Resultados do ensaio RMN ara os ligantes envelhecidos em laboratório.

Figura 28 - Envelhecimento do ligante asfáltico durante a usinagem, estocagem, transporte e aplicação e vida de serviço do pavimento.

Figura 29 - Etapas de estudo do envelhecimento em campo

Figura 30 - Localização do trecho experimental. Em (a) localização do trecho na Estrada do Leite, em (b) localização dos segmentos e em (c) pavimento executado

Figura 31 - Extração dos corpos de prova dos revestimentos asfálticos. Em (a) processo de extração com perfuratriz, em (b) revestimento perfurado e em (c) amostra

Figura 32 - Curvas mestras de $\left|G^{*}\right|$ e $\delta$ dos ligantes envelhecido em campo. Em (a) CAP 50/70 e em (b) CAP 30/45.

Figura 33 - Curvas mestras de $\left|\mathrm{G}^{*}\right|$ e $\delta$ dos ligantes envelhecido em campo. Em (a) CAP 50/70 e em (b) CAP 30/45. 76

Figura 34 - Comparação do crossover frequency $\left(\omega_{c}\right)$ e do parâmetro $R$ para os ligantes envelhecidos em campo. 79

Figura 35 - Diagrama de Espaço Black dos ligantes nos diferentes níveis de envelhecimento em campo. Em (a) CAP 50/70 e em (b) CAP 30/45. 80

Figura 36 - Resultados de Jnr para cada ligantes nos diferentes níveis de envelhecimento em campo. Em (a) tensão de 100Pa e em (b) tensão de 3200 Pa. 82

Figura 37 - Curva característica de dano (a) e curva de fadiga (b) para o CAP 50/70 envelhecido em campo.

Figura 38 - Curva característica de dano (a) e curva de fadiga (b) para o CAP 30/45 envelhecido em campo. 
Figura 39 - Resultado fracionamento SARA dos ligantes envelhecidos em campo. Em (a) CAP 50/70 e em (b) CAP 30/45. 86

Figura 40 - Resultados en saio GPC dos ligantes envelhecidos em campo. Em (a) CAP 50/70 e em (b) CAP 30/45 88

Figura 41 - Índice de carbonila dos ligantes em diferentes níveis de envelhecimento .89

Figura 42 - Resultados do ensaio RMN 90

Figura 43 - Comparação das curvas mestras de $\left|G^{*}\right|$ e $\delta$ dos ligantes envelhecidoem campo e em laboratório. Em (a) CAP 50/70 e em (b) CAP 30/45. 92

Figura 44 - Comparação das curvas mestras de $\left|\mathrm{G}^{*}\right|$ e $\delta$ dos ligantes envelhecido em campo e em laboratório. Em (a) CAP 50/70 e em (b) CAP 30/45. 93

Figura 45 - Resultados de Jnr para cada ligante nos diferentes níveis de envelhecimento em campo e em laboratório. Em (a) tensão de 100Pa e em (b) ten são de $3200 \mathrm{~Pa}$. 95

Figura 46 - Diagrama de Espaço Black com dos ligantes envelhecidos em campo e em laboratório. Em (a) CAP 50/70 e em (b) CAP 30/45. 96

Figura 47 - Comparação da curva característica de dano (a) e da curva de fadiga (b) para o CAP 50/70 envelhecido em laboratório e em campo. .98

Figura 48 - Comparação da curva característica de dano (a) e da curva de fadiga (b) para o CAP 30/45 envelhecido em laboratório e em campo. 99

Figura 49 - Blending chart dos parâmetros reológicos em função do teor de AR. .114 Figura 50 - Teores máximos e mínimos de diferentes agentes rejuvenescedores.115 Figura 51 - Etapas de estudo do envelhecimen to em campo 116 
Figura 52 - Procedimento de incorporação de AR. Em (a) pesagem do ligante envelhecido, em (b) pesagem do AR, em (c) aparato para mistura e em (d) processo de mistura do ligante com o AR.

Figura 53 - Curvas mestras de $\left|\mathrm{G}^{*}\right|$ e $\delta$ dos ligantes envelhecidos e rejuvenescidos. Em (a) 50/70 e em (b) 30/45. 120

Figura 54 - Curvas mestras de $\left|G^{*}\right|$ e $\delta$ dos ligantes envelhecidos e rejuvenescidos. Em (a) 50/70 e em (b) 30/45 121

Figura 55 - Comparação do crossover frequency $(\omega c)$ e do parâmetro $R$ para os ligantes envelhecidos e rejuvenescidos. 123

Figura 56 - Diagrama de Espaço Black dos ligantes envelhecimentos e rejuvenescidos. Em (a) CAP 50/70 e em (b) CAP 30/45. 124

Figura 57 - Tendências observadas no Diagrama de Espaço Black dos ligantes envelhecimentos e rejuvenescidos. Em (a) CAP 50/70 e em (b) CAP 30/45. 125

Figura 58 - Resultados de Jnr para os ligantes envelhecidos e rejuvenescidos. Em (a) tensão de 100Pa e em (b) tensão de $3200 \mathrm{~Pa}$.

Figura 59 - Curva característica de dano (a) e curva de fadiga (b) do CAP 50/70 envelhecido e rejuvenescido.

Figura 60 - Curva característica de dano (a) e curva de fadiga (b) do CAP 30/45 envelhecido e rejuvenescido.

Figura 61 - Blending charts dos parâmetros avaliados para rejuvenescimento do CAP 50/70. Em (a) $\left|G^{*}\right| / \operatorname{sen} \delta$, em (b) $\left|G^{*}\right|$.sen $\delta$, em (c) $\left|G^{*}\right|-G R$, em (d) $\delta-G R$ e em (d) $\mathrm{Jnr}, 3200$

Figura 62 - Blending charts dos parâmetros avaliados para rejuvenescimento do CAP 30/45. Em (a) $\left|G^{*}\right| / \operatorname{sen} \delta$, em (b) $\left|G^{*}\right|$.sen $\delta$, em (c) $\omega_{c}$ e em (d) $\left|G^{*}\right|-G R$ e em (d) Jnr,3200. 


\section{LISTA DE TABELAS}

Tabela 1 - Métodos de envelhecimento de ligantes asfálticos

Tabela 2 - Crossover Modulus, Crossover Frequency e parâmetro R dos ligantes envelhecidos em laboratório.

Tabela 3 - Crossover modulus, crossover frequency e parâmetro $\mathrm{R}$ dos ligantes envelhecidos em campo.

Tabela 4 - Tipos de agentes rejuvenescedores 103

Tabela 5 - Agentes rejuvenescedores, métodos de dosagem e teores utilizados (continua). 104

Tabela 6 - Agentes rejuvenescedores, métodos de dosagem e teores utilizados (continuação 1). 105

Tabela 7 - Agentes rejuvenescedores, métodos de dosagem e teores utilizados (continuação 2). 106

Tabela 8 - Agentes rejuvenescedores, métodos de dosagem e teores utilizados (continuação 3).

Tabela 9 - Agentes rejuvenescedores, métodos de dosagem e teores utilizados (continuação 4). 108

Tabela 10 - Agentes rejuvenescedores, métodos de dosagem e teores utilizados (conclusão). 109

Tabela 11 - Ensaios de caracterização do ligante asfáltico envelhecido e rejuvenescido (continua).

Tabela 12 - Ensaios de caracterização do ligante asfáltico envelhecido e rejuvenescido (conclusão).

Tabela 13 - Crossover modulus, crossover frequency e parâmetro $R$ dos ligantes envelhecidos e rejuvenescidos. 


\section{LISTA DE ABREVIATURAS E SIGLAS}

\begin{tabular}{|c|c|}
\hline AASHTO & $\begin{array}{l}\text { American Association of State Highway and Transportation } \\
\text { Officials }\end{array}$ \\
\hline ABNT & Associação Brasileira de Normas Técnicas \\
\hline AFM & Atomic Force Microscopy - Microscópio de força atômica \\
\hline ANP & Agência Nacional do Petróleo \\
\hline AR & Agente Rejuvenescedor \\
\hline ASTM & American Society for Testing and Materials \\
\hline ATR & Attenuated Total Reflectance - Reflexão total atenuada \\
\hline BBR & Reômetro de Fluência em Viga \\
\hline CAP & Cimento Asfáltico de Petróleo \\
\hline Car & Carbono aromático \\
\hline $\mathrm{CM}$ & Curva Mestra \\
\hline CNT & Confederação Nacional do Transporte \\
\hline DMA & Dynamic Mechanical Analysis - Análise dinâmico-mecânica \\
\hline DSR & Dynamic Shear Rheometer - Reômetro de cisalhamento dinâmico \\
\hline FTIR & $\begin{array}{l}\text { Fourier Transform Infrared Spectroscopy - Espectroscopia no } \\
\text { infravermelho por transformada de Fourier }\end{array}$ \\
\hline GPC & $\begin{array}{l}\text { Gel Permeation Chromatography - Cromatografia de permeação } \\
\text { em gel }\end{array}$ \\
\hline GR & Glover-Rowe \\
\hline H-alfa & Hidrogênios na posição alfa \\
\hline Har & Hidrogênios aromáticos \\
\hline Ic & Índice de carbonila \\
\hline ISA & Índice de Substituição Aromática \\
\hline $\mathrm{Jnr}$ & Compliância não-recuperada \\
\hline
\end{tabular}




$\begin{array}{ll}\text { LAS } & \begin{array}{l}\text { Linear Amplitude Sweep - Varredura linear de amplitude de } \\ \text { deformação }\end{array} \\ \text { MSCR } & \begin{array}{l}\text { Multiple Stress Creep Recovery - Fluência e recuperação sob } \\ \text { tensão múltipla }\end{array} \\ \text { P.A. } & \text { Ponto de amolecimento } \\ \text { PAV } & \text { Pressure Aging Vessel - Vaso de pressão para envelhecimento de } \\ & \text { longo prazo } \\ \text { Pene } & \text { Penetração } \\ \text { PG } & \text { Performance Grade } \\ \text { PI } & \text { Penetration Index Índice de penetração } \\ \text { PVN } & \text { Pentration Vicosity Number- Número penetração viscosidade } \\ \text { R } & \text { R-value- Índice reológico } \\ \text { RAP } & \text { Reclaimed Asphalt Pavement- Revestimento Asfáltico Reutilizável } \\ \text { RMN } & \text { Ressonância Magnética Nuclear } \\ \text { RTFOT } & \begin{array}{l}\text { Rolling Thin Film Oven Test - Estufa de filme fino rotativo para } \\ \text { envelhecimento de curto prazo }\end{array} \\ \text { SARA } & \text { Saturados, Aromáticos, Resinas, Asfaltenos } \\ \text { SHRP } & \text { Strategic Highway Research Program } \\ \text { SUNTEST } & \text { Envelhecimento em laboratório por radiação ultravioleta } \\ \text { SUPERPAVE } & \text { Superior Performing Asphalt Pavements } \\ \text { TGA } & \text { Thermal Gravimetric Analysis - Análise Termogravimétrica } \\ \text { UV } & \text { Vistravioleta } \\ \text { Visc. } & \end{array}$




\section{SUMÁRIO}

1. INTRODUÇÃO

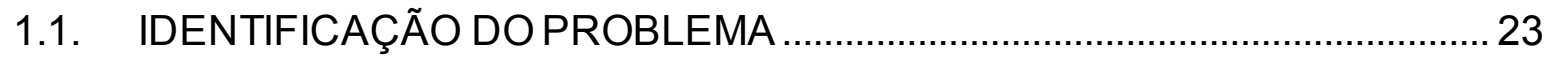

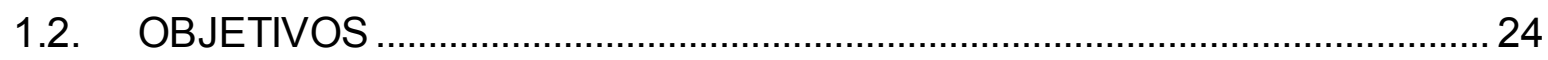

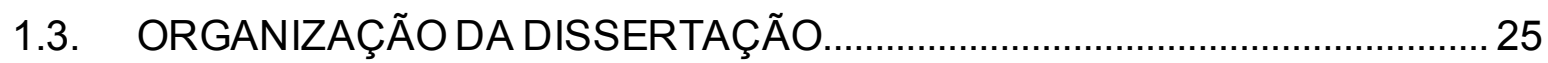

2. PARÂMETROS UTILIZADOS PARA A ANÁLISE DO ENVELHECIMENTO DE

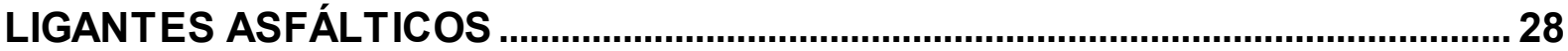

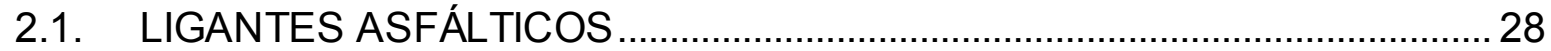

2.2. AVALIAÇÃO DO ENVELHECIMENTO DE LIGANTES ASFÁLTICOS .........29

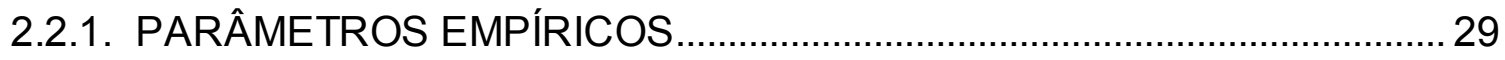

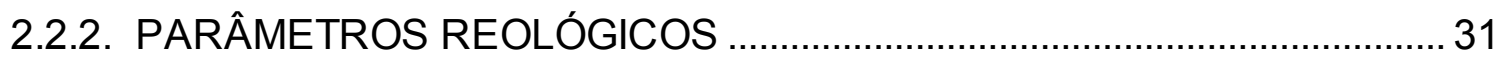

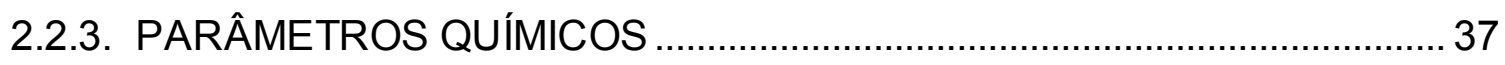

3. ENVELHECIMENTO DE LIGANTES ASFÁLTICOS EM LABORATÓRIO ....... 45

3.1. INTRODUÇÃO E REVISÃO BIBLIOGRÁFICA ….............................................. 45

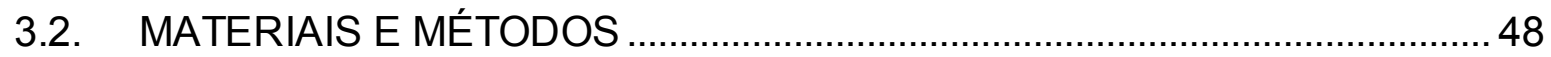

3.2.1. Envelhecimento em laboratório ............................................................... 48

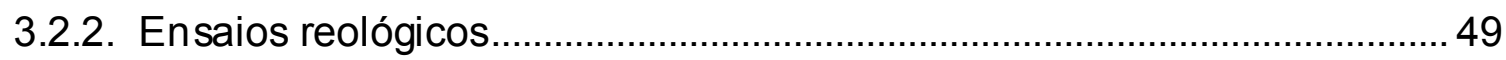

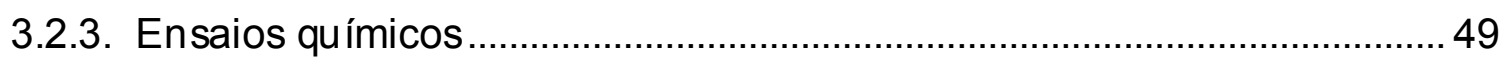

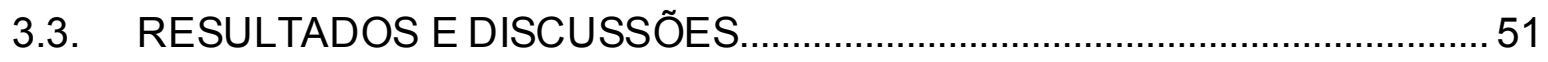

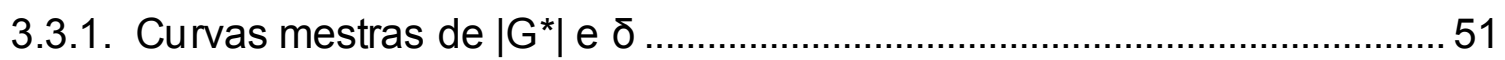

3.3.2. Crossover modulus $\left(G^{*}\right)$, crossover frequency $\left(\omega_{c}\right)$ e parâmetro $R$........55

3.3.3. Parâmetro Glover-Rowe (GR) ………………………………………...... 56

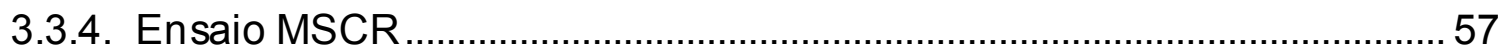

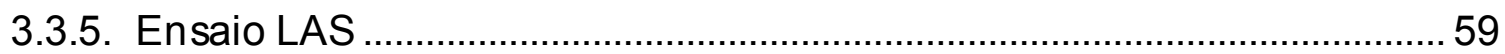

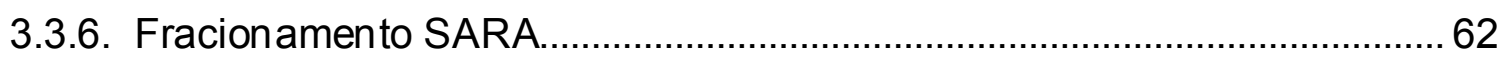

3.3.7. Distribuição do tamanho molecular (GPC) …………………………...... 64

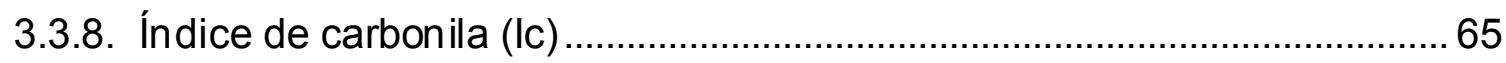

3.3.9. Ressonância Magnética Nuclear............................................................. 66

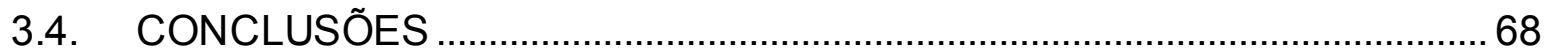

4. ENVELHECIMENTO DE LIGANTES ASFÁLTICOS EM CAMPO .......................70

4.1. INTRODUÇÃO E REVISÃO BIBLIOGRÁFICA...............................................70 
4.2. MATERIAIS E MÉTODOS ………………...............................................

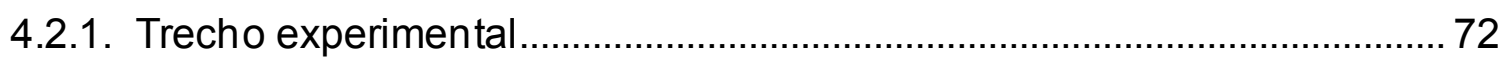

4.2.2. Ensaios reológicos e químicos ………………………………………........ 74

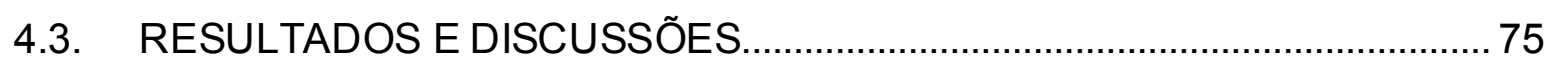

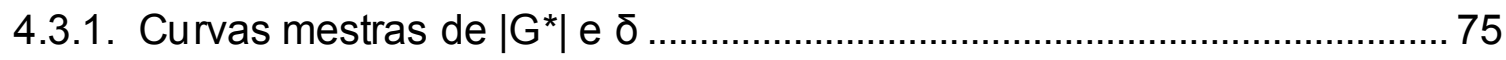

4.3.2. Crossover modulus $\left(G^{*}\right)$, crossover frequency $\left(\omega_{c}\right)$ e parâmetro $R$........78

4.3.3. Parâmetro Glover-Rowe (GR) ……………………………………..... 79

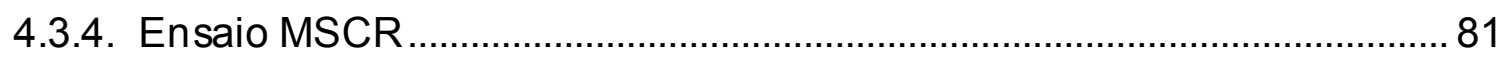

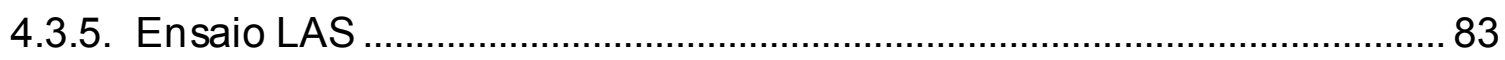

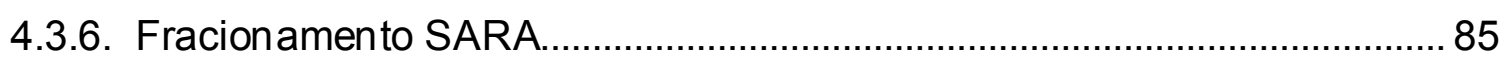

4.3.7. Distribuição do peso molecular (GPC) ………………………................ 87

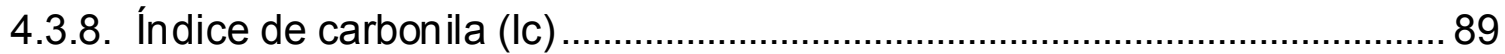

4.3.9. Ressonância Magnética Nuclear (RMN) .................................................... 89

4.4. COMPARAÇÃO DO ENVELHECIMENTO EM CAMPO E EM

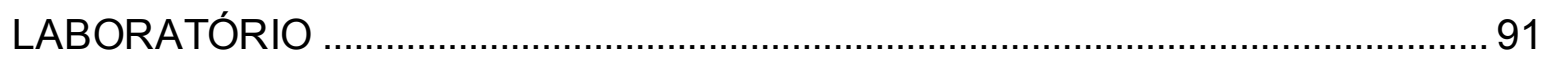

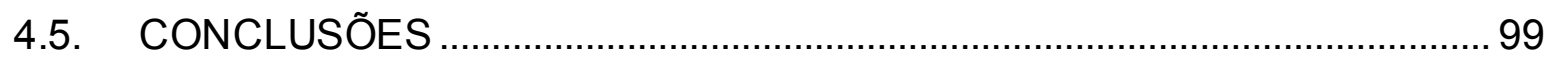

5. REJUVENESCIMENTO DE LIGANTES ASFÁLTICOS .....................................101

5.1. AGENTES REJUVENESCEDORES.......................................................102

5.1.1. Dosagem de agente rejuvenescedor.....................................................113

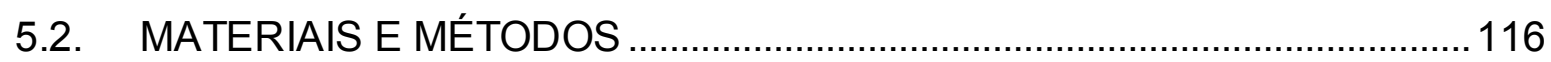

5.2.1. In corporação do agente rejuvenescedor...................................................117

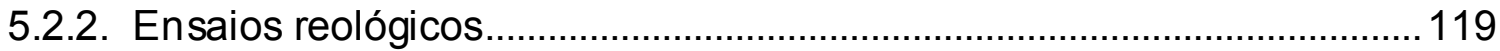

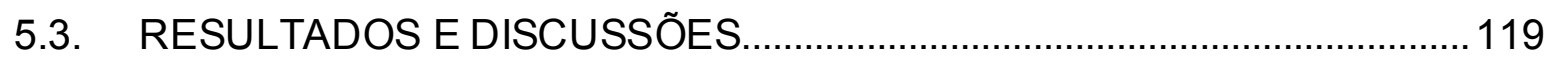

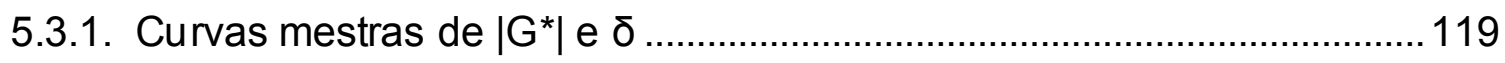

5.3.2. Crossover modulus $\left(G^{*}{ }^{*}\right)$, crossover frequency $\left(\omega_{c}\right)$ e parâmetro $R$......121

5.3.3. Parâmetro Glover-Rowe (GR) ………………………..........................123

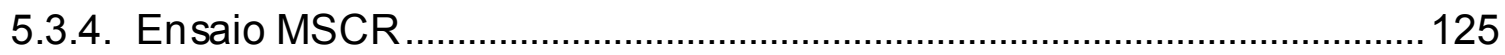

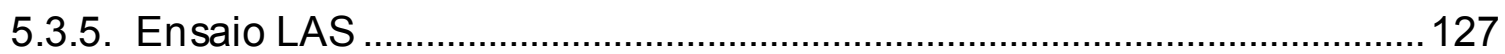

5.3.6. Avaliação da dosagem de AR ............................................................... 130

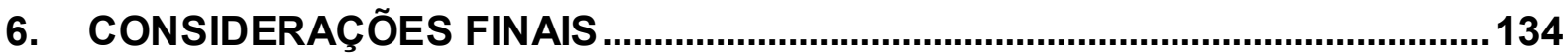

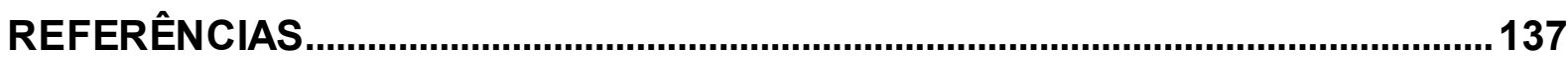




\section{INTRODUÇÃO}

Atualmente, a malha rodoviária brasileira possui cerda de $213.500 \mathrm{~km}$ de vias pavimentadas. No entanto, $59 \%$ das rodovias federais e estaduais avaliadas pela Pesquisa CNT de Rodovias apresentaram classificação regular, ruim ou péssima (CNT, 2019). Consideran do que o modo rodoviário é o principal meio de transporte no Brasil, sendo responsável por $61 \%$ do transporte de cargas e $95 \%$ do transporte de passageiros (CNT, 2019), a má qualidade das vias implica em maior custo aos usuários com a manutenção dos veículos, maior tempo de viagem $e$, consequentemente, maior consumo de combustível (BARTHOLOMEU; CAIXETA FILHO, 2008).

Com o passar dos anos, houve um gran de aumento do volume de tráfego nas estradas brasileiras assim como o aumento das cargas transportadas pelos caminhões, excedendo até $20 \%$ do limite por eixo (BOSSO et al., 2016). Isso aliado à falta de manutenção resultaram em grande número de pavimentos deteriorados (DAVID, 2006).

No Brasil, cerca de $95 \%$ das estradas brasileiras são pavimentadas com revestimento asfáltico (BERNUCCl et al., 2010). Segundo Airey (2003), os principais fatores que afetam a durabilidade dos pavimentos asfálticos, considerando que sua execução foi realizada de forma correta, são o enrijecimento pelo envelhecimento e o dano pela umidade. Os principais defeitos desses pavimentos são a deformação permanente, 0 trincamento por fadiga e o trincamento térmico (BERNUCCl et al., 2010; PIRES et al., 2017).

Quando um pavimento asfáltico se en contra deteriorado, há necessidade de restaurar as condições de trafegabilidade da via de modo a garantir segurança e conforto aos usuários. Essa restauração pode ser feita por meio de novas camadas sobre o pavimento, ou por meio do corte de todo ou parte do revestimento deteriorado e execução de nova camada de revestimento asfáltico (BERNUCCl et al., 2010). 
Devido à crise do petróleo nos anos 70 , viu-se necessária a busca por soluções técnicas que permitiam aproveitar os recursos de maneira mais racional e eficiente (ARRA, 2001; DAVID, 2006; AL-QADI et al., 2012). Dessa forma, nas últimas décadas, a reciclagem de pavimentos asfálticos vem sendo cada vez mais utilizada na manutenção e restauração de estradas devido aos ganhos ambientais e econômicos, como a redução do consumo de recursos naturais e energia, contribuindo para o desenvolvimento sustentável e preservação do meio ambiente (BROSSEAUD, 2011). Além disso, a reciclagem permite resolver o problema associado à disposição final dos resíduos dos pavimentos deteriorados (COSTA; PINTO, 2011; FREIRE et al., 2014). Segundo Chen et al. (2009), o material asfáltico reciclado dos pavimentos, ou RAP (do inglês, Reclaimed Asphalt Pavement), é um dos materiais mais reciclados no mundo.

Zaumanis et al. (2016) mostram uma comparação dos custos de produção por tonelada de mistura asfáltica virgem com a produção de misturas asfálticas recicladas com diferentes teores de RAP, entre $0 \%$ a $100 \%$ RAP (Figura 1). Dependendo da disponibilidade do RAP, os custos por tonelada de uma mistura $100 \%$ RAP podem reduzir entre 50 a $70 \%$ dos custos de uma mistura com materiais novos.

Figura 1 - Comparação dos custos de produção entre misturas asfáltica nova e mistura asfáltica reciclada a quente.

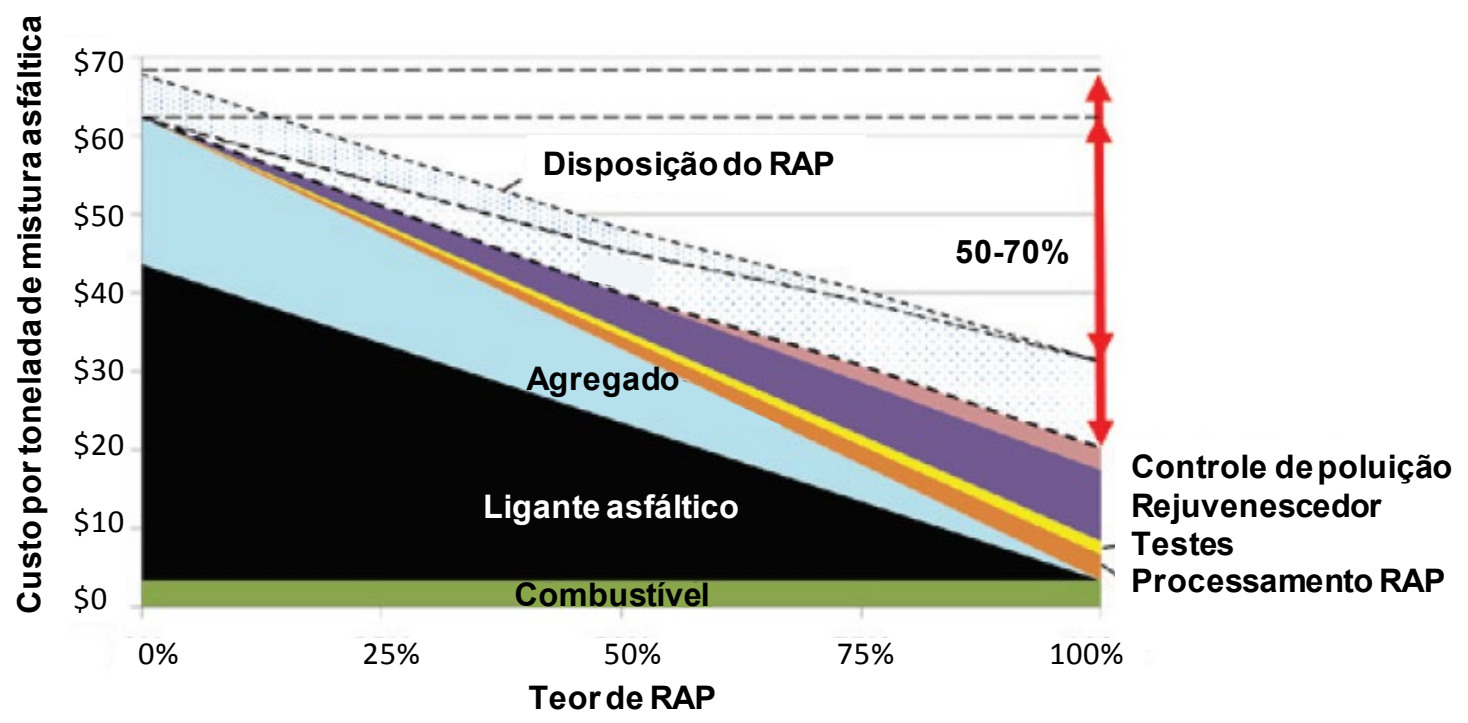

Fonte: Adaptado de Zaumanis et al. (2016) 


\subsection{IDENTIFICAÇÃO DO PROBLEMA}

No processo de reciclagem, o material asfáltico fresado dos pavimentos deteriorados é reutilizado na produção de novas misturas, reaproveitando os agregados e o ligante asfáltico do antigo revestimento, com adição ou não de agentes rejuvenescedores, espuma de asfalto, ligante asfáltico novo, ou aglomerantes hidráulicos para a fabricação da mistura reciclada (BERNUCCl et al., 2010).

No entanto, a inclusão de altas taxas de RAP levanta preocupações sobre o ligante que a mistura recebe do RAP devido ao seu grau de envelhecimento. Esse envelhecimento ocorre ao longo do tempo durante a usinagem, transporte, compactação e vida de serviço (LU; ISACSSON 2002; MASSON et al., 2006; GENNESSEAUX, 2015; DONDI et al., 2016). O envelhecimento do ligante asfáltico tem uma influência importante sobre a vida útil de um pavimento asfáltico, pois o ligante é o responsável pelo recobrimento dos agregados e coesão da mistura asfáltica dos revestimentos.

O envelhecimento torna o ligante mais rígido e quebradiço, resultando na perda de propriedades mecânicas e afetando a durabilidade do pavimento (QIN et al., 2014). O processo de envelhecimento do ligante é complexo, sendo influenciado pela origem do petróleo, pelo processo de produção do CAP, pelas condições de usinageme pelas condições ambientais durante a vida de serviço do pavimento (LU; ISACSSON, 2002; CRAVO, 2016). Devido à essas variáveis, pesquisadores continuam tentando desenvolver métodos de ensaios em laboratório que sejam representativos do envelhecimento que o ligante sofre, em campo, ao longo do tempo. No entanto, a maioria dos métodos já desenvolvidos consideram apenas o envelhecimento termo oxidativo. Segundo Silva et al. (2005), a radiação solar que incide no pavimento asfáltico provoca reações radicalares no ligante asfáltico, tornando a camada superficial do pavimento altamente oxidada.

A compreensão da influência do envelhecimento sobre as propriedades do ligante asfáltico se faz necessária para o correto emprego da técnica de reciclagem de pavimentos. A rigidez da mistura asfáltica reciclada com RAP depende do tipo de agregado, sua graduação e rigidez, e da quantidade de ligante asfáltico envelhecido 
contido no RAP, podendo apresentar baixo desempenho em relação a fadiga (ONGEL; HUGENER, 2015).

Atualmente, muitas pesquisas vêm sendo realizadas com a utilização de agentes rejuvenescedores (ARs) com o intuito de restaurar as propriedades do ligante envelhecido e, consequentemente, aumentar a taxa de incorporação de RAP nas misturas recicladas (ALI et al., 2016). Nessas diversas pesquisas, diferentes tipos de agentes rejuvenescedores vêm sendo testados, assim como diferentes métodos de dosagem de AR vêm sendo empregados.

Neste contexto, este trabalho visa avaliar o envelhecimento, em laboratório e em campo, de dois ligantes asfálticos convencionais, de forma a melhor compreender as alterações provocadas por esses processos, verificando se a simulação de laboratório representa o envelhecimento de campo e quais parâmetros permitem melhor análise do envelhecimento sofrido pelo ligante. $O$ trabalho pretende ainda avaliar 0 rejuvenescimento dos ligantes asfálticos envelhecidos, verificando métodos de dosagem de agentes rejuvenescedores e o efeito do mesmo no eventual processo de reciclagem a quente das misturas asfálticas.

\subsection{OBJETIVOS}

O objetivo geral desta dissertação de mestrado é avaliar o envelhecimento e o rejuvenescimento de ligantes asfálticos visando a melhor compreensão desses dois processos na técnica de reciclagem a quente de pavimentos asfálticos. O envelhecimento será avaliado em ligantes envelhecidos em laboratório e em campo, a partir de ensaios reológicos e químicos. O rejuvenescimento será avaliado em dois ligantes convencionais envelhecidos em laboratório, a partir de ensaio reológicos.

Os objetivos específicos da dissertação são:

- Avaliar o envelhecimento do ligante asfáltico em laboratório em diferentes níveis de envelhecimento termo oxidativo e por radiação UV, a partir da análise de parâmetros reológicos e químicos. 
- Avaliar o envelhecimento do ligante asfáltico em campo em diferentes tempos de envelhecimento, a partir da análise de parâmetros reológicos e químicos.

- Avaliar comparativamente os processos de envelhecimento em laboratório e em campo.

- Avaliar o processo de rejuvenescimento de ligantes asfálticos envelhecidos em laboratório.

- Avaliar dosagem de agente rejuvenescedor por diferentes parâmetros.

\subsection{ORGANIZAÇÃO DA DISSERTAÇÃO}

O trabalho é dividido em 6 capítulos, nos quais os capítulos 3, 4 e 5 foram escritos em formato de artigo, da seguinte forma:

Capítulo 1 apresenta a introdução geral, a identificação do problema, o objetivo geral e específicos e a organização da dissertação.

Capítulo 2 apresenta a revisão bibliográfica dos parâmetros utilizados para análise do envelhecimento de ligantes asfálticos de modo a fundamentar as escolhas das análises realizadas nos capítulos subsequentes.

Capítulo 3 apresenta o estudo do envelhecimento em laboratório a partir de processo termo oxidativo e radiação UV.

Capítulo 4 apresenta o estudo do envelhecimento em campo, comparando com os envelhecimentos de laboratório de modo a validar a simulação do envelhecimento em laboratório.

Capítulo 5 apresenta uma revisão bibliográfica sobre os agentes rejuvenescedores utilizados em diferentes estudos e apresenta o estudo do rejuvenescimento de dois ligantes asfálticos, avalian do o efeito de um agente rejuvenescedor nas propriedades dos ligantes envelhecidos em laboratório e fazendo uma avaliação do método de dosagem.

Capítulo 6 traz as considerações finais do trabalho e algumas sugestões para trabalhos futuros. 
A Figura 2 apresenta a organização e as etapas da dissertação 
Figura 2 - Organização e etapas da dissertação

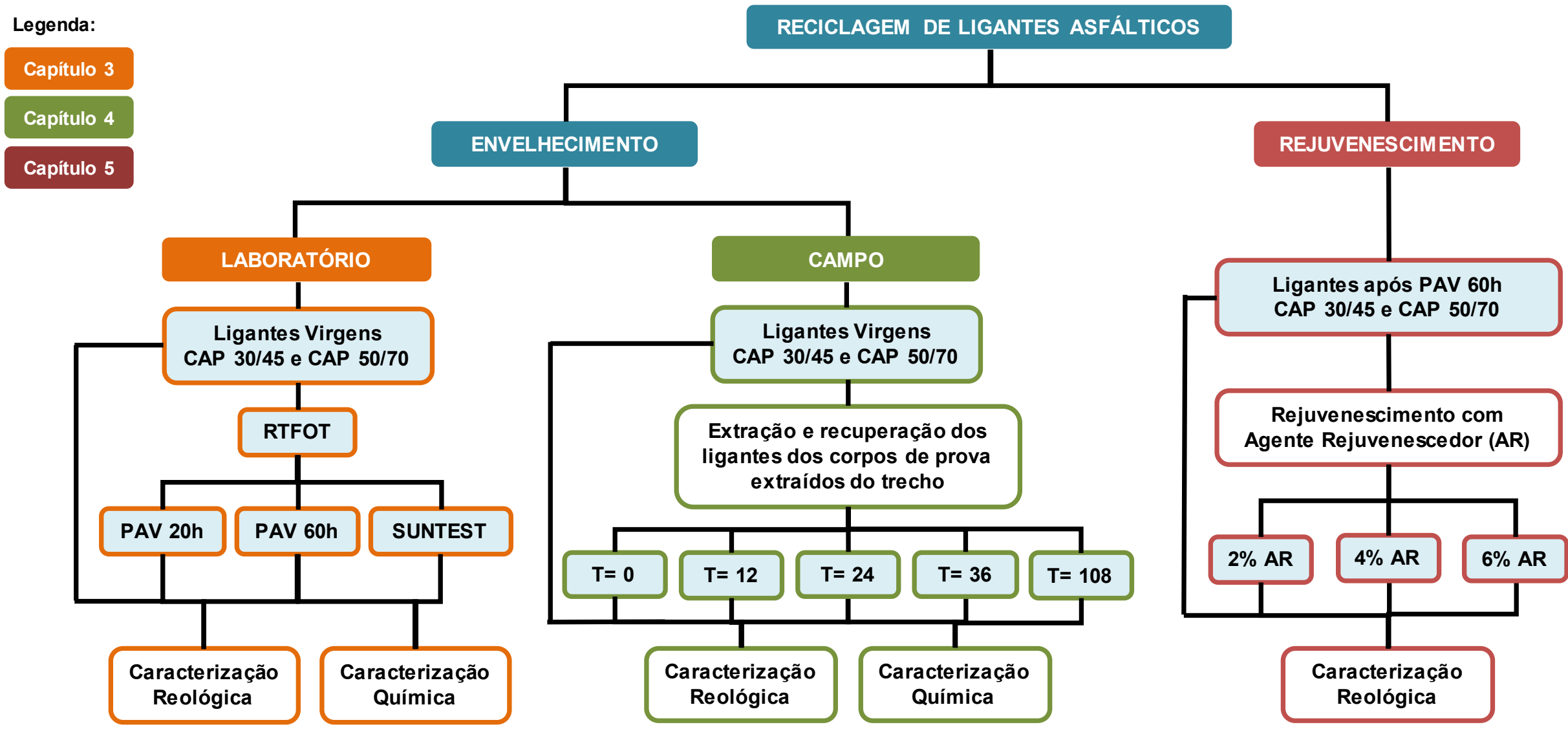

Fonte: Autora 


\section{PARÂMETROS UTILIZADOS PARA A ANÁLISE DO ENVELHECIMENTO DE LIGANTES ASFÁLTICOS}

\subsection{LIGANTES ASFÁLTICOS}

O ligante asfáltico, como é denominado o asfalto utilizado na pavimentação, provém do refino do petróleo e possui propriedades importantes que estimulam sua intensa utilização no setor rodoviário. Por ser um adesivo termoviscoelástico, ao ser aquecido a temperaturas superiores a $100^{\circ} \mathrm{C}$ torna-se um líquido viscoso, que permite recobrir os agregados proporcionando forte união entre eles. Além disso, o ligante permite flexibilidade ao pavimento, é impermeável à água e pouco reativo (USIRF, 2001; BERNUCCl et al., 2010).

A composição química dos ligantes asfálticos é bastante complexa, poden do variar de acordo com a origem e o processo de refin o do petróleo bruto (BERNUCClet al., 2010; CRAVO, 2016). Segundo Petersen (1984), a qualidade dos ligantes depende da origem do petróleo bruto, pois diferentes petróleos apresentam composições químicas diferentes. Dessa forma, pavimentos construídos com ligantes asfálticos que possuem a mesma classificação podem apresentar desempen ho e manuten ção diferentes.

O ligante é composto predominantemente por hidrocarbonetos, de 90 a $95 \%$, apresentando também de 5 a 10\% de heteroátomos (oxigênio, enxofre, nitrogênio)e metais (vanádio, níquel, ferro, alumínio, magnésio, cálcio e silício) (USIRF, 2001; HUNTER SELF; READ, 2015; BERNUCCl et al., 2010).

Os hidrocarbonetos presentes no ligante asfáltico apresentam estrutura molecular variada na forma de cadeias lineares com ramificações ou não, anéis simples ou complexos saturados ou insaturados (USIRF, 2001; BROWN et al., 2009). Segundo Petersen (1984), o tipo e a estrutura molecular são importantes para compreender como a composição afeta as propriedades físicas e a reatividade química do ligante. 


\subsection{AVALIAÇÃOdO ENVELHECIMENTO DE LIGANTES ASFÁLTICOS}

Durante o processo de usinagem e vida de serviço, o ligante asfáltico sofre envelhecimento especialmente sob altas temperaturas, luz solar, contato com o oxigênio, ou a combinação desses fatores. $O$ envelhecimento altera as propriedades do ligante asfáltico, causando perda de desempenho e reduzindo a durabilidade do pavimento (LU; ISACSSON, 2002; QIN et al., 2014; CRAVO, 2016).

Por ser um material orgânico, o ligante é oxidado na presença de oxigênio, formando compostos polares que ten dem a se associar em micelas, grupos de grande tamanho molecular (HUNTER SELF; READ, 2015). O envelhecimento é caracterizado pelo endurecimento do ligante, resultando no aumento da viscosidade e diminuição da penetração do material.

Cravo (2016) observou que ligantes obtidos por diferentes rotas de produção apresentam comportamento diferente quanto ao envelhecimento. Segunda a autora, o ligante produzido por destilação direta apresentou menor susceptibilidade ao processo de envelhecimento quando comparado a um ligante produzido pela diluição do resíduo da desasfaltação a propano (RASF) com gasóleo pesado.

\subsubsection{PARÂMETROS EMPÍRICOS}

Muitos autores utilizam os ensaios empíricos, presentes nas normas brasileira e européia de classificação dos ligantes asfálticos, para verificação do seu envelhecimento. Os parâmetros mais utilizados são a penetração, o ponto de amolecimento e a viscosidade.

A partir desses parâmetros foram criados os ín dices PI (Índice de penetração) e o PVN (Número penetração-viscosidade) que também permitem avaliar o nível de envelhecimento dos ligantes. O PI descreve a suscetibilidade térmica de um ligante asfáltico, variando de -3 , suscetível à temperatura alta, a +7 , suscetível a temperatura baixa (ZAUMANIS; MALLICK; FRANK, 2013; HUNTER SELF; READ, 2015). 
O PI pode ser calculado pelas eq.(1) e eq.(2). As temperaturas de 4 e $25{ }^{\circ} \mathrm{C}$ são sugeridas para o cálculo de $\mathrm{PI}$ como um indicador do desempenho da mistura asfáltica a baixa temperatura (ZAUMANIS; MALLICK; FRANK, 2015). Um material com baixo valor de $\mathrm{PI}$ é mais suscetível à variação de temperatura, quando alta, alterando sua consistência rapidamente (HESP; SHURVELL, 2010).

$$
\begin{gathered}
P I=\frac{20(1-25 * A)}{1+50 * A} \\
A=\frac{(\log P E N \text { em } T 1)-(\log P E N \text { em } T 2)}{T 1-T 2}
\end{gathered}
$$

Onde: $\quad$ T1 é a temperatura de ensaio $1\left(4{ }^{\circ} \mathrm{C}\right)$

T2 é a temperatura de ensaio $2\left(25^{\circ} \mathrm{C}\right)$

O índice PVN desenvolvido por McLeod, considera medidas de viscosidade a altas temperaturas, sendo uma alternativa ao PI (HESP; SHURVELL, 2010). O cálculo é realizado a partir da viscosidade medida a $135^{\circ} \mathrm{C}$ e da penetração a $25^{\circ} \mathrm{C}$, de acordo com as eq.(3) a eq.(5) (MCLEOD, 1976). Um valor elevado de PVN indica baixa suscetibilidade térmica (ZAUMANIS; MALLICK; FRANK, 2015).

$$
\begin{gathered}
P V N=\frac{\log L-\log X}{\log L-\log M} *(-1,5) \\
\log L=4,2580-0,79674 * \log P \\
\log M=3,46289-0,61094 * \log P
\end{gathered}
$$

Onde: $\quad \mathrm{X}$ é a viscosidade cinemática medida a $135{ }^{\circ} \mathrm{C}$, centistokes

$\mathrm{P}$ é a penetração a $25^{\circ} \mathrm{C}, 1 / 10 \mathrm{~mm}$

$L$ é a viscosidade a $135^{\circ} \mathrm{C}$ para um $P N V=0,0$ (cSt)

$M$ é a viscosidade a $135^{\circ} \mathrm{C}$ para um $\mathrm{PVN}=-1,5$ (cSt) 
Hesp e Shurvell (2010), observam que os índices PI e PVN correlacionam os problemas observados nos pavimentos com as características do ligantes asfáltico. Os resultados da pesquisa mostraram que os ligantes que apresentaram característica mais elástica (alto valor de $\mathrm{PI}$ e baixo valor de $\mathrm{PVN}$ ) foram significantemente mais propensos a trincas térmicas. Quando o ligante asfáltico envelhece, o valor de índice de penetração $(\mathrm{Pl})$ geralmente aumenta, indicando material menos capaz de fluir, ou seja, mais estruturado, quebradiço e mais propenso ao trincamento.

\subsubsection{PARÂMETROS REOLÓGICOS}

A especificação Superpave (Superior Performing Asphalt Pavements) do SHRP (Strategic Highway Research Program) contribuiu para melhor compreensão das propriedades dos ligantes asfálticos, uma vez que considera as propriedades viscoelásticas e realiza a classificação de acordo com o grau de desempenho do ligante, frente aos principais defeitos encontrados nos pavimentos asfálticos. Muitas pesquisas foram desenvolvidas utilizando equipamentos e ensaios propostos pela especificação, que também continuou sendo aprimorada ao longo dos últimos anos. Novos ensaios e critérios foram adicionados a especificação americana de forma a melhor caracterizar e classificar os ligantes asfálticos.

O envelhecimento do ligante é verificado a partir das mudanças nas propriedades viscoelásticas, módulo de cisalhamento dinâmico $\left(\left|G^{*}\right|\right)$ e ângulo de fase ( $\delta$ ), como no trabalho de Osmari et al. (2017) sobre o estudo do rejuvenescimento de ligantes asfálticos com diferentes agentes rejuvenescedores (Figura 3).

O valor do módulo de cisalhamento dinâmico aumenta com o nível de envelhecimento dos ligantes. Valores elevados de $\left|\mathrm{G}^{*}\right|$ são favoráveis para deformação permanente, no entanto são geralmente desfavoráveis para o desempenho quanto ao trincamento térmico (KIM, 2008). 
Figura 3 - Módulo de cisalhamento dinâmico e ângulo de fase a $25^{\circ} \mathrm{C}$ (a) PG 64-22 S e em (b) PG 70-22 S.
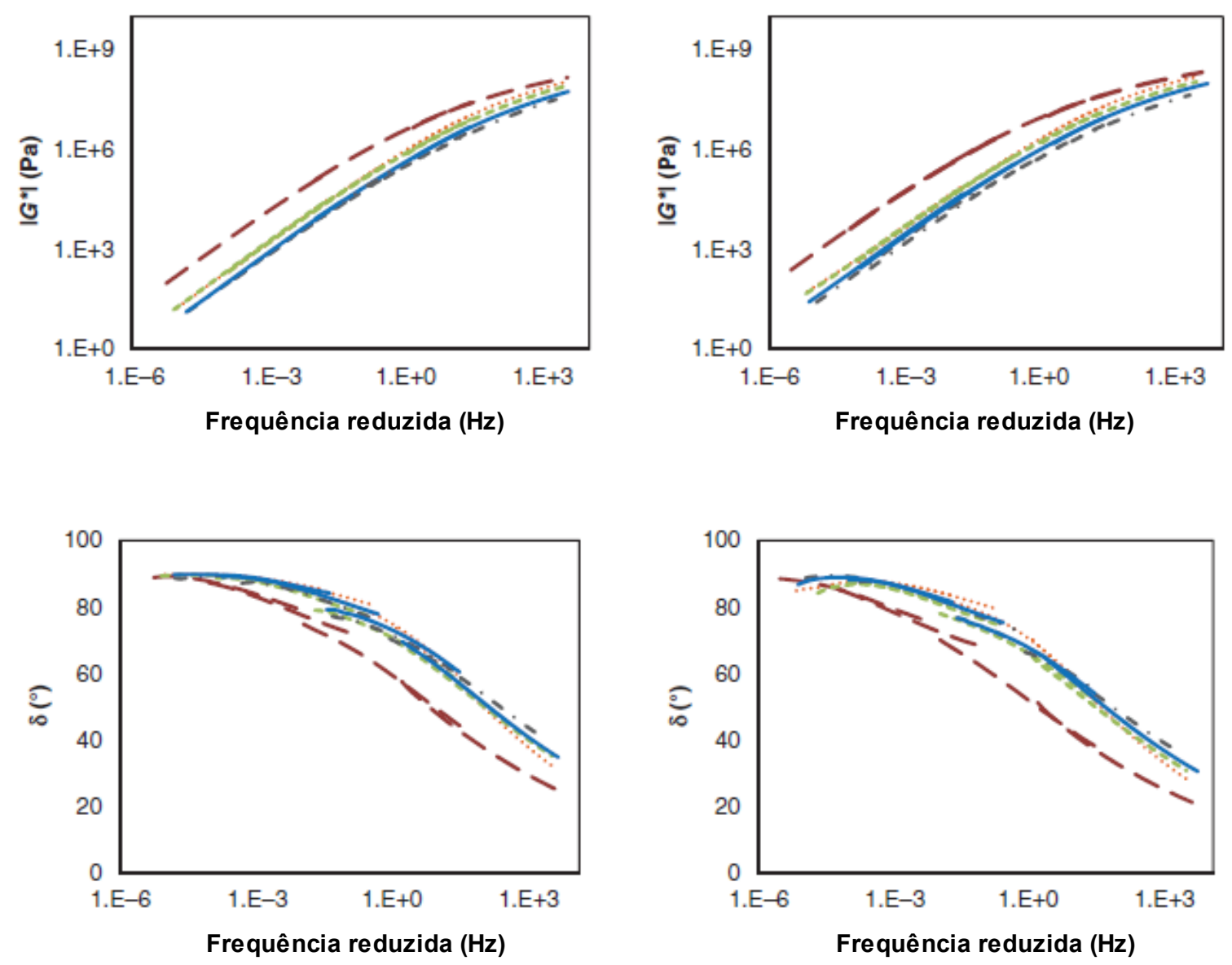

(a)

(b)

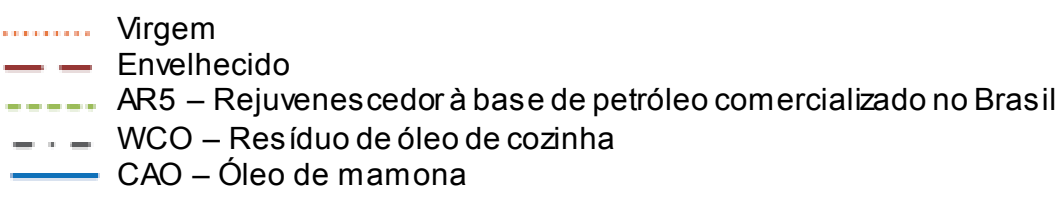

Fonte: Adaptado de Osmari et al. (2017)

A intensa utilização dos ensaios reológicos para caracterização de ligantes asfálticos levou ao estudo mais aprofundado dos resultados para tentar correlacioná-los com o desempenho do pavimento em campo. Nesta busca, alguns parâmetros foram desenvolvidos para avaliar o comportamento de ligantes asfálticos como, por 
exemplo: o parâmetro G-R (Glover-Rowe), o crossover modulus $\left(\mathrm{G}_{\mathrm{c}}\right)$, o crossover frequency, o índice $\mathrm{R}$ ( $R$-value) e o parâmetro $\Delta \mathrm{T}_{\mathrm{c}}$.

Rowe, King e Anderson (2014) descrevem o desenvolvimento do parâmetro GR, que inicialmente foi criado por Glover e adaptado por Rowe. Esse parâmetro, determinado a $15{ }^{\circ} \mathrm{C}$ e $0.005 \mathrm{rad} / \mathrm{s}$, representado no espaço de Black (Black Space), permite avaliar a resistência ao trincamento do ligante asfáltico. Quanto maior o valor do parâmetro GR mais susceptível ao trincamento o material está. Os limites propostos por Rowe (2016), a partir da relação da ductilidade do ligante com as rachadu ras nos pavimentos de aeroportos, indicam que um valor de $\mathrm{GR}=180 \mathrm{kPa}$ corresponde ao início da zona de dano, enquanto um valor de GR superior a $600 \mathrm{kPa}$, o pavimento está sujeito ao trincamento em bloco (LEITE et al., 2018).

A Figura 4 apresenta a região de dano de acordo com as eq.(6) e eq.(7), assim como o resultado de dois ligantes com diferentes níveis de envelhecimento por UV analisados por Leite et al. (2018). Os autores observam que o envelhecimento por radiação UV é severo o suficiente para, após 100 horas de envelhecimento, colocar o ligante dentro da região de dano sendo ele modificado ou não.

Figura 4 - Black espace dos ligantes envelhecidos por radiação UV.

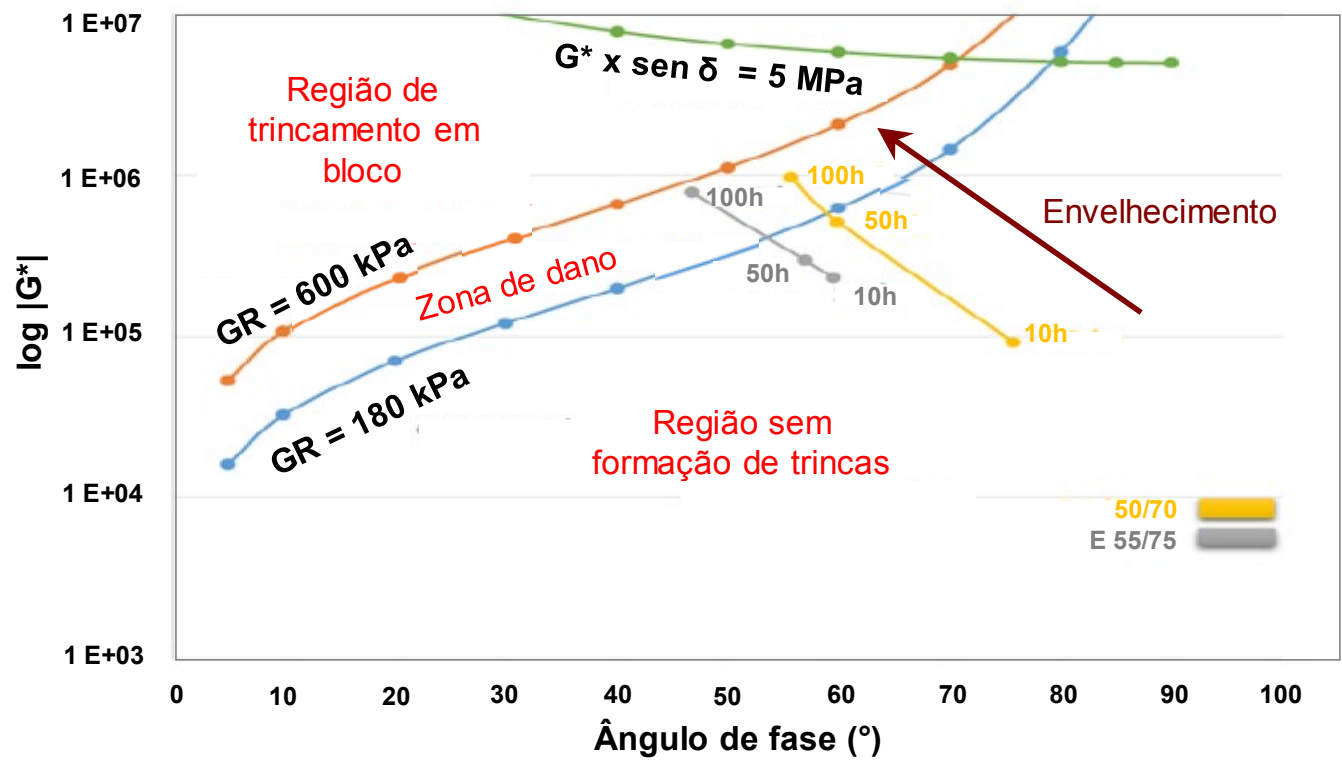

Fonte: Adaptado de Leite et al. (2018) 


$$
\begin{aligned}
& \left|G^{*}\right| * \frac{\cos \delta^{2}}{\operatorname{sen} \delta}=180 \mathrm{kPa} \\
& \left|G^{*}\right| * \frac{\cos \delta^{2}}{\operatorname{sen} \delta}=600 \mathrm{kPa}
\end{aligned}
$$

Onde: $\quad\left|G^{*}\right|$ é o módulo de cisalhamento dinâmico $\delta$ é o ângulo de fase

O crossover modulus $\left(\mathrm{G}_{c}\right)$ é valor do módulo de cisalhamento dinâmico no qual a curva mestra do módulo de armazenamento (G') e a curva mestra do módulo de perda ( $G$ ") se cruzam, assim como o crossover frequency $(\omega c)$ é a frequência na qual o ângulo de fase é igual a $45^{\circ}$, ou seja, $G^{\prime}=G$ " (GARCIA CUCALON et al., 2018). $O$ índice reológico, $\mathrm{R}$, descreve a forma e a assimetria do espectro de relaxação, sendo calculado a partir da diferença entre o glassy modulus e o crossover modulus. (CHRISTENSEN; ANDERSON; ROWE, 2017). Esses parâmetros fazem parte do modelo de Christensen-Anderson apresentado nas eq.(8) e eq.(9) (TURNER; TAYLOR; TRAN, 2015), conhecido por CA model e desenvolvido durante o programa SHRP. A Figura 5 ilustra os parâmetros do modelo.

$$
\begin{gathered}
\left|G^{*}(\omega)\right|=G_{g}\left[1+\left(\frac{\omega_{c}}{\omega_{r}}\right)^{\frac{\log 2}{R}}\right]^{\frac{-R}{\log 2}} \\
\delta\left(\omega_{r}\right)=\frac{90}{\left[1+\left(\frac{\omega}{\omega_{c}}\right)^{\frac{\log 2}{R}}\right]}
\end{gathered}
$$

Onde: $\quad\left|G^{*}(\omega)\right|$ é o módulo de cisalhamento dinâmico, $\mathrm{Pa}$

$\mathrm{Gg}$ é o Glassy Modulus, tipicamente $1 \mathrm{GPa}$

$\omega r$ é a frequência reduzida na temperatura de referência, $\mathrm{rad} / \mathrm{s}$

$\omega c$ é o crossover frequency na temperatura de referência, rad/s

$\mathrm{R}$ é índice reológico 
As mudanças reológicas provocadas pelo envelhecimento podem ser capturadas pelos parâmetros reológicos do modelo $\mathrm{CA}$. Considerando uma temperatura de referência To, o valor do índice reológico ( $R$-value) aumenta com o envelhecimento, o crossover frequency diminui, assim como o crossover modulus (FARRAR et al, 2013; GARCIA CUCALON et al., 2018).

Figura 5 - llustração dos parâmetros crossover modulus, crossover frequency e índice R do modelo CA

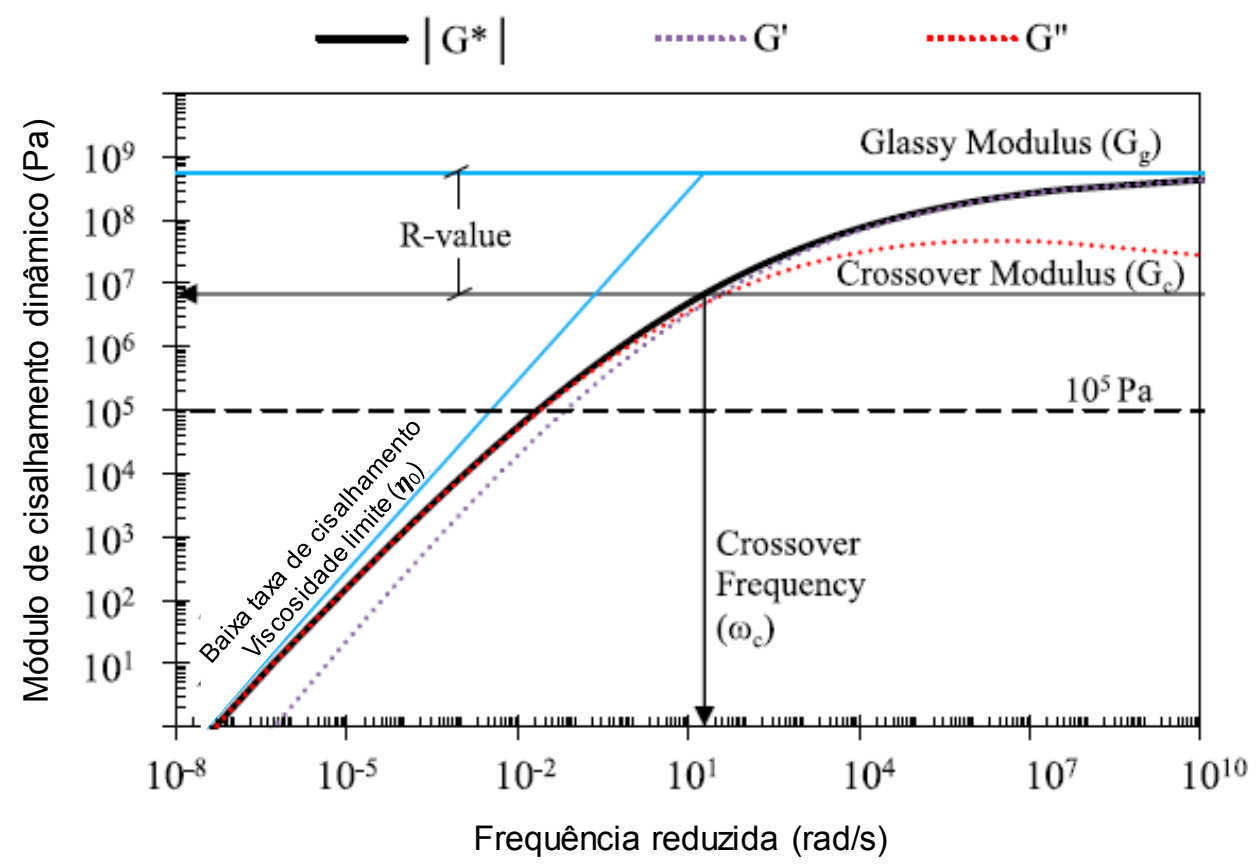

Fonte: Adaptado de Garcia Cucalon et al. (2018)

Nos últimos anos o parâmetro $\Delta T c$ foi proposto como um indicador da durabilidade e de resistência ao trincamento de ligantes asfálticos (Sadek et al., 2020). O parâmetro é calculado a partir da diferença entre as temperaturas baixas críticas (eq. 10) definidas de acordo com a norma ASTM D7643 após o ensaio no BBR (Bending Beam Rheometer). 


$$
\Delta T_{c}=T_{c, S}-T_{c, m}
$$

Onde: $\quad T_{c}, s e$ é temperatura baixa obtida pelo critério de creep stiffness

$\mathrm{T}_{\mathrm{c}, \mathrm{m}}$ é a temperatura baixa obtida pelo critério de creep slope

A Figura 6 apresenta os valores de $\Delta T c$ para os ligantes avaliados por Zhang et al. (2019). Os autores observaram que o valor positivo de $\Delta T c$ representa que o ligante asfáltico ainda apresenta boas propriedades de relaxamento com pequenas chances de rachaduras térmicas e que o aumento do envelhecimento reduz o valor de $\Delta T c$, indicando perda nas propriedades de relaxamento dos ligantes asfálticos. Este parâmetro serve como indicador para avaliar a resistência à fissuração não associados à carga, apesar da divergência entre as referências consultadas, o valor limite é apontado como $-2,5^{\circ} \mathrm{C}$ (ZHANG et al., 2019) e -5,0 ${ }^{\circ} \mathrm{C}$ (OZER et al., 2017; KARKI; ZHOU, 2019).

Figura 6 - Parâmetro $\Delta T c$ de ligantes asfálticos modificados em diferentes níveis de envelhecimento.

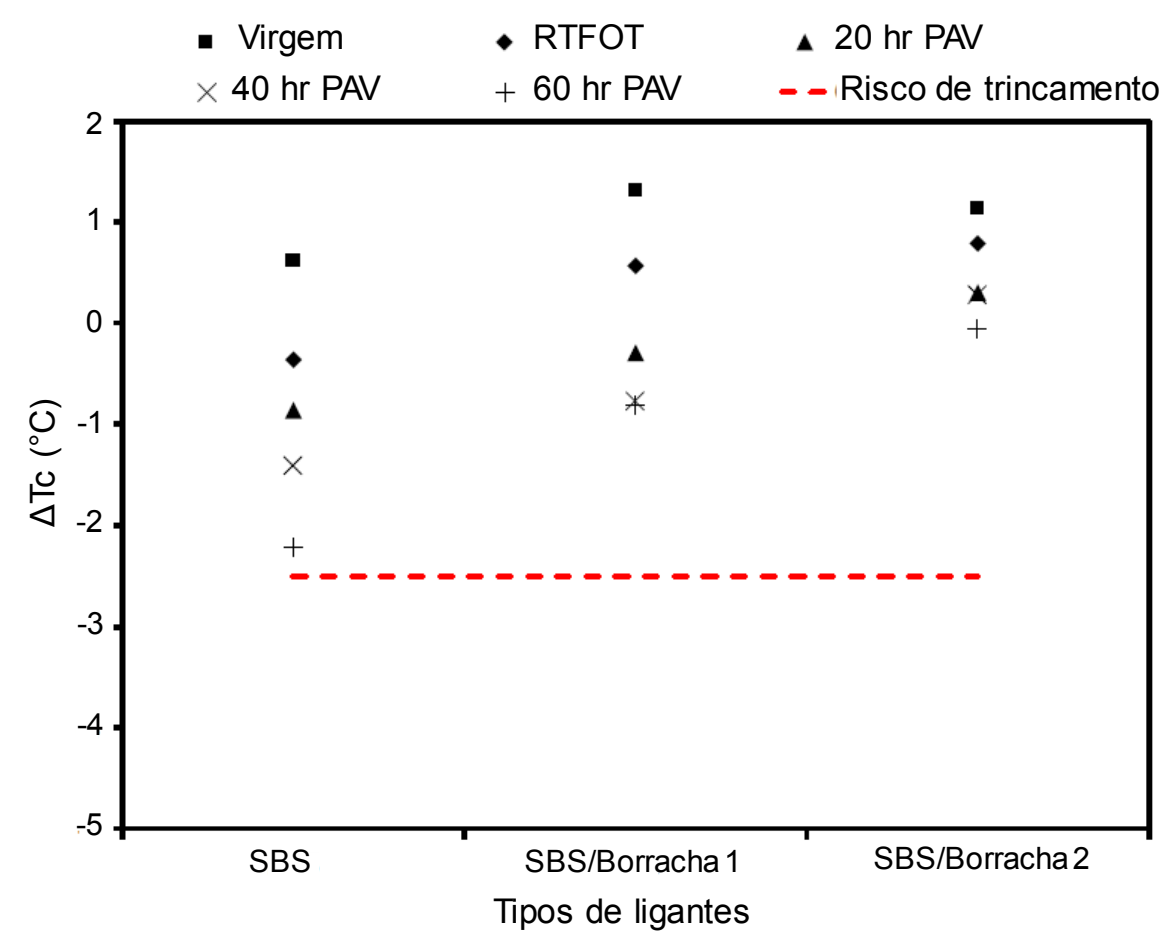

Fonte: Adaptado de Zhang et al. (2019) 


\subsubsection{PARÂMETROS QUÍMICOS}

A composição química do ligante asfáltico é bastante complexa e durante o envelhecimento podem ocorrer diversos tipos de reações químicas. Siddiqui e Ali (1999a) apresentam uma possível representação dos tipos de reações em uma estrutura hipotética de ligante asfáltico durante o processo de envelhecimento (Figura 7). A aromatização das estruturas durante o envelhecimento é caracterizada pela formação de anéis benzênicos, resultando no aumento da taxa de carbonos aromáticos (SIDDIQUI; ALI, 1999a; EL BEZE, 2008). Haley (1975) observou, em ligantes soprados, que as reações de radicais livres que ocorrem durante o sopro formam mais radicais livres em temperatura alta, resultando em maior reticulação interna, pesos moleculares mais baixos e uma estrutura química mais rígida.

Figura 7 - Representação de possíveis tipos de reações em uma estrutura hipotética de ligante asfáltico durante o envelhecimento.

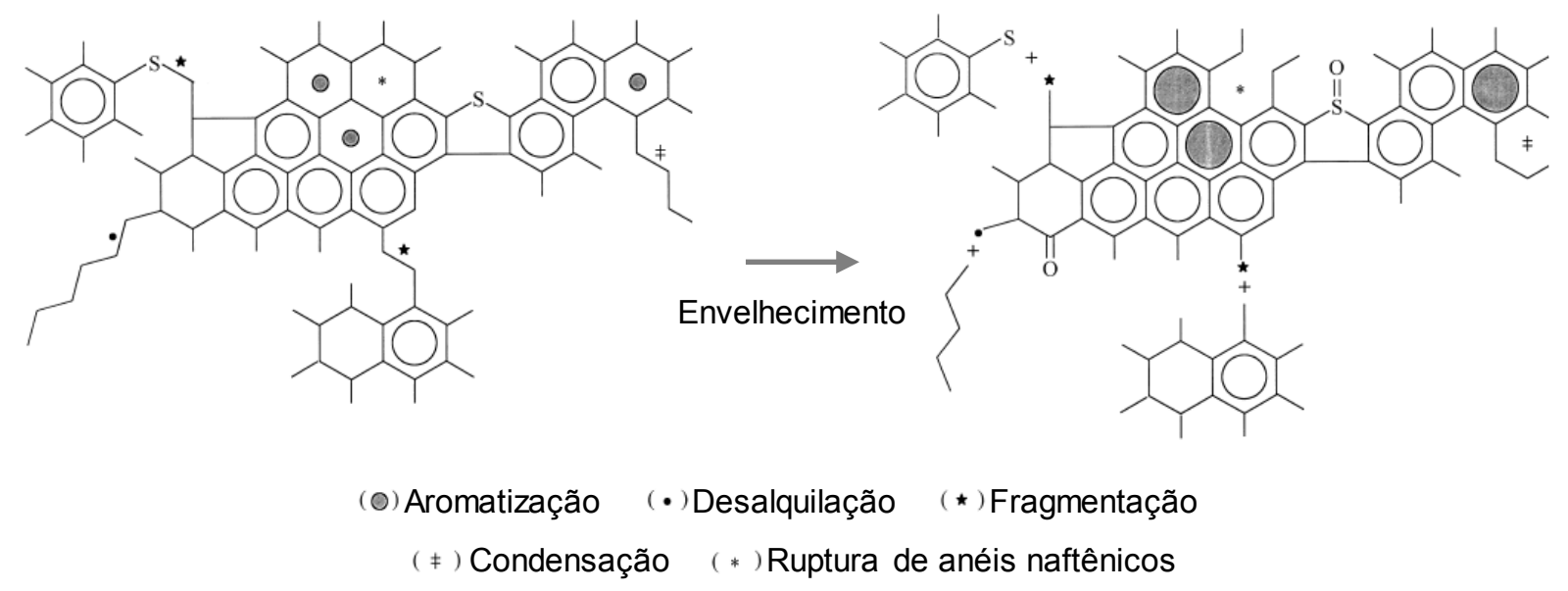

Fonte: Adaptado de Siddiqui e Ali (1999)

A presença de heteroátomos e sistemas de anéis aromáticos contribuem consideravelmente para a polaridade ou polarizabilidade das moléculas que produzem as principais forças associativas, afetando as propriedades físicas (PETERSEN, 1984). As configurações dos heteroátomos são chamadas de grupos funcionais ou polares (BROWN et al., 2009). Dessa forma, para caracterizar os 
diversos constituintes do ligante asfáltico, o químico Corbett elaborou o método de fracionamento do ligante em quatro frações de acordo com a diferença de solubilidade e polaridade (Figura 8), sendo elas: saturados, aromáticos, resinas e asfaltenos, conhecidas por fracionamento SARA (CRAVO, 2016).

Figura 8 - Fracionamento desenvolvido por Corbett.

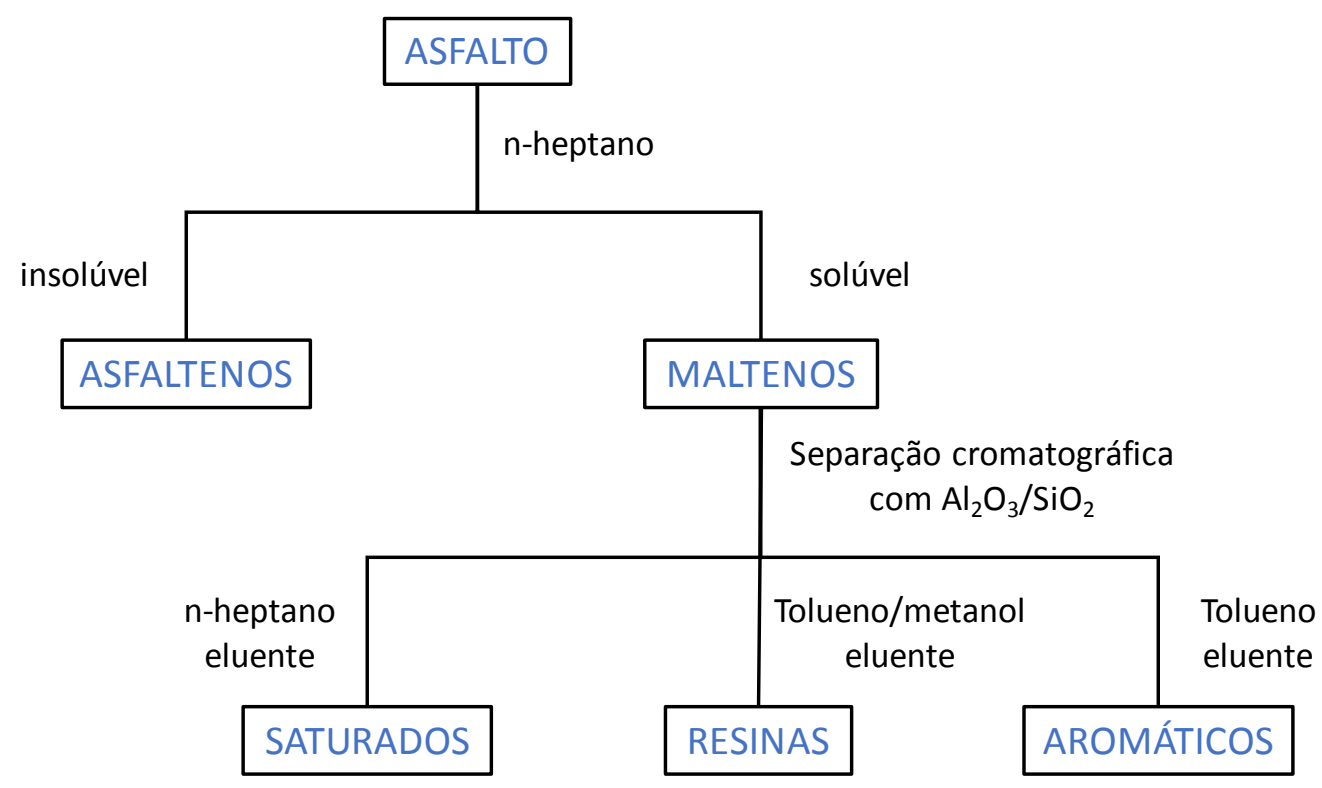

Fonte: Adaptado de Cravo (2016).

Atualmente, diversas técnicas vêm sendo empregadas para avaliar as mudanças químicas que ocorrem durante o processo de envelhecimento dos ligantes asfálticos, visando compreen der melhoras mudanças cau sadas pela oxidação do ligante e como essas mudanças alteram o desempenho dos mesmos nas misturas asfálticas. $O$ fracionamento SARAé um dos métodos bastante utilizados para avaliar as mudanças químicas nos ligantes asfálticos após o envelhecimento. Além do processo de fracionamento físico a partir de solubilização e filtragem da amostra, existe a possibilidade de realizar o fracionamento a partir da técnica de cromatografia em camada delgada com detecção por ionização de chama (TLC-FID). Lu e Isacsson (2002) utilizaram a técnica para avaliar o efeito do envelhecimento em laboratório (Figura 9). Os autores observam que o envelhecimento diminui a quantidade de 
aromáticos, aumentando as resinas e os asfaltenos, sendo observada pequena variação dos saturados devido a sua natureza inerte ao oxigênio.

Figura 9 - Efeito do envelhecimento em análise de cromatografia TLC-FID

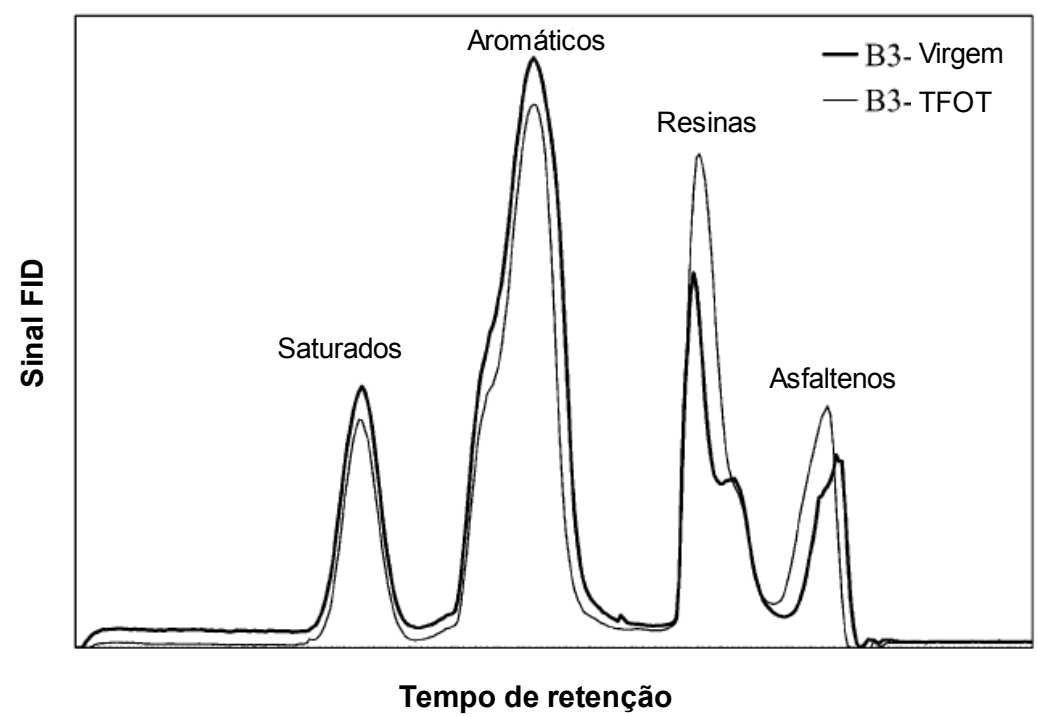

Fonte: Adaptado de Lu; Isacsson (2002)

Muitos pesquisadores utilizam a técnica de espectroscopia por Infravermelho com Transformada de Fourier (FTIR) para verificar transformações após o envelhecimento. A oxidação do ligante asfáltico produz compostos de carbonila, principalmente pela oxidação de compostos aromáticos em aromáticos naftênicos e asfaltenos (GLOVER et al., 2005). Lin et al. (1995) observaram o aumento da rigidez e da viscosidade do ligante asfáltico com o aumento do teor de asfaltenos decorrente da formação de compostos carbonados durante o processo de oxidação.

Qin et al. (2014) analisaram as mudanças na composição química através da técnica FTIR. A Figura 10 apresenta os espectros dos ligantes virgem, após o envelhecimento de laboratório e após o envelhecimento de campo, com detalhe para os grupos de carbonila e sulfóxidos, que tendem a aumentar após o envelhecimento (LU; ISACSSON, 2002; AGUIAR-MOYA et al., 2017). 
Figura 10 - Espectro de infravermelho de ligantes virgem e após envelhecimento em laboratório e em campo

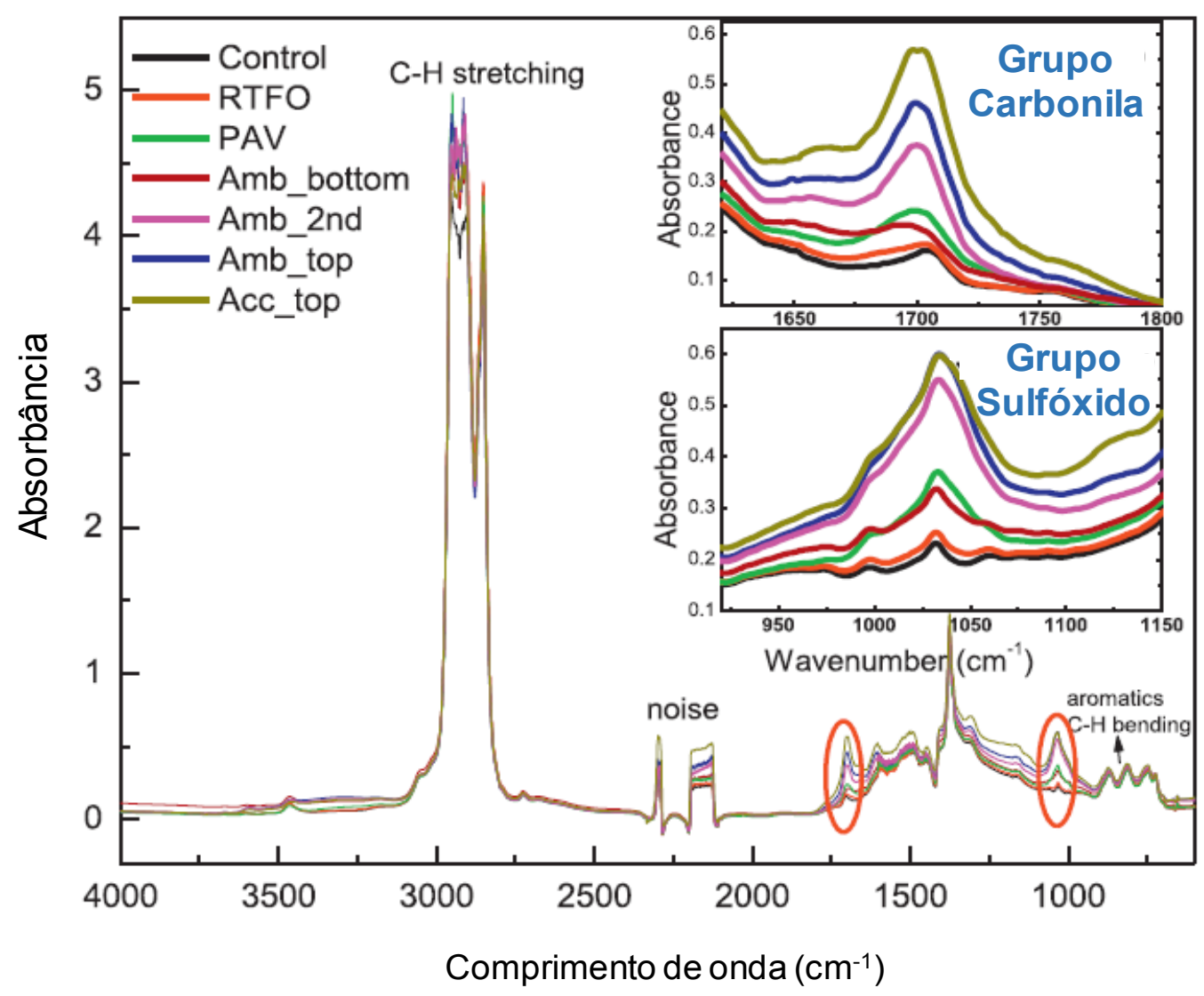

Fonte: Adaptado de Qin et al. (2014)

Outros autores utilizaram a técnica de Cromatografia de Permeação em Gel (GPC). Essa técnica avalia as mudanças na distribuição do tamanho/peso das moléculas. Quanto maior o tamanho/peso da molécula, menor o tempo de retenção, sendo logo detectada pelo sistema de deteç̧ão (CRAVO, 2016). Dessa forma, o resultado final do ensaio é apresentado como uma curva de distribuição, no qual a primeira parte corresponde aos compostos de grande tamanho molecular (GTM), a parte intermediária corresponde ao médio tamanho molecular (MTM) e a última parte corresponde aos compostos de pequeno tamanho molecular (PTM).

Lu e Isacsson (2002) observaram que após o envelhecimento houve um aumento das moléculas de GTM, enquanto as moléculas de PTM diminuíram, mostrando que a 
técnica pode demostrar que a associação das moléculas de pequeno tamanho e alta polaridade podem contribuir para o aumento da fração de grande tamanho molecular (Figura 11).

Figura 11 - Curva GPC do ligante virgem e após envelhecimento TFOT

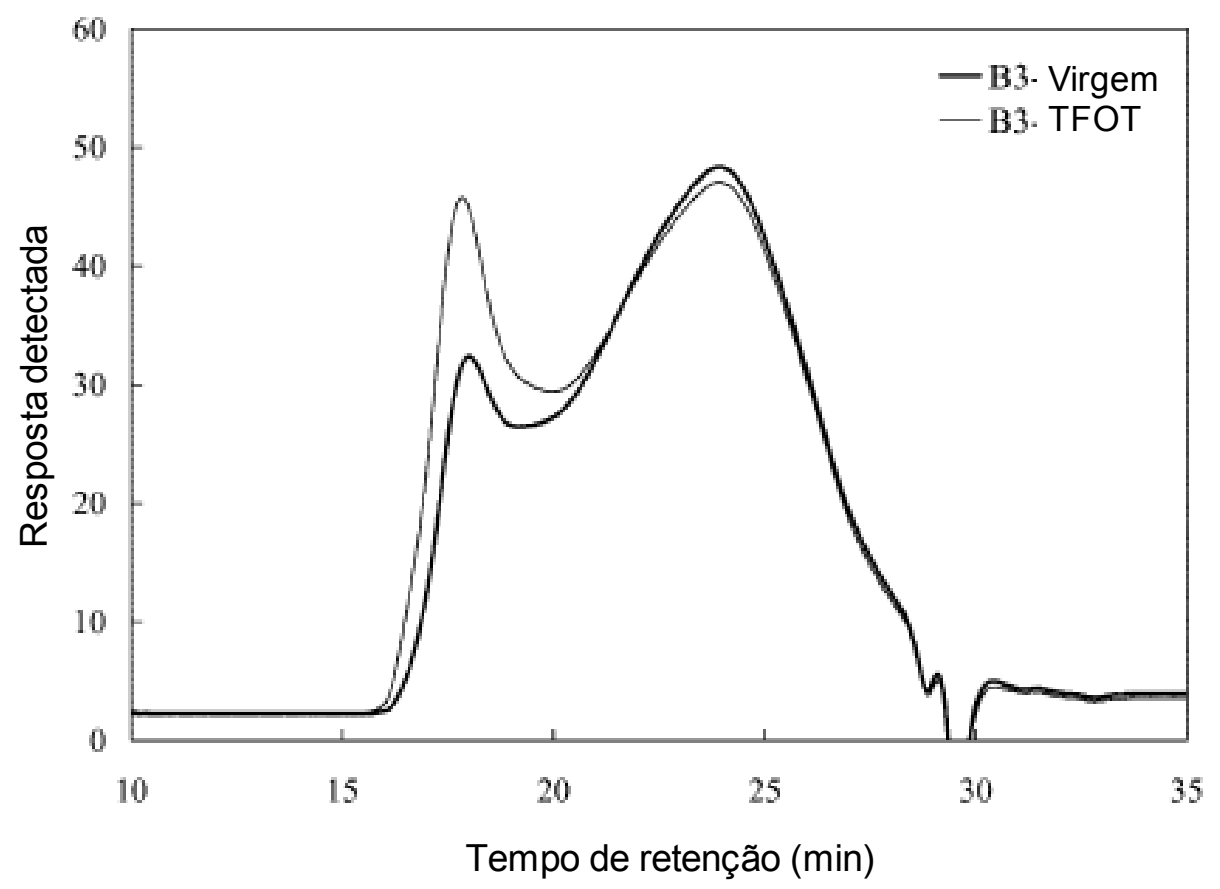

Fonte: Adaptado de Lue Isacsson (2002)

A espectroscopia de Ressonância Magnética Nuclear (RMN) é outra técnica utilizada para avaliar as características químicas de materiais. A técnica permite identificara estrutura de moléculas a partir da quantificação da absorção de radiação eletromagnética por isótopos magneticamente ativos da amostra como, por exemplo, os isótopos de ${ }^{1} \mathrm{H},{ }^{13} \mathrm{C},{ }^{19} \mathrm{~F}$ e ${ }^{31} \mathrm{P}$ (HOLLER; SKOOG; CROUCH, 2009). A absorção de radiação eletromagnética é quantizada resultando em um espectro que permite identificar as estruturas químicas presentes na amostra (CRAVO, 2016). A Figura 12 apresenta os espectros de RMN de ${ }^{1} \mathrm{H}$ (Figura 12a) e de ${ }^{13} \mathrm{C}$ (Figura 12b) obtidos para uma fração de asfaltenos. 
Figura 12 - Espectros de RMN obtidos para uma fração de asfaltenos. Em (a) RMN ${ }^{1} \mathrm{H}$ e (b) RMN ${ }^{13} \mathrm{C}$

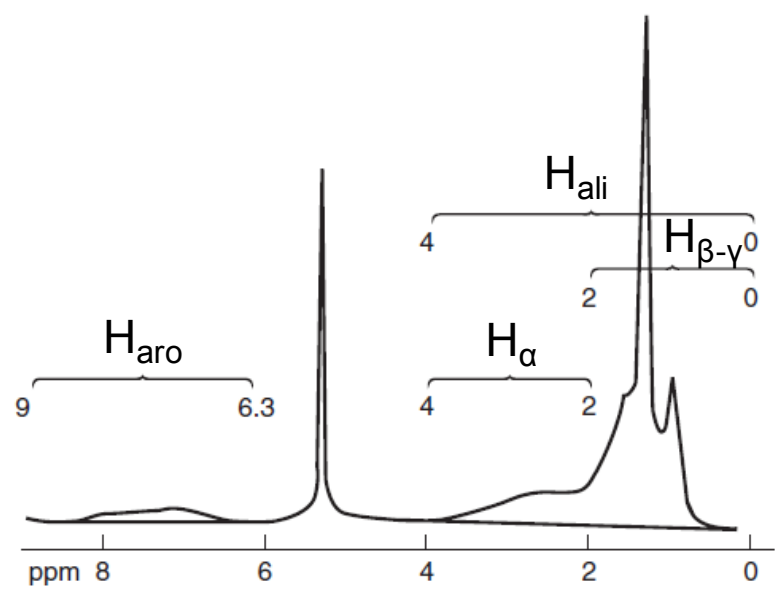

(a)

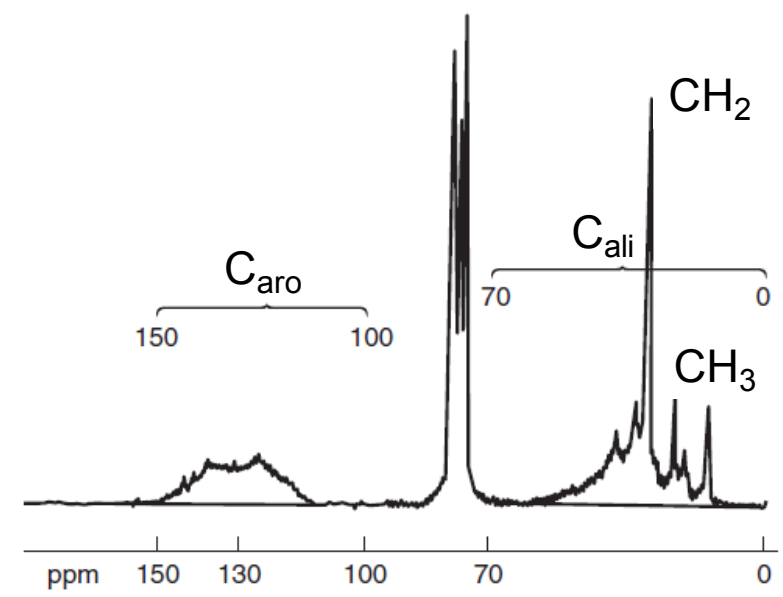

(b)

Fonte: Adaptado de Merdrignac e Espinat (2007)

Muitos pesquisadores utilizaram a RMN para avaliar as alterações químicas decorrentes do processo de envelhecimento, avaliando os isótopos de ${ }^{1} \mathrm{H}$ e ${ }^{13} \mathrm{C}$ (SIDDIQUI; ALI, 1999a; SILVA, 2005; LIMA, 2008; SIDDIQUI, 2010; CRAVO, 2016; OSMARI et al., 2019). Lima (2008) ilustrou em seu estudo uma molécula hipotética de asfalteno conten do os diferentes tipos de hidrogênio: aromático, satu rado, alfa, beta e gama (Figura 13a) e diferentes tipos de carbono: aromático, saturado, aromático ligado a alquila ou heteroátomo, aromático ligado a hidrogênio e aromático em junção de anel (Figura 13b).

Siddiqui e Ali (1999a) observaram, pelas análises de RMN, que a isomerização, o crosslinking interno e a desidrogenação foram as principais reações químicas observadas dos grupos hidrocarbonetos durante o envelhecimento dos ligantes estudados. 
Figura 13 - Molécula hipotética de asfalteno contendo os parâmetros moleculares obtidos por (a) $\mathrm{RMN}{ }^{1} \mathrm{He}$ (b) RMN ${ }^{13} \mathrm{C}$.

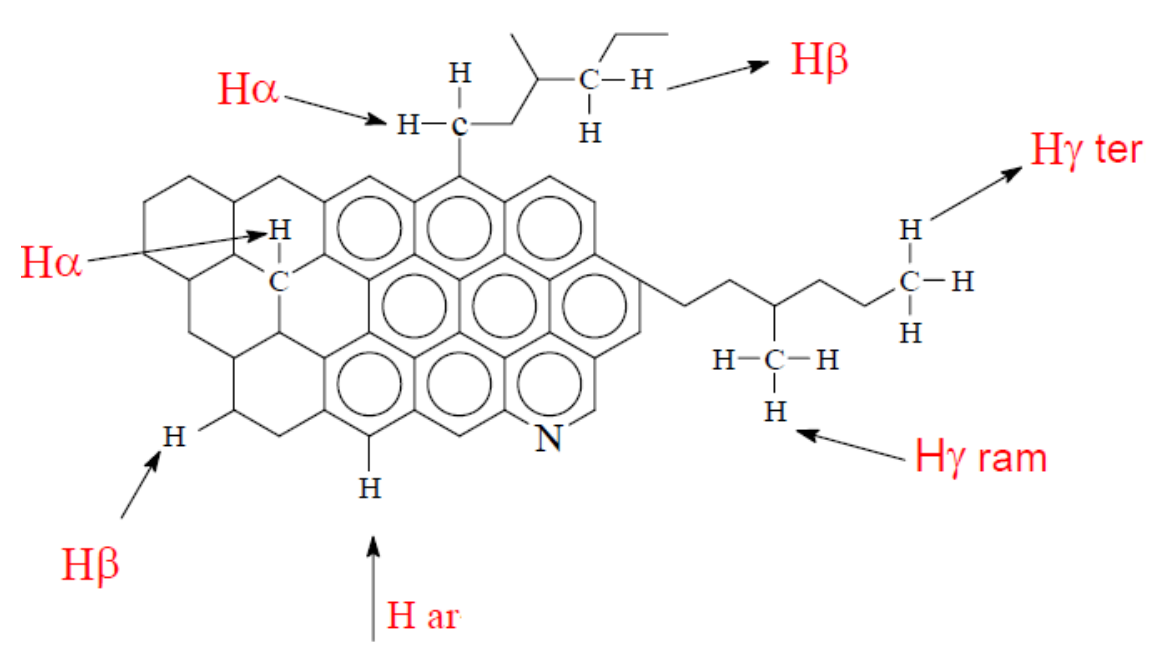

(a)

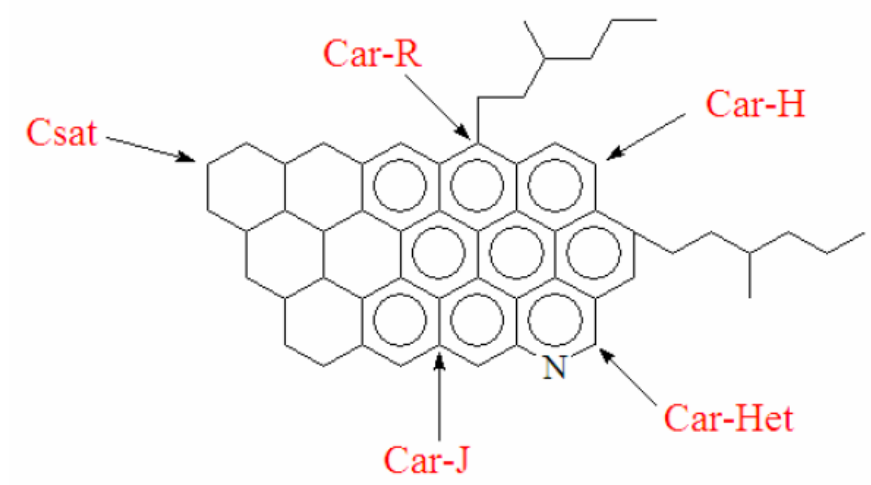

(b)

Fonte: Adaptado de Lima (2008)

O microscópio de força atômica (do inglês, AFM) também tem sido utilizado para entender a evolução da microestrutura do ligante. Muitos autores observaram estruturas elípticas características no ligante asfálticos, denominadas "estruturas de abelha" (bee structures em inglês), tanto nos ligantes virgens como nos ligantes envelhecidos (OSMARI, 2016; OSMARI et al., 2017; AGUIAR-MOYA et al., 2017). 
Nahar et al. (2014) observam que o ligante envelhecido apresentou uma microestrutura menos "rica" quando comparado ao ligante virgem, apresentando uma distribuição de tamanho praticamente bimodal com pequenos domínios e elípticos grandes. Osmari et al. (2017) verificou microestrutura semelhante, onde os ligantes envelhecidos apresentaram maiores "estruturas de abelha", porém em quantidade inferior ao ligante virgem (Figura 14).

Figura 14 - Imagens captadas pelo AFM do ligante CAP 30/45. Em (a) virgem e (b) envelhecido.
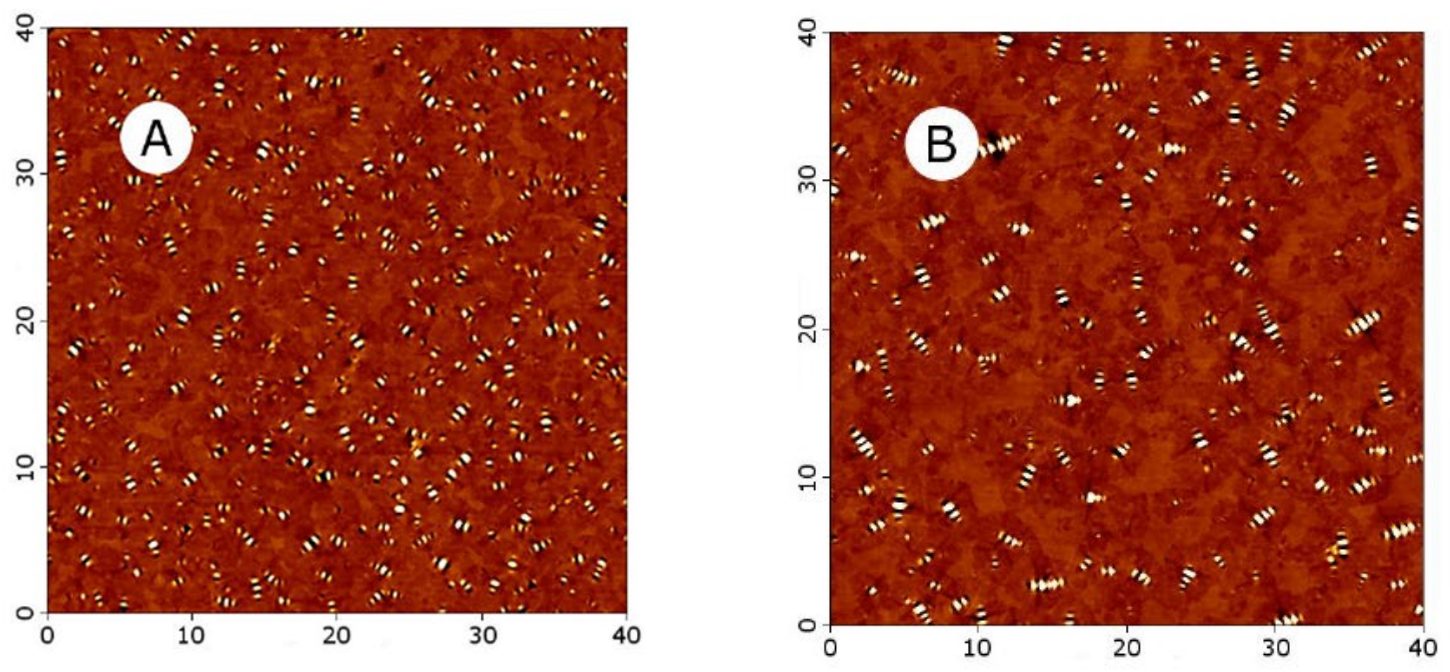

Fonte: Adaptado de Osmari (2016)

Aguiar-Moya et al. (2015) relataram que as "estruturas-abelha" estavam relacionadas à fração aromática do ligante. Também observaram que a oxidação térmica e a combinação entre aromáticos com as demais frações SARA poderiam influenciar o tamanho, a forma e a topografia dessas estruturas.

A utilização da técnica de AFM permite identificar as mudanças decorrentes do envelhecimento. Apesar de a avaliação ser ainda realizada de uma forma mais qualitativa, os resultados alcançados até o momento sugerem que a técnica de AFM, aliada a outros ensaios de caracterização química, poderá contribuir de forma mais consistente para o entendimento das transformações que decorrem do processo de envelhecimento do ligante asfáltico. 


\section{ENVELHECIMENTO DE LIGANTES ASFÁLTICOS EM LABORATÓRIO}

\subsection{INTRODUÇÃO E REVISÃO BIBLIOGRÁFICA}

Ao longo dos anos, muitos métodos foram desenvolvidos com o intuito de correlacionar o envelhecimento acelerado em laboratório com o envelhecimento sofrido pelo ligante durante o processo de usinagem e vida de serviço. Segundo Airey (2003), a maioria das pesquisas utilizam procedimentos com aquecimento prolongados em estufas e filmes finos de ligante. A Tabela 1 apresenta os métodos desenvolvidos para simulação do envelhecimento de curto e longo prazo dos ligantes asfálticos em laboratório.

Tabela 1 - Métodos de envelhecimento de ligantes asfálticos

\begin{tabular}{|c|c|c|c|c|c|}
\hline Método de teste & $\begin{array}{l}\text { Temperatura } \\
\left({ }^{\circ} \mathrm{C}\right)\end{array}$ & Duração & Amostra (g) & $\begin{array}{l}\text { Espessura filme } \\
\text { de ligante }\end{array}$ & $\begin{array}{l}\text { Detalhes } \\
\text { extra }\end{array}$ \\
\hline $\begin{array}{l}\text { Thin film oven test (TFOT) } \\
\text { - ASTM D1754, EN 12607- } \\
2\end{array}$ & 163 & $5 \mathrm{~h}$ & 50 & $3,2 \mathrm{~mm}$ & - \\
\hline $\begin{array}{l}\text { Modified thin film oven test } \\
\text { (MTFOT) }\end{array}$ & 163 & $24 \mathrm{~h}$ & - & $100 \mu \mathrm{m}$ & - \\
\hline $\begin{array}{l}\text { Rolling thin film oven test } \\
\text { (RTFOT) } \\
\text { AASHTO T240, ASTM } \\
\text { D2872, EN12607-1 }\end{array}$ & 163 & $75 \min$ & 35 & $1,25 \mathrm{~mm}$ & $\begin{array}{l}\text { Fluxo de } \\
\text { ar }-4 \\
\text { L/min }\end{array}$ \\
\hline $\begin{array}{l}\text { Extended rolling thin film } \\
\text { oven test (ERTFOT) }\end{array}$ & 163 & $8 \mathrm{~h}$ & 35 & $1,25 \mathrm{~mm}$ & $\begin{array}{l}\text { Fluxo de } \\
\text { ar }-4 \\
\text { L/min }\end{array}$ \\
\hline $\begin{array}{l}\text { Nitrogen rolling thin film } \\
\text { oven test (NRTFOT) }\end{array}$ & 163 & $75 \min$ & 35 & $1,25 \mathrm{~mm}$ & $\begin{array}{l}\text { Fluxo } \mathrm{N}_{2}- \\
4 \mathrm{~L} / \mathrm{min}\end{array}$ \\
\hline $\begin{array}{l}\text { Rotating Flask Test (RFT) - } \\
\text { DIN 52016, EN12607-3 }\end{array}$ & 163 & $150 \min$ & 100 & - & $\begin{array}{l}\text { Rotação } \\
\text { do frasco - } \\
20 \text { rpm }\end{array}$ \\
\hline Shell microfilm test & 107 & $2 \mathrm{~h}$ & - & $5 \mu \mathrm{m}$ & - \\
\hline $\begin{array}{l}\text { Modified Shell microfilm } \\
\text { test }\end{array}$ & 99 & $24 \mathrm{~h}$ & - & $20 \mu \mathrm{m}$ & - \\
\hline
\end{tabular}




\begin{tabular}{|c|c|c|c|c|c|}
\hline $\begin{array}{l}\text { Modified Shell microfilm } \\
\text { test }\end{array}$ & 107 & $2 \mathrm{~h}$ & - & $15 \mu \mathrm{m}$ & - \\
\hline $\begin{array}{l}\text { Rolling microfilm oven test } \\
\text { (RMFOT) }\end{array}$ & 99 & $24 \mathrm{~h}$ & 0,5 & $20 \mu \mathrm{m}$ & $\begin{array}{l}\text { Solvente } \\
\text { de } \\
\text { benzeno }\end{array}$ \\
\hline Modified RMFOT & 99 & $48 \mathrm{~h}$ & 0,5 & $20 \mu \mathrm{m}$ & $\begin{array}{l}\text { Abertura } \phi \\
1,04 \mathrm{~mm}\end{array}$ \\
\hline $\begin{array}{l}\text { Tilt-oven durability test } \\
\text { (TODT) }\end{array}$ & 113 & $168 \mathrm{~h}$ & 35 & $1,25 \mathrm{~mm}$ & - \\
\hline Alternative TODT & 115 & $100 \mathrm{~h}$ & 35 & $1,25 \mathrm{~mm}$ & - \\
\hline $\begin{array}{l}\text { Thin film accelerated } \\
\text { ageing test (TFAAT) }\end{array}$ & 130 ou 113 & $\begin{array}{l}24 \text { ou } \\
72 \mathrm{~h}\end{array}$ & 4 & $160 \mu \mathrm{m}$ & $\begin{array}{l}\text { Abertura } \phi \\
3 \mathrm{~mm}\end{array}$ \\
\hline $\begin{array}{l}\text { Modified rolling thin film } \\
\text { oven test (RTFOTM) }\end{array}$ & 163 & $75 \min$ & 35 & $1,25 \mathrm{~mm}$ & $\begin{array}{l}\text { Hastes de } \\
\quad \text { aço }\end{array}$ \\
\hline lowa durability test (IDT) & 65 & $1000 \mathrm{~h}$ & $\begin{array}{l}\text { Resíduo } \\
\text { TFOT - } 50\end{array}$ & $3,2 \mathrm{~mm}$ & $\begin{array}{c}2,07 \mathrm{MPa}- \\
\text { oxigênio } \\
\text { puro }\end{array}$ \\
\hline $\begin{array}{l}\text { Pressure oxidation bomb } \\
\text { (POB) }\end{array}$ & 65 & $96 \mathrm{~h}$ & $\begin{array}{l}\text { Resíduo } \\
\text { ERTFOT }\end{array}$ & $30 \mu \mathrm{m}$ & $\begin{array}{c}2,07 \mathrm{MPa}- \\
\text { oxigênio } \\
\text { puro }\end{array}$ \\
\hline $\begin{array}{l}\text { Accelerated ageing test } \\
\text { device/Rotating cylinder } \\
\text { ageing test (RCAT) }\end{array}$ & $70-110$ & $144 \mathrm{~h}$ & 500 & $2 \mathrm{~mm}$ & $\begin{array}{l}4-5 \mathrm{~L} / \mathrm{h}- \\
\text { oxigênio } \\
\text { puro }\end{array}$ \\
\hline $\begin{array}{l}\text { Pressure ageing vessel } \\
\text { (PAV) }\end{array}$ & $90-110$ & $20 \mathrm{~h}$ & $\begin{array}{l}\text { Resíduo } \\
\text { RTFOT ou } \\
\text { TFOT - } 50\end{array}$ & $3,2 \mathrm{~mm}$ & $\begin{array}{c}2,07 \mathrm{MPa}- \\
\quad \text { ar }\end{array}$ \\
\hline $\begin{array}{l}\text { High pressure ageing test } \\
\text { (HiPAT) }\end{array}$ & 85 & $65 \mathrm{~h}$ & $\begin{array}{l}\text { Resíduo } \\
\text { RTFOT - } 50\end{array}$ & $3,2 \mathrm{~mm}$ & $\begin{array}{c}2,07 \mathrm{MPa}- \\
\mathrm{ar}\end{array}$ \\
\hline
\end{tabular}

Fonte: Adaptado de Airey (2003)

Dentre esses métodos, os ensaios RTFOT e PAV são os mais utilizados e fazem parte das especificações Superpave para os processos de envelhecimentos do ligante asfáltico de curto e longo prazo, respectivamente. As especificações Superpave foram desenvolvidas através do programa SHRP com o intuito de classificar os ligantes asfálticos a partir de seu grau de desempenho (PG - performance grade) (BERNUCCI et al, 2010). Segundo Kennedy et al. (1994), o ensaio RTFOT foi incluído no sistema Superpave devido a sua maior precisão no controle de temperatura, por comportar 
uma quantidade maior de amostra e também pela duração do ensaio ser mais curta em relação ao ensaio TFOT, mais utilizado na época.

De acordo com Airey (2003), o ensaio RTFOT é capaz de simular o envelhecimento de curto prazo de ligantes em misturas convencionais a quente. Outros estudos mostram a possibilidade de utilizar o mesmo procedimento reduzindo apenas a temperatura de ensaio para simular o envelhecimento de curto prazo de ligantes em misturas asfálticas mornas (GANDHI, 2008; TAKAHASHI et al., 2014; FERROTTI et al., 2019). No entanto, algumas dificuldades operacionais foram observadas du rante a simulação do envelhecimento de ligantes modificados (AIREY, 2003; CAMARGO, 2016; YAN; HUANG; TANG, 2017).

O ensaio PAV vem sendo utilizado comumente para o envelhecimento de longo prazo dos ligantes asfálticos, segundo a norma D6521 da ASTM (American Society for Testing and Materials). O ensaio tem como objetivo simular o envelhecimento depois de vários anos do pavimento em serviço. A norma R-28 da AASHTO (American Association of State and Highway Transportation Officials) reporta que o ensaio PAV pode ser usado para estimar as propriedades físicas e químicas de ligantes asfálticos depois de 5 a 10 anos em serviço (FARRAR et al., 2006). Outros autores mencionam que o envelhecimento PAV deveria ser equivalente a um período entre 7 a 10 anos em serviço (ERSKINE; HESP; KAVEH, 2012; VILLEGAS-VILLEGAS et al., 2018).

Muitos estudos avaliaram o envelhecimento real de campo comparado ao envelhecimento simulado em laboratório utilizando o ensaio PAV, alguns deles observaram diferenças significativas nos níveis de envelhecimento (ERSKINE; HESP; KAVEH, 2012; BESAMUSCA et al., 2012; QIN et al., 2014; SMITH et al., 2018).

Dessa forma, este capítulo tem o objetivo de avaliar o envelhecimento dos ligantes asfálticos em laboratório, especialmente o envelhecimento após longo prazo com diferentes níveis de envelhecimento, incluindo o envelhecimento por radiação UV. A Figura 15 apresenta as etapas de estudo deste capítulo. 
Figura 15 - Etapas de estudo do envelhecimento em laboratório

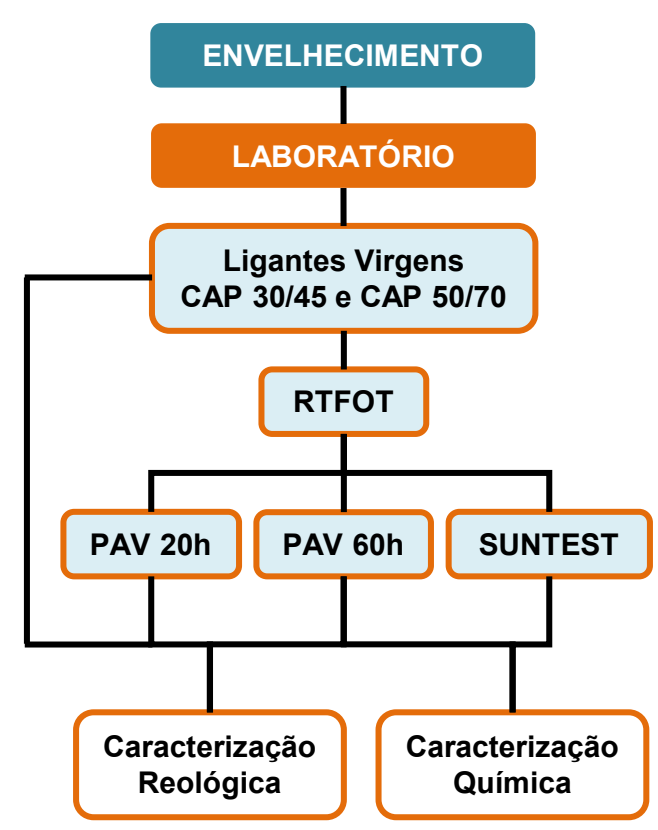

Fonte: Autora

\subsection{MATERIAIS E MÉTODOS}

\subsubsection{Envelhecimento em laboratório}

Para este estudo, formam utilizados um CAP 30/45 (PG 70S-XX) e um CAP 50/70 (PG 64S-XX). Os ligantes virgens foram envelhecidos em curto prazo por meio do ensaio RTFOT (ASTM D2872, 2012), e envelhecidos em longo prazo em três condições diferentes: (i) PAV 20h (ASTM D6521, 2013); (ii) PAV 60h, duração estendida para 60 horas mantendo as demais condições de acordo com o ensaio normatizado; (iii) SUNTEST, envelhecimento por radiação UV.

O envelhecimento por radiação UV foi realizado usan do o equipamento Suntest CPS+ da Atlas Material Testing Technology LLC. As amostras foram feitas com o ligante asfáltico espalhado formando uma película de $0,7 \mathrm{~mm}$ de espessura e envelhecidas usando u ma lâmpada de xenônio com intensidade de radiação de $70 \mathrm{~W} / \mathrm{m}^{2}$, durante 120 horas a $90{ }^{\circ} \mathrm{C}$. Este procedimento de ensaio foi estabelecido por Cravo (2016), ondea autora observou que 120 horas de teste correspondem a aproximadamente 62 
horas de exposição solar em condições solares constantes: intensidade da luz ao meio-dia, nos limites do equadore sem nuvens.

\subsubsection{Ensaios reológicos}

A caracterização reológica foi realizada em um reômetro de cisalhamento dinâmico (DSR), modelo Discovery HR-3 da TA Instruments. Foram realizados ensaios de varredura de frequência de $0,1 \mathrm{~Hz}$ a $10 \mathrm{~Hz}$, sob deformação controlada de $0,1 \%$, nas temperaturas de $0{ }^{\circ} \mathrm{C}$ a $80{ }^{\circ} \mathrm{C}$ com aumento de $10{ }^{\circ} \mathrm{C}$, incluindo a temperatura de $15^{\circ} \mathrm{C}$, utilizan do geometria de placas paralelas de diâmetro de $25 \mathrm{~mm}$ e gap de $1 \mathrm{~mm}$ e de $8 \mathrm{~mm}$ com gap de $2 \mathrm{~mm}$. Os ensaios de fluência e recuperação sob tensão múltipla (MSCR - ASTM D7405, 2015) foram realizados temperatura de $70{ }^{\circ} \mathrm{C}$, para avaliar a resistência à deformação permanente. Os ensaios de varredura linear de amplitude de deformação (LAS - AASHTO TP 101) também foram realizados na temperatura de $20^{\circ} \mathrm{C}$, para avaliar a resistência à fadiga dos ligantes nos diferentes níveis de envelhecimento.

\subsubsection{Ensaios químicos}

As frações SARA (saturados, asfaltenos, resinas e aromáticos) dos ligantes foram determinadas através do equipamento latroscan MK-3 (cromatografia em camada delgada com deteç̧ão por ionização de chama, TLC-FID), Figura 16a. A distribuição da massa molar do ligante foi determinada por cromatografia de permeação em gel (GPC) utilizando uma bomba cromatográfica Agilent 1200 (Figura 16b). Ensaios de ressonância magnética nuclear (RMN) foram realizados em um Agilent INOVA 300 (Figura 16c) para analisar as mudanças estruturais nos ligantes. As quantidades de carbono aromático (Car), hidrogênio aromático (Har), hidrogênio alfa ( $\mathrm{H}$-alfa) foram medidos. O ensaio de espectroscopia de infravermelho com transformada de Fourier (FTIR) com reflexão total atenuada (ATR) foi realizado usando um espectrômetro Nicolet Avatar 360 com uma célula de diamante (Figura 16d). Os espectros foram obtidos com 32 varreduras e resolução de $4 \mathrm{~cm}^{-1}$ na região de 4000 a $650 \mathrm{~cm}^{-1}$. 
Figura 16 - Equipamentos utilizados na análise química. Em (a) SARA (latroscan MK-3), em (b) GPC (Agilent 1200), em (c) RMN (INOVA 300) e em (d) FTIR-ATR (Nicolet Avatar 360)

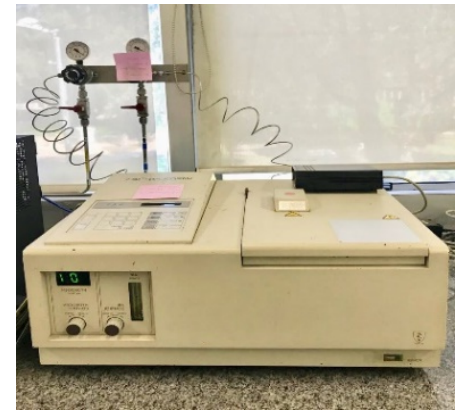

(a)

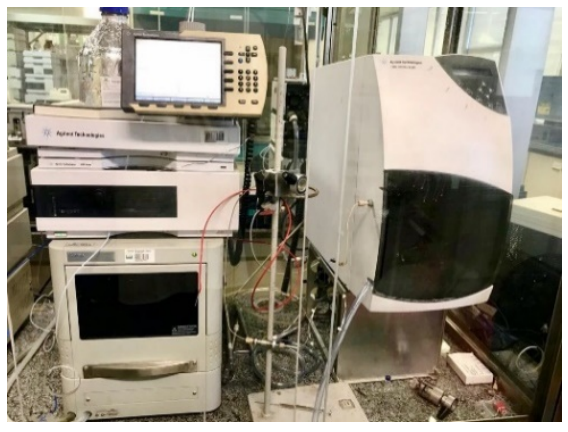

(b)
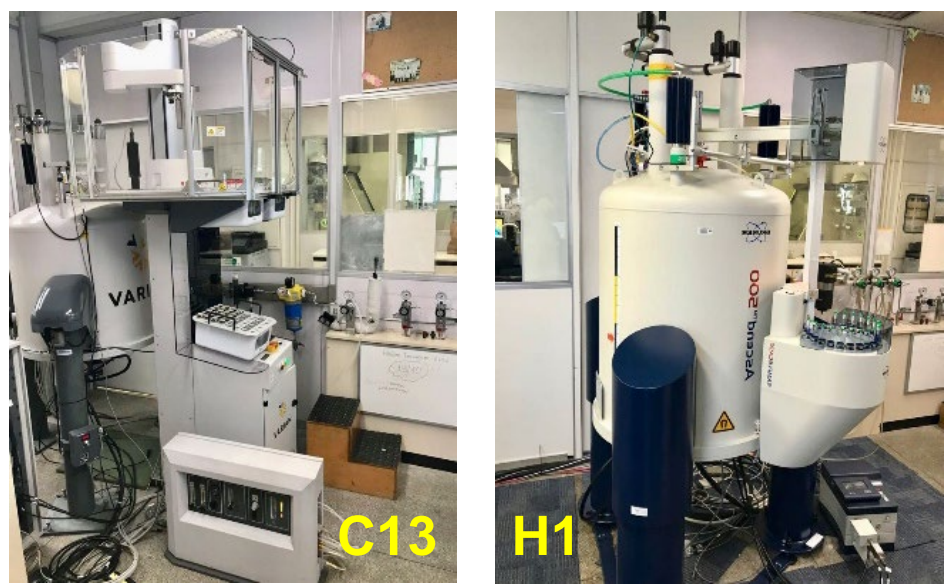

(c)

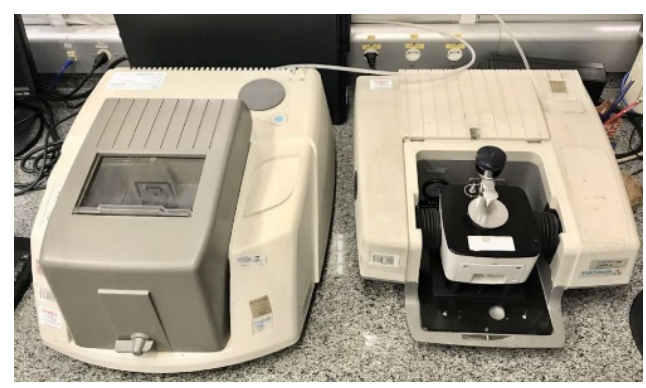

(d)

Fonte: CENPES/PETROBRÁS

As mudanças do índice de carbonila foram calculadas com base na razão entre as áreas de compostos de carbonila e as áreas de grupos $\mathrm{CH}_{2}$ e $\mathrm{CH}_{3}$, conforme eq.(11). 


$$
I_{c=o}=\frac{A_{c=o}}{A_{C H_{2}+C H_{3}}}
$$

Onde: $\quad A_{c}=0$ é a área da banda entre 1720 e $1650 \mathrm{~cm}^{-1}$ dos compostos de carbonila $(C=O)$ Aсн2+CH3 é a área da banda entre 1480 e $1410 \mathrm{~cm}^{-1}$ dos grupos de cadeias hidrocarbônicas

\subsection{RESULTADOSE DISCUSSÕES}

\subsubsection{Curvas mestras de $\left|G^{*}\right|$ e $\delta$}

As propriedades reológicas dos ligantes virgem e envelhecidos foram avaliadas a partir do ensaio de varredura de frequência e temperatura. As curvas mestras do módulo de cisalhamento dinâmico $\left(\left|\mathrm{G}^{*}\right|\right)$ e ângulo de fase $(\delta)$ foram construídas na temperatura de referência de $15{ }^{\circ} \mathrm{C}$, utilizando o princípio de superposição tempotemperatura, esta temperatura foi escolhida de forma a facilitara análise do parâmetro Glover-Rowe (GR) a partir dos mesmos resultados reológicos. As curvas mestras são apresentadas na Figura 17 para o CAP 50/70 e na Figura 18 para o CAP 30/45. 
Figura 17 - Curvas mestras do ligante CAP 50/70 envelhecido em laboratório, na temperatura de referência de $15^{\circ} \mathrm{C}$. Em (a) $\left|\mathrm{G}^{*}\right|$ e em (b) $\delta$.

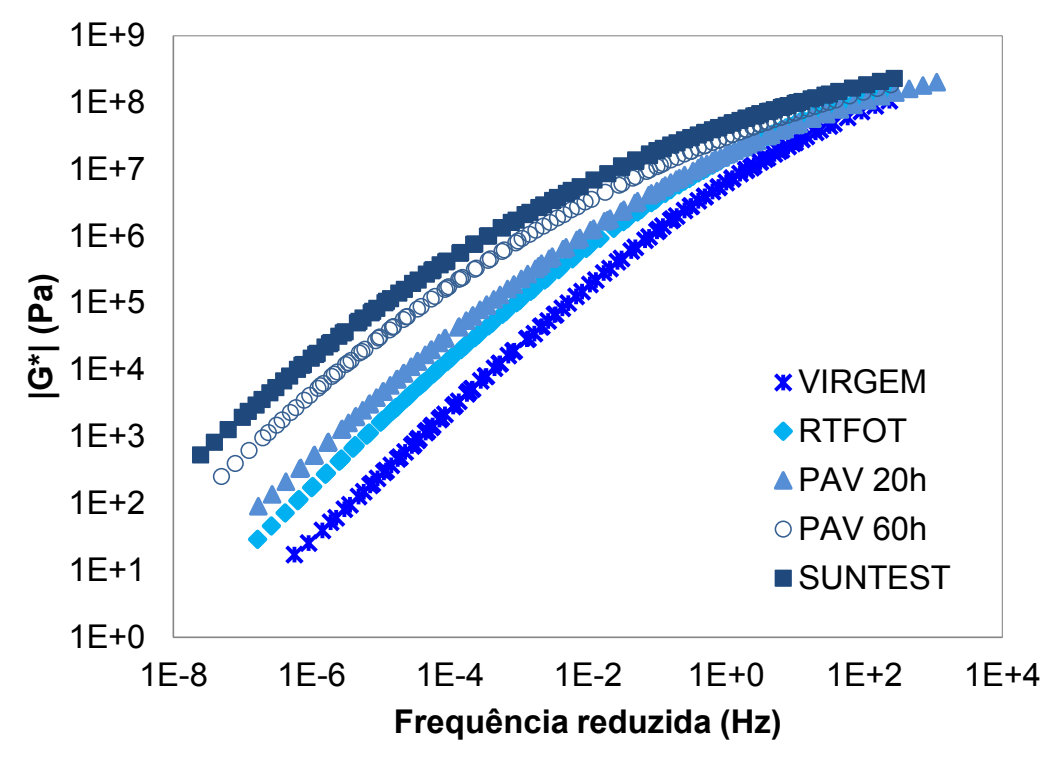

(a)

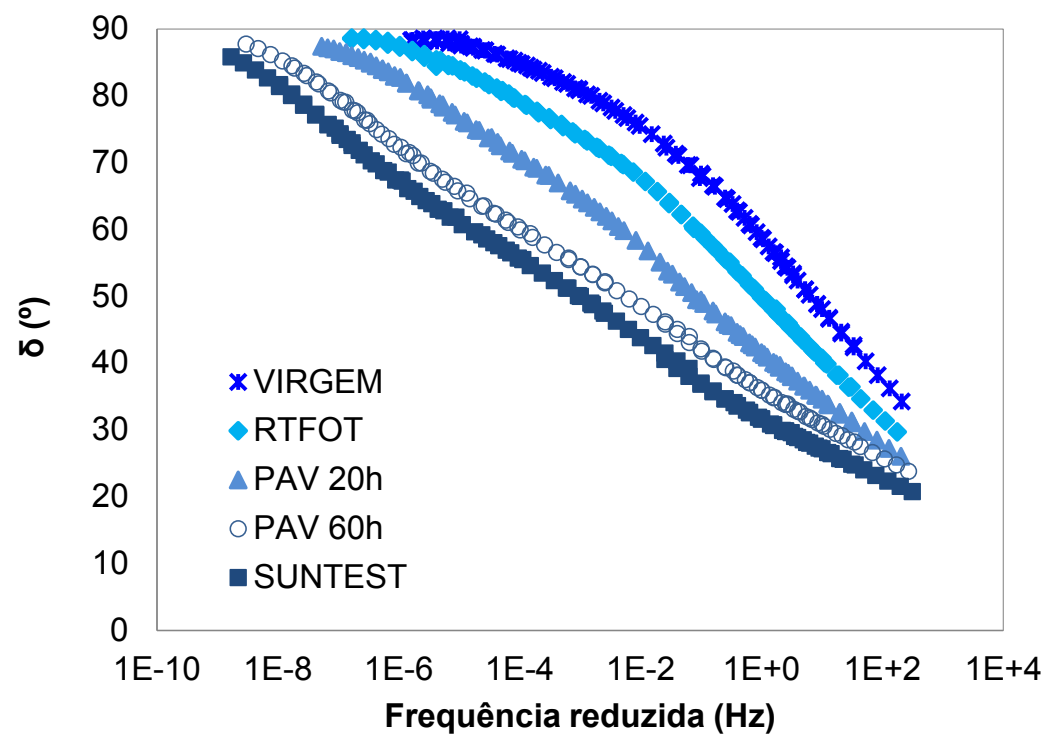

(b)

Fonte: Autora 
Figura 18 - Curvas mestras do ligante CAP 30/45 envelhecido em laboratório, na temperatura de referência de $15^{\circ} \mathrm{C}$. Em (a) $\left|\mathrm{G}^{\star}\right|$ e em (b) $\delta$.

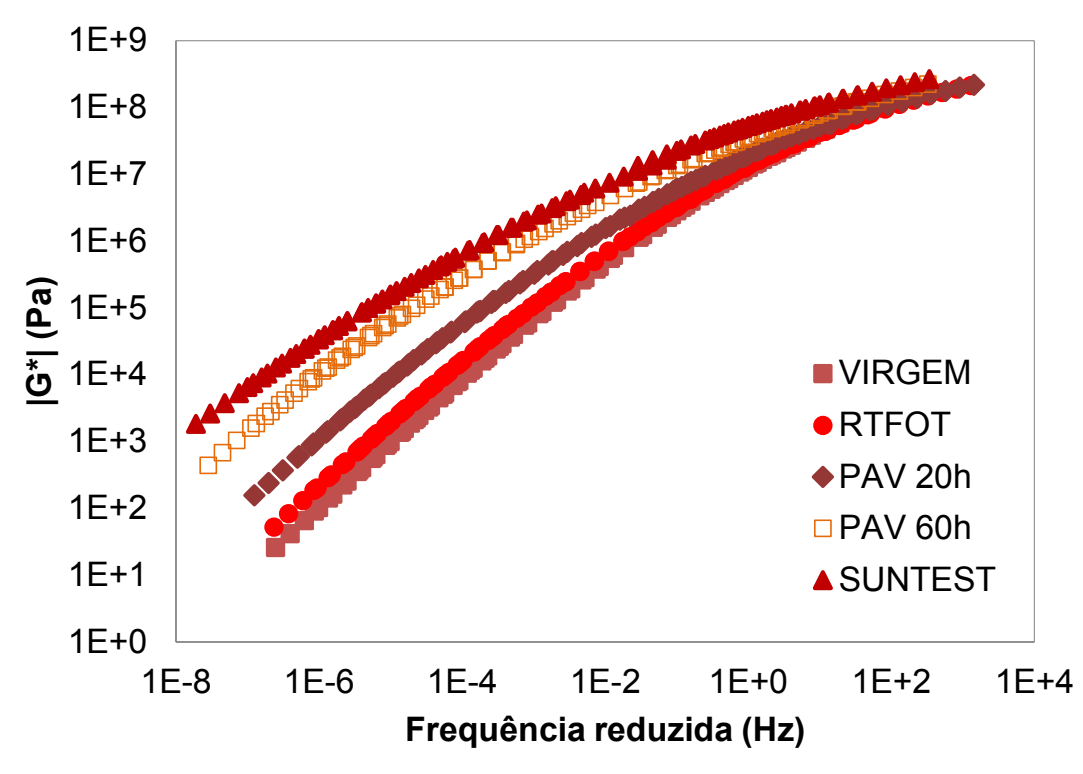

(a)

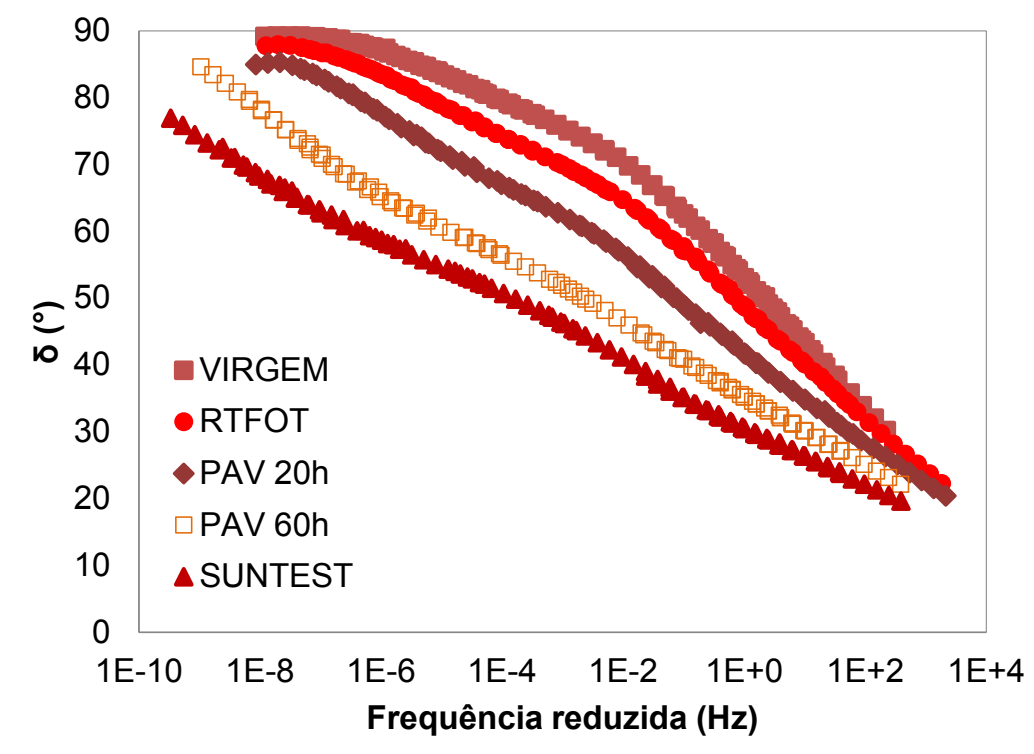

(b)

Fonte: Autora

Os resultados mostram também que em baixas frequências, equivalente a temperaturas altas, o ligante 30/45 apresenta maiores valores de $\left|G^{*}\right|$, o que pode conferir maior resistência à deformação permanente. No entanto, em altas 
frequências, ou baixas temperaturas, apesar da proximidade das curvas, é possível observar um incremento da rigidez que pode ser prejudicial à resistência à fadiga, principalmente no caso dos ligantes após SUNTEST.

\subsubsection{Crossover modulus $\left(\mathrm{G}^{*} \mathrm{c}\right)$, crossover frequency $\left(\omega_{c}\right)$ e parâmetro $R$}

A partir dos resultados do mesmo ensaio, foram determinados o crossover modulus $\left(G^{*} c\right)$, o crossover frequency $\left(\omega_{c}\right)$ e o parâmetro $R$, na temperatura de $15{ }^{\circ} \mathrm{C}$, para cada ligante nos diferentes níveis de envelhecimento (Tabela 2). Como observado por diversos autores, os valores de $\mathrm{G}^{{ }^{*}} \mathrm{e} \mathrm{e} \omega_{\mathrm{c}}$ tendem a diminuir e o parâmetro R aumenta com o aumento do envelhecimento (FARRAR et al., 2013; HUANG e TURNER, 2014; MORIAN; ZHU e HAJJ, 2015; CRAVO, 2016; CAVALLI et al., 2018; JING et al., 2019).

Muitos autores propuseram correlações entre esses parâmetros reológicos com outras propriedades dos ligantes asfálticos. Christensen, Anderson e Rowe (2017), afirmam a relação do parâmetro $R$ com diferentes propriedades importantes no ligante como resistência a fadiga, composição química e grau de endurecimento devido a oxidação (ou rejuvenescimento). Farrar et al. (2013) observaram uma correlação aproximadamente linear entre oxigênio total e o inverso do log do crossover modulus, no qual o oxigênio total é quantificado a partir do aumento dos compostos de oxigênio durante a reação de oxidação, principalmente a formação de bandas de carbonila e sulfóxido. Essa correlação é dependente do tipo do ligante. 
Tabela 2 - Crossover Modulus, Crossover Frequency e parâmetro R dos ligantes envelhecidos em laboratório.

\begin{tabular}{ccccc}
\hline Ligante & Envelhecimento & $\mathrm{G}^{*}{ }_{\mathrm{c}}$ & $\omega_{\mathrm{c}}$ & $\mathrm{R}$ \\
\hline \multirow{5}{*}{ CAP 50/70 } & Virgem & $3.48 \mathrm{E}+07$ & $1.2 \mathrm{E}+02$ & 1.46 \\
& RTFOT & $2.96 \mathrm{E}+07$ & $2.3 \mathrm{E}+01$ & 1.53 \\
& PAV 20h & $1.53 \mathrm{E}+07$ & $5.3 \mathrm{E}+00$ & 1.81 \\
& PAV 60h & $9.29 \mathrm{E}+06$ & $4.4 \mathrm{E}-01$ & 2.03 \\
& SUNTEST & $5.58 \mathrm{E}+06$ & $5.0 \mathrm{E}-02$ & 2.25 \\
& Virgem & $3.56 \mathrm{E}+07$ & $4.1 \mathrm{E}+01$ & 1.45 \\
& RTFOT & $2.23 \mathrm{E}+07$ & $1.6 \mathrm{E}+01$ & 1.65 \\
CAP 30/45 & PAV 20h & $1.21 \mathrm{E}+07$ & $2.4 \mathrm{E}+00$ & 1.92 \\
& PAV 60h & $5.83 \mathrm{E}+06$ & $1.1 \mathrm{E}-01$ & 2.23 \\
& SUNTEST & $4.95 \mathrm{E}+06$ & $2.8 \mathrm{E}-02$ & 2.31 \\
\hline
\end{tabular}

A Figura 19 apresenta graficamente a comparação dos resultados do crossover frequency $\left(\omega_{c}\right)$ e do parâmetro R para os ligantes avaliados. Os resultados mostram que o CAP 50/70 apresenta valores de $\omega_{c}$ superiores ao CAP 30/45 em todos os níveis de envelhecimento. Segundo Huang e Turner (2014), o crossover frequency indica a consistência geral do ligante em determinada temperatura, quanto maior o valor de $\omega_{c}$, mais fluxo viscoso o material apresentará.

Figura 19 - Comparação do crossover frequency $\left(\omega_{c}\right)$ e do parâmetro R para os ligantes envelhecidos em laboratório.
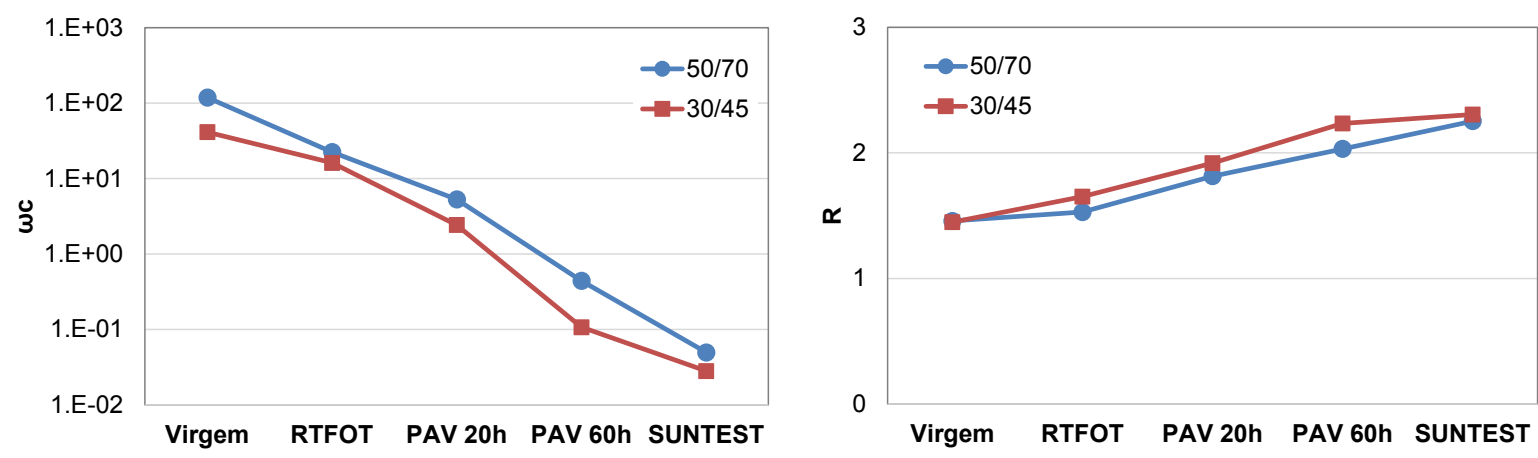

Fonte: Autora 
O parâmetro $\mathrm{R}$ descreve a forma e a assimetria do espectro de relaxação, ligantes asfálticos com maiores valores de $\mathrm{R}$ relaxam mais lentamente quando comparados as ligantes com baixos valores de $\mathrm{R}$, ou seja, esses ligantes tendem a ser mais suscetíveis a ter problemas (CHRISTENSEN; ANDERSON; ROWE, 2017). Dessa forma, é possível inferir que O CAP 30/45 será o ligante mais propenso a ter problemas relacionados ao aumento do envelhecimento, quando comparado ao CAP 50/70 na mesma condição.

\subsubsection{Parâmetro Glover-Rowe (GR)}

O parâmetro Glover-Rowe (GR) também foi determinado a partir das propriedades reológicas, utilizando a temperatura de $15^{\circ} \mathrm{C}$ e $0.005 \mathrm{rad} / \mathrm{s}$, com o objetivo avaliar a resistência ao trincamen to dos ligantes envelhecidos. Os resultados são apresentados no diagrama do Espaço Black (Figura 20) juntamente com os limites da zona de dano e de trincamento em bloco (ROWE, 2016).

Figura 20 - Diagrama de Espaço Black dos ligantes nos diferentes níveis de envelhecimento em laboratório. Em (a) CAP 50/70 e em (b) CAP 30/45.

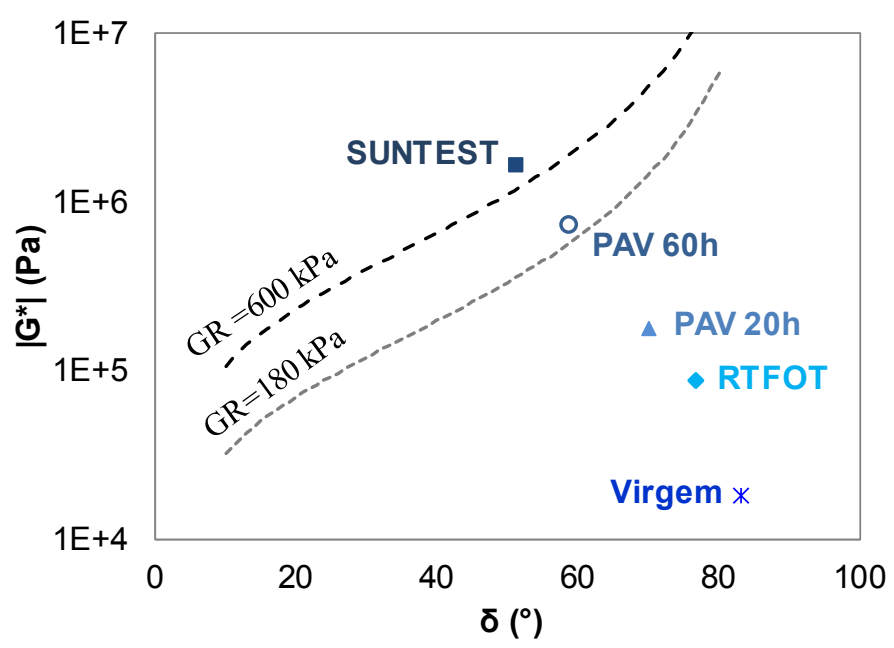

(a) 


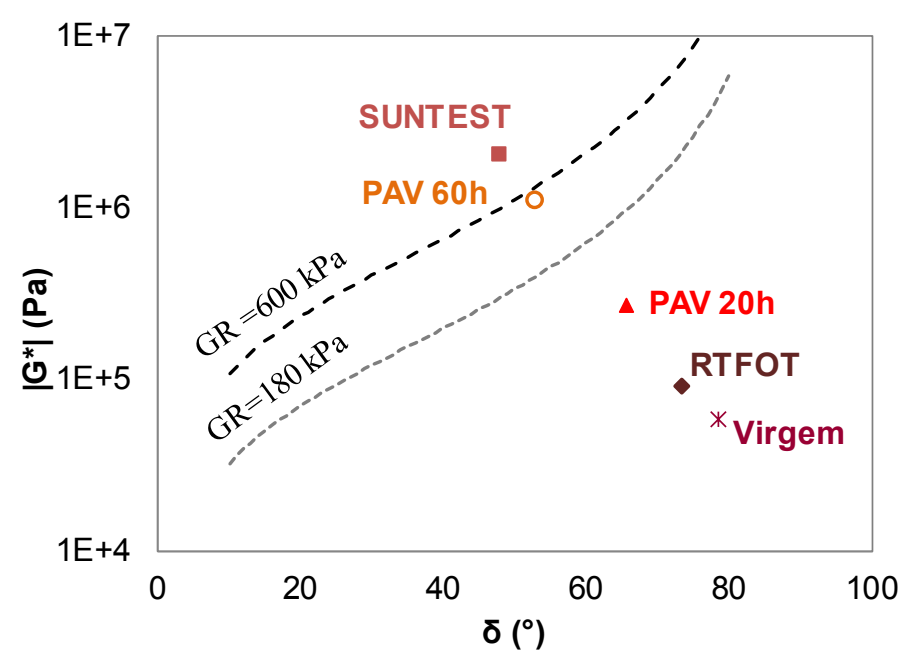

(b)

Fonte: Autora

Da Figura 20, para ambos os ligantes, verifica-se que os envelhecimentos RTFOT e PAV 20h provocam alteração do parâmetro $G R$, no entanto, os resultados mostram um afastamento considerável em relação ao início da zona de dano ( $G R=180 \mathrm{kPa})$. Já o envelhecimento PAV 60h é mais rigoroso, colocando os dois ligantes na zona de dano, com o CAP 30/45 bem próximo do limite ( $\mathrm{GR}=600 \mathrm{kPa}$ ). Osmari et al. (2018) avaliou o envelhecimento PAV com duração prolongada de 60 e 80 horas, encontrando resultados similares de GR para o envelhecimento de 60 horas de um de seus ligantes, e mostrando que o envelhecimento com duração de 80 horas pode colocar o ligante na região de trincamento em bloco.

O SUNTEST foi o mais severo entre todos os procedimentos de envelhecimento, colocando ambos os ligantes na região de trincamento em bloco. Mostrando que o parâmetro GR é uma ferramenta importante para avaliar os ligantes quanto à resistência ao trincamento a partir das propriedades viscoelásticas lineares.

\subsubsection{Ensaio MSCR}

O ensaio de fluência e recuperação sob tensão múltipla (MSCR), incluído nas especificações Superpave, tem o objetivo de caracterizar a resistência a deformação permanente de ligantes asfálticos. 
Apesar de o MSCR ser utilizado para classificação do PG (performance grade) de ligantes asfálticos de acordo com o nível de tráfego, neste trabalho, ele é utilizado para avaliar a influência do envelhecimento na resistência a deformação permanente dos ligantes. Dessa forma, o ensaio foi realizado na temperatura de $70{ }^{\circ} \mathrm{C}$ e os resultados de Jnr (compliância não recuperável), são apresentados na Figura 21a para a tensão de 100Pa e na Figura 21b para a tensão de 3200 Pa.

Figura 21 - Resultados de Jnr para cada ligantes nos diferentes níveis de envelhecimento em laboratório. Em (a) tensão de 100Pa e em (b) tensão de $3200 \mathrm{~Pa}$.

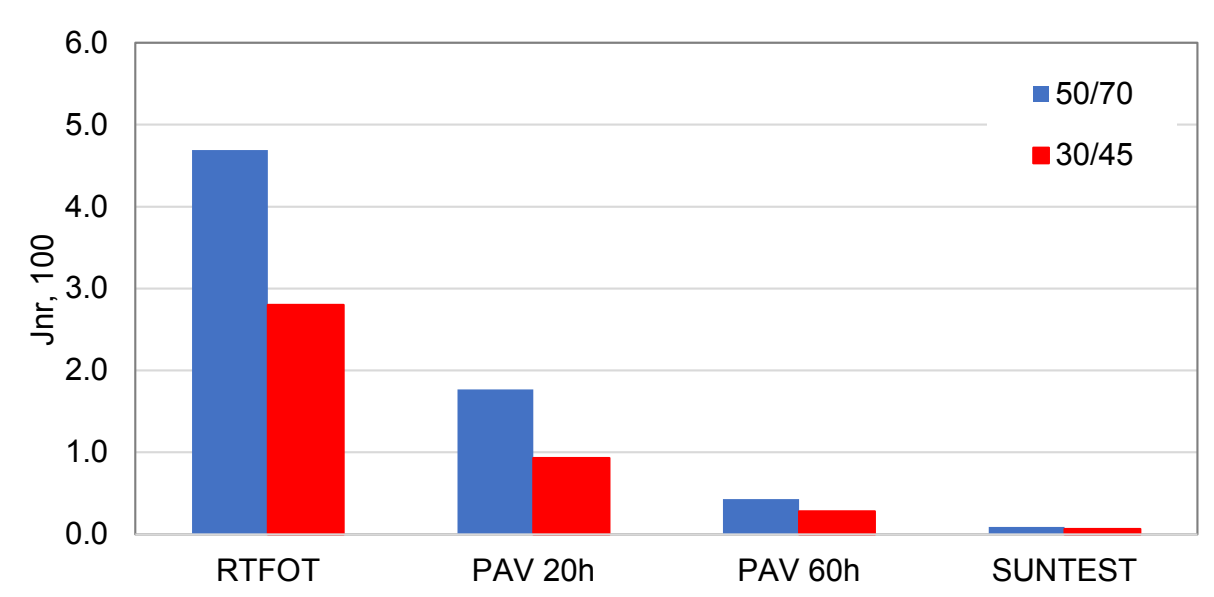

(a)

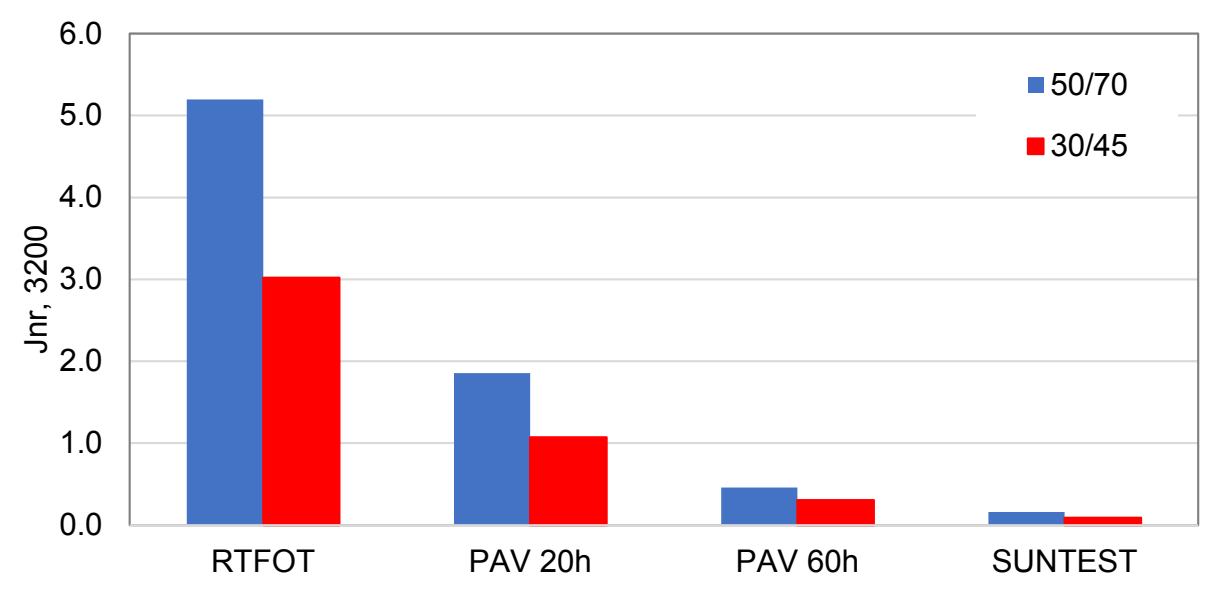

(b)

Fonte: Autora 
Como esperado, os resultados confirmam o que foi observado a partir da curva mestra, o envelhecimento melh ora a resistência à deformação permanente reduzindo os valores de Jnr, outros autores observaram a mesma tendência (OSMARI, 2016; ZHANG et al., 2018; BORGHI et al., 2017).

O ligante 30/45 é menos susceptível a deformação permanente entre os dois ligantes avaliados, isso está associado a diferença rigidez inicial que se mantém nos diferentes níveis de envelhecimento.

\subsubsection{Ensaio LAS}

O ensaio de varredura linear de amplitude de deformação (LAS) permite avaliar as propriedades dos ligantes asfálticos com relação à resistên ciaà fadiga. $O$ trincamento por fadiga é um dos danos mais comuns nos pavimentos asfálticos e ocorre de forma progressiva devido às tensões aplicadas pelo carregamento repetido do tráfego. $O$ envelhecimento aumenta a rigidez do ligante asfáltico e diminui sua capacidade de relaxação das tensões, tornando-o mais susceptível ao trincamento por fadiga (MARTINS, 2014; ELKASHEF e WILLIAMS, 2017).

As curvas característica de dano e de fatiga resultante dos ensaios LAS realizados, na temperatura de $20^{\circ} \mathrm{C}$, nos ligantes nos diferentes níveis de envelhecimento em laboratório são apresentadas na Figura 22 para o CAP 50/70 e na Figura 23 para o CAP 60/45.

$\mathrm{Na}$ curva característica de dano, verifica-se a queda da integridade (C) inicial do material com o aumento da intensidade do dano (S). A integridade do material é reduzida ao longo do ensaio para todos os ligantes, ocorrendo de forma mais intensa para os ligantes com maior nível de envelhecimento, especialmente o SUNTEST.

A curva característica de dano é plotada até o ponto de ruptura, onde ocorre a ten são máxima aplicada ao material, pelas curvas é possível observar que o ligante 50/70PAV 20h resiste mais ao dano que o 50/70-RTFOT. Ainda para o CAP 50/70, o aumento do nível de envelhecimento altera a inclinação da curva de fadiga, mostran do que o envelhecimento permite resistir a um maior número de solicitações em baixas 
deformações considerando os níveis de envelhecimento PAV 60h e SUNTEST em relação ao PAV 20h. No entanto, o ligante perde resistência de forma acentuada com o aumento da deformação, mostrando que a rigidez exerce grande influência na resistência à fadiga.

Figura 22 - Curvas característica de dano em (a) e curvas de fadiga em (b) para o CAP 50/70 envelhecido em laboratório.

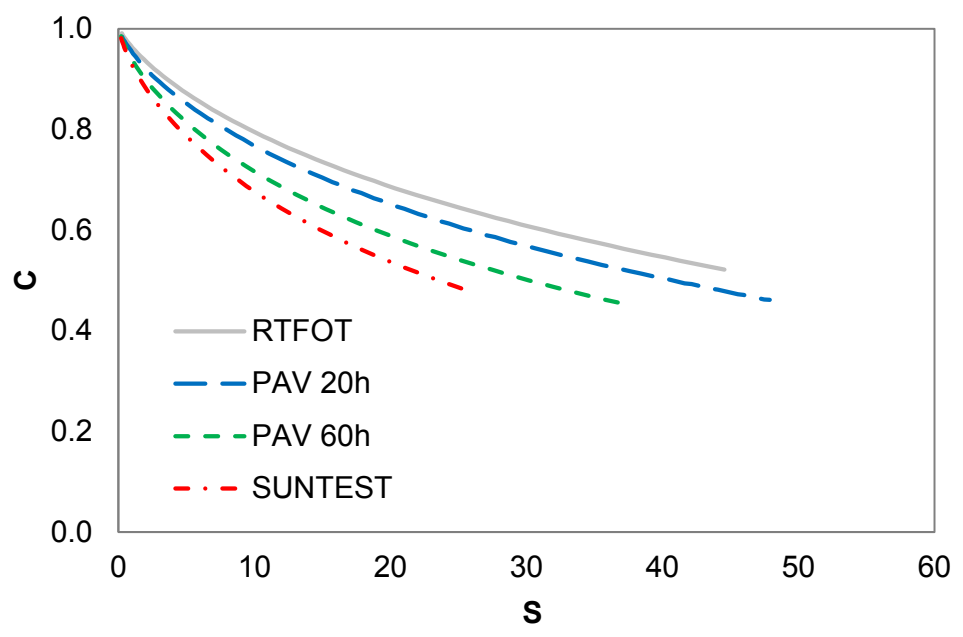

(a)

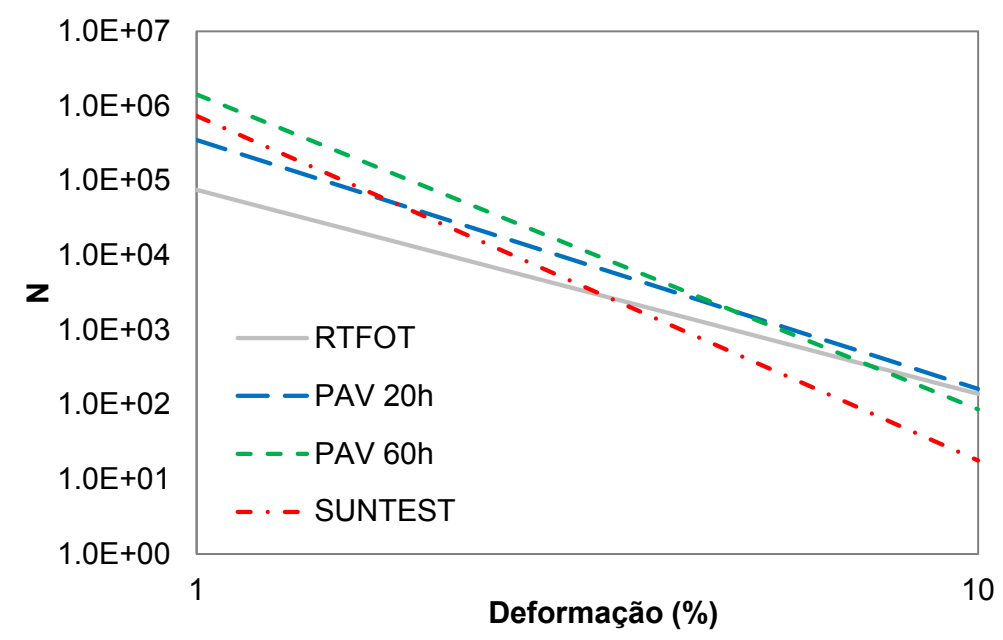

(b)

Fonte: Autora 
Figura 23 - Curvas característica de dano em (a) e curvas de fadiga em (b) para o CAP 30/45 envelhecido em laboratório.

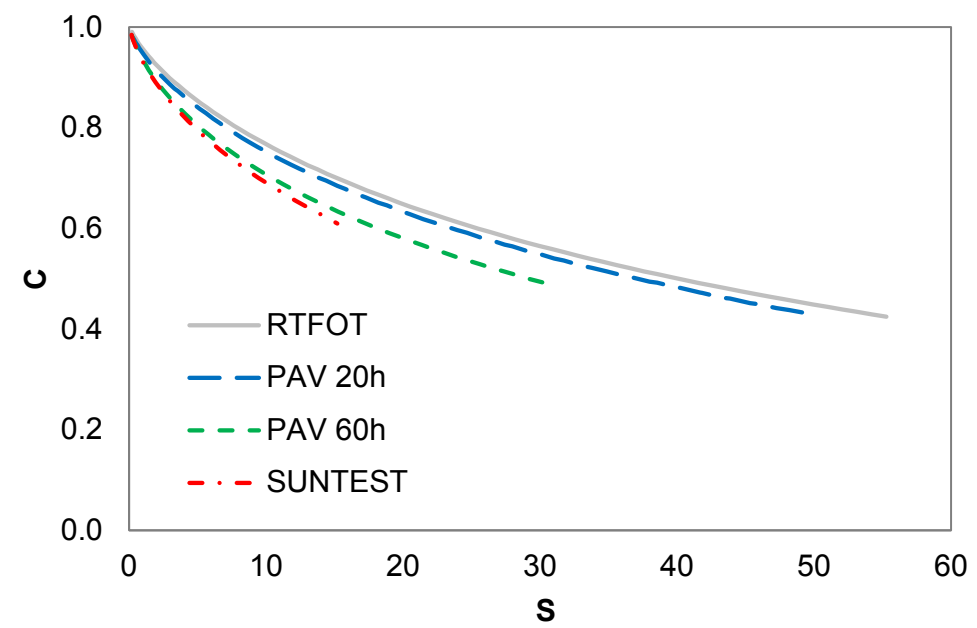

(a)

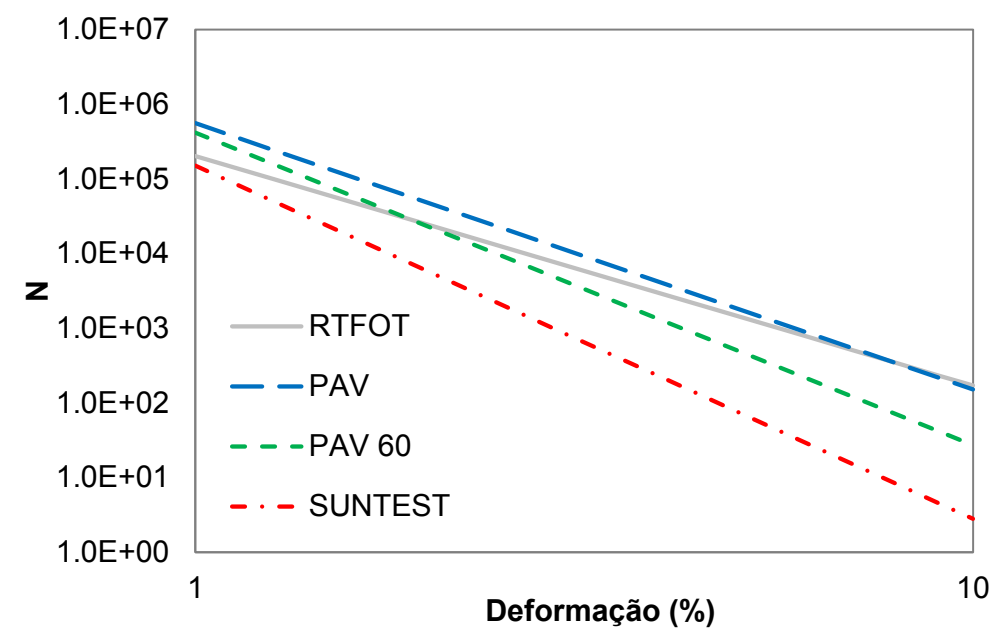

(b)

Fonte: Autora

No caso do CAP 30/45, o aumento do nível de envelhecimento também provoca alteração da inclinação da curva de fadiga. No entanto, diferentemente do CAP 50/70, os ligantes após envelhecimento PAV 60h e SUNTEST apresentam curvas de fadiga significativamente inferiores à curva de fadiga do PAV 20h, indicando menor resistência à fadiga nesses dois níveis de envelhecimento. Esses resultados reafirmam o que é observado pela curva característica de dano, na qual o CAP 30/45 
apresenta maior susceptibilidade ao dano, principalmente após o envelhecimento SUNTEST.

\subsubsection{Fracionamento SARA}

O ligante asfáltico é considerado um sistema coloidal constituído por micelas de asfalteno, que possuem alto peso molecular, dispersas ou dissolvidas em meio oleoso (maltenos: saturados + aromáticos + resinas) de menor peso molecular (HUNTER SELF; READ, 2015; SIDDIQUI e ALI, 1999b). Os resultados do fracionamento SARA dos dois ligantes, nos diferentes níveis de envelhecimento, são apresentados na Figura 24.

Conforme observado por pesquisadores, durante o processo oxidativo, as frações não-polares são transformadas em frações polares, os aromáticos são transformados em resinas, e as resinas são transformadas em asfaltenos (DOMKE et al., 1999; LIU et al, 2014; HAGHSHENAS et al., 2018).

Figura 24 - Resultado fracionamento SARA para os ligantes envelhecidos em laboratório.

Em (a) CAP 50/70 e em (b) CAP 30/45.

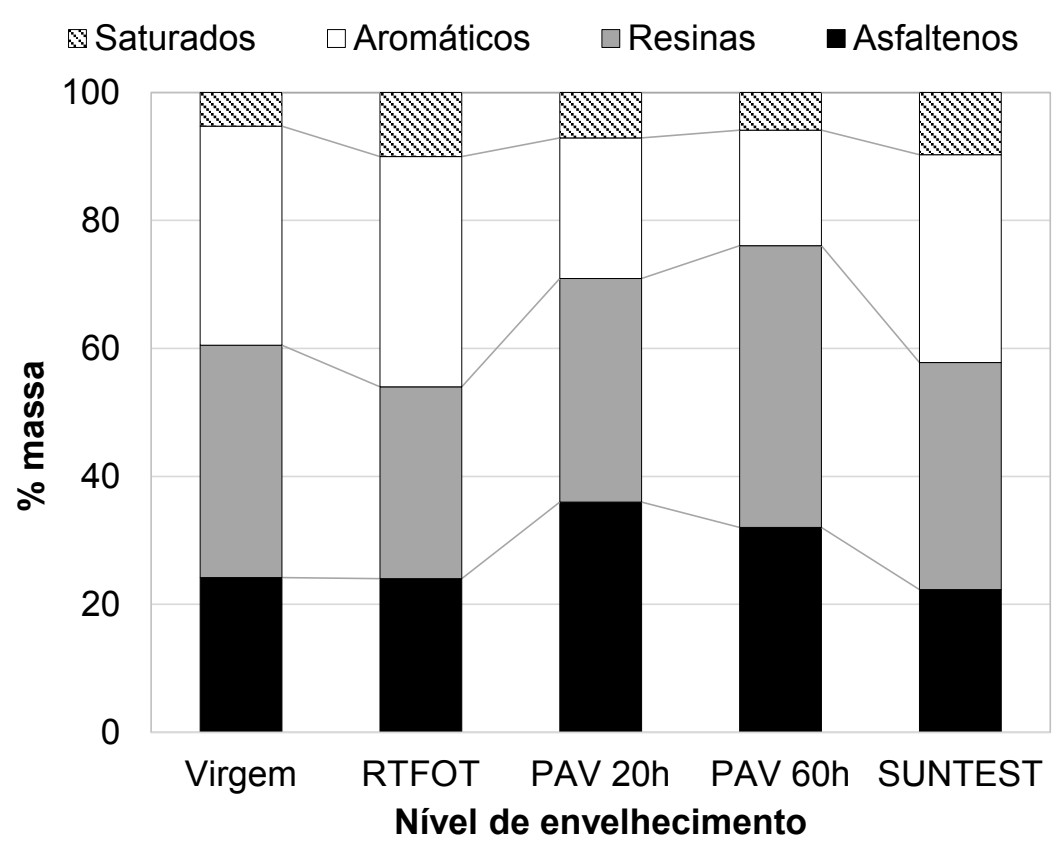


(a)

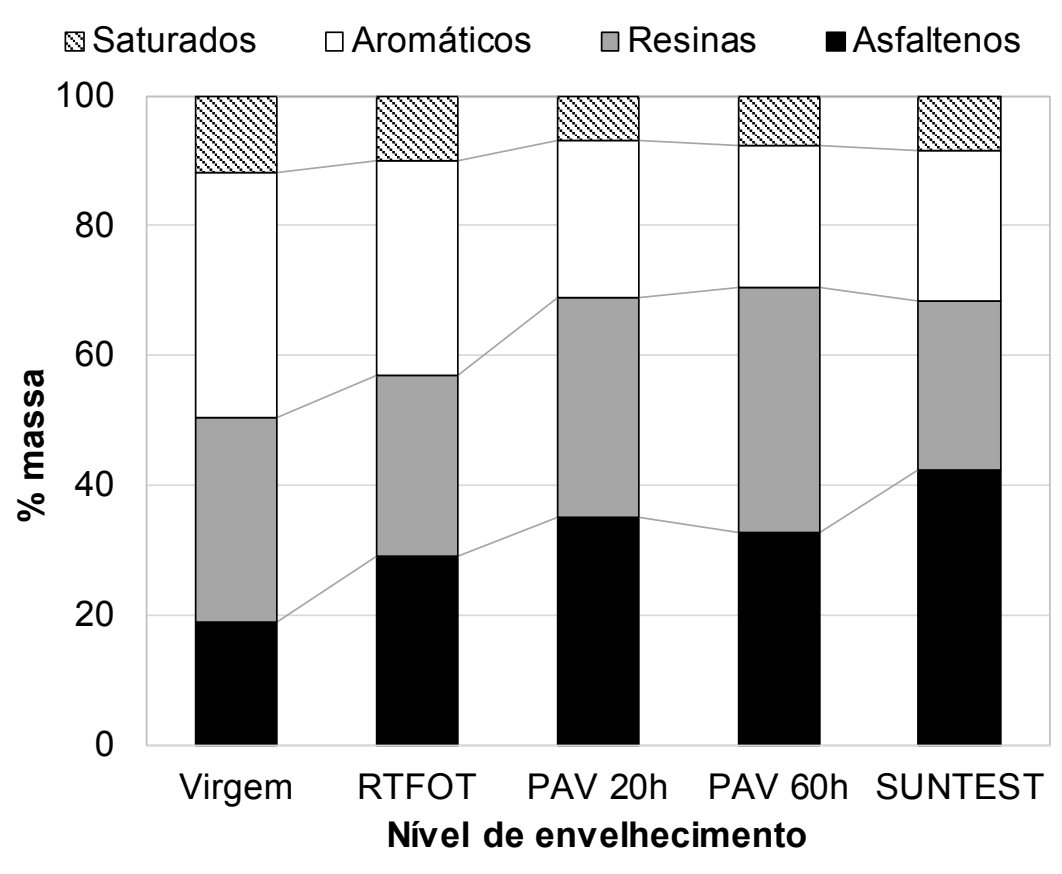

(b)

Fonte: Autora

As mudanças físico-químicas que ocorrem durante o processo de envelhecimento resultam no aumento da fração de asfaltenos, tornan do o ligante asfáltico mais rígido e diminuído sua elasticidade (MULLINS, 2010; CAVALLI et al., 2018).

Era esperado o aumento do teor de asfaltenos e a redução do teor de aromáticos com o aumento do nível de envelhecimento. No entanto, essa tendência acontece apenas para o CAP 30/45, acompanhando os resultados reológicos que indicavam o SUNTEST mais rigoroso. O CAP 50/70 apresenta aumento no teor de aromáticos após o envelhecimento RTFOT, seguido de redução após PAV 20h e PAV 60h e retornan do a elevar o teor após o SUNTEST. Segundo Siddiqui e Ali (1999a), reações concomitantes podem acontecer durante o processo de envelhecimento como: aromatização, fragmentação, desalquilação, condensação e a ruptura de ciclos naftênicos. Essas reações competindo entre si, podem ter resultados nos valores menores de aromáticos após o RTFOT. Já no envelhecimento SUNTEST, a composição química do ligante pode ter influência mais significativa no envelhecimento foto-oxidativo. 


\subsubsection{Distribuição do tamanho molecular (GPC)}

A Figura 25 apresenta os resultados do ensaio GPC para os ligantes avaliados. Como esperado, a fração de grande tamanho molecular (GTM) aumenta durante o envelhecimento, porém de forma sutil. Por outro lado, é verificado um aumento mais significativo da fração de pequen o tamanho molecular(PTM), seguindo uma ten dência contrária ao observado por Zhao et al. (2019) que também utiliza o ensaio PAV com duração prolongada de 40 e 60 horas.

Figura 25 - Resultados ensaio GPC para os ligantes envelhecidos em laboratório. Em (a) CAP 50/70 e em (b) CAP 30/45.

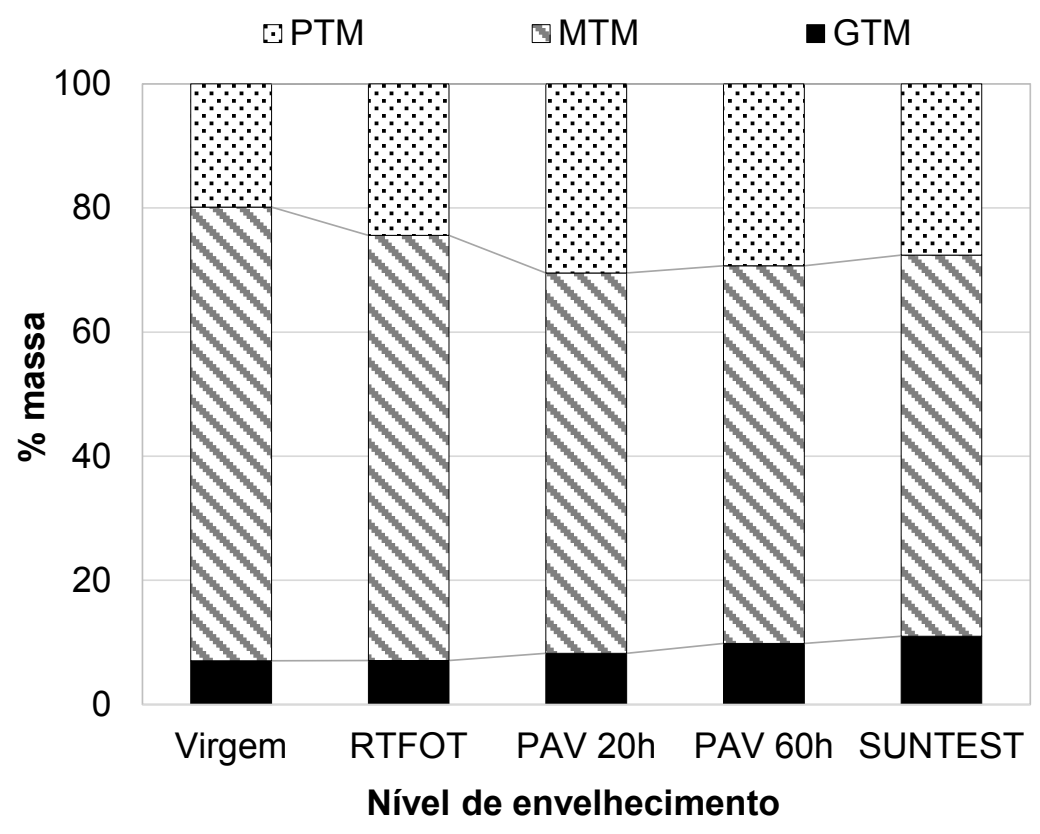

(a) 


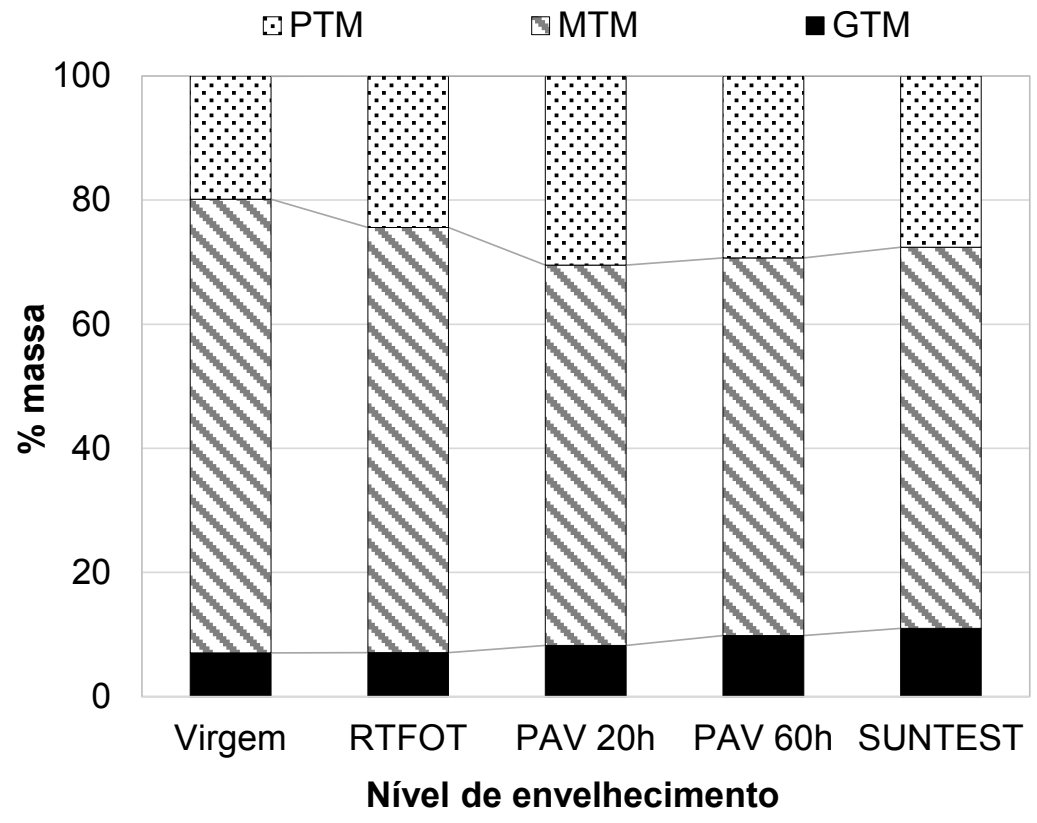

(b)

Fonte: Autora

\subsection{8. Índice de carbonila (Ic)}

O envelhecimento dos ligantes foi avaliado pelo índice de carbonila (Figura 26). Para os ligantes na condição virgem, os compostos de carbonila não foram observados durante o ensaio FTIR.

De acordo com Lin et al. (1995), o processo de oxidação resulta na formação de compostos de carbonila. Os resultados mostram que o índice de carbonila aumenta com o aumento do envelhecimento, exceto para a condição após SUNTEST. Apesar dos parâmetros reológicos indicarem que o SUNTEST seja o procedimento de envelhecimento mais severo, aumentando consideravelmente os valores de $\left|G^{*}\right|$, pode-se inferir que reações químicas diferentes ocorrem durante o envelhecimento por radiação UV. 
Figura 26 - Índice de carbonila dos ligantes em diferentes níveis de envelhecimento em laboratório.

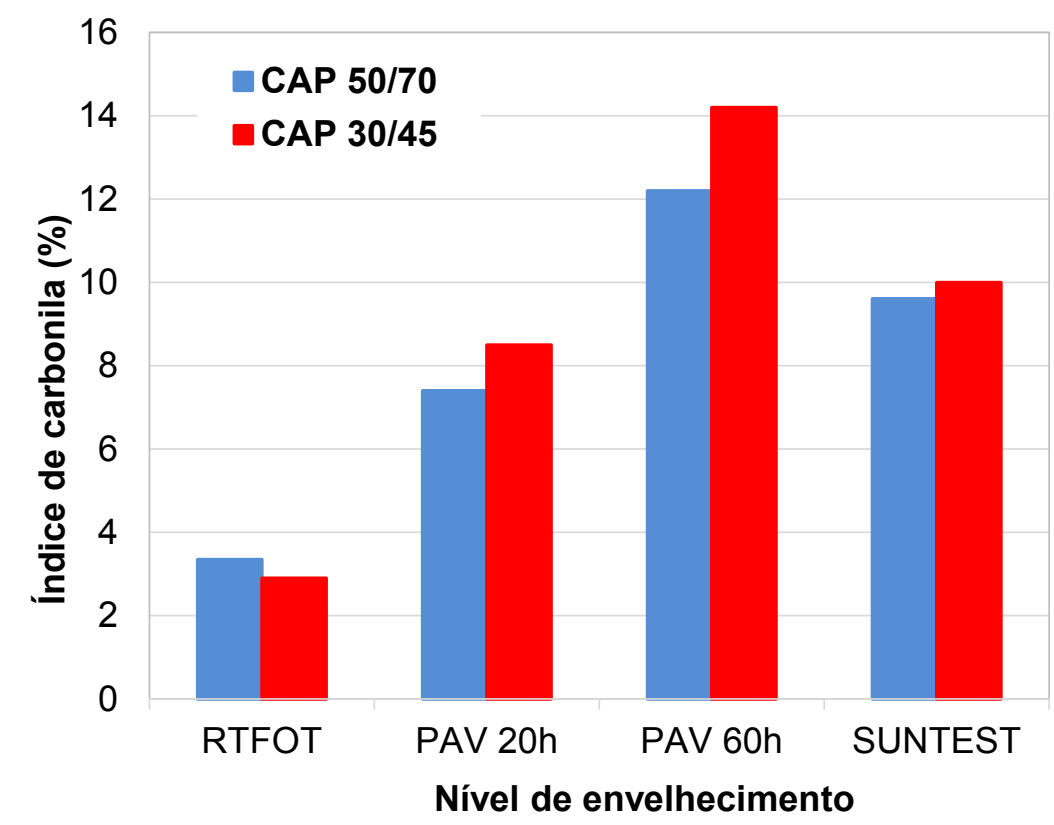

Fonte: Autora

\subsubsection{Ressonância Magnética Nuclear}

A técnica de ressonância magnética nuclear (RMN) permite avaliar a composição química dos ligantes asfálticos. Por meio da análise de $\mathrm{RMN}$ de ${ }^{1} \mathrm{H}$ e ${ }^{13} \mathrm{C}$, pode se obter o esqueleto de carbono de moléculas orgânicas complexas com a distribuição dos átomos de carbono e hidrogênio presentes no ligante (HASAN; ALI; BUKHARI, 1983; SIDDIQUI, 2010).

A avaliação dos ligantes virgens e envelhecidos pela técnica de RMN buscou medir as quantidades de carbono aromático $(\mathrm{Car})$, hidrogênio aromático $(\mathrm{Har})$ e hidrogênio alfa $\left(\mathrm{H}_{\alpha}\right)$. A partir dos resultados foi determinado o ISA (índice de substituição de anéis aromáticos), calculado pela relação entre o percentual de carbonos aromáticos e o percentual de hidrogênios aromáticos. Os valores do ISA e de $\mathrm{H}_{a}$ para cada ligante, nos diferentes níveis de envelhecimento em laboratório, são apresentados na Figura 27. 
Figura 27 - Resultados do ensaio RMN ara os ligantes envelhecidos em laboratório.

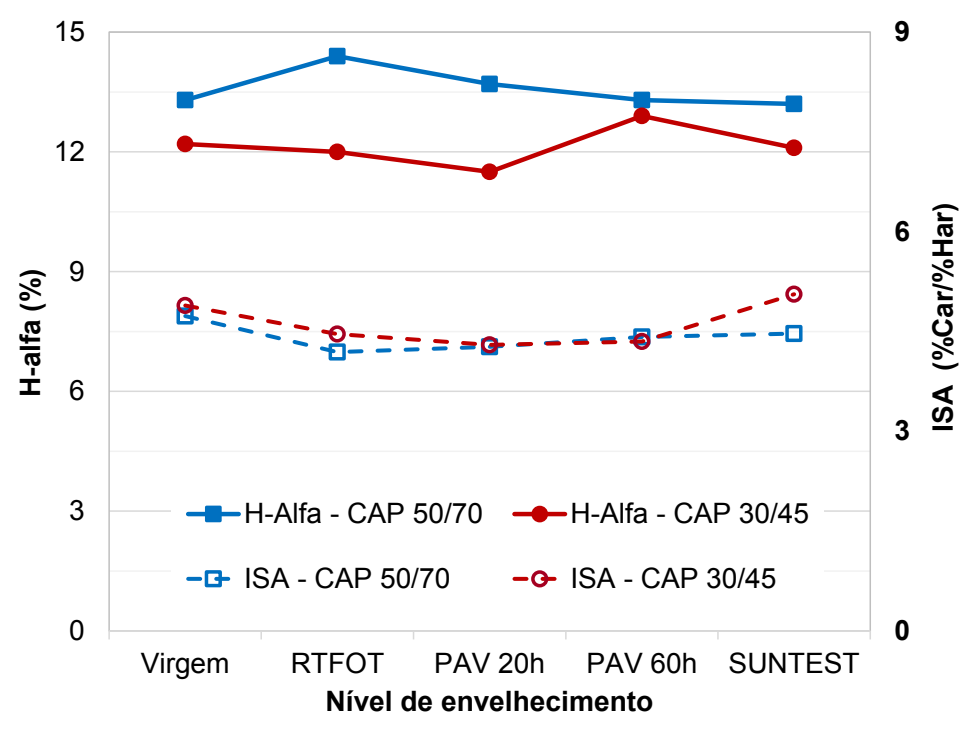

Fonte: Autora

Segundo Cravo (2016), o teor de carbonos aromáticos aumenta durante o processo de envelhecimento devido as reações de aromatizações e condensação. Dessa forma, era esperado que o valor do ISA aumentasse com o nível de envelhecimento, porém essa tendência não é observada para os ligantes analisados. Como o parâmetro ISA é calculado pela relação entre o percentual de carbonos aromáticos e o percentual de hidrogênios aromáticos, a tendência contrária após RTFOT pode ter ocorrido pela diminuição de carbonos aromáticos em decorrência de reações de oxidação que transformam moléculas aromáticas em quinonas e reações de abertura de anéis aromáticos devido à perda de voláteis (JENNINGS et al., 1993; LUCENA; SOARES; SOARES, 2003). Osmari et al. (2017) verificaram ainda que este parâmetro não varia de forma considerável com o envelhecimento, para ligantes com PG de alta temperatura similares.

Ma, Li e Huang (2011) observaram que a quantidade de Ha diminuiu com o envelhecimento, Siddiqui e Ali (1999a) também observaram a redução de $\mathrm{H}_{\alpha}$, atribuindo este resultado a processos de isomerização de $\mathrm{Ha}$ durante os 
envelhecimentos de curto e longo prazo. Segundo Cravo (2016), o hidrogênio alfa se encontra na posição mais fraca com relação ao anel aromático, sendo facilmente retirado durante a reação de oxidação.

Assim como o ISA, o parâmetro Ha não apresentou uma tendência clara com relação ao nível de envelhecimento. Para o CAP 50/70, após uma elevação do valor de $\mathrm{H}_{\alpha}$ no envelhecimento de curto prazo, os valores decrescem com o aumento de envelhecimento. No entanto, o valor de $\mathrm{H}_{\alpha}$ após o envelhecimento de longo prazo é muito próximo do valor do ligante virgem. O CAP 30/45 apresenta a tendência de diminuir o valor de $\mathrm{H}_{\alpha}$, porém após o envelhecimento PAV 60h apresenta valor superior a condição virgem.

Os resultados mostram que os parâmetros avaliados não apresentaram a tendência esperada com relação ao nível de envelhecimento, para ambos os ligantes. Devido a complexidade da composição química dos ligantes asfálticos, diversas reações como aromatização, condensação, fragmentação, desalquilação e a ruptura de ciclos naftênicos podem acontecer durante o processo de envelhecimento (SIDDIQUI; ALI, 1999a). Além disso, essas reações podem acontecer concomitantemente e competir entre si (CRAVO, 2016).

\subsection{CONCLUSÕES}

Neste capítulo, foram avaliados o envelhecimento em laboratório de dois ligantes convencionais em diferentes níveis, considerando o envelhecimento termo oxidativo e por radiação UV.

A partir dos resultados reológicos e químicos foi possível avaliar a influência do envelhecimento sobre as propriedades dos ligantes asfálticos. A du ração prolongada do ensaio PAV para 60 horas provocou um maior envelhecimento dos ligantes asfálticos, colocandoambos os ligan tes na zona de dano pela avaliação do parâmetro GR. O envelhecimento pelo SUNTEST foi o mais severo, mostran do a importân cia da radiação UV no processo de envelhecimento dos ligantes asfálticos. Apesar análise química ser mais sensível e não ter apresentado uma tendência específica, como observado na literatura, as técnicas permitem avaliar as alterações provocadas nos 
ligantes pelos diferentes níveis de envelhecimento, principalmente com relação a diferença entre o envelhecimento termo oxidativo e por radiação UV, mostrando que reações químicas diferentes podem ocorrer durante o envelhecimento por radiação UV. No entanto, uma abordagem mais aprofundada dos resultados se faz necessária para melhor compreender a influência da composição química do ligante no processo de envelhecimento, assim como, as diferentes reações químicas decorrentes de tal processo. 


\section{ENVELHECIMENTO DE LIGANTES ASFÁLTICOS EM CAMPO}

\subsection{INTRODUÇÃO E REVISÃO BIBLIOGRÁFICA}

O ligante asfáltico é um material orgânico que envelhece em presença do oxigênio, especialmente em altas temperaturas. $O$ envelhecimento do ligante ocorre durante $o$ processo de usinagem, transporte, aplicação e compactação (envelhecimento de curto prazo) e ao longo da vida de serviço do pavimento (envelhecimento de longo prazo) (LU; ISACSSON 2002; HUNTER SELF; READ, 2015; MASSON et al. 2006; BERNUCCl et al., 2010; GENNESSEAUX, 2015; DONDI et al. 2016).

O envelhecimento provoca o aumento da rigidez e da viscosidade do ligante, sendo associado principalmente à perda de compostos voláteis e à oxidação do ligante durante o envelhecimento de curto prazo (AIREY, 2003). Na Figura 28 é apresentado o índice de envelhecimento do ligante asfáltico du rante as etapas de construçãoe vida de serviço do pavimento (HUNTER SELF; READ, 2015).

Figura 28 - Envelhecimento do ligante asfáltico durante a usinagem, estocagem, transporte e aplicação e vida de serviço do pavimento

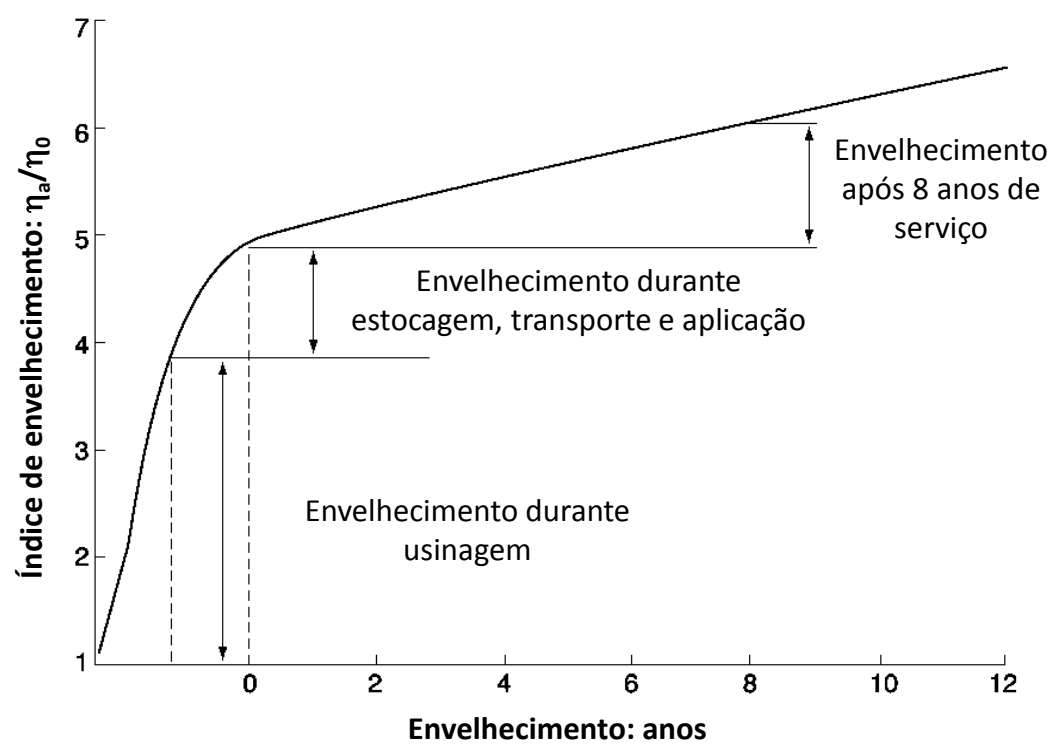

Fonte: Adaptado de Hunter, Self e Read, 2015. 
No entanto, o processo de envelhecimento do ligante asfáltico é complexo devido à influência da origem do ligante asfáltico, das condições de usinagem e condições ambientais a que o pavimento está sujeito em campo (LU; ISACSSON, 2002; ERKENS et al., 2016).

De acordo com alguns autores, o envelhecimento em campo ocorre devido a processos físico-químicos complexos, principalmente atribuídos a oxidação, volatização de compostos, polimerização do ligante asfáltico devido à radiação UV e steric hardening (WU et al., 2008; MENAPACE et al., 2018). O volume de vazios, quando alto, facilita o processo de envelhecimento (BAHIA; ANDERSON, 1995; LU; TALON; REDELIUS, 2008) e a espessura do filme de ligante também influencia nesse processo.

Dessa forma, muitos estudos buscaram entender o efeito do envelhecimento nas propriedades físicas, químicas e reológicas dos ligantes e seu efeito no desempenho e a durabilidade dos pavimentos asfálticos (LIN et al., 1995; LU; ISACSSON, 2002; FENG et al., 2013; QIN et al., 2014; OSMARI et al., 2017; TARSI et al., 2018; ZENG et al., 2018).

Segundo El Beze (2008), os principais fatores que influenciamo processo de oxidação do ligantes asfáltico em campo são: (i) a luz solar, através de reações de foto-oxidação na parte superficial do pavimento provocando a polimerização de resinas em asfaltenos; (ii) a temperatura, responsável por acelerar a difusão do oxigênio e também ser parte da energia de ativação das reações de oxidação; (iii) a água, pois favorece a degradação do pavimento e solubiliza os produtos de degradação; (iv) o oxigênio, principal composto para oxidação do ligante asfáltico, penetra lentamente no pavimento asfáltico por difusão.

Nos últimos anos, o efeito da radiação UV no envelhecimento a longo prazo vem sendo cada vez mais estudado (WU et al., 2010; LEITE et al, 2018). Feng et al. (2013) mostraram que o envelhecimento por UV aumenta a viscosidade e os valores de $\left|\mathrm{G}^{*}\right|$, e que reações de cisão em cadeia, aromatização e oxidação ocorrem simultaneamente no processo de envelhecimento. 
Neste contexto, esse capítulo tem por objetivo avaliar o envelhecimento em campo de ligantes asfálticos a partir de caracterização reológica e química, assim como, fazer um paralelo do estudo do envelhecimento em laboratório e em campo, comparandoos de modo a validar a simulação do envelhecimento em laboratório e determinar um procedimento de envelhecimento para o capítulo subsequente de rejuvenescimento. As etapas do estudo do envelhecimento em campo são apresentadas na Figura 29.

Figura 29 - Etapas de estudo do envelhecimento em campo

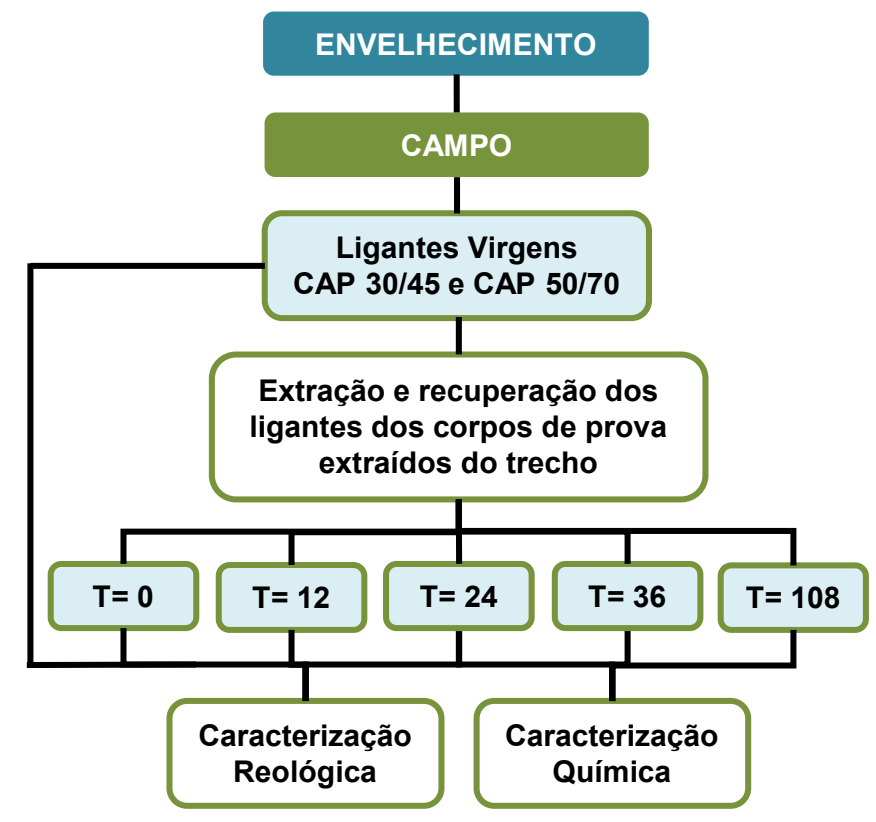

Fonte: Autora

\subsection{MATERIAIS E MÉTODOS}

\subsubsection{Trecho experimental}

Os ligantes asfálticos avaliados neste capítulo são os mesmos utilizados no envelhecimento de laboratório (Capítulo 3). Os ligantes foram envelhecidos em campo em dois segmentos de um trecho experimental localizado na Estrada do Leite no município de Patrocínio Paulista, estado de São Paulo (Figura 30). O trecho experimental faz parte da Rede Temática de Asfalto e foi construído em abril/2010. 
Ambos os revestimentos foram executados com mistura asfáltica usinada a quente densa, com $4 \mathrm{~cm}$ de espessura, constituída por agregados basálticos com tamanho máximo nominal de 12,5 cm. Foram utilizados o CAP 30/45 (PG 70S-XX) no teor de $4,9 \%$ e o CAP 50/70 (PG 64S-XX) no teor de 4,7\%.

O tráfego previsto (número "N") foi igual a $2,5 \times 10^{6}$ para 10 an os da via, tomando como base projetos estudados anteriormente para estradas do mesmo porte, considerando também a crescente expansão do cultivo de cana-de-açúcar, devido à proximidade de uma usina açucareira.

Figura 30 - Localização do trecho experimental. Em (a) localização do trecho na Estrada do Leite, em (b) localização dos segmentos e em (c) pavimento executado

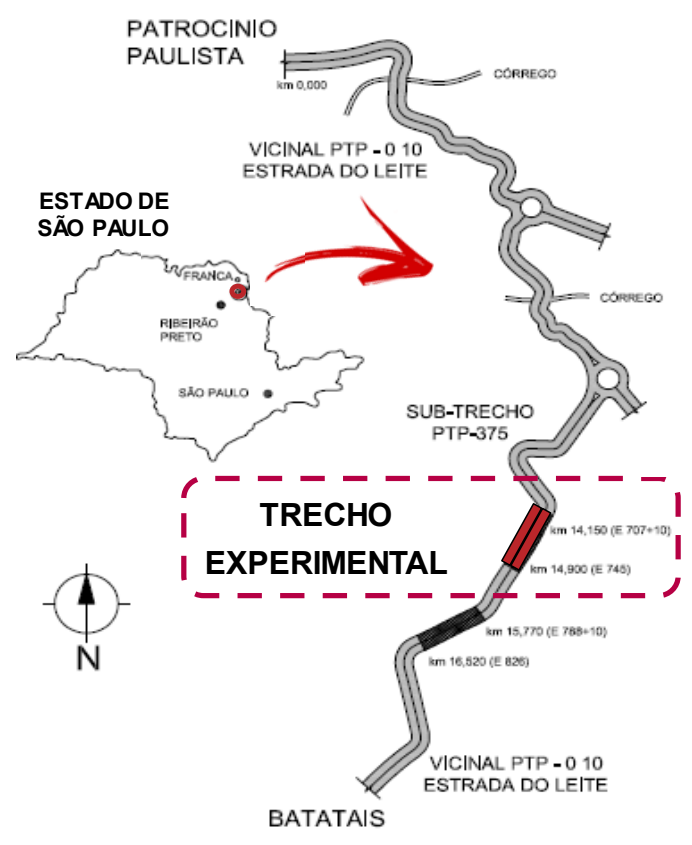

(a)

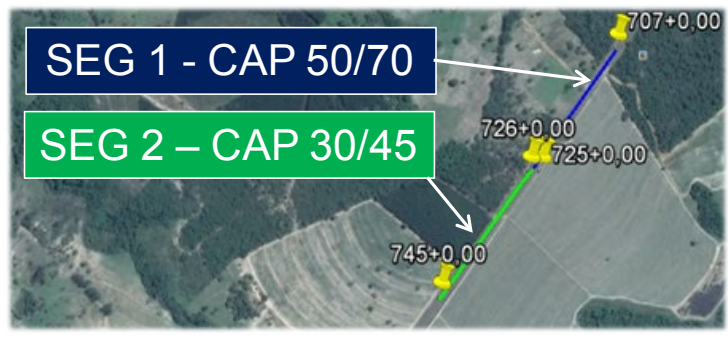

(b)

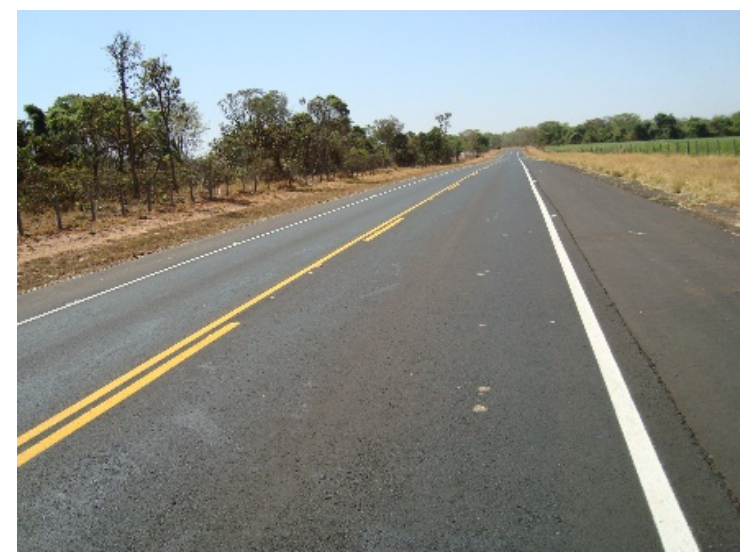

(c)

Fonte: Projeto Rede Temática de Asfálto

As amostras foram extraídas dos revestimentos (Figura 31) em diferentes períodos ( $T=0,12,24,36$ e 108 meses após a construção do pavimento), sendo as amostras de 108 meses coletadas durante o desenvolvimento dessa dissertação. Em 
laboratório as amostras passaram por raspagem para retirada solo proveniente da camada inferior ao revestimento. Os ligantes foram extraídos e recuperados das amostras inteiras, com $4 \mathrm{~cm}$ de altura (Figura 31c), de acordo com as normas ASTM D2172 - Método B (2017) e ASTM D1856 (2015), respectivamente, ao menos 3 amostras foram utilizadas no processo para resultar em quantidade suficiente para o estudo. Para quantificaro envelhecimento no campo, foram avaliadas as propriedades químicas e reológicas dos ligantes asfálticos recuperados.

Figura 31 - Extração dos corpos de prova dos revestimentos asfálticos. Em (a) processo de extração com perfuratriz, em (b) revestimento perfurado e em (c) amostra

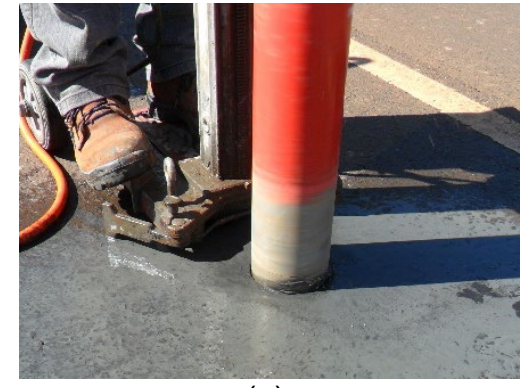

(a)

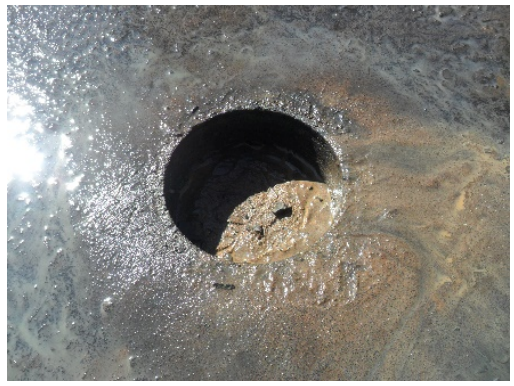

(b)

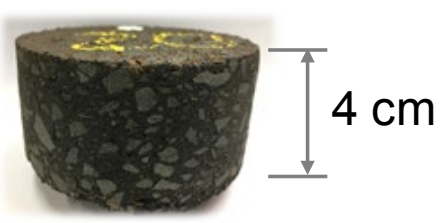

(c)

Fonte: Projeto Rede Temática de Asfálto

\subsubsection{Ensaios reológicos e químicos}

A caracterização reológica e química dos ligantes foi realizada da mesma forma que o estudo do Capítulo 3. Foram realizados ensaios de varredura de frequência e temperatura para avaliação das propriedades viscoelásticas lineares e análise dos parâmetros crossover modulus, crossover frequency, parâmetro $R$ e Glover-Rowe (GR). Além disso, os ensaios MSCR (ASTM D7405, 2015) e LAS (AASHTO TP 101), foram realizados nas temperaturas de $70{ }^{\circ} \mathrm{C}$ e $20^{\circ} \mathrm{C}$, respectivamente, para avaliar a resistência à deformação permanente e à fadiga dos ligantes nos diferentes níveis de envelhecimento. Os ensaios de fracionamento SARA, cromatografia de permeação em gel (GPC), espectroscopia de infravermelho com tran sformada de Fourier (FTIR) e ressonância magnética nuclear (RMN) foram realizados no Cenpes/Petrobras para avaliar as alterações químicas decorrentes do envelhecimento em campo. Os 
procedimentos dos ensaios realizados encontram-se descritos nas seções 3.2 .2 e 3.2.3.

\subsection{RESULTADOSE DISCUSSÕES}

\subsubsection{Curvas mestras de $\left|G^{*}\right|$ e $\delta$}

A Figura 32 apresenta as curvas mestras do módulo de cisalhamento dinâmico $\left(\left|G^{*}\right|\right)$ e do ângulo de fase $(\delta)$ dos dois ligantes, na temperatura de $15^{\circ} \mathrm{C}$, para os cinco períodos de envelhecimento em campo. Diferentemente dos resultados de laboratório, as curvas mestras se sobrepõem, principalmente em altas frequências (baixas temperaturas), não ficando tão evidente a influência do envelhecimento. Quando os resultados são comparados um par de curva por vez, é possível verificar a evolução de $\left|G^{*}\right|$, para baixas frequências (temperaturas altas).

Figura 32 - Curvas mestras de $\left|G^{*}\right|$ e $\delta$ dos ligantes envelhecido em campo. Em (a) CAP 50/70 e em (b) CAP 30/45.

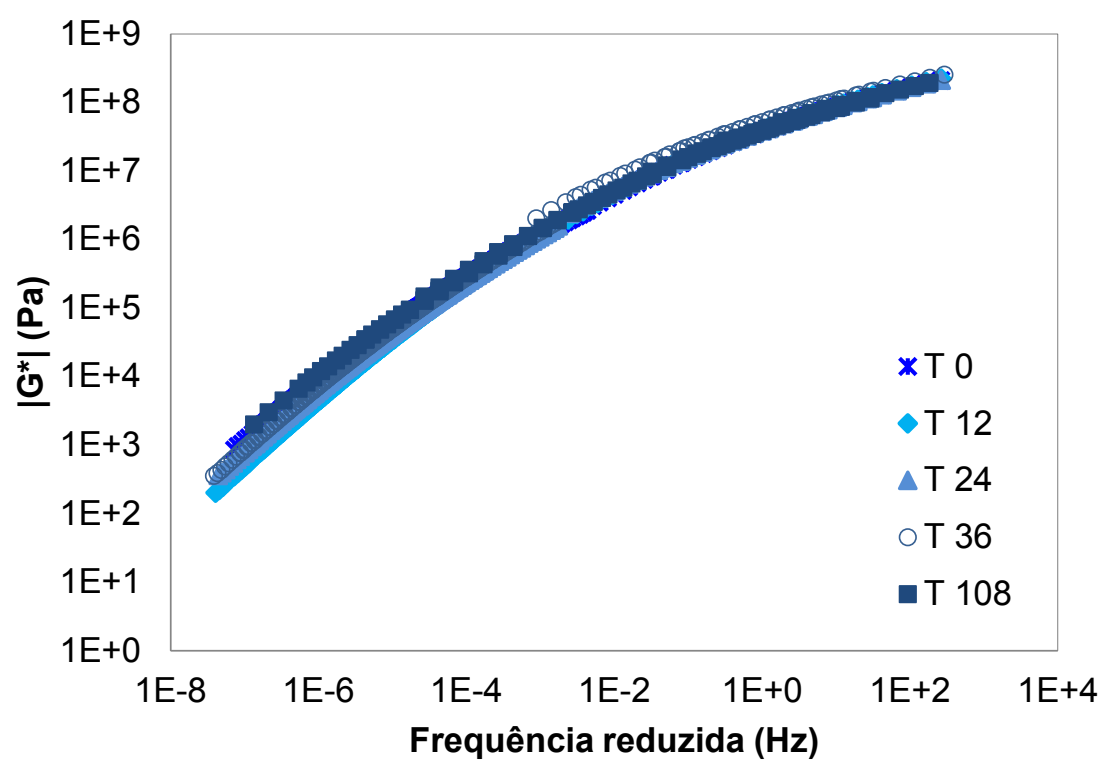

(a) 


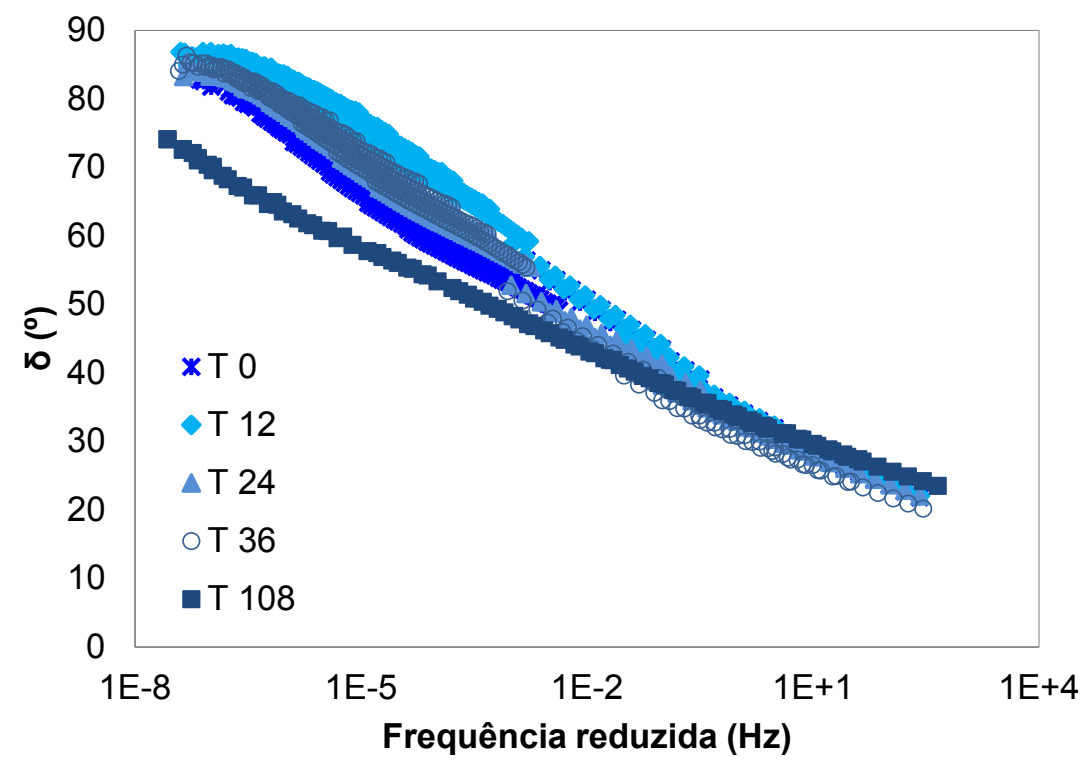

(b)

Fonte: Autora

Figura 33 - Curvas mestras de $\left|G^{*}\right|$ e $\delta$ dos ligantes envelhecido em campo. Em (a) CAP 50/70 e em (b) CAP 30/45.

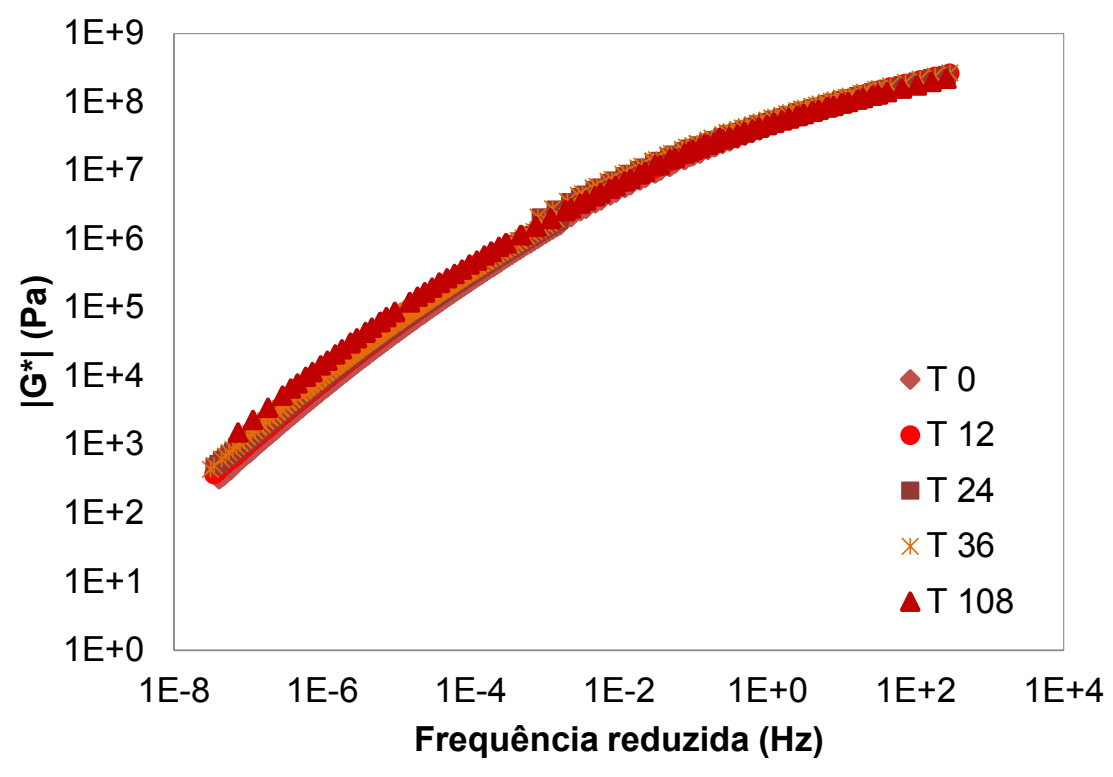

(a) 


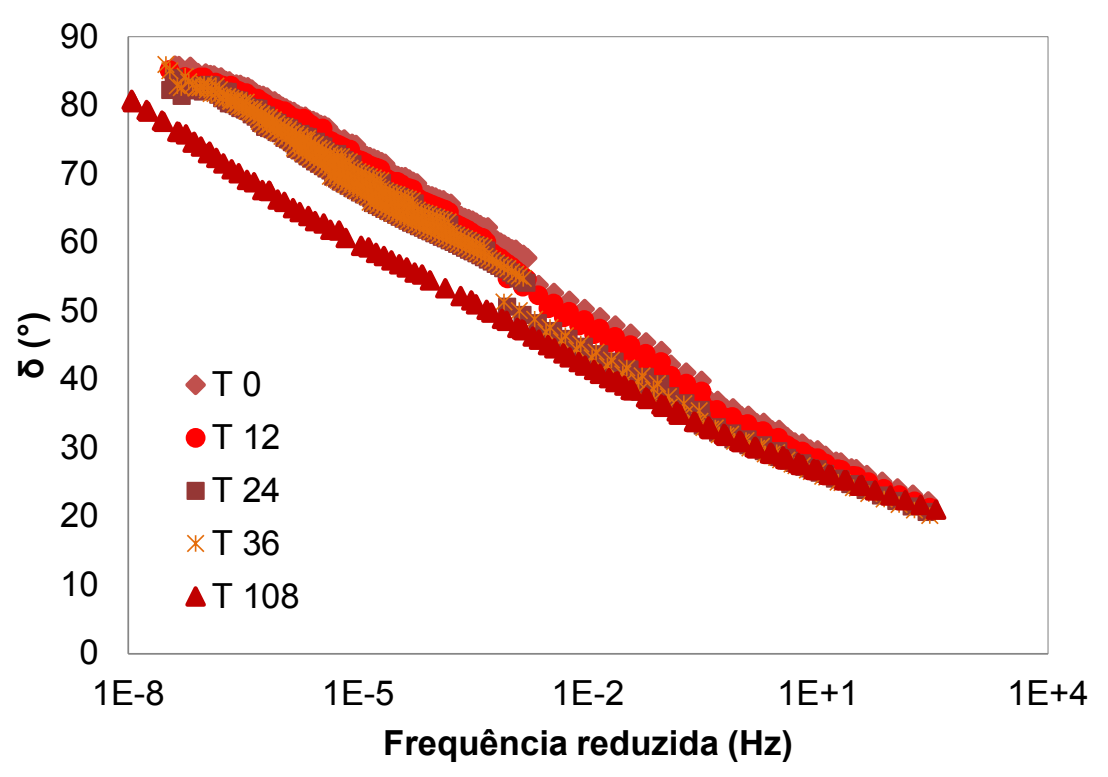

(b)

Fonte: Autora

Contudo, o CAP 50/70 em $\mathrm{T}=0$ apresentou resultados diferentes do esperado, apresentando rigidez superior a $\mathrm{T}=24$ meses, bem próximo de $\mathrm{T}=36$ meses, mais perceptível em baixas frequências (altas temperaturas). Acredita-se que isso pode ser decorrente de todos os processos empregados desde a construção do pavimento, extração dos corpos de prova e do processo de extração e recuperação do ligante asfáltico, como por exemplo: um super aquecimento durante a usinagem, interação do ligante com o material pétreo (CRAVO, 2016), ou mesmo a sobra de finos não filtrados adequadamente durante o processo de extração e recuperação do ligante asfáltico Como observado por Gaspar (2016), os processos de extração e recuperação de ligantes asfálticos mais empregados utilizam altas temperaturas e solventes, como o método B (ASTM D2172) utilizado neste trabalho. Essas temperaturas elevadas e a presença de solvente podem alterar as propriedades do ligante recuperado. Um outro fator a ser considerado é que o envelhecimento em campo não ocorre de forma homogênea ao longo da profundidade do revestimento, porém durante o processo de extração e recuperação, as diferentes profundidades são colocadas em conjunto, favorecendo uma maior similaridade entre os diferentes períodos. 


\subsubsection{Crossover modulus $\left(\mathrm{G}^{*} \mathrm{c}\right)$, crossover frequency $\left(\omega_{c}\right)$ e parâmetro $R$}

Os parâmetros crossover modulus $\left(\mathrm{G}^{*} \mathrm{c}\right)$, crossover frequency $\left(\omega_{c}\right)$ e parâmetro $R$, foram determinados na temperatura de $15{ }^{\circ} \mathrm{C}$, para cada ligante nos diferentes níveis de envelhecimento (Tabela 3). Os resultados dos ligantes virgens foram incluídos na tabela para que fosse possível verificar a influência do envelhecimento durante o processo de usinagem e compactação das misturas asfálticas (envelhecimento de curto prazo).

A partir dos resultados é possível verificar a evolução dos parâmetros com o envelhecimento, uma vez que os valores de $\mathrm{G}^{{ }^{*}} \mathrm{e}$ e $\omega_{\mathrm{c}}$ tendem a reduzir e do parâmetro $\mathrm{R}$ tende a aumentar com o aumento do nível de envelhecimento. No entanto, é observada uma tendência con trária para $\mathrm{t}=108$ meses em ambos os ligantes. A Figura 34 apresenta graficamente os parâmetros do $\omega_{c}$ e do parâmetro $R$, para facilitar a interpretação dos resultados.

Tabela 3 - Crossover modulus, crossover frequency e parâmetro $\mathrm{R}$ dos ligantes envelhecidos em campo.

\begin{tabular}{ccccc}
\hline Ligante & Envelhecimento & $\mathrm{G}^{*}{ }_{\mathrm{c}}$ & $\omega_{\mathrm{c}}$ & $\mathrm{R}$ \\
\hline \multirow{5}{*}{$50 / 70$} & Virgem & $3.48 \mathrm{E}+07$ & $1.2 \mathrm{E}+02$ & 1.46 \\
& T 0 & $1.03 \mathrm{E}+07$ & $3.0 \mathrm{E}-01$ & 1.99 \\
& T12 & $1.07 \mathrm{E}+07$ & $3.1 \mathrm{E}-01$ & 1.97 \\
& T 24 & $6.91 \mathrm{E}+06$ & $1.1 \mathrm{E}-01$ & 2.16 \\
& T 36 & $7.43 \mathrm{E}+06$ & $5.9 \mathrm{E}-02$ & 2.13 \\
& T 108 & $8.84 \mathrm{E}+06$ & $1.8 \mathrm{E}-01$ & 2.05 \\
& Virgem & $3.56 \mathrm{E}+07$ & $4.1 \mathrm{E}+01$ & 1.45 \\
& T 0 & $9.12 \mathrm{E}+06$ & $1.9 \mathrm{E}-01$ & 2.04 \\
$30 / 45$ & T12 & $8.92 \mathrm{E}+06$ & $1.3 \mathrm{E}-01$ & 2.05 \\
& T 24 & $6.12 \mathrm{E}+06$ & $4.1 \mathrm{E}-02$ & 2.21 \\
& T 36 & $6.65 \mathrm{E}+06$ & $4.1 \mathrm{E}-02$ & 2.18 \\
& T 108 & $9.97 \mathrm{E}+06$ & $1.5 \mathrm{E}-01$ & 2.00 \\
\hline
\end{tabular}


Figura 34 - Comparação do crossover frequency $\left(\omega_{c}\right)$ e do parâmetro R para os ligantes envelhecidos em campo.

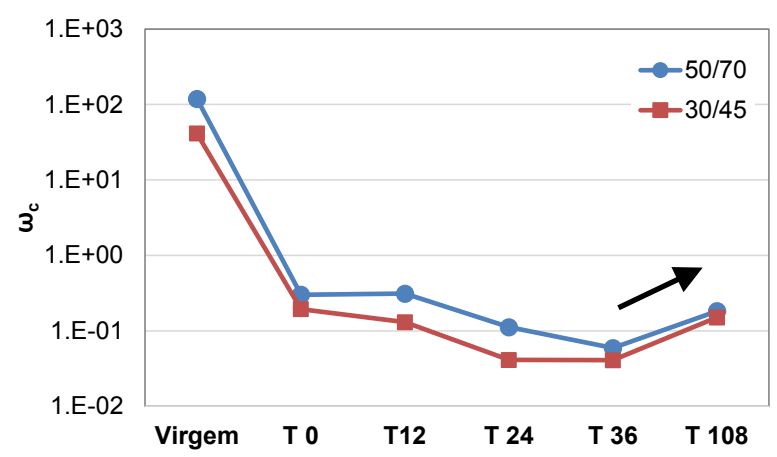

(a)

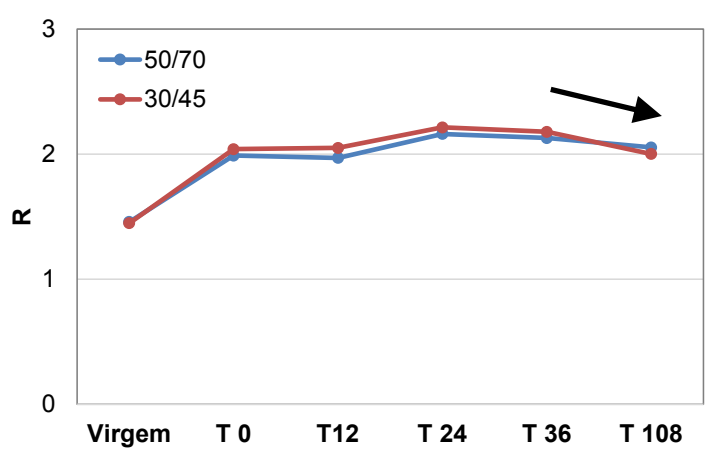

(b)

Fonte: Autora

Pela Figura 34 é possível verificar que os ligantes em $\mathrm{T}=108$ meses apresentam algum tipo de alteração que não foi claramente evidenciada pelas curvas mestras (apresentadas em escala log). Outro ponto levantado são os resultados para o CAP 50/70 em T= 12 meses, que não segue a tendência esperada. Contudo, essa observação não é conclusiva, pois este resultado pode estar sendo mascarado pelo resultado de $\mathrm{T}=0$, uma vez que foi verificado alterações na curva mestra dessas amostras.

\subsubsection{Parâmetro Glover-Rowe (GR)}

Outro parâmetro utilizado na análise dos resultados é o parâmetro GR, que permite avaliar a resistência ao trincamento dos ligantes asfálticos a partir dos resultados de propriedades viscoelásticas lineares. A Figura 35 apresenta os resultados plotados no diagrama de Espaço Black. 
Figura 35 - Diagrama de Espaço Black dos ligantes nos diferentes níveis de envelhecimento em campo. Em (a) CAP 50/70 e em (b) CAP 30/45.

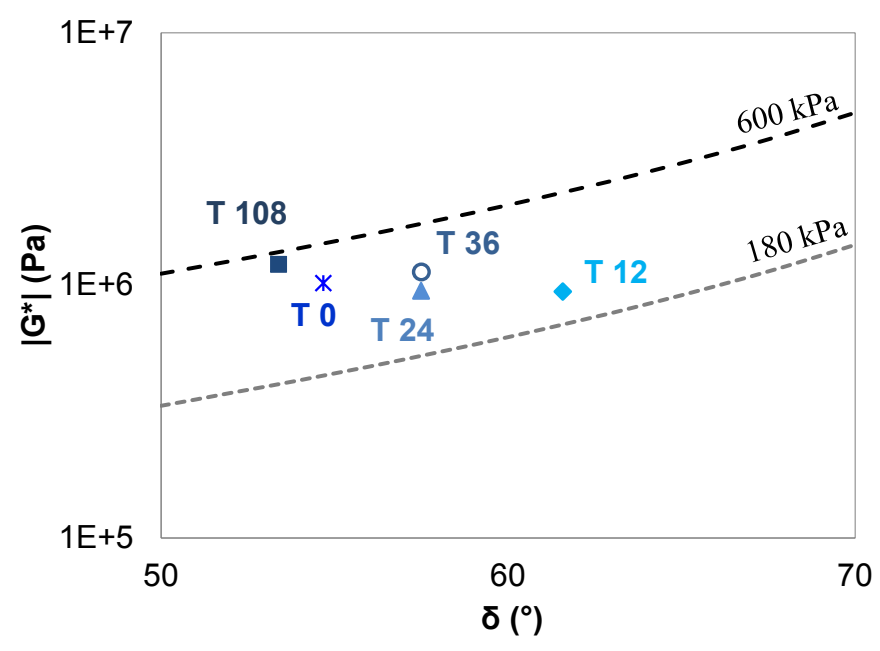

(a)

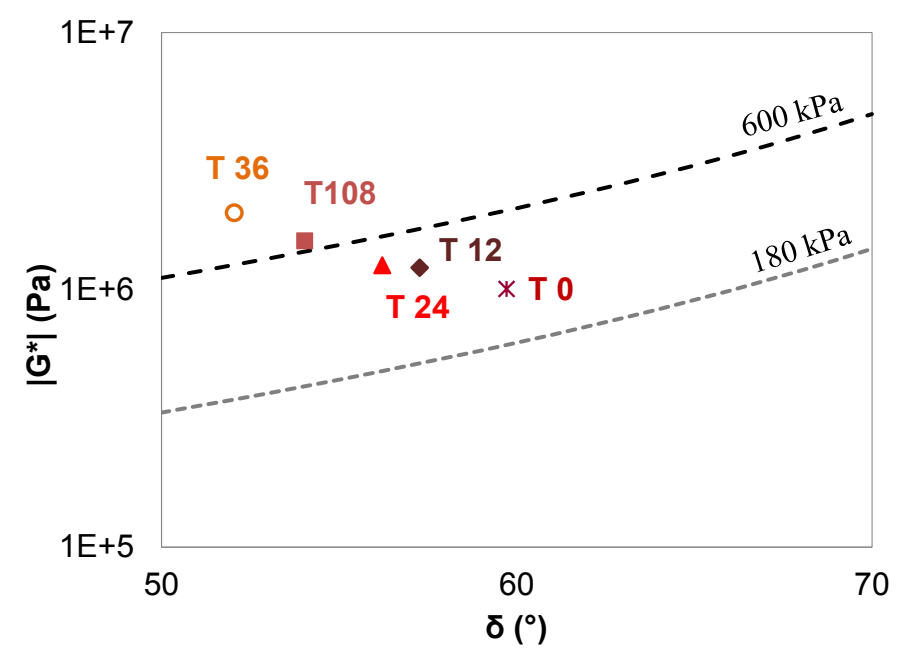

(b)

Fonte: Autora

Os resultados mostram que para o CAP 50/70 todos os níveis de envelhecimento encontram-se nazona de dano, enquanto que para o CAP 30/45 ligantes recuperados em T= 36 e T= 108 meses já estão na região de trincamento em bloco, embora o resultado de $\mathrm{T}=36$ meses seja um pouco questionável, por estar em uma posição avançada da região de trincamento em bloco. Esse resultado para o CAP 30/45 em $\mathrm{T}=108$ meses corrobora com os resultados da análise de crossover. 
Os valores plotados para o CAP 50/70 em T= 0 e $\mathrm{T}=108$ meses (extremos do tempo de avaliação do envelhecimento em campo) ficam muito próximos no diagrama, mostrando mais uma vez, a possibilidade de alteração dessas amostras durante o processo de extração e recuperação. Vale ressaltar que esses parâmetros foram calculados a partir do mesmo resultado do ensaio de varredura de frequência e temperatura, sendo esperado que a variação verificada em um parâmetro seja refletida em outro. Porém, a avaliação pelo parâmetro GR torna mais clara e perceptível a compreensão dos resultados observados nos parâmetros anteriores, mostrando sua contribuição para a análise objetiva dos resultados.

\subsubsection{Ensaio MSCR}

A resistência à deformação permanente dos ligantes envelhecidos em campo foi avaliada através do MSCR (Figura 36). Devido as alterações verificadas nos ligantes em $\mathrm{T}=108$ meses, essas amostras não foram ensaiadas. O CAP 30/45 apresenta valor de Jnr (compliância não recuperável) inferior ao CAP 50/70 em todos os tempos de envelhecimento, indicando que o ligante pode resistir melhor à deformação permanente que o CAP 50/70. Após 36 meses no campo, a diferença entre os ligantes é reduzida, o que sugere que eles passam a apresentar desempenho similar com o tempo. 
Figura 36 - Resultados de Jnr para cada ligantes nos diferentes níveis de envelhecimento em campo. Em (a) tensão de 100Pa e em (b) tensão de 3200 Pa.

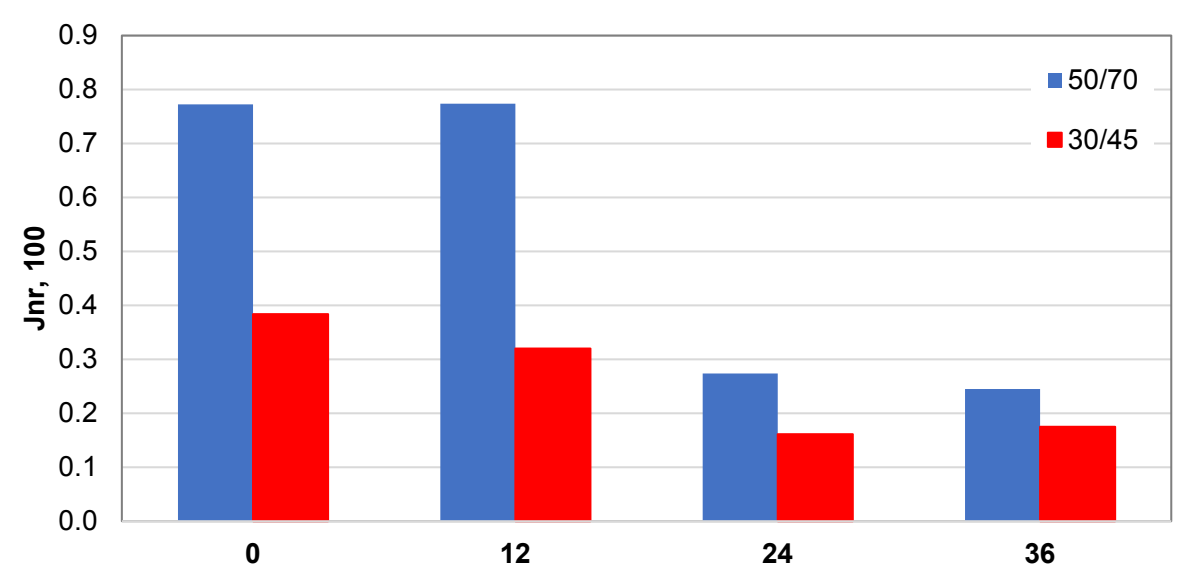

(a)

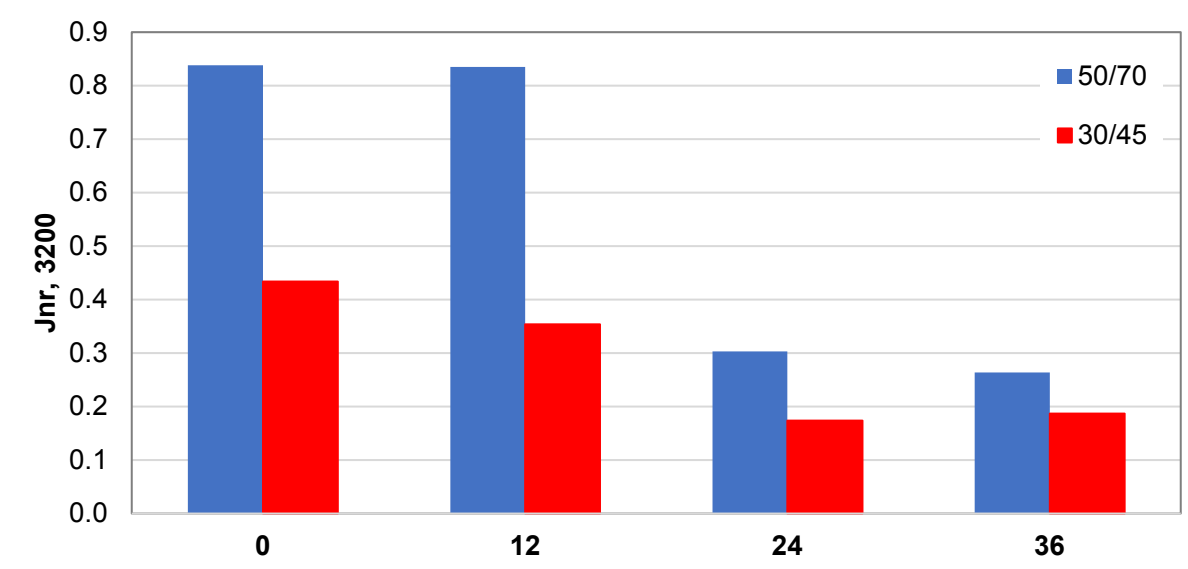

(b)

Fonte: Autora

Os resultados mostram também que o envelhecimento favorece a resistência a deformação permanente. Contudo, observa-se que os valores de Jnr para os ligantes em $\mathrm{T}=0$ são muito baixos, considerando que o ensaio foi realizado na temperatura de $70{ }^{\circ} \mathrm{C}$, o CAP $50 / 70$ poderia ser utilizado para um tráfego muito pesado, enquanto que - CAP 30/45 poderia ser utilizado para um tráfego extremamente pesado de acordo com a norma ASSHTO M332 (2018). Esses níveis de tráfego, nessa temperatura, são incomuns considerando que os ligantes tenham passado apenas pelo envelhecimento de curto prazo. Pelos resultados, é possível inferir que algum processo, ou mesmo uma combinação deles, desde a construção do pavimento até o processo de extração 
e recuperação do ligante asfáltico, tenha causado alteração nas propriedades dos ligantes.

\subsubsection{Ensaio LAS}

O ensaio de varredura linear de amplitude de deformação (LAS) foi realizado nos ligantes para avaliar a resistência à fadiga dos ligantes envelhecidos em campo, em dois níveis de envelhecimento: (i) T= 0 (após usinagem e compactação) e (ii) T= 36 meses. Os resultados da curva característica do dano e da curva de fadiga são apresentados na Figura 37.

Figura 37 - Curva característica de dano (a) e curva de fadiga (b) para o CAP 50/70 envelhecido em campo.

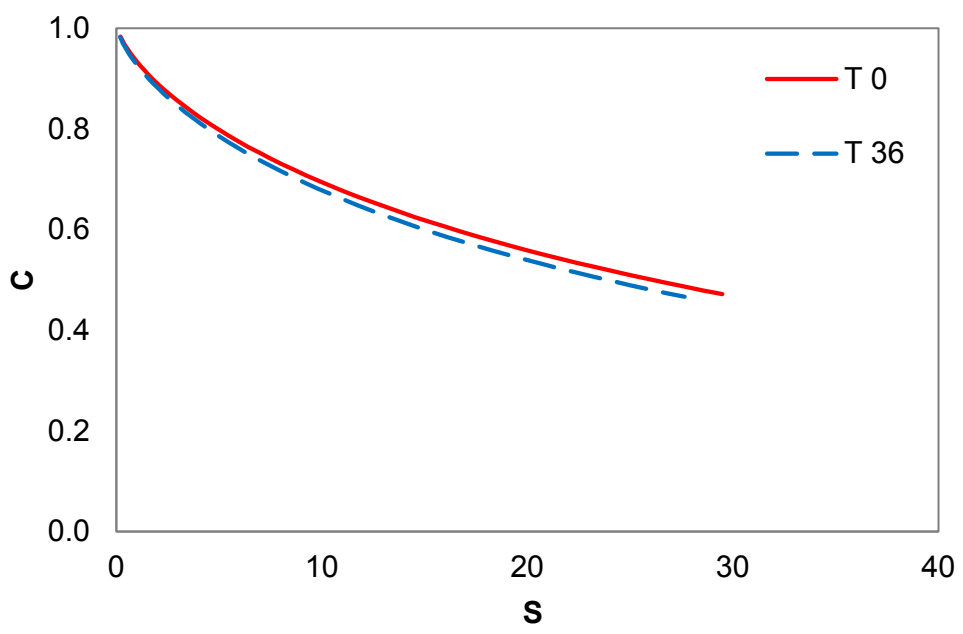

(a) 


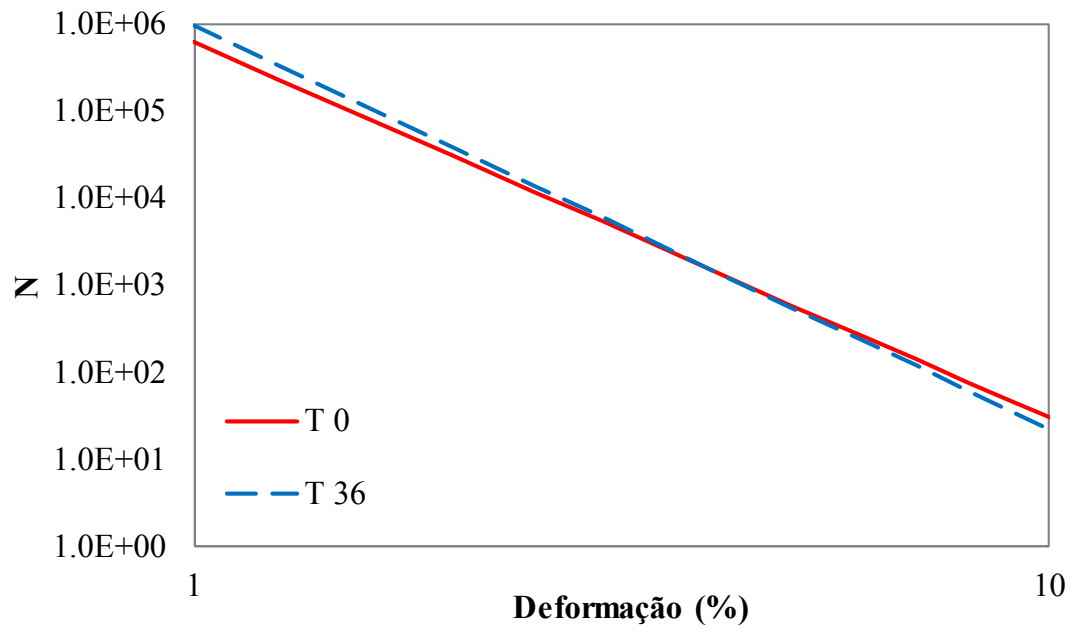

(b)

Fonte: Autora

Figura 38 - Curva característica de dano (a) e curva de fadiga (b) para o CAP 30/45 envelhecido em campo.

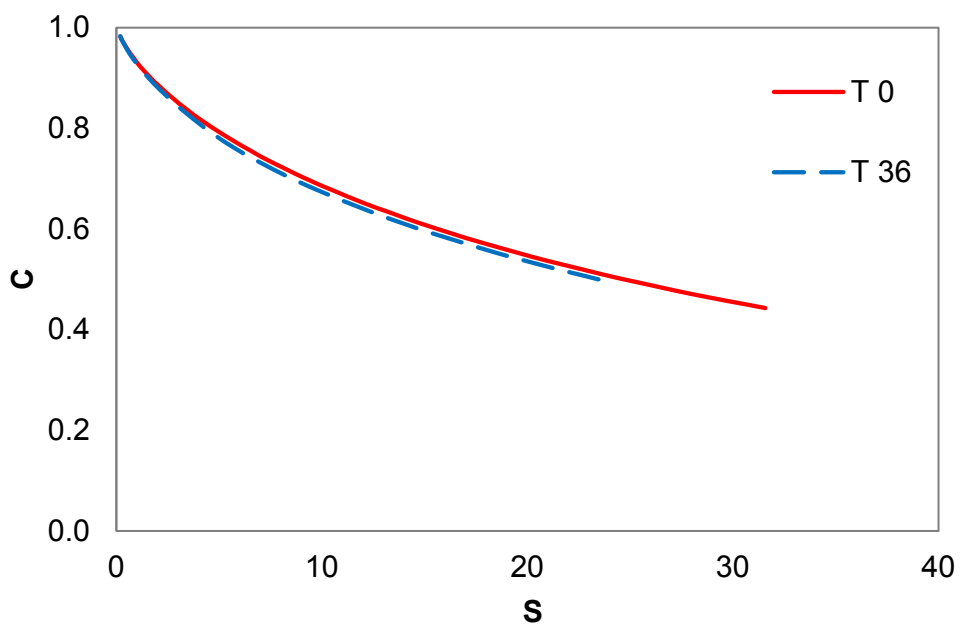

(a) 


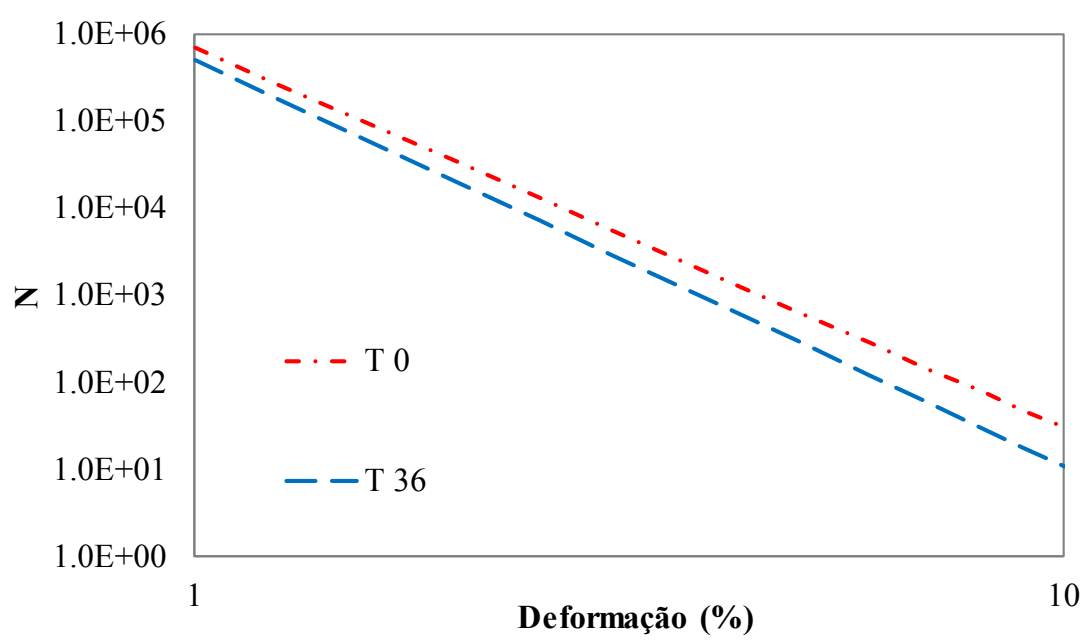

(b)

Fonte: Autora

Os ligantes em $\mathrm{T}=0$ foram escolhidos para fazer a comparação e avaliar $\mathrm{o}$ desempenho entre os dois ligantes aplicados no trecho experimental. A partir das curvas característica de dano é possível verificar que o CAP 30/45 sofre maior influência do en velhecimento em campo, resistindo menos ao dano que o CAP 50/70. Pela curva de fadiga fica evidente o efeito do envelhecimento sobre o CAP 30/45, apresentando resistência inferior após 36 meses em campo. Já para o CAP 50/70, o envelhecimento proporciona um aumento da rigidez que, para baixas deformação, é benéfico. No entanto com o aumento da deformação o ligante mais envelhecido perde resistência e apresenta pior comportamento quanto ao trincamento por fadiga.

\subsubsection{Fracionamento SARA}

A Figura 39 apresenta os resultados das análises químicas das frações SARA. O teor de asfaltenos aumenta e o teor de aromáticos diminui, principalmente durante 0 envelhecimento de curto prazo $(\mathrm{T}=0)$. Porém, ao longo dos anos as frações de asfaltenos, diminuem entre $T=12$ e $T=24$ meses e em seguida volta a aumentar em $\mathrm{T}=36$ meses, e volta a reduzir em $\mathrm{T}=108$ meses. Assim como o aumento de aromáticos em $\mathrm{T}=24$ meses para o CAP 30/45 e em $\mathrm{T}=36$ meses para o CAP 50/70, 
é uma tendência não esperada de acordo com a literatura (QIN et al., 2014; Wu et al., 2017).

Figura 39 - Resultado fracionamento SARA dos ligantes envelhecidos em campo. Em (a) CAP 50/70 e em (b) CAP 30/45

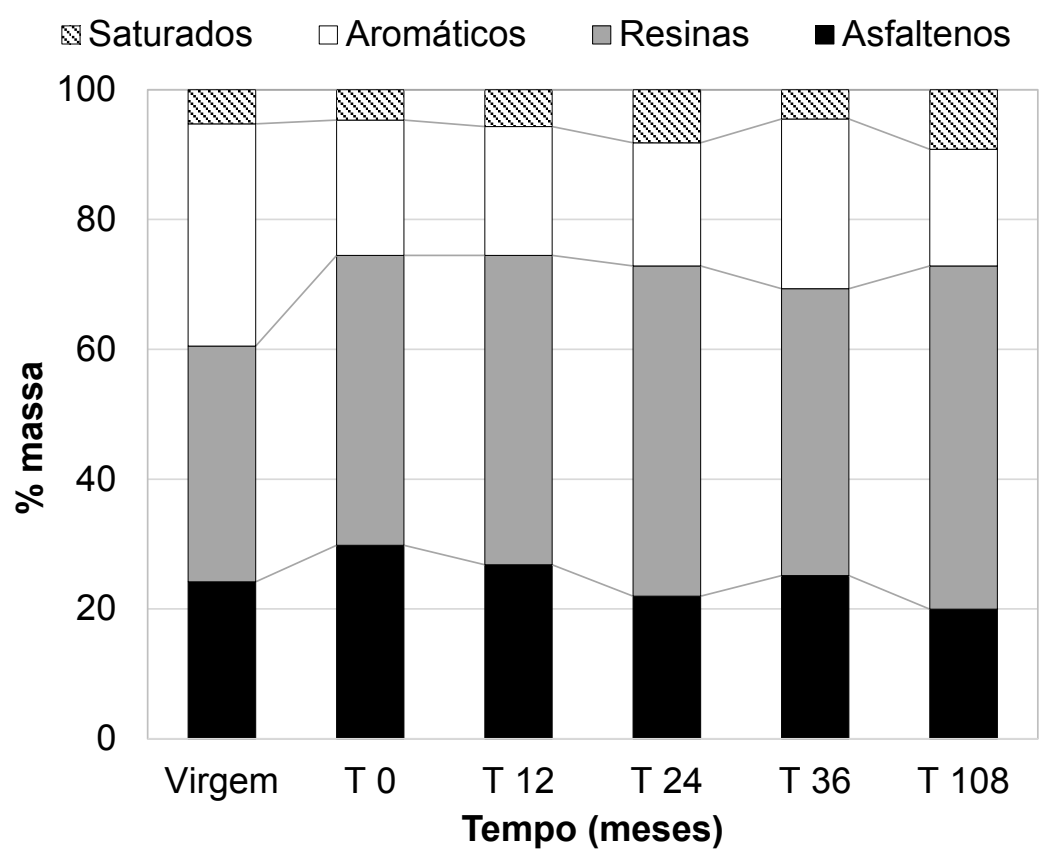

(a)

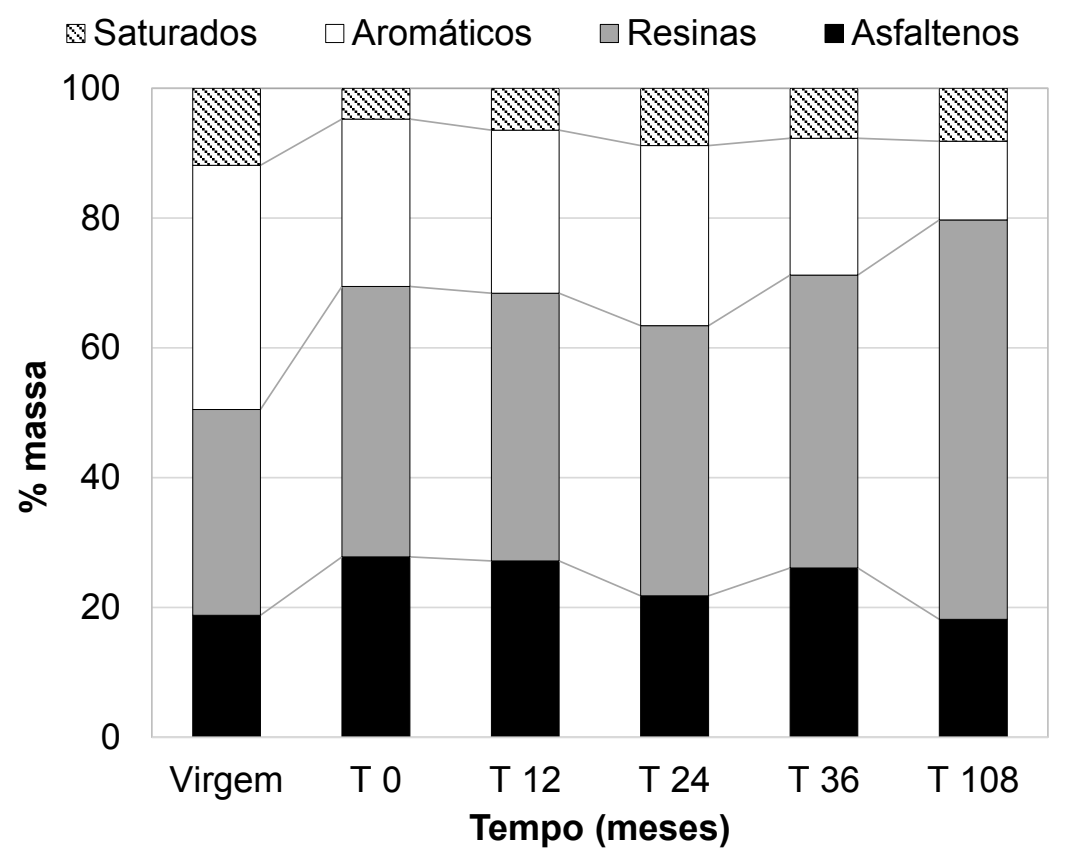

(b) 
Fonte: Autora

Após nove anos exposto a intempéries e ao tráfego, os ligantes apresentam grande redução da fração de aromáticos, porém, diferente do esperado, a fração de asfaltenos não aumentou proporcionalmente, apresentando redução no teor de asfaltenos após 108 meses em ambos os ligantes.

\subsubsection{Distribuição do peso molecular (GPC)}

Na Figura 40 são apresentados os resultados da análise de distribuição do tamanho molecular dos ligantes envelhecidos em campo. Os resultados para $\mathrm{T}=108$ meses não são apresentados, pois não foi possível concluir as análises. De acordo com Cravo (2016), o aumento do envelhecimento resulta no aumento das moléculas de grande tamanho molecular, devido as reações que acontecem durante o envelhecimento. Diferente do fracionamento SARA, a evolução desse parâmetro com o envelhecimento é bem sutil, sendo possível verifica o aumento da fracção de grande tamanho molecular em ambos os ligantes. 
Figura 40 - Resultados ensaio GPC dos ligantes envelhecidos em campo. Em (a) CAP 50/70 e em (b) CAP 30/45

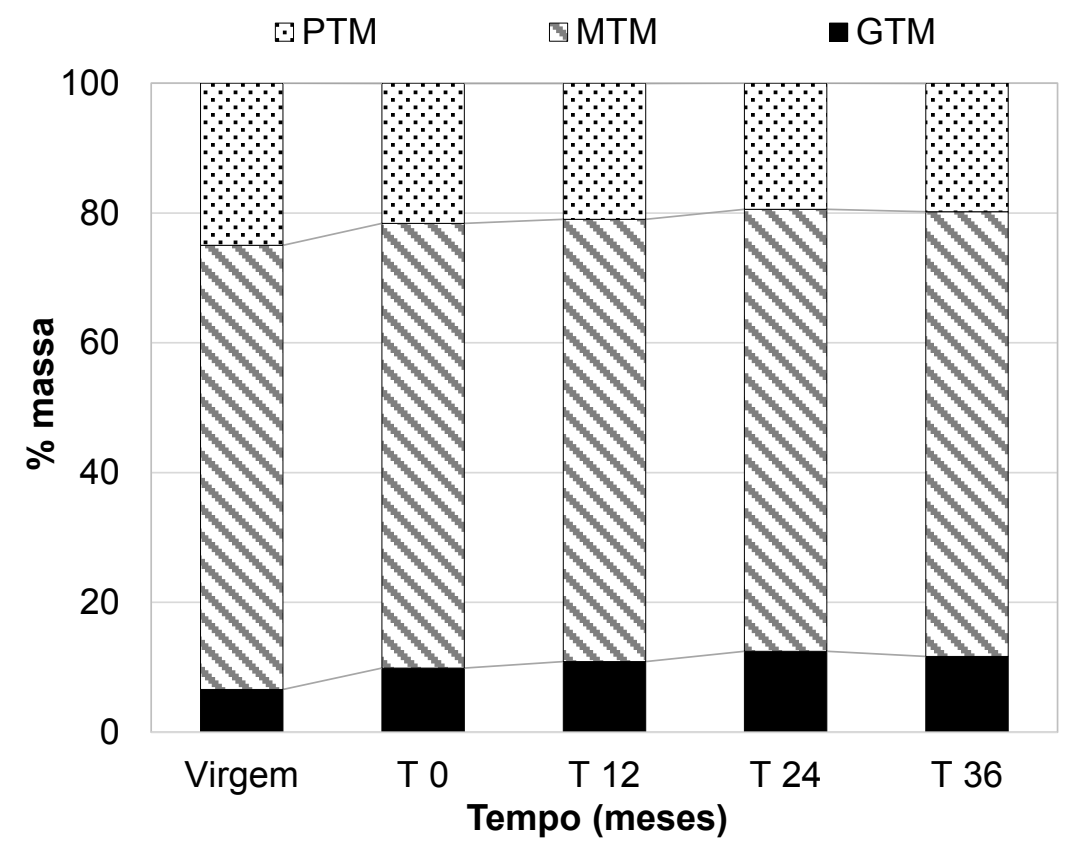

(a)

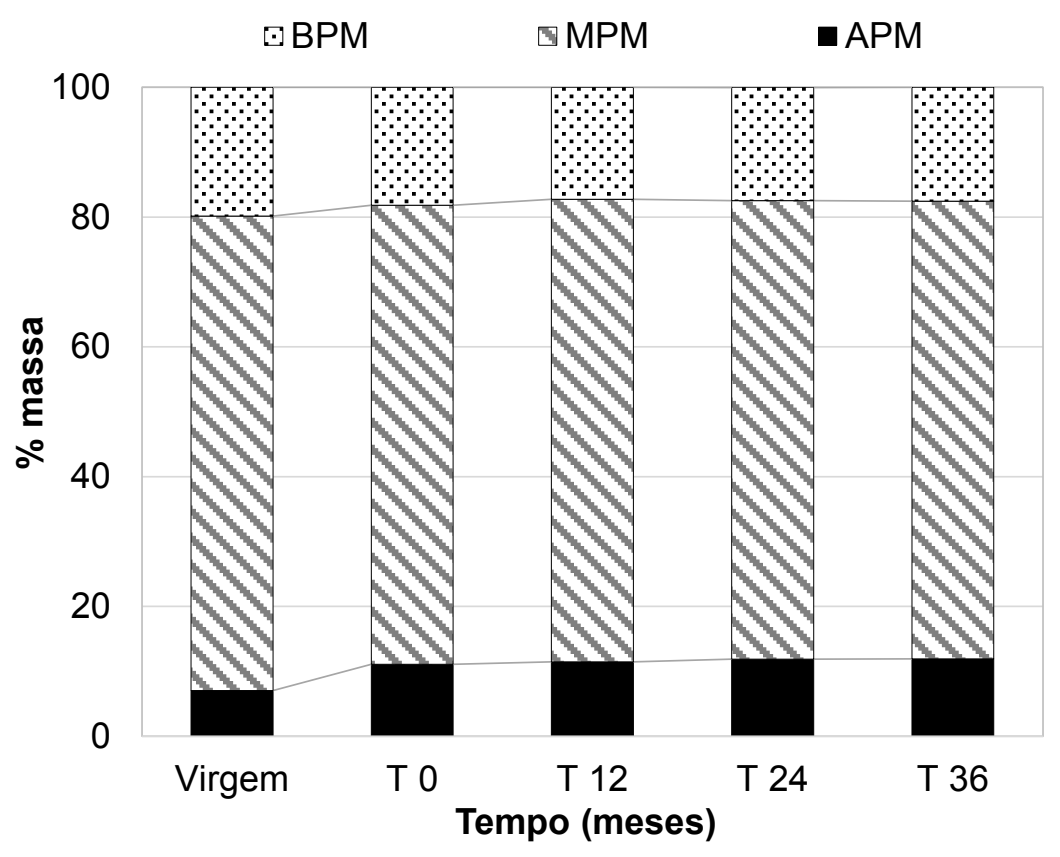

(b)

Fonte: Autora 


\subsection{8. Índice de carbonila (Ic)}

Os resultados dos ensaios FTIR são apresentados na Figura 41. O envelhecimento em campo aumentou o índice de carbonila $(\mathrm{l}=0)$ nos dois ligantes asfálticos, apresentando resultados bem próximos em $\mathrm{T}=24$ meses e em $\mathrm{T}=36$ meses para cada ligante e bem próximos entre os ligantes em $T=36$ meses, com maior evolução do índice após maior tempo de exposição do pavimento em $\mathrm{T}=108$ meses, principalmente para o CAP 30/45.

Figura 41 - Índice de carbonila dos ligantes em diferentes níveis de envelhecimento

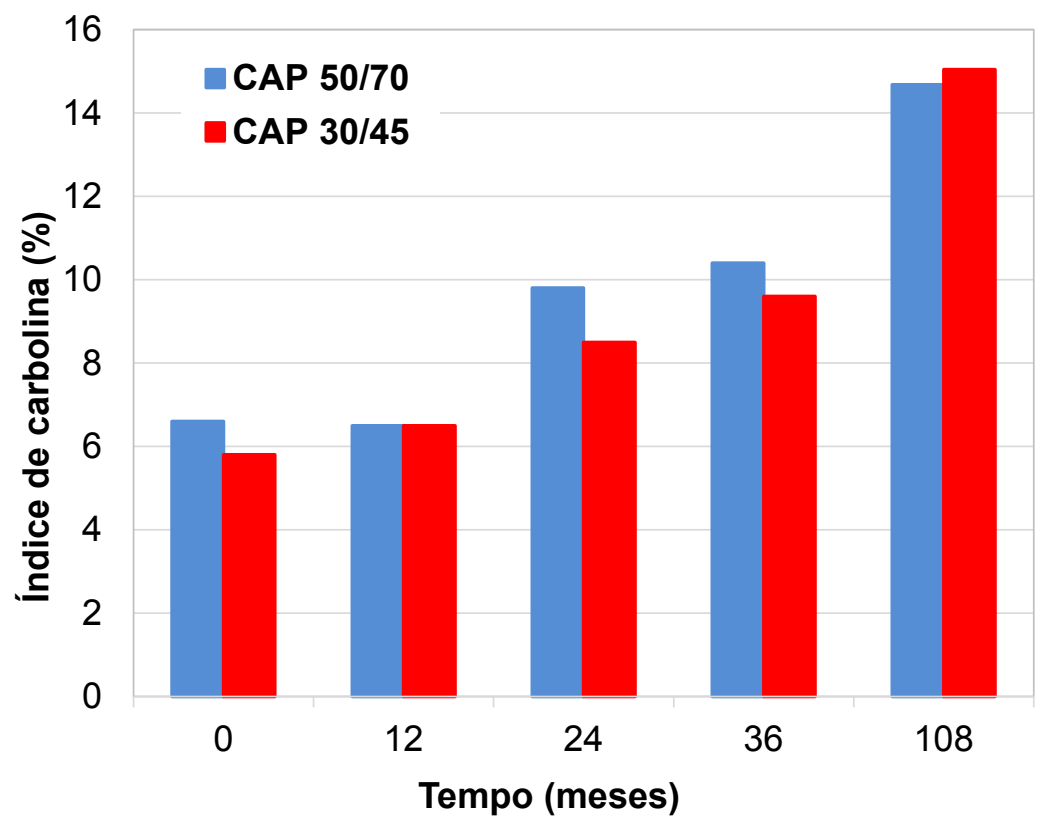

Fonte: Autora

\subsubsection{Ressonância Magnética Nuclear (RMN)}

A análise de RMN foi realizada para todos os níveis de envelhecimento. Os resultados do são apresentados na Figura 42, incluindo a condição virgem de cada ligante.

Como observado para os resultados de envelhecimento em laboratório, os resultados de $\mathrm{RMN}$ variam bastante, principalmente o $\mathrm{H}_{\alpha}$, o qual diminui até $\mathrm{T}=12$ meses e depois muda a tendência, chegan do em $T=108$ meses a valores superiores ao ligante 
virgem, tendên cia contrária ao esperado, uma vez que a Ha encontra-se na posição mais fraca e facilmente pode ser consumido por reação com radicais livres. Com relação aos valores do ISA, em campo, a tendência a aumentar é seguida em ambos os ligantes, exceto para o CAP 35/45 em T= 24 meses e $T=108$ meses.

Considerando que a avaliação do envelhecimento em campo implica em diversos processos, desde a construção do pavimento até a extração e recuperação do ligante asfáltico, somados aos processos degradativos ao qual está exposto no ambiente, diferentes variáveis são adicionadas ao processo de envelhecimento, sendo necessária uma avaliação mais detalhada para melhor compreensão dos resultados.

Figura 42 - Resultados do ensaio RMN

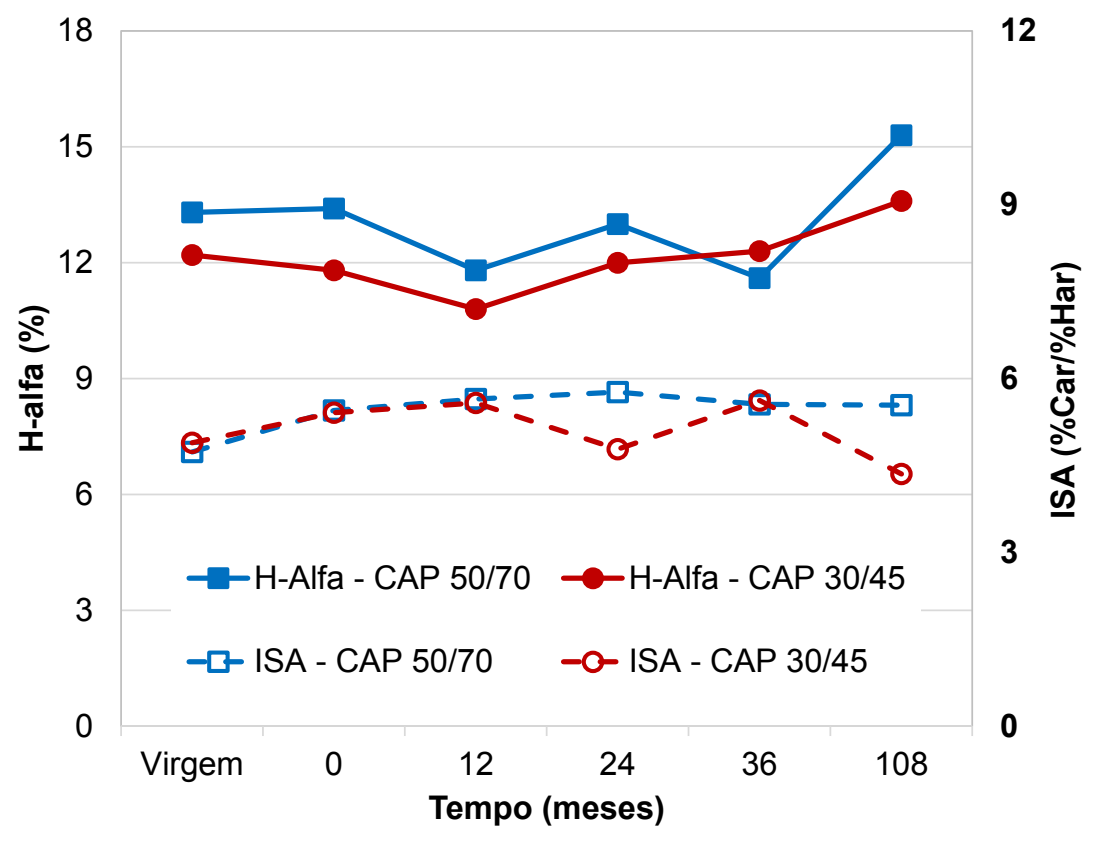

Fonte: Autora 


\subsection{COMPARAÇÃODO ENVELHECIMENTO EM CAMPOE EM LABORATÓRIO}

O envelhecimento do ligante provoca alterações significativas nas propriedades do ligante que podem resultar na perda de desempenho da mistura asfáltica, levando o pavimento a apresentar defeitos e diminuir sua vida de serviço.

Nesta seção, os resultados obtidos neste capítulo para o envelhecimento em campo são comparados aos resultados do envelhecimento em laboratório (Capítulo 3). A comparação foi realizada apenas para o envelhecimento de longo prazo, levando em consideração o questionamento levantado por pesquisadores sobre a eficiência do ensaio PAV em reproduzir o envelhecimento de campo (ERSKINE; HESP; KAVEH, 2012; BESAMUSCA et al., 2012; QIN et al., 2014; SMITH et al., 2018). Segundo Erskine, Hesp e Kaveh (2012), o ensaio PAV normatizado não é capaz de reproduzir as mesmas mudanças químicas que ocorrem durante o envelhecimento em campo.

Qin et al. (2014) avaliaram o efeito do envelhecimento de campo na reologia e estrutura de ligantes extraídos e recuperados a partir de corpos de prova de várias profundidades do revestimento asfáltico. Os autores observaram que o envelhecimento da superfície do pavimento foi mais severo que o envelhecimento de longo prazo realizado em laboratório.

Smith et al. (2018) compararam o envelhecimento em diferentes profundidades do revestimento com o envelhecimento do ligante asfáltico em diferentes tempos de duração do ensaioPAV. Os resultados mostraram que o envelhecimento de dois anos em campo na superfície $(1,3 \mathrm{~cm}$ da superfície) seria equivalente a 21 horas do envelhecimento no PAV, enquanto que o envelhecimento da camada a $5 \mathrm{~cm}$ da superfície seria equivalente a 3 horas no ensaio PAV.

Outros estudos sugerem empregar mais de um ciclo do ensaio PAV, com duas temperaturas diferentes e tempos diferentes (ERKENS et al., 2016), ou com ciclos repetidos de um ensaio PAV modificados [PAV modificado (24horas) = RTFOT+PAV] como sugerem Porot e Eduard (2016a), para atingir um envelhecimento similar ao do campo.

Neste contexto, a avaliação entre campo e laboratório foi realizada levando em consideração os envelhecimentos PAV 20h, PAV 60h, SUNTEST em laboratório e 
apenas o envelhecimento em $\mathrm{T}=36$ meses em campo, devido aos resultados dos ligantes em $\mathrm{T}=108$ meses terem sido inconclusivos na maior parte das análises realizadas.

As Figura 43 e Figura 44 apresentam a comparação das curvas mestras dos ligantes envelhecidos em campo e em laboratório. Como observado anteriormente, os envelhecimentos em campo tiveram resultados de curvas mestras (tanto de $\left|G^{*}\right|$ como de $\delta)$ muito próximas, enquanto que para o envelhecimento em laboratório é visivelmente observada a diferença entre os procedimentos de envelhecimento.

Figura 43 - Comparação das curvas mestras de $\left|G^{*}\right|$ e $\delta$ dos ligantes envelhecido em campo e em laboratório. Em (a) CAP 50/70 e em (b) CAP 30/45.

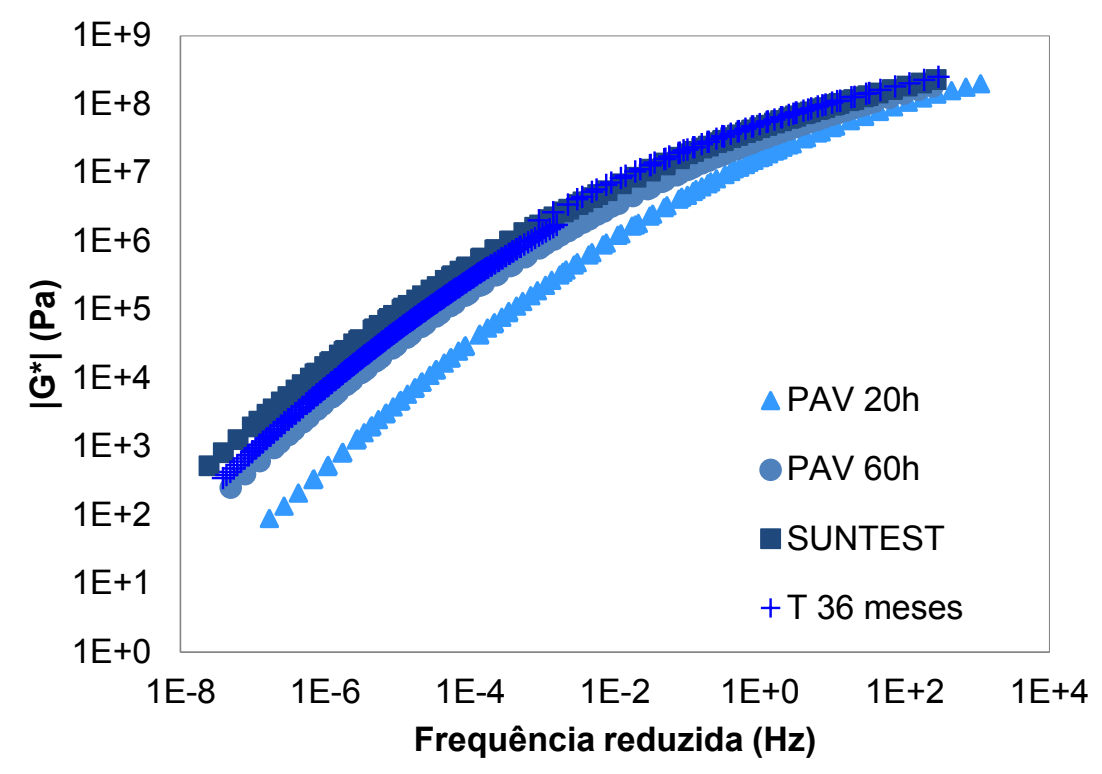

(a) 


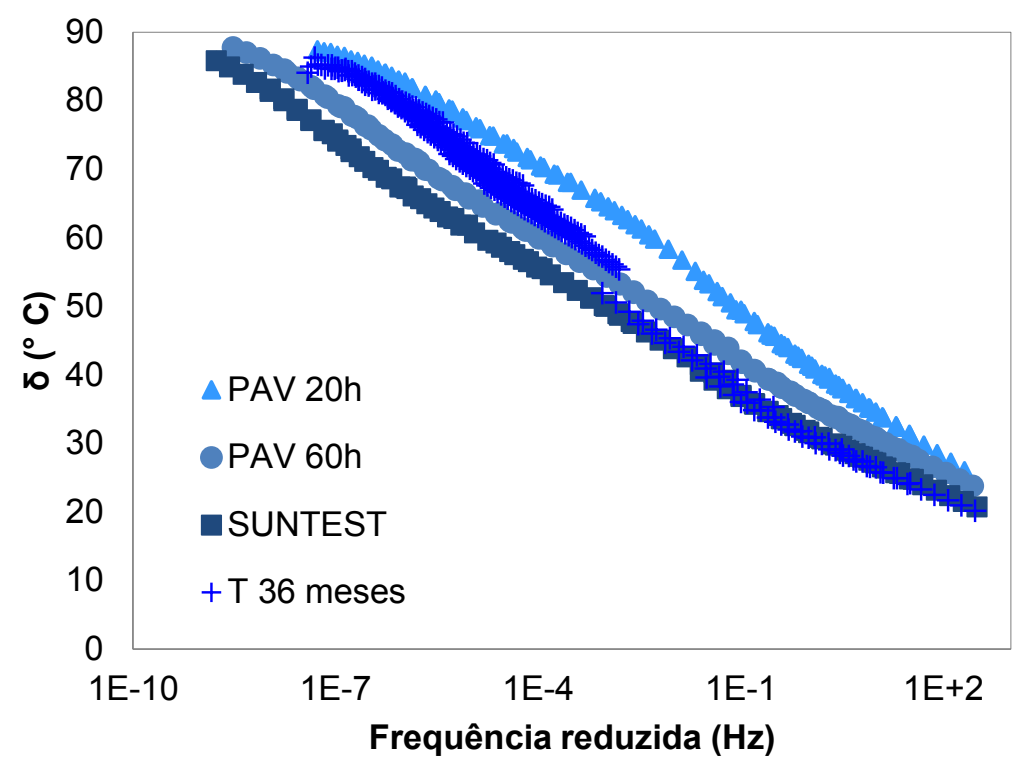

(b)

Fonte: Autora

Figura 44 - Comparação das curvas mestras de $\left|G^{*}\right|$ e $\delta$ dos ligantes envelhecido em campo e em laboratório. Em (a) CAP 50/70 e em (b) CAP 30/45.

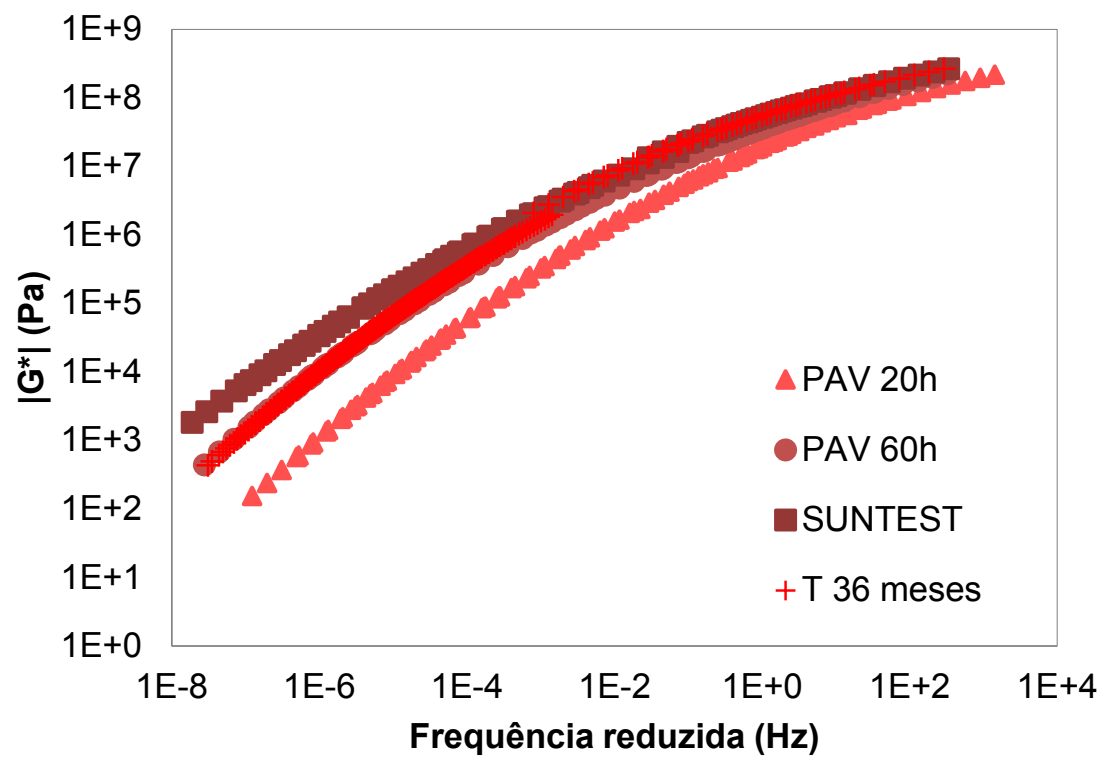

(a) 


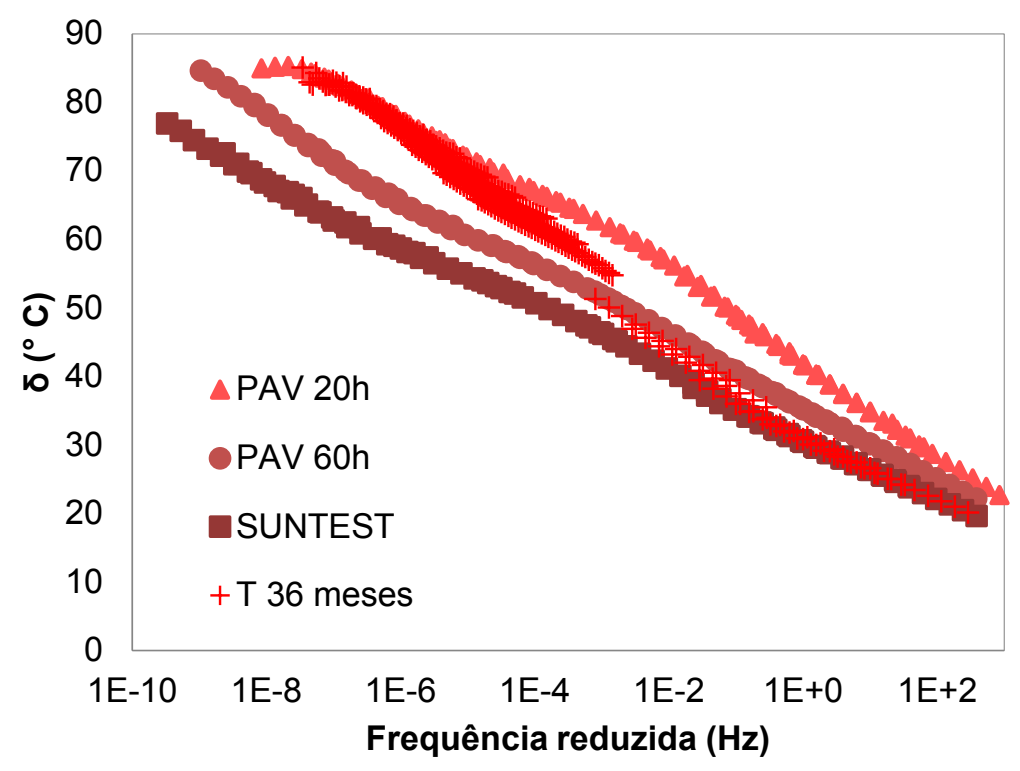

(b)

Fonte: Autora

Besamusca et al. (2012) também observam que o envelhecimento de campo é muito mais severo que o envelhecimento em laboratório, sendo que a amostra de ligante envelhecido por 10 anos não apresentou correlação com nenhuma das outras condições testadas em laboratório, inclusive quando comparada ao procedimento do Superpave (RTFOT+PAV).

Os resultados do envelhecimento PAV 60h ficam bem próximos do envelhecimento de campo em ambos os ligantes após 36 meses, enquanto que o envelhecimento SUNTEST apresenta resultados de rigidez superiores principalmente em baixas frequências/altas temperaturas.

Embora a deformação permanente seja um defeito que aconteça com maior frequência nos primeiros anos após a construção do pavimento, foi realizada uma comparação da resistência à deformação dos ligantes envelhecidos em campo e em laboratório nos diferentes níveis de envelhecimento. Os resultados são apresentados na Figura 45.

Pelos resultados é possível verificar que o envelhecimento PAV 20h apresenta resultados superiores a todos os níveis de envelhecimento em campo, em ambos os 
ligantes, o que corrobora com os resultados de curva mestra, demonstrando que o envelhecimento em campo, no local e configurações desse estudo, foi mais severo. Os resultados para os ligantes após PAV 60h mostram que a diferença na rigidez observada pela curva mestra de $\left|\mathrm{G}^{*}\right|$ se reflete no desempenho quanto à deformação permanente dos ligantes. Observa-se também que, no envelhecimento em campo, os ligantes apresentaram desempenho similar ao longo do tempo.

Figura 45 - Resultados de Jnr para cada ligante nos diferentes níveis de envelhecimento em campo e em laboratório. Em (a) tensão de 100Pa e em (b) tensão de 3200 Pa.

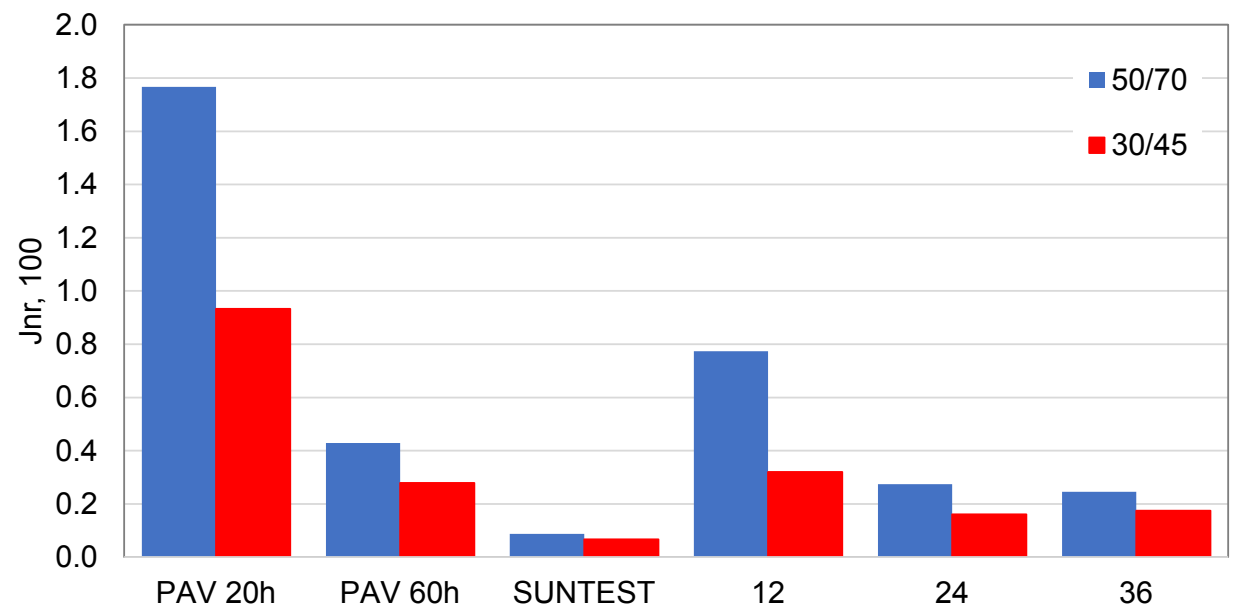

(a)

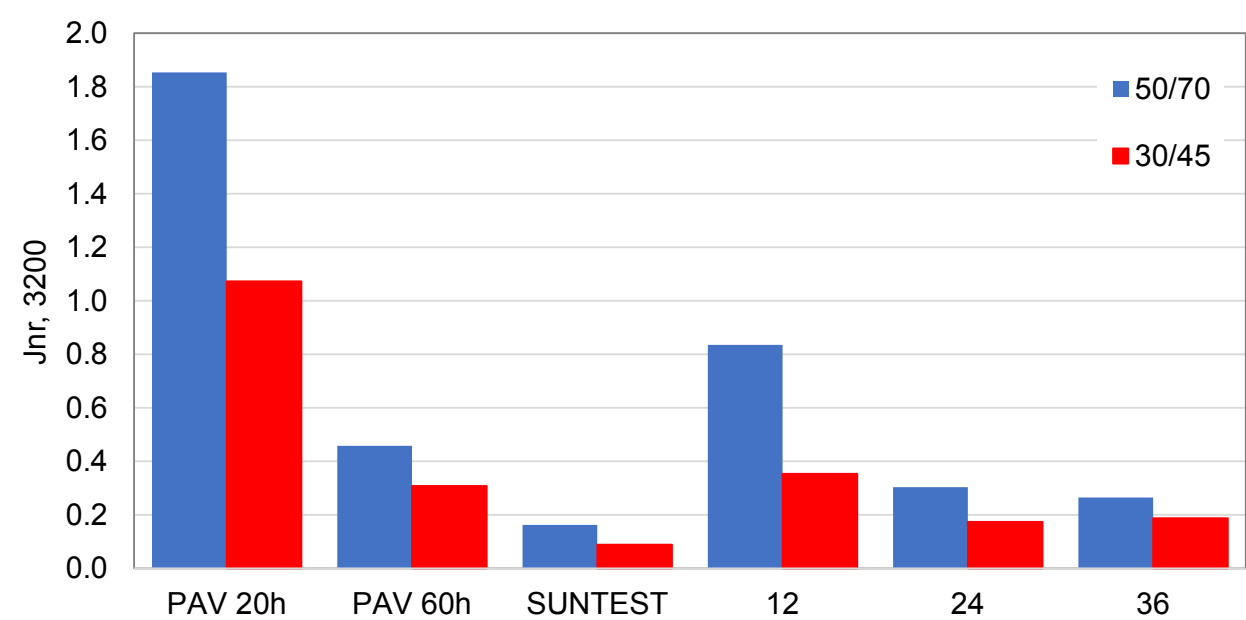

(b)

Fonte: Autora 
O envelhecimento torna o ligante mais rígido e susceptível ao trincamento (ELKASHEF; WILLIAMS; COCHRAN, 2018). As resistências ao trincamento dos ligantes envelhecidos foram comparados após envelhecimento em laboratório e em campo, por meio do parâmetro GR plotado no diagrama de Espaço Black (Figura 46).

Figura 46 - Diagrama de Espaço Black com dos ligantes envelhecidos em campo e em laboratório.

Em (a) CAP 50/70 e em (b) CAP 30/45.

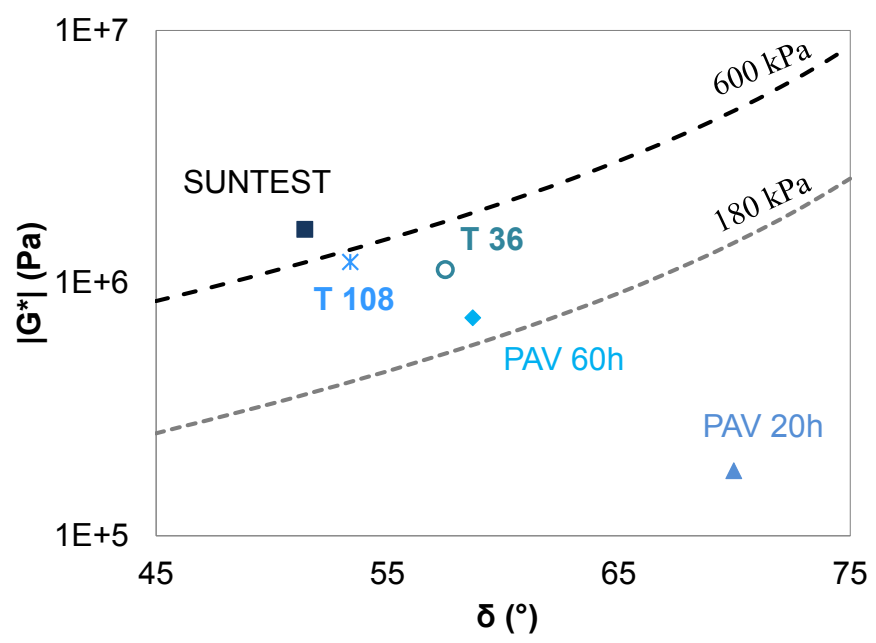

(a)

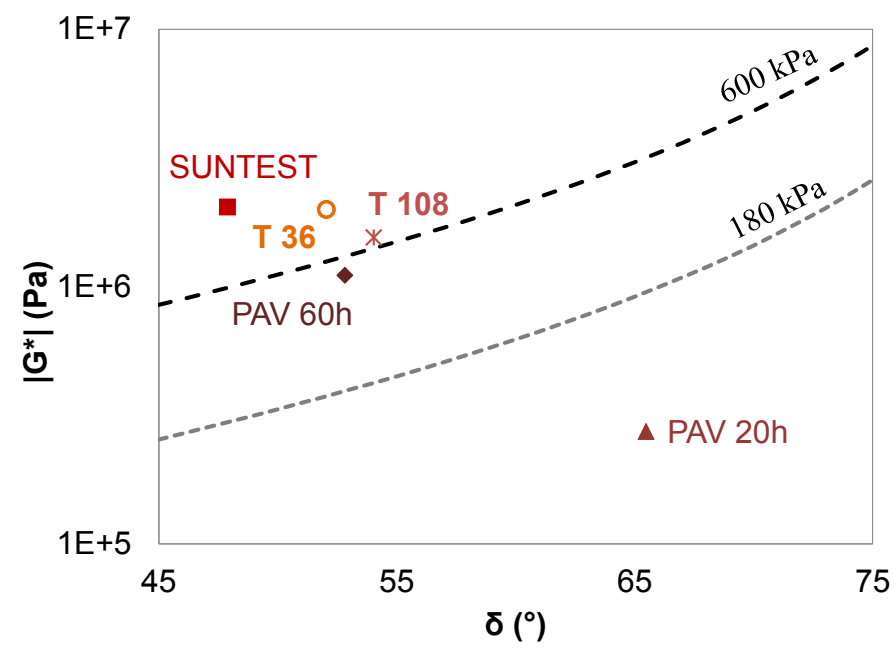

(b)

Fonte: Autora 
Pelos resultados, em ambos os ligantes, verifica-se que o envelhecimento SUNTEST é o mais propenso ao trincamento em bloco, e o envelhecimento PAV 60h coloca os ligantes na zona de dano. No entanto, quando observado o envelhecimento em campo, o CAP 30/45 apresenta resultados na região de trincamento em bloco, enquanto que o CAP 50/70 nos mesmos níveis de envelhecimento ( $T=36$ meses e $T=$ 108 meses) encontra-se na zona de dano. Isso sugere que a rigidez, apresentada pelo CAP 30/45 na condição virgem se mantém ao longo do tempo, indicando que o efeito do envelhecimento sobre o desempenho dos ligantes é similar. É importante observar que os resultados dos ligantes envelhecidos no PAV $20 \mathrm{~h}$ encontra-se posicionado bem distante dos demais níveis de envelhecimento, fora da zona de dano, indicando que o ensaio PAV normatizado pode não simular as condições de campo, como observados por outros pesquisadores (ERSKINE; HESP; KAVEH, 2012; BESAMUSCA et al., 2012; POROT; EDUARD, 2016a; SMITH et al., 2018).

Para analisartambém a resistência ao trincamento por fadiga, os resultados do en saio LAS foram comparados e são apresentados na Figura 47. Os resultados mostram que, em ambos os ligantes, o envelhecimento em campo provoca maior influência na curva característica de dano. O envelhecimento SUNTEST para o CAP 50/70 é o que resulta em uma curva característica de dano e de fadiga mais parecida com o campo após 36 meses. Já para o CAP 30/45, o envelhecimento SUNTEST teve influência mais severa e o PAV 60h apresenta o resultado de curva de fadiga mais próximo em relação ao envelhecimento após $T=36$ meses, no entanto, menos rigoroso para deformação mais elevadas. 
Figura 47 - Comparação da curva característica de dano (a) e da curva de fadiga (b) para o CAP 50/70 envelhecido em laboratório e em campo.

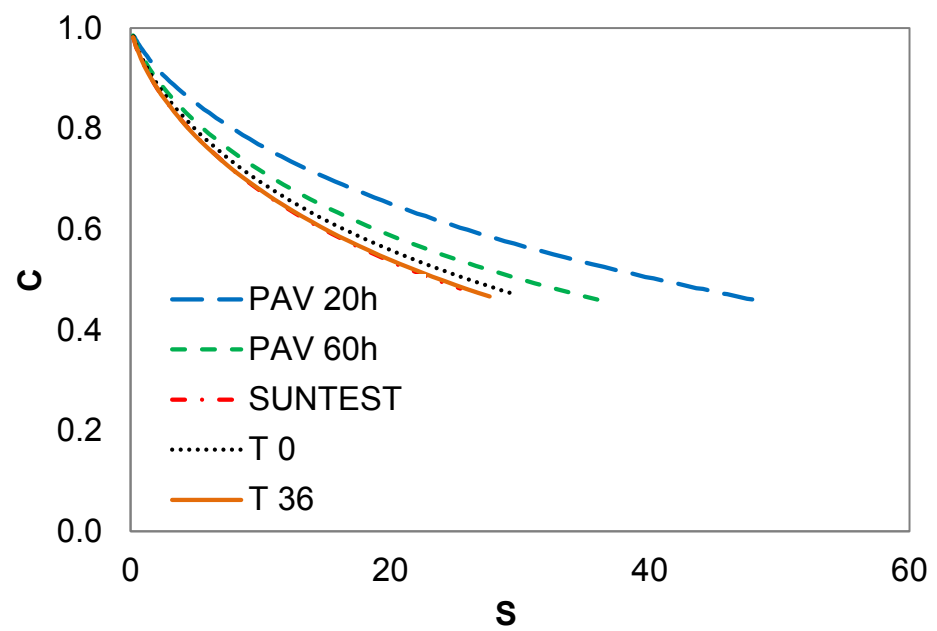

(a)

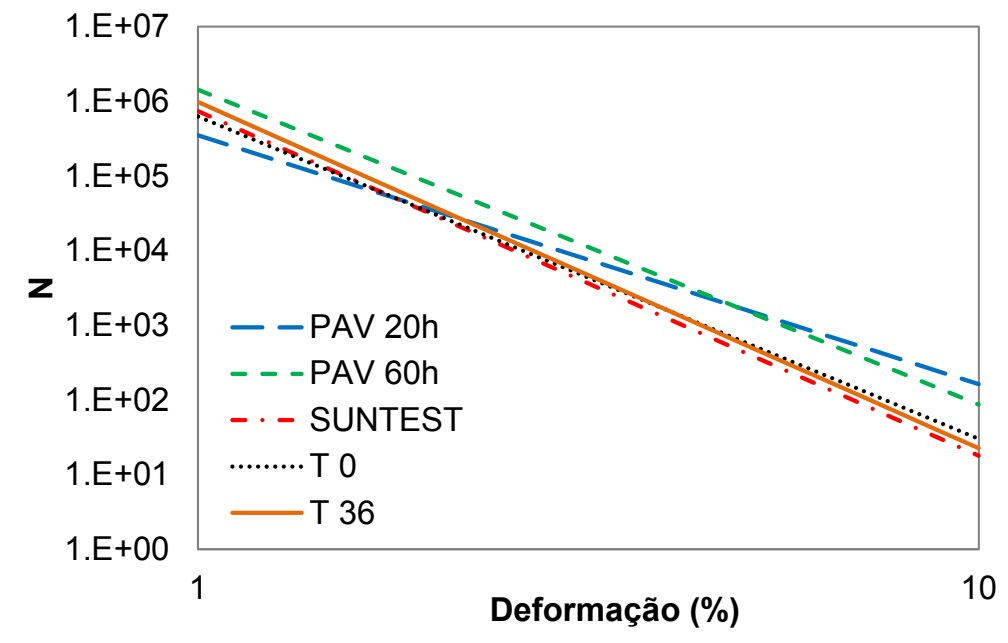

(b)

Fonte: Autora 
Figura 48 - Comparação da curva característica de dano (a) e da curva de fadiga (b) para o CAP 30/45 envelhecido em laboratório e em campo.

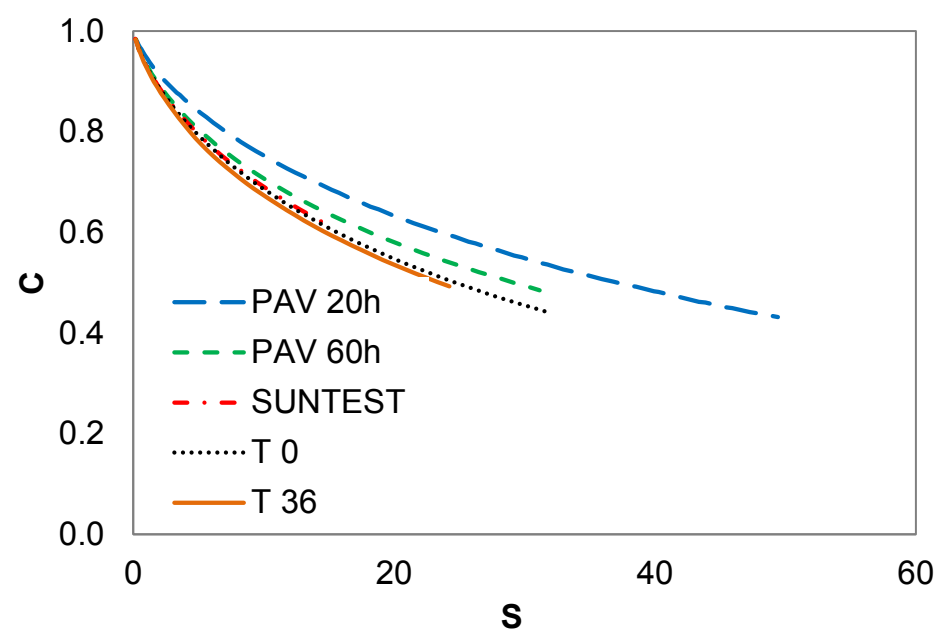

(a)

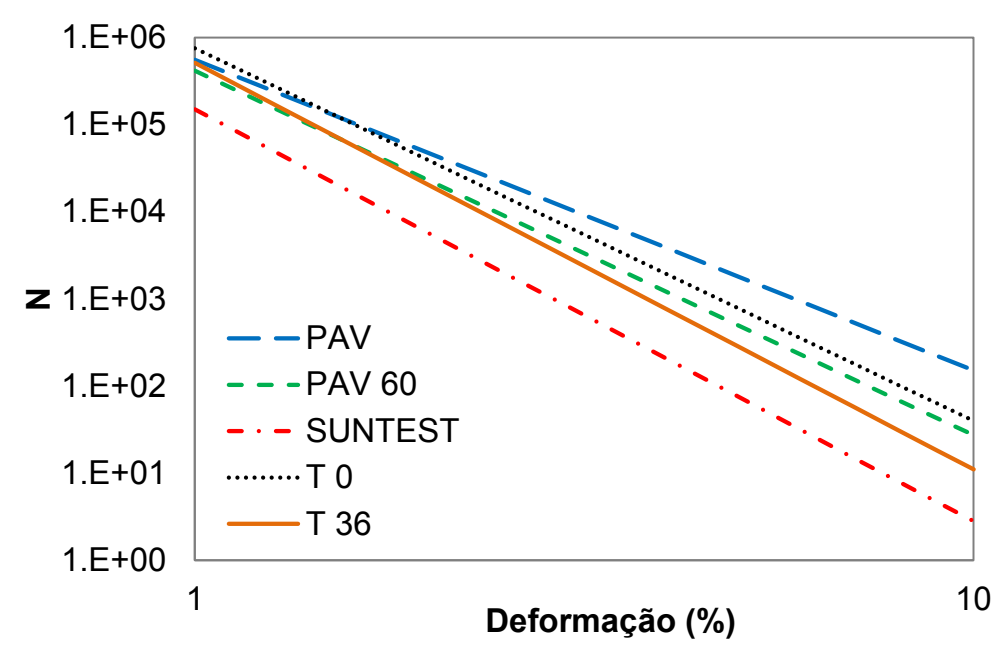

(b)

Fonte: Autora

\subsection{CONCLUSÕES}

A avaliação do envelhecimento do ligante asfáltico é importante pois ele altera as propriedades viscoelásticas do ligante, podendo comprometer o desempenho dos pavimentos asfálticos ao longo do tempo. Com o intuito de melhor compreender os efeitos decorrente do aumento do nível de envelhecimento, dois ligantes asfálticos envelhecidos em trecho experimental foram avaliados por meio de ensaios reológicos 
e químicos. Além disso, foi realizada uma comparação entre os envelhecimentos em campo e em laboratório, a partir dos resultados obtidos neste capítulo e no Capítulo 3 (envelhecimento em laboratório).

A partir dos resultados reológicos do ligantes envelhecidos em campo, foi possível verificar o aumento do nível de envelhecimento ao longo do tempo, no entanto, inconsistências foram verificadas nos resultados para ligantes recuperados em $T=0$ para o CAP 50/70 e em T= 108 meses, para ambos os ligantes. Conforme abordado anteriormente, isso pode ser decorrência dos processos envolvidos desde a construção do pavimento, como também do processo de extração e recuperação do ligante.

Os resultados mostram que o envelhecimento no campo continua acontecendo, provocando alterações químicas e alterando o desempenho dos ligantes asfálticos. A análise química permite confirmar alterações que são observadas pelos ensaios reológicos, mostrando que a análise conjunta das propriedades é essencial para melhor compreensão das alterações provocadas pelo envelhecimento, assim como se faz necessário um maior conhecimento das técnicas de análise e das reações químicas para uma análise mais aprofundada do processo.

A comparação entre os envelhecimentos em laboratório e em campo mostrou que o envelhecimento em campo, nas configurações construtivas e cenário ambiental on de os pavimentos foram implantados, é mais rigoroso que o ensaio PAV 20h normatizado, apresentando resultados mais próximos do PAV 60h, para ambos os ligantes. O envelhecimento pelo SUNTEST mostrou-se mais severo entre todos os processos de envelhecimento, in dicando que o envelhecimento por radiação UV pode ter gran de contribuição no processo de degradação do pavimento asfáltico e, portan to, deve ser levado em consideração para que o processo de simulação do envelhecimento em laboratório seja o mais parecido com o real de campo. 


\section{REJUVENESCIMENTO DE LIGANTES ASFÁLTICOS}

Nos últimos anos a reciclagem de pavimentos tem se mostrado uma solução técnica e economicamente viável. No entanto, apesar de ser uma técnica promissora devido aos ganhos econômicos e ambientais, a porcentagem de RAP utilizada nas misturas recicladas são limitadas. Nos EUA, onde mais de 80 milhões de toneladas de RAP são reciclados por ano (BROSSEAUD, 2011), muitos Departamentos Estaduais de Transporte (DOTs) limitam a taxa de utilização de RAP entre 15\% e 45 \% (ALI et al., 2016).

A inclusão de altas taxas de RAP levanta preocupações sobre o ligante que a mistura recebe do RAP devido ao seu grau de envelhecimento. Segundo Ali et al. (2016), a utilização de altas taxas de RAP pode resultar em misturas asfálticas mais susceptíveis a fadiga, trincas térmicas e reflexão de trincas.

Dessa forma, os métodos de reciclagem utilizam a mistura do RAP com um ligante menos viscoso (mais mole), ou um agente rejuvenescedor (BLOOMQUIST et al., 1993), com o propósito de restaurar as propriedades do ligante asfáltico envelhecido de forma $a$ atender às especificações. Os ligantes mais moles diminuema viscosidade dos ligantes envelhecidos, enquanto que os agentes rejuvenescedores ajudam a restaurar as propriedades físicas e químicas do ligante envelhecido às condições iniciais do ligante novo (BROWN et al., 2009; MOGHADDAM; BAAJ, 2016).

Recentemente, muitas pesquisas vêm sendo desenvolvidas sobre a utilização de agentes rejuvenescedores, ou agentes de reciclagem, em misturas asfálticas recicladas para aumentar a taxa de incorporação de RAP, com o intuito de melhorar as propriedades das misturas asfálticas, diminuindo a rigidez e melhorando a resistência ao trincamento térmico (IM et al., 2014; ONGEL;HUGENER, 2015; ALI et al., 2016, OSMARI, 2017; KASEER et al., 2018).

No entanto, o tipo e quantidade de agente rejuvenescedor precisa ser bem dosado para que o desempenho a baixa temperatura seja melhorado enquanto que o desempenho a altas temperaturas não seja muito afetado (MOGHADDAM; BAAJ, 2016). 
Neste contexto, a primeira parte deste capítulo visa fazer um levantamento dos tipos de agentes rejuvenescedores (AR), assim como, dos métodos de dosagem e incorporação desses ARs utilizados e discutidos na literatura.

\subsection{AGENTES REJUVENESCEDORES}

A utilização de agentes rejuvenescedores (AR) em misturas asfálticas visa melhorar as propriedades do ligante asfáltico envelhecido contido no RAP, de forma a resgatar, pelo menos em parte, suas propriedades a uma condição próxima do ligante novo, diminuindo sua viscosidade e rigidez e melhorando sua adesividade (ALI et al., 2016; MOGHADDAM; BAAJ, 2016).

Os ARs tradicionalmente comercializados são derivados do petróleo ou contém derivados de petróleo (GONDIM, 2017). Além de serem não renováveis, podem conter compostos que são considerados carcinogênicos (ZAUMANIS et al., 2014a; CAO et al., 2018). Dessa forma, atualmente, muitas pesquisas vêm sendo realizadas com o intuito de avaliar a utilização de diferentes materiais, de fontes renováveis ou do aproveitamento de resíduos, como agentes rejuvenescedores alternativos (OSMARI, 2016)

Moghaddam e Baaj (2016) apresentam uma revisão sistemática do uso de agentes rejuvenescedores na produção de misturas asfálticas recicladas a quente. Os autores observam que a utilização do AR atendeu aos critérios de curto e longo prazo, sua viscosidade pode ser um parâmetro efetivo na taxa de difusão, dessa forma, o tipo e a dosagem do AR precisam ser determinados com precisão.

A Tabela 4 apresenta uma lista preparada por pesquisadores do National Center for Asphalt Technology (NCAT) dos rejuvenescedores organizados por categoria. Os pesquisadores afirmam que futuramente mais produ tos de fonte renovável (bio-based) estarão disponíveis no mercado. 
Tabela 4 - Tipos de agentes rejuvenescedores

\begin{tabular}{|c|c|c|}
\hline Categorias & Tipos & Descrição \\
\hline \multirow{4}{*}{ Óleos parafínicos } & Waste Engine Oil & \multirow{4}{*}{ Óleos lubrificantes usados refinados } \\
\hline & (WEO) Waste Engine Oil Bottoms & \\
\hline & Valero VP $165^{\circledR}$ & \\
\hline & Storbit ${ }^{\circledR}$ & \\
\hline \multirow{4}{*}{ Extratos aromáticos } & Hydrolene ${ }^{\circledR}$ & \multirow{4}{*}{$\begin{array}{l}\text { Produtos petrolíferos refinados com } \\
\text { componentes aromáticos polares }\end{array}$} \\
\hline & Reclamite $^{\circledR}$ & \\
\hline & Cyclogen $L^{\circledR}$ & \\
\hline & Valero $130 A^{\circledR}$ & \\
\hline \multirow{2}{*}{ Óleos naftênicos } & SonneWarmix RJTM & \multirow{2}{*}{$\begin{array}{l}\text { Hidrocarbonetos projetados para } \\
\text { modificação de asfalto }\end{array}$} \\
\hline & Ergon HyPrene ${ }^{\circledR}$ & \\
\hline \multirow{4}{*}{$\begin{array}{l}\text { Triglicerídeos e } \\
\text { ácidos graxos }\end{array}$} & Waste Vegetable Oil & Derivado de óleos vegetais \\
\hline & Waste Vegetable Grease & \multirow{3}{*}{$\begin{array}{l}\text { *Possui outros elementos químicos } \\
\text { importantes, além de triglicerídeos e } \\
\text { ácidos graxos }\end{array}$} \\
\hline & Brown Grease & \\
\hline & Delta $S^{*}$ & \\
\hline \multirow{2}{*}{ Tall oils } & Sylvaroad ${ }^{\mathrm{TM}}$ RP1000 & \multirow{2}{*}{$\begin{array}{l}\text { Subprodutos da indústria de papel. } \\
\text { Mesma família química de agentes } \\
\text { adesivo líquidos e emulsionantes }\end{array}$} \\
\hline & Hydrogreen ${ }^{\circledR}$ & \\
\hline
\end{tabular}

Fonte: Adaptado de Willis e Tran (2015)

A partir da literatura, foram grupados em tabela os dados de trabalhos realizados com a utilização de agente rejuvenescedor (Tabela 5 a Tabela 10), identificando os tipos de agentes rejuvenescedores, os métodos de dosagem e teores utilizados. Além disso são relacionados os ensaios realizados para a avaliação do ligantes asfálticos envelhecidos e rejuvenescidos nas Tabela 11 e Tabela 12. 
Tabela 5 - Agentes rejuvenescedores, métodos de dosagem e teores utilizados (continua).

\begin{tabular}{|c|c|c|c|c|c|c|}
\hline Referência & AR/Tipo & Descrição & Método de dosagem & Teor & $\begin{array}{c}\text { Ligante } \\
\text { Envelhecido }\end{array}$ & $\begin{array}{c}\text { Incorporação } \\
\text { AR/ligante }\end{array}$ \\
\hline $\begin{array}{l}\text { Shen et al. } \\
(2007 a)\end{array}$ & Oil type & Comercial & $\begin{array}{l}\text { Determinado através } \\
\text { de DSR (G*/sin (d) e } \\
\left.G^{*} \sin (d)\right) \text { e BBR para } \\
\text { chegar o } P G \text { desejado }\end{array}$ & $2-3$ & $\begin{array}{c}\text { RAP } \\
\text { Produzido } \\
\text { em LAB }\end{array}$ & - \\
\hline $\begin{array}{l}\text { Shen et al. } \\
(2007 \mathrm{~b})\end{array}$ & Soft binder & Com baixa quantidade de asfaltenos $(2 \%)$ & - & 2 e 7,4 & - & - \\
\hline \multirow{9}{*}{$\begin{array}{l}\text { Zaumanis; } \\
\text { Mallick; } \\
\text { Frank } \\
(2013)\end{array}$} & Distilled tall oil & \multirow[b]{2}{*}{ - } & \multirow{9}{*}{-} & 12.7 & \multirow{9}{*}{$\begin{array}{l}\text { RAP } \\
\text { Extraído }\end{array}$} & \multirow{9}{*}{$\begin{array}{c}\text { Mistura por } 40 \\
\text { min a } 135^{\circ} \mathrm{C}\end{array}$} \\
\hline & $\begin{array}{l}\text { WEO (Waste } \\
\text { engine oil) }\end{array}$ & & & 18.2 & & \\
\hline & WEO bottoms & residue from re-refining & & $>20$ & & \\
\hline & $\begin{array}{l}\text { WEO + FT wax } \\
\text { (Fischer-Tropsch - } \\
\text { usado como } \\
\text { aditvo para WMA) }\end{array}$ & \multirow{2}{*}{ e } & & $>20$ & & \\
\hline & Naphthenic flux oil & & & $>20$ & & \\
\hline & Aromatic extract & $\begin{array}{l}\text { Anél aromático polar insaturados, pode ser } \\
\text { carcinogênico }\end{array}$ & & 18.3 & & \\
\hline & Paraffinic base oil & \multirow[t]{3}{*}{ ( } & & 18.3 & & \\
\hline & Refined tallow & & & 9.7 & & \\
\hline & Organic blend & & & 11.2 & & \\
\hline \multirow{3}{*}{$\begin{array}{l}\text { Mogawer et } \\
\text { al. }(2013)\end{array}$} & BituTech RAP & Produzido por Engineered Additives & \multirow{3}{*}{$\begin{array}{l}\text { Recomendado pelo } \\
\text { fabricante }\end{array}$} & 5.218 & \multirow{3}{*}{ RAP } & \multirow{3}{*}{$\begin{array}{c}\text { Mistura por } 5 \mathrm{~min} \\
\text { a } 150^{\circ} \mathrm{C}\end{array}$} \\
\hline & $\begin{array}{c}\text { SonneWarmix } \\
\text { RJT }\end{array}$ & Produzido por Sonneborn Inc & & 5.218 & & \\
\hline & SonneWarmix RJ & & & 5.218 & & \\
\hline \multirow{2}{*}{$\begin{array}{l}\text { Nahar et al. } \\
\quad(2014)\end{array}$} & $\begin{array}{l}\text { rejuvenescedor } \\
\text { tipo emulsão }\end{array}$ & \multirow{2}{*}{-} & \multirow{2}{*}{$\begin{array}{l}\text { Dosagem com } \\
\text { equação utilizando G* }\end{array}$} & 20 & \multirow{2}{*}{$\begin{array}{c}70 / 100 \text { no } \\
\text { RCAT }(18 \mathrm{~h} \text { a } \\
\left.163^{\circ} \mathrm{C}\right)\end{array}$} & \multirow{2}{*}{$\begin{array}{c}\text { Mistura por } 15 \\
\min , \text { a } 150^{\circ} \mathrm{C}\end{array}$} \\
\hline & $\begin{array}{l}\text { rejuvenescedor } \\
\text { tipo líquido }\end{array}$ & & & 10 e 25 & & \\
\hline
\end{tabular}


Tabela 6 - Agentes rejuvenescedores, métodos de dosagem e teores utilizados (continuação 1).

\begin{tabular}{|c|c|c|c|c|c|c|}
\hline Referência & AR/Tipo & Descrição & Método de dosagem & Teor & $\begin{array}{c}\text { Ligante } \\
\text { Envelhecido }\end{array}$ & $\begin{array}{c}\text { Incorporação } \\
\text { AR/ligante }\end{array}$ \\
\hline \multirow{3}{*}{$\begin{array}{l}\text { Chen et al. } \\
\text { (2014) }\end{array}$} & Rejuvenator ( $R$ & \multirow{3}{*}{ - } & \multirow{3}{*}{ - } & 5 & \multirow{3}{*}{$\begin{array}{l}3 \text { tipos RAP } \\
\text { Extraído }\end{array}$} & \multirow{3}{*}{$\begin{array}{l}\text { Mistura por } 15 \\
\min , \text { com } 200 \\
\text { rpm, a } 145^{\circ} \mathrm{C}\end{array}$} \\
\hline & Cotton seed oil (O) & & & 5 & & \\
\hline & $\begin{array}{l}\text { Waste cooking oil } \\
\text { (W) }\end{array}$ & & & 5 & & \\
\hline \multirow{6}{*}{$\begin{array}{l}\text { Zaumanis } \\
\text { et al. } \\
\text { (2014a) }\end{array}$} & $\begin{array}{l}\text { Waste vegetable } \\
\text { oil (WVO) }\end{array}$ & $\begin{array}{l}\text { Óleo vegetal usado, óleo de fritura com } \\
\text { grandes concentrações de ácidos oléico e } \\
\text { linolico. }\end{array}$ & \multirow{6}{*}{-} & \multirow{6}{*}{12} & \multirow{6}{*}{ RAP Extraído } & \multirow{6}{*}{$\begin{array}{l}\text { Mistura por } 40 \\
\min \text { a } 140^{\circ} \mathrm{C}\end{array}$} \\
\hline & $\begin{array}{l}\text { Waste vegetable } \\
\text { grease (WVG) }\end{array}$ & $\begin{array}{l}\text { resíduos orgânicos da indústria alimentícia, } \\
\text { rico em ácidos graxos livres (>40\%) }\end{array}$ & & & & \\
\hline & Organic oil & $\begin{array}{c}\text { Produto comercial. É composto de pirólise } \\
\text { rápida de biomassa de pinheiro com outros } \\
\text { óleos adicionados para equilibrar o } \\
\text { desempenho. Hydrogreen STM (BituTech } \\
\text { RAPTM) }\end{array}$ & & & & \\
\hline & Distilled tall oil & $\begin{array}{l}\text { Subproduto da fabricação do papel e é } \\
\text { concentrado a partir de licores kraft. O tall oil } \\
\text { bruto contém ácidos graxos, ácidos resínicos e } \\
\text { insaponificáveis em proporções variáveis }\end{array}$ & & & & \\
\hline & $\begin{array}{l}\text { Waste engine oil } \\
\text { (WEO) }\end{array}$ & $\begin{array}{c}\text { O óleo lubrificante para motor é produzido a } \\
\text { partir de óleos de base parafínica com } \\
\text { pequena dose de compostos especiais } \\
\text { adicionados para melhorar as características } \\
\text { de viscosidade, estabilidade, limpeza e } \\
\text { inflamabilidade. }\end{array}$ & & & & \\
\hline & Aromatic extract & $\begin{array}{l}\text { Contêm aproximadamente } 75 \% \text { de óleos } \\
\text { aromáticos e compostos de resina com } \\
\text { equilibrio de óleos saturados. }\end{array}$ & & & & \\
\hline
\end{tabular}


Tabela 7 - Agentes rejuvenescedores, métodos de dosagem e teores utilizados (continuação 2).

\begin{tabular}{|c|c|c|c|c|c|c|}
\hline Referência & AR/Tipo & Descrição & Método de dosagem & Teor & $\begin{array}{l}\text { Ligante } \\
\text { Envelhecido }\end{array}$ & $\begin{array}{l}\text { Incorporação } \\
\text { AR/ligante }\end{array}$ \\
\hline \multirow{6}{*}{$\begin{array}{l}\text { Zaumanis et } \\
\text { al. (2014b) }\end{array}$} & aromatic extract & \multirow{6}{*}{ Mesmos ARs de Zaumanis (2014a) } & \multirow{6}{*}{ - } & \multirow{2}{*}{$12+18$} & \multirow{6}{*}{ RAP Extraído } & \multirow{6}{*}{$\begin{array}{l}\text { Mistura por } 40 \\
\min \text { a } 140^{\circ} \mathrm{C}\end{array}$} \\
\hline & waste engine oil & & & & & \\
\hline & $\begin{array}{l}\text { waste vegetable } \\
\text { oil }\end{array}$ & & & \multirow{4}{*}{$12+6$} & & \\
\hline & organic oil & & & & & \\
\hline & $\begin{array}{l}\text { waste vegetable } \\
\text { grease }\end{array}$ & & & & & \\
\hline & distilled tall oil & & & & & \\
\hline \multirow[b]{2}{*}{$\begin{array}{l}\text { Yu et al. } \\
(2014)\end{array}$} & Aromatic extract & \multirow[b]{2}{*}{ Mesmos ARs de Zaumanis (2014a) } & \multirow[b]{2}{*}{ - } & \multirow[b]{2}{*}{12} & \multirow{2}{*}{$\begin{array}{c}\text { Envelhecido } \\
\text { no LAB } \\
\text { (RTFOT + } \\
\text { PAV) }\end{array}$} & \multirow{2}{*}{$\begin{array}{c}\text { Ligante aquecido } \\
\text { a } 145^{\circ} \mathrm{C} \text { por } 40 \\
\text { min, mistura } \\
\text { manual por } 5 \text { min } \\
\text { com AR e } \\
\text { aquecido por } 10 \\
\text { min para } \\
\text { remoção das } \\
\text { bolhas. }\end{array}$} \\
\hline & $\begin{array}{l}\text { WV oil (Waste } \\
\text { vegetable oil) }\end{array}$ & & & & & \\
\hline \multirow{6}{*}{$\begin{array}{c}\text { Zaumanis; } \\
\text { Mallick; } \\
\text { Frank } \\
(2015)\end{array}$} & $\begin{array}{l}\text { Waste vegetable } \\
\text { oil (WVO) }\end{array}$ & \multirow{6}{*}{ Mesmos ARs de Zaumanis (2014a) } & \multirow{6}{*}{$\begin{array}{l}\text { Temperatura alta e } \\
\text { baixa do } P G\end{array}$} & \multirow{6}{*}{12} & \multirow{6}{*}{ RAP Extraído } & \multirow{6}{*}{$\begin{array}{l}\text { Mistura por } 40 \\
\text { min a } 140^{\circ} \mathrm{C}\end{array}$} \\
\hline & $\begin{array}{l}\text { Waste vegetable } \\
\text { grease (WVG) }\end{array}$ & & & & & \\
\hline & Organic oil & & & & & \\
\hline & Distilled tall oil & & & & & \\
\hline & Waste engine oil & & & & & \\
\hline & Aromatic extract & & & & & \\
\hline \multirow{3}{*}{$\begin{array}{l}\text { Ongel; } \\
\text { Hugener } \\
(2015)\end{array}$} & RJ1 & $\begin{array}{l}\text { Resina produzida a partir de casca de } \\
\text { castanha de caju }\end{array}$ & \multirow{3}{*}{ - } & 6 & \multirow{3}{*}{ RTFOT+PAV } & \multirow{3}{*}{$\begin{array}{c}\text { Mistura realizada } \\
\text { no rotavapor por } \\
5 \text { min, a } 145^{\circ} \mathrm{C} \\
\text { devido a } \\
\text { viscosidade do } \\
\text { AR }\end{array}$} \\
\hline & RJ2 & Similar ao RJ1, mesmo produtor & & 5.5 & & \\
\hline & RJ3 & $\begin{array}{l}\text { Composto por asfalto, óleo vegetal, óleos } \\
\text { nafténicos, aditivos }\end{array}$ & & 5 & & \\
\hline
\end{tabular}


Tabela 8 - Agentes rejuvenescedores, métodos de dosagem e teores utilizados (continuação 3).

\begin{tabular}{|c|c|c|c|c|c|c|c|}
\hline Referência & AR/Tipo & Descrição & Método de dosagem & \multicolumn{2}{|c|}{ Teor } & $\begin{array}{c}\text { Ligante } \\
\text { Envelhecido }\end{array}$ & $\begin{array}{l}\text { Incorporação } \\
\text { AR/ligante }\end{array}$ \\
\hline \multirow{5}{*}{$\begin{array}{l}\text { Mohammadafzali } \\
\text { et al. (2015) }\end{array}$} & \multirow{2}{*}{$\begin{array}{l}\text { Water-base } \\
\text { emulsion } \\
\quad(\text { CWE })\end{array}$} & \multirow{2}{*}{$\begin{array}{l}\text { From wax free naphthenic crude, } \\
\text { Measured residue content: } 60 \%\end{array}$} & \multirow{5}{*}{$\begin{array}{l}\text { Dosagem por curva de } \\
\text { amolecimento que } \\
\text { foram criadas na forma } \\
\text { de alta temperatura } 16 \\
\text { grau de desempenho } \\
\text { vs. índice de } \\
\text { rejuvenescimento }\end{array}$} & $\begin{array}{l}\text { Ligante } \\
1\end{array}$ & $\begin{array}{l}\text { Ligante } \\
\quad 2\end{array}$ & \multirow{5}{*}{$\begin{array}{c}\text { O } \\
\text { envelhecimento } \\
\text { do ligante } \\
\text { continuou até } \\
\text { que o grau de } \\
\text { alta } \\
\text { temperatura } \\
\text { excedeu o } \\
\text { ponto de falha } \\
\text { de } 95^{\circ} \mathrm{C}\end{array}$} & \multirow{5}{*}{$\begin{array}{l}\text { Mistura manual } \\
\text { com espátula na } \\
\text { temperatura de } \\
140 \text { a } 160^{\circ} \mathrm{C} .\end{array}$} \\
\hline & & & & 33 & 30 & & \\
\hline & $\begin{array}{l}\text { Heavy paraffinic } \\
\text { distilled solvent } \\
\text { extract (HPE) } \\
\end{array}$ & High aromatic content & & 27 & 22 & & \\
\hline & $\begin{array}{l}\text { Petroleum } \\
\text { natural distillate } \\
\text { (PND) }\end{array}$ & $\begin{array}{l}\text { Containing about half aromatic and } \\
\text { half naphthenic molecules }\end{array}$ & & 20 & 18 & & \\
\hline & $\begin{array}{l}\text { Oil base bio- } \\
\text { rejuvenator } \\
\text { (BOF) }\end{array}$ & $\begin{array}{l}\text { Mixture of long chain and tricyclic } \\
\text { organic acids, resin acids, fatty acids } \\
\text { and vegetable oils }\end{array}$ & & 15 & 13 & & \\
\hline $\begin{array}{l}\text { Turner; Taylor; } \\
\text { Tran (2015) }\end{array}$ & $\begin{array}{c}\text { Sylvaroad RP } \\
1000 \\
\end{array}$ & Base de pinho (Arizona Chemical) & - & $5 \epsilon$ & & RAP & - \\
\hline $\begin{array}{c}\text { Porot; Eduard } \\
(2016 b)\end{array}$ & $\begin{array}{c}\text { Sylvaroad RP } \\
1000 \\
\end{array}$ & Base de pinho (Arizona Chemical) & - & & & RAP & Mistura manual \\
\hline $\begin{array}{c}\text { Porot et al. } \\
(2016)\end{array}$ & $\begin{array}{c}\text { Liquid pine- } \\
\text { based additive }\end{array}$ & $\begin{array}{l}\text { Desenvolvido para ser altamente } \\
\text { eficaz em ligante envelhecido }\end{array}$ & - & $5 \epsilon$ & 10 & & \\
\hline $\begin{array}{l}\text { Porot; Grady } \\
\quad(2016)\end{array}$ & $\begin{array}{l}\text { Bio-based } \\
\text { rejuvenating } \\
\text { agent }\end{array}$ & $\begin{array}{l}\text { Aditivo líquido com estrutura química } \\
\text { específica que permite dispersão das } \\
\text { frações altamente polares e limita a } \\
\text { aglomeração de asfaltenos. }\end{array}$ & - & & & RAP & \\
\hline & AR5 & liente do netróleo (Petrob & & $50 / 70$ & $30 / 45$ & & \\
\hline & Año & rioverileme do petruteo (retrunas) & Viscosidade & 12 & 12 & & Mistura manual \\
\hline Osmari (2016) & $\begin{array}{l}\text { Resíduo óleo } \\
\text { de cozinha }\end{array}$ & ( & $\begin{array}{c}\text { (temperaturas: } 135^{\circ} \mathrm{C} \\
150^{\circ} \mathrm{C} \text { e } 177^{\circ} \mathrm{C} \text { ) }\end{array}$ & 7 & 8 & RTFOT+ PAV & $\begin{array}{l}\text { por } 5 \text { min, a } \\
140^{\circ} \mathrm{C}\end{array}$ \\
\hline & $\begin{array}{l}\text { Öleo de } \\
\text { mamona }\end{array}$ & $\begin{array}{c}\text { Elevada viscosidade, miscibilidade } \\
\text { em álcool }\end{array}$ & & 7 & 8 & & \\
\hline
\end{tabular}


Tabela 9 - Agentes rejuvenescedores, métodos de dosagem e teores utilizados (continuação 4).

\begin{tabular}{|c|c|c|c|c|c|c|}
\hline Referência & AR/Tipo & Descrição & Método de dosagem & Teor & $\begin{array}{c}\text { Ligante } \\
\text { Envelhecido }\end{array}$ & $\begin{array}{c}\text { Incorporação } \\
\text { AR/ligante }\end{array}$ \\
\hline \multirow{5}{*}{$\begin{array}{l}\text { Ali et al. } \\
(2016)\end{array}$} & Naphthenic oil & - & \multirow{5}{*}{$\begin{array}{l}\text { Dosagem } \\
\text { recomendada pelo } \\
\text { fabricante }\end{array}$} & & \multirow{5}{*}{ RAP } & \multirow{5}{*}{-} \\
\hline & Paraffinic oil & $\begin{array}{c}\text { Produced from refined used } \\
\text { lubricating oils }\end{array}$ & & 5 & & \\
\hline & Aromatic extract & $\begin{array}{l}\text { Refined crude oil with polar } \\
\text { aromatic oil products }\end{array}$ & & & & \\
\hline & $\begin{array}{l}\text { Triglycerides and Fatty } \\
\text { Acids (TFA) }\end{array}$ & Produced from vegetable oils & & 2.5 & & \\
\hline & Tall oil & - & & 3 & & \\
\hline \multirow{2}{*}{$\begin{array}{l}\text { Baldino et } \\
\text { al. }(2017)\end{array}$} & Aromatic oils mixture & \multirow{2}{*}{ Industrial products } & \multirow[b]{2}{*}{ - } & 0.9 & & \multirow{2}{*}{$\begin{array}{l}\text { Mistura por } 30 \\
\min , \text { a } 120^{\circ} \mathrm{C}\end{array}$} \\
\hline & $\begin{array}{c}\text { Benzo amide-based } \\
\text { surfactant }\end{array}$ & & & 0.5 & & \\
\hline \multirow[b]{2}{*}{$\begin{array}{l}\text { Nayak; } \\
\text { Sahoo } \\
(2017)\end{array}$} & Pongamia oil & $\begin{array}{c}\text { Óleo a base de planta (ácidos } \\
\text { graxos, ácidos oléico e linolico., } \\
\text { non-polar in nature) }\end{array}$ & \multirow[b]{2}{*}{$\begin{array}{l}\text { Dosagem baseada na } \\
\text { literatura para o } \\
\text { mesmo tipo de } \\
\text { rejuvenescedor }\end{array}$} & \multirow[b]{2}{*}{$5,10,15$} & \multirow[b]{2}{*}{ RTFOT+ PAV } & \multirow[b]{2}{*}{$\begin{array}{c}\text { Mistura manual } \\
\text { por } 5 \text { mim }+10 \\
\text { min para retirar } \\
\text { bolhas. Não } \\
\text { menciona a } \\
\text { temperatura }\end{array}$} \\
\hline & Composite oil & $\begin{array}{l}70 \% \text { de óleo de mamona e } 30 \% \text { de } \\
\text { gás de forno de coque condensado } \\
\text { em peso do óleo compos + C28: } \\
\text { E29ite (alta quantidade de ácido } \\
\text { ricinoleico, que é altamente polar e, } \\
\text { portanto, é esperado que dissolva o } \\
\text { asfalteno polar presente no asfalto } \\
\text { envelhecido }\end{array}$ & & & & \\
\hline \multirow{4}{*}{$\begin{array}{l}\text { Koudelka } \\
\text { et al. } \\
(2017)\end{array}$} & A & Produto protroquímico & \multirow{4}{*}{$\begin{array}{l}\text { Curva de fluxo exibindo } \\
\text { mudanças na } \\
\text { penetração a } 25^{\circ} \mathrm{C}\end{array}$} & 10 & \multirow{4}{*}{ 3xRTFOT } & \multirow{4}{*}{ - } \\
\hline & $\mathrm{B}$ & Óleo hidráulico & & 9,5 & & \\
\hline & $\mathrm{C}$ & Óleo de residuo de motor & & 10 & & \\
\hline & $\mathrm{D}$ & Light burning oil & & 5 & & \\
\hline \multirow{2}{*}{$\begin{array}{l}\text { Taziani et } \\
\text { al. (2017) }\end{array}$} & $\begin{array}{l}\text { Tetraethylenepentamine } \\
\text { (TEPA) }\end{array}$ & - & - & \multirow{2}{*}{2 e 4} & \multirow{2}{*}{ RAP } & \multirow{2}{*}{$\begin{array}{c}\text { Mistura em } \\
\text { agitador por } 5 \\
\text { min com ligante } \\
\text { aquecido a } 160 \\
{ }^{\circ} \mathrm{C}\end{array}$} \\
\hline & Vegetal oil & - & - & & & \\
\hline
\end{tabular}


Tabela 10 - Agentes rejuvenescedores, métodos de dosagem e teores utilizados (conclusão).

\begin{tabular}{|c|c|c|c|c|c|c|}
\hline Referência & AR/Tipo & Descrição & Método de dosagem & Teor & $\begin{array}{c}\text { Ligante } \\
\text { Envelhecido }\end{array}$ & $\begin{array}{l}\text { Incorporação } \\
\text { AR/ligante }\end{array}$ \\
\hline \multirow{3}{*}{$\begin{array}{l}\text { Menapace } \\
\text { et al. } \\
\text { (2018) }\end{array}$} & Tall oil & Resíduo indústria de papel & \multirow{3}{*}{$\begin{array}{l}\text { Método proposto por } \\
\text { Arámbula-Mercado, } \\
\text { restaurar uma das } \\
\text { opções: (i)Temperatura } \\
\text { baixa do } \mathrm{PG} \text {, (ii) } \Delta \mathrm{tc}_{\mathrm{c}} \\
\text { para }-5^{\circ} \mathrm{C} \text { ou (iii) } \\
\text { temperatura alta do } \mathrm{PG}\end{array}$} & $\begin{array}{c}4,5 / 7,5 / 11,5 / \\
12,5 \\
\end{array}$ & \multirow{3}{*}{ RAP e RAS } & \multirow{3}{*}{$\begin{array}{c}\text { Incorporação a } \\
200^{\circ} \mathrm{C}\end{array}$} \\
\hline & Vegetal oil & $\begin{array}{c}\text { Resíduo do milho após produção de } \\
\text { etanol }\end{array}$ & & 8.5 & & \\
\hline & Aromatic extract & $\begin{array}{l}\text { Derivado de petróleo com uma } \\
\text { composição semelhante aos } \\
\text { aromáticos polares da fase de } \\
\text { malteno em ligantes de asfalto }\end{array}$ & & 5.5 & & \\
\hline
\end{tabular}


Tabela 11 - Ensaios de caracterização do ligante asfáltico envelhecido e rejuvenescido (continua)

\begin{tabular}{|c|c|c|c|c|c|c|c|c|c|c|c|c|c|c|}
\hline Referência & Pene(1) & P.A. (2) & Visc. (3) & DSR & BBR & AFM & SARA & GPC & RMN & FTIR & DMA & DSC & TGA & $\begin{array}{l}\text { Envelhecimento } \\
\text { após } \\
\text { rejuvenescimento }\end{array}$ \\
\hline Shen et al. (2007a) & - & - & - & $x$ & $x$ & - & - & - & - & - & - & - & - & - \\
\hline Shen et al. (2007b) & - & - & - & $x$ & $x$ & - & - & - & - & - & & & & RTFOT+ PAV \\
\hline $\begin{array}{l}\text { Zaumanis et al. } \\
(2013)\end{array}$ & $X$ & - & $X$ & - & - & - & - & - & - & - & - & - & - & - \\
\hline $\begin{array}{l}\text { Mogawer et al. } \\
(2013)\end{array}$ & - & - & $x$ & $x$ & $x$ & - & - & - & - & - & - & - & - & RTFOT+ PAV \\
\hline Nahar et al. (2014) & - & - & - & $x$ & - & $x$ & - & - & - & - & - & - & - & - \\
\hline Chen et al. (2014) & - & - & $x$ & $x$ & - & - & - & - & - & - & - & - & - & - \\
\hline $\begin{array}{l}\text { Zaumanis et al. } \\
(2014 a)\end{array}$ & - & - & $x$ & $x$ & $x$ & - & - & - & - & - & - & - & - & RTFOT+ PAV \\
\hline $\begin{array}{l}\text { Zaumanis et al. } \\
(2014 b)\end{array}$ & $x$ & - & - & $x$ & $x$ & - & - & - & - & - & - & - & - & RTFOT+ PAV \\
\hline Yu et al. (2014) & - & - & - & $x$ & $x$ & $x$ & $x$ & - & - & - & - & - & - & RTFOT+ PAV \\
\hline $\begin{array}{l}\text { Zaumanis; Mallick; } \\
\text { Frank (2015) }\end{array}$ & $x$ & $x$ & $x$ & $x$ & - & - & - & - & - & - & - & - & - & - \\
\hline $\begin{array}{l}\text { Ongel; Hugener } \\
\text { (2015) }\end{array}$ & $x$ & $x$ & - & $x$ & - & - & - & - & - & $x$ & - & - & - & - \\
\hline
\end{tabular}


Tabela 12 - Ensaios de caracterização do ligante asfáltico envelhecido e rejuvenescido (conclusão)

\begin{tabular}{|c|c|c|c|c|c|c|c|c|c|c|c|c|c|c|}
\hline Referência & Pene(1) & P.A. (2) & Visc. (3) & DSR & BBR & AFM & SARA & GPC & RMN & FTIR & DMA & DSC & TGA & $\begin{array}{c}\text { Envelhecimento } \\
\text { após } \\
\text { rejuvenescimento }\end{array}$ \\
\hline $\begin{array}{l}\text { Mohammadafzali et } \\
\text { al. (2015) }\end{array}$ & - & - & - & $x$ & - & - & - & - & - & - & - & - & - & PAV $(20,40$ e $60 h)$ \\
\hline $\begin{array}{l}\text { Turner; Taylor; Tran } \\
\text { (2015) }\end{array}$ & - & - & - & $x$ & $x$ & - & - & - & - & - & - & - & - & RTFOT+ PAV \\
\hline $\begin{array}{l}\text { Porot; Eduard } \\
\text { (2016b) }\end{array}$ & - & - & - & - & - & - & - & - & - & - & - & - & - & - \\
\hline Porot et al. (2016) & - & - & - & & - & - & - & - & - & - & - & - & - & - \\
\hline Porot; Grady (2016) & $x$ & $x$ & $x$ & $x$ & - & - & - & - & - & - & - & - & - & - \\
\hline Osmari (2016) & - & - & $x$ & $x$ & - & $x$ & $x$ & $x$ & $x$ & $x$ & - & - & - & - \\
\hline Ali et al. (2016) & - & - & - & - & - & - & - & - & - & - & - & - & - & - \\
\hline $\begin{array}{l}\text { Baldino et al. } \\
(2017)\end{array}$ & $x$ & $x$ & - & $x$ & - & - & - & - & $x$ & - & $x$ & - & - & - \\
\hline $\begin{array}{l}\text { Nayak; Sahoo } \\
(2017)\end{array}$ & - & - & - & $x$ & - & - & - & - & - & - & - & $x$ & $x$ & - \\
\hline $\begin{array}{l}\text { Koudelka et al. } \\
\text { (2017) }\end{array}$ & $x$ & $x$ & - & $x$ & $x$ & - & - & - & - & - & - & - & - & RTFOT / 3xRTFOT \\
\hline \multicolumn{15}{|l|}{ Taziani et al. (2017) } \\
\hline $\begin{array}{l}\text { Menapace et al. } \\
(2018)\end{array}$ & - & - & - & $x$ & - & $x$ & - & - & - & - & - & - & - & RTFOT+ PAV \\
\hline
\end{tabular}

(1) Penetração, (2) Ponto de amolecimento, (3) Viscosidade cinemática 
Devido a questão da sustentabilidade, muitas pesquisas vêm sendo desenvolvidas e diversos agentes provenientes de fontes renováveis variadas, ou da utilização de resíduos, passaram a ganhar interesse. Isso resulta em uma quantidade razoável de possibilidades, com teores variáveis de acordo com a pesquisa.

Os ARs foram avaliados a partir de ensaios convencionais, químicos, reológicos e de microestrutura (AFM). Zaumanis et al. (2014a) avaliaram o efeito de seis agentes rejuvenescedores diferentes, a partir de ensaios reológicos, aplicando o processo de envelhecimento em laboratório após o rejuvenescimento. Os autores verificaram que a temperatura alta do PG do ligante virgem foi atingida por todas as amostras de ligantes rejuvenescidos, indicando ganho na resistência a deformação permanente desses ligantes quando comparados ao ligante virgem. Em outro estudo, Zaumanis, Mallick e Frank (2015) observaram que os teores necessários de ARs de base orgânica são menores que os teores de ARs a base de petróleo, para proporcionar o mesmo efeito de amolecimento do RAP.

Nayak e Sahoo (2017) utilizaram técnicas de DSC (Calorimetria exploratória diferencial)e TGA (Termogravimetria) para verificar o ligante rejuvenescido exposto ao calor. Os autores verificaram que os ligantes rejuvenescidos apresentaram um pico semelhante ao ligante não envelhecido, indicando que o AR conseguiu deixar os ligantes em condições semelhantes, mostran do ain da que os ligantes rejuvenescidos são termo estáveis.

Ongel e Hugener (2015) observaram que o AR com menor viscosidade apresentou o melhor efeito para reduzir a rigidez do ligante envelhecido utilizando pequena quantidade. No entanto, o ligante com AR de menor viscosidade, apresentou rigidez maior após o envelhecimento de curto prazo, sendo mais suscetível ao processo de oxidação.

Turner, Taylor e Tran (2015) verificam que a utilização de agente a base de pinho, apesar de reduzir a rigidez do ligante reju venescido, não melhorou nas propriedades de elasticidade/relaxação dos ligantes rejuvenescidos, pelos resultados apresentados no gráfico de Black Space. 
Menapace et a. (2018) avaliaram as propriedades de ligantes asfálticos rejuvenescidos com três diferentes $A R$, avaliando o efeito desses aditivos após os envelhecimentos de curto e longo prazo em laboratório. Os autores verificaram que o efeito do rejuvenescimento pode ocorrer apenas a curto prazo. Após o envelhecimento, o efeito pode ser perdido, principalmente para reju venescimento com baixos teores de AR.

A partir da análise química, Osmari (2016) observou que o rejuvenescimento recuperou propriedades como teores de aromáticos e asfaltenos, a proporção de alto peso molecular e a quantidade de hidrogênios alfa dos ligantes envelhecidos. Baldino verificou a partir da técnica de RMN que um dos ARs utilizados em sua pesquisa conseguiu modificar a estrutura do ligante envelhecido, restaurando as propriedades avaliadas de forma similar ao do ligante virgem.

A utilização da técnica de microscopia de força atômica (AFM) permiti visualizar as alterações da microestrutura do ligante envelhecido e do ligante rejuvenescido (NAHAR et al., 2014), porém o efeito do agente rejuvenescedor é verificado apenas qualitativamente, sendo necessária uma análise de tratamento da imagem para quantificar o efeito do rejuvenescimento, embora o processo químico seja bem complexo e novas fases sejam criadas durante o processo de envelhecimento e rejuvenescimento. De forma geral, a avaliação do efeito do agente rejuvenescedor é baseada nas propriedades reológicas dos ligantes, assim como no desempenho dos mesmos em relação a deformação permanente e a fadiga. Trabalhos mais recentes buscam a associação de análises químicas e reológicas para melhorentendimento do processo de envelhecimento e rejuvenescimento dos ligantes asfálticos, mas ainda ficando restritos ao fato de o AR melhorar ou não as propriedades dos ligantes.

\subsubsection{Dosagem de agente rejuvenescedor}

$\mathrm{Na}$ literatura, muitos estudos utilizaram parâmetros convencionais, como a penetração, o ponto de amolecimento e a viscosidade para a dosagem do AR, comparando esses parâmetros do ligante rejuvenescido com o ligante desejável. Experiências como de Osmari et al. (2017) e Gadler (2018) indicam que o método de 
dosagem através de parâmetros como a viscosidade e penetração, pode não ser adequada para a dosagem do agente rejuvenescedor.

Outros pesquisadores utilizaram blending charts para avaliar o efeito do rejuvenescimento sobre as propriedades reológicas do ligante asfáltico, usando valores de $\left|\mathrm{G}^{*}\right|,\left|\mathrm{G}^{*}\right| / \operatorname{sen}(\delta)$, ou valores de temperatura alta ou baixa para escolha do teor de AR, de forma a atender aos critérios do PG (performance grade) desejado (ARÁMBULA-MERCADO et al., 2018).

Arámbula-Mercado et al. (2018) avaliaram três métodos de dosagem utilizando blendings charts das temperaturas altas e baixas do $P G$ e do parâmetro $\Delta T_{c}$ (Figura 49). A partir dos resultados, os autores concluíram que o uso do método de temperatura alta do $P G$ seria o mais recomendado para determinar o teor de $A R$ necessário.

Figura 49 - Blending chart dos parâmetros reológicos em função do teor de AR.

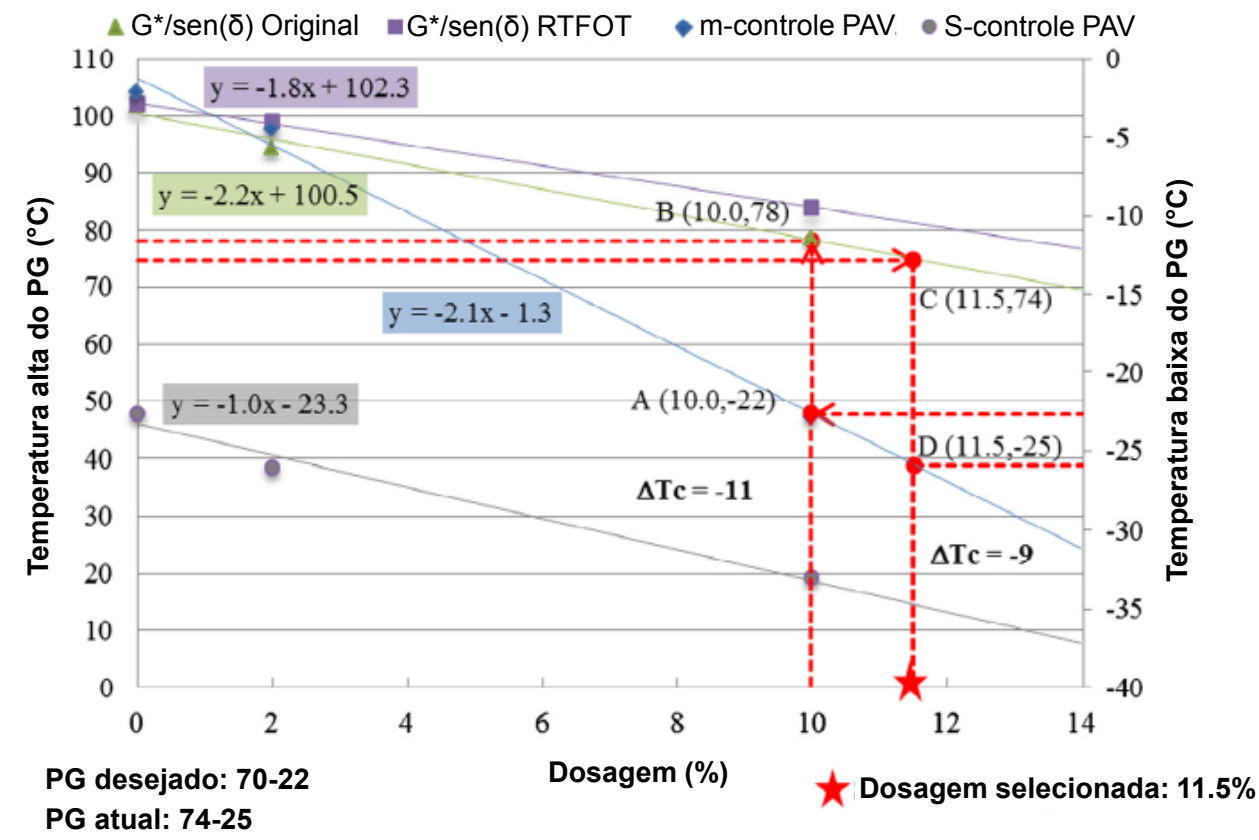

Fonte: Adaptado Arámbula-Mercado et al. (2018) 
Zaumanis, Mallick e Frank (2014) propuseram um procedimento de dosagem de agente rejuvenescedor também baseado nos parâmetros da especificação Superpave, com o objetivo de reduzir o número de ensaios necessários para determinar do teor de AR. A partir de bledings charts das termperaturas altas, intermediárias e baixas do $P G$ em função do teor de $A R$, desenvolveram equações para determinar os teores máximos e mínimos de AR que atendam o PG estipulado para o ligante rejuvenescido (Figura 50).

Figura 50 - Teores máximos e mínimos de diferentes agentes rejuvenescedores.

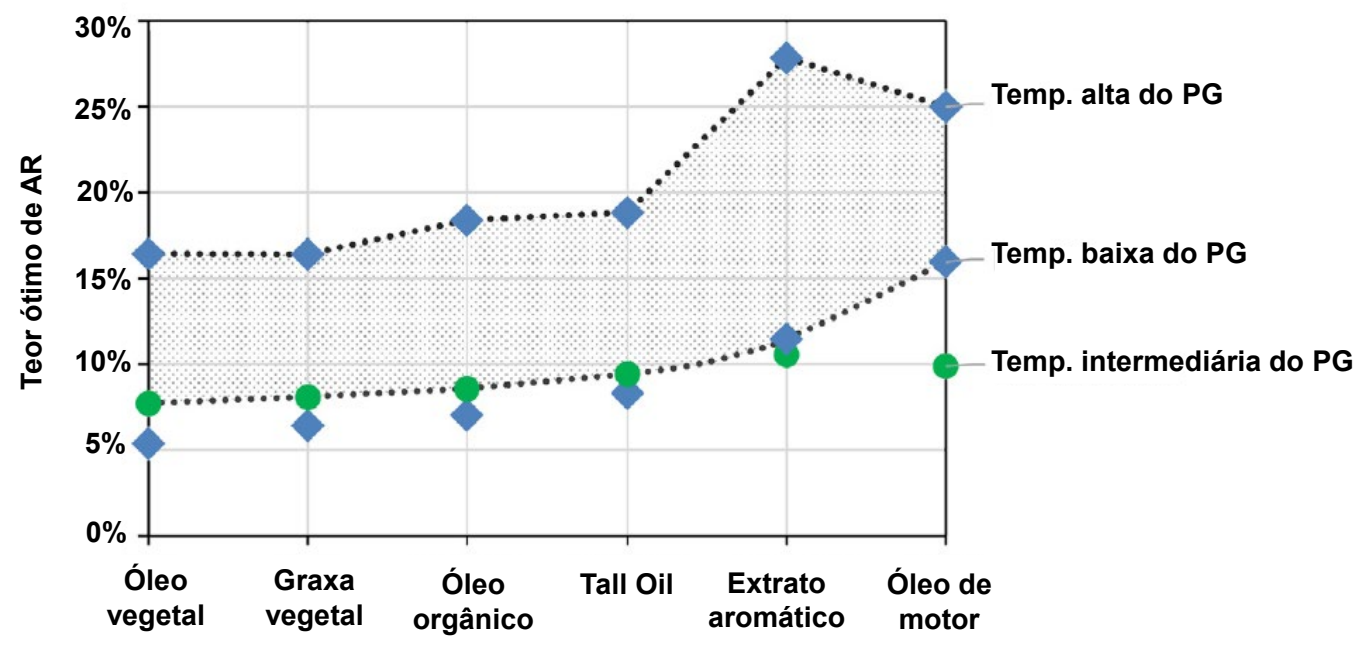

Fonte: Zaumanis, Mallick e Frank (2014)

Neste contexto, este capítulo visa avaliar o efeito de um agente rejuvenescedor (bioóleo) em ligantes asfálticos convencionais envelhecidos em laboratório, avaliando as propriedades reológicas desses ligantes rejuvenescidos, assim como, fazer uma análise da dosagem de AR a partir de propriedades viscoelásticas lineares e das resistências à deformação permanente (MSCR) e à fadiga (LAS). A Figura 51 apresenta as etapas do estudo de rejuvenescimento dos ligantes asfálticos neste capítulo. 
Figura 51 - Etapas de estudo do envelhecimento em campo

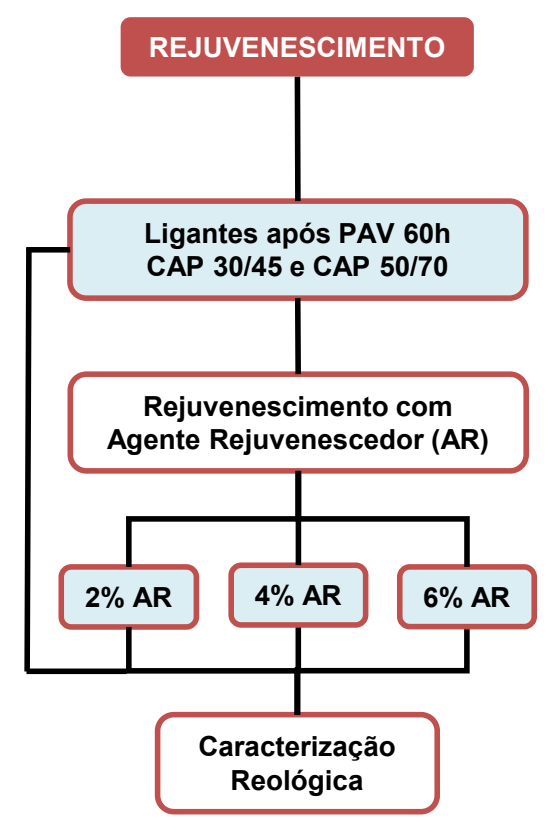

Fonte: Autora

\subsection{MATERIAIS E MÉTODOS}

Para o estudo de rejuvenescimento, foram utilizados um CAP 30/45 (PG 70S-XX) e um CAP 50/70 (PG 64S-XX), os mesmos ligantes utilizados nos capítulos 3 e 4. O nível de envelhecimento dos ligantes foi determinado baseado no estudo do capítulo 3 , sendo escolhido o procedimento PAV $60 \mathrm{~h}$ para envelhecimento dos ligantes deste estudo, uma vez que este procedimento resultou em maior nível de envelhecimento que o ensaio padronizado (PAV 20h).

Foi utilizado um agente rejuvenescedor a base de óleo vegetal de pinho, fornecido pela Kraton Polymers, com o nome comercial SYLVAROAD ${ }^{T M}$ RP 1000. Este AR foi desenvolvido especificamente para restaurar as propriedades do ligante envelhecido e ativar o ligante do RAP. Sendo produzido $90 \%$ a partir de do refino do óleo de pinho, é u m aditivo liquido à temperatura ambiente, com elevado ponto de fulgor e coloração amarelo claro (POROT et al., 2014; POROT et al., 2017). A dosagem típica é realizada de 3 a $7 \%$ em massa do ligante envelhecido, dependendo das características do ligante do RAP (POROT; EDUARD, 2016b). Porot e Grady (2016), observaram que uma dosagem de $5 \%$ em massa restaurou em até 2 graus o PG do ligante 
envelhecido, além disso, os autores verificaram que o AR é compatível e miscível e mantém seu efeito mesmo após o envelhecimento.

Para escolha dos teores de AR, foi realizada uma análise prévia com as porcentagens de $2 \%$ e $10 \%$ em massa de ligante envelhecido. Nesse estudo, foi constatado que o teor de $10 \%$ de AR era excessivo devido à consistência do ligante, impossibilitando a retirada da amostra dos moldes de silicone para realizar o ensaio no reômetro. Dessa forma, foram escolhidos os teores de AR iguais a $2 \%, 4 \%$ e $6 \%$ em massa de ligante envelhecido.

\subsubsection{Incorporação do agente rejuvenescedor}

Para a incorporação do agente rejuvenescedor ao ligante envelhecido foi utilizada a mesma metodologia descrita por Raul (2019) com pequenas alterações. O procedimento utiliza um misturador com rotação controlada e haste adaptada para homogeneização e um Thermosel do viscosímetro Brookfield para manter a temperatura do ligante asfáltico durante o processo de mistura. $O$ procedimento seguiu as seguintes etapas para cada teor de AR avaliado:

a) Os ligantes envelhecidos após PAV $60 \mathrm{~h}$ foram aquecidos em estufa a $130{ }^{\circ} \mathrm{C}$ até que estivessem fluidos o suficiente para a pesagem; as amostras foram pesadas em recipiente de silicone (aproximadamente $16 \mathrm{~g}$ ) e antes que esfriassem por completo utilizou-se o próprio recipiente para dar a forma cilíndrica à amostra e facilitarque ela fosse inserida na cápsula do viscosímetro Brookfield;

b) Após as amostras esfriarem a temperatura ambiente, elas foram inseridas na capsula do viscosímetro, em seguida as capsulas foram colocadas dentro do Thermosel aquecido a $150{ }^{\circ} \mathrm{C}$ e mantidas durante 5 min para aquecimento do ligante;

c) A capsula foi retirada do Thermosel e posicionada em balança de alta precisão para adicionar a quantidade referente ao teor de AR a ser avaliado; 
d) Após recolocar a capsula no Thermosel, o aparato padronizado para o estudo foi montado para que a haste ficasse bem próxima ao fundo da capsula e garantisse a homogen eização completa da mistura ligante envelhecido + AR.

e) A mistura foi realizada a $150{ }^{\circ} \mathrm{C}$, por 15 min a 150 rotações por minuto.

A principal alteração realizada no procedimento utilizado por Raul (2019) foi o tempo de mistura que foi reduzido de 60 min para 15 min. Essa alteração foi realizada visto que o este estudo utiliza apenas ligantes convencionais que, na temperatura de $150^{\circ} \mathrm{C}$, apresentam viscosidade suficiente para proporcionar uma boa mistura.

Figura 52 - Procedimento de incorporação de AR. Em (a) pesagem do ligante envelhecido, em (b) pesagem do AR, em (c) aparato para mistura e em (d) processo de mistura do ligante com o AR.

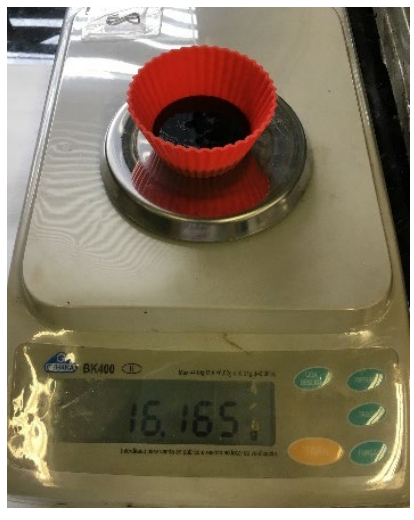

(a)

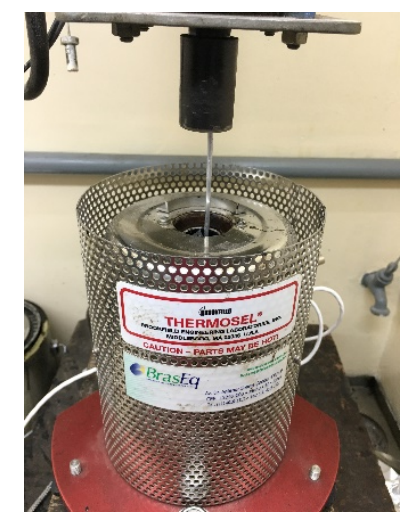

(c)

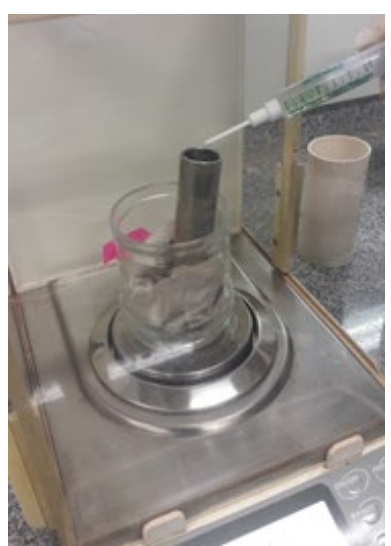

(b)

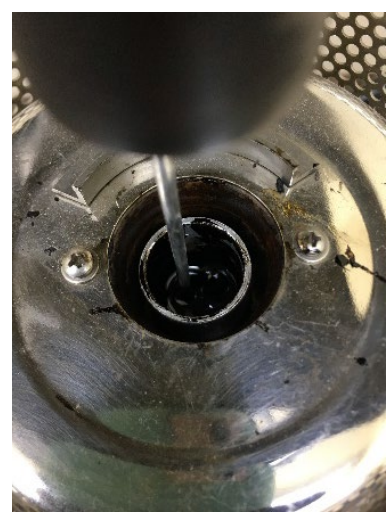

(d)

Fonte: Autora - Imagens (a), (c) e (d); Raul (2019) - Imagem (b) 


\subsubsection{Ensaios reológicos}

A caracterização reológica dos ligantes envelhecidos e rejuvenescidos foi realizada da mesma forma que o estudo dos Capítulos 3 e 4 . Foram realizados ensaios de varredura de frequência e temperatura e a partir dos resultados foram construídas as curvas mestras de $\left|G^{*}\right|$ e $\delta$, assim como calculados os parâmetros crossover modulus, crossover frequency, parâmetro R e Glover-Rowe (GR). O ensaio MSCR (ASTM D7405, 2015) foi realizado para avaliar a resistência à deformação permanente dos ligantes, na temperatura de $64{ }^{\circ} \mathrm{C}$, a temperatura é diferente dos Capítulos 3 e 4 , para avaliar melhoro efeito do rejuvenescimento. O en saio LAS (AASHTO TP 101) também foi realizado, na mesma temperatura de $20^{\circ} \mathrm{C}$ para avaliar a resistência à fadiga, como nos capítulos anteriores.

Os procedimentos dos ensaios realizados são descritos nas seções 3.2.2.

\subsection{RESULTADOSE DISCUSSÕES}

\subsubsection{Curvas mestras de $\left|G^{*}\right|$ e $\delta$}

O estudo do rejuvenescimento avaliou o efeito do agente rejuvenescedor em dois ligantes convencionais envelhecidos a longo prazo pelo procedimento PAV 60h. Utilizando os teores de $2 \%, 4 \%$ e $6 \%$ de AR, buscou-se comparar os resultados dos ligantes reju venescidos com o ligante após o RTFOT, pensando que este será o nível de envelhecimento que u ma mistura asfáltica reciclada a quente terá após a usinagem e compactação. As Figura 53 e Figura 54 apresentam curva mestra de $\left|G^{*}\right|$ e $\delta$ para os ligantes CAP 50/70 E CAP 30/45, respectivamente, envelhecidos e rejuvenescidos com os três teores de AR.

A partir dos resultados é possível verificar as alterações provocadas pela presença do AR nos valores de $\left|G^{*}\right|$ e $\delta$ para ambos os ligantes. $O A R$ atua reduzin do a rigidez do ligante envelhecido em toda a faixa de frequência e temperatura avaliada. Pelos resultados da curva mestra de $\left|G^{*}\right|$, o teor de $4 \%$ de AR é o que resulta em valores de rigidez mais próximo do ligante após RTFOT em ambos os ligantes. Além disso, observa-se que o AR diminui a rigidez do ligante envelhecido em altas frequências 
(baixas temperaturas), o que pode resultar em melhor desempenho à fadiga. Essa tendência é verificada pelas curvas mestras do ângulo de fase, nas quais são observados valores de $\delta$ superiores em altas frequências, mostrando que o ligante apresenta comportamento mais viscosos nessa faixa de frequência/temperatura.

Figura 53 - Curvas mestras de $\left|G^{*}\right|$ e $\delta$ dos ligantes envelhecidos e rejuvenescidos. Em (a) 50/70 e em (b) 30/45.

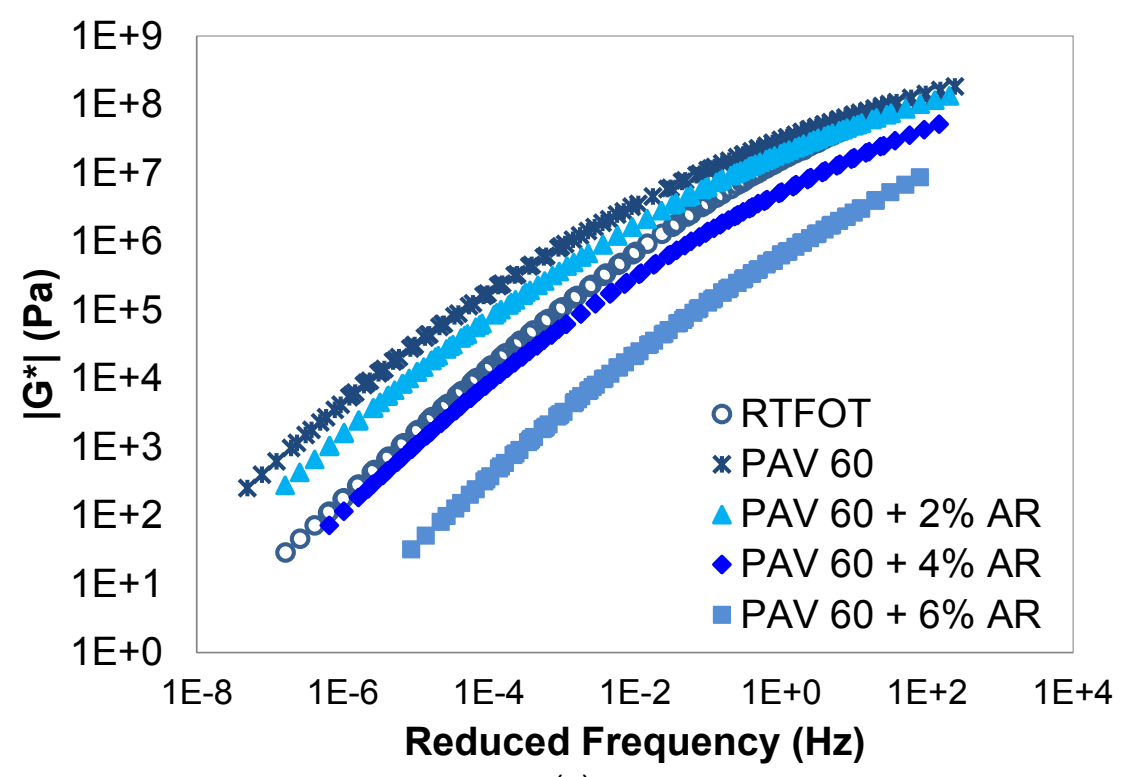

(a)

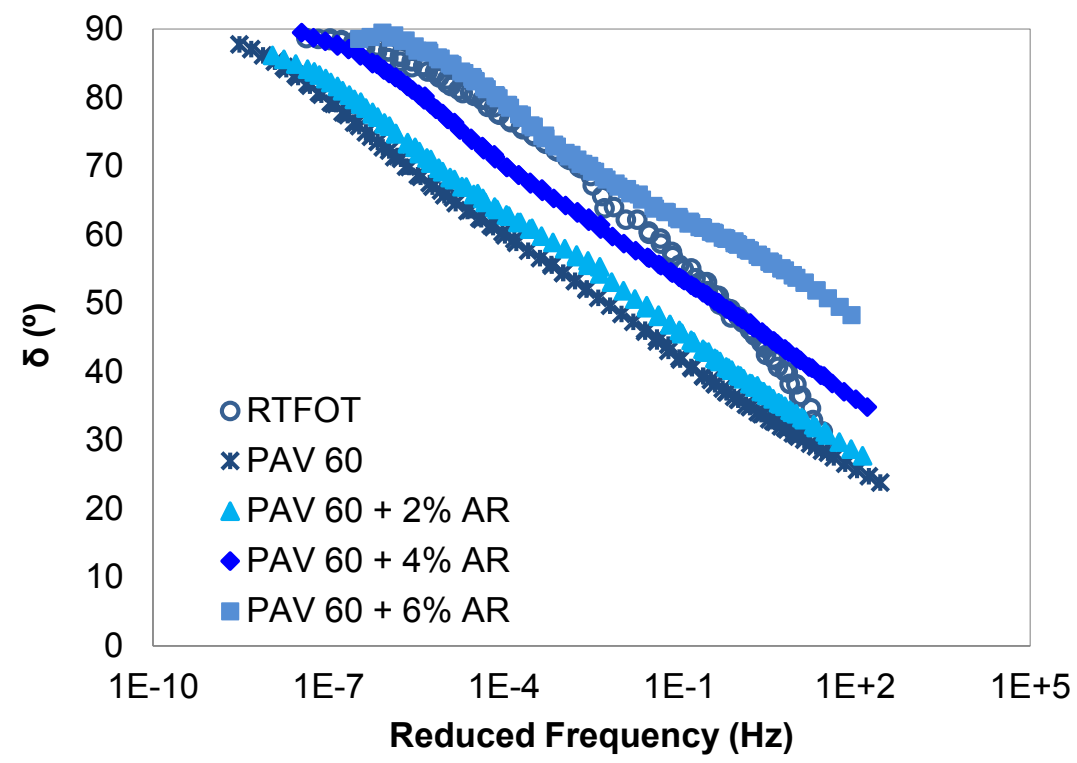

(b)

Fonte: Autora 
Figura 54 - Curvas mestras de $\left|G^{*}\right|$ e $\delta$ dos ligantes envelhecidos e rejuvenescidos. Em (a) 50/70 e em (b) $30 / 45$.

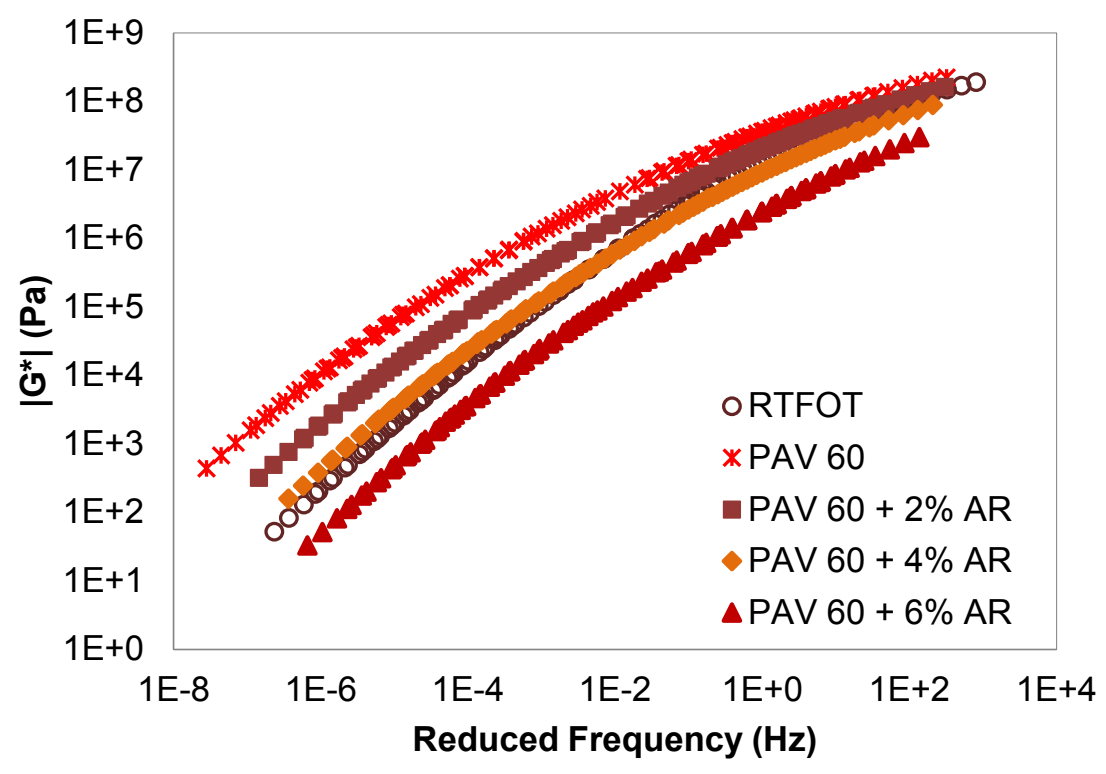

(a)

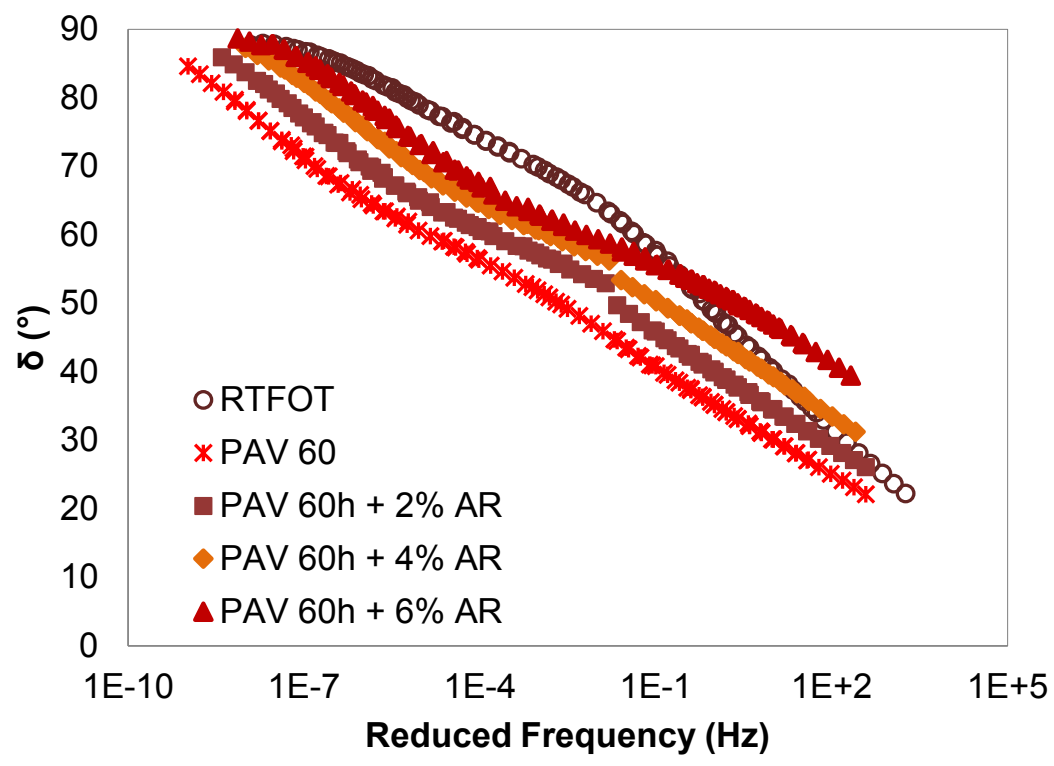

Fonte: Autora

(b)

5.3.2. Crossover modulus $\left(G^{*}\right)$, crossover frequency $\left(\omega_{c}\right)$ e parâmetro $R$

Os parâmetros crossover modulus $\left(\mathrm{G}^{*} \mathrm{c}\right)$, crossover frequency $\left(\omega_{c}\right)$ e parâmetro $\mathrm{R}$ dos ligantes envelhecidos e rejuvenescidos foram determinados e encontram-se apresentados na Tabela 13. Para o CAP 50/70 com o teor de $6 \%$ de AR não foi possível determinar o os valores de crossover modulus e crossover frequency, pois 
as curvas mestras de G' e G" não apresentaram intersecção na faixa de frequênciae temperaturas avaliadas.

Os resultados apresentados mostram que, diferentemente do que foi observado pelas curvas mestras de $\left|\mathrm{G}^{*}\right|$, os parâmetros de crossover não são conclusivos quanto ao teor mais indicado para o rejuvenescimento dos ligantes, devido as alterações provocadas pelo AR principalmente em altas frequências. A Figura 55 apresenta graficamente os resultados do crossover frequency $\left(\omega_{c}\right)$ e do parâmetro $R$, visualmente é possível constatar que o teor de $4 \%$ de AR é que o apresenta resultados mais próximos do ligante após RTFOT, porém apresentando variação tanto para $\omega_{c}$ quanto para o parâmetro $R$.

Tabela 13 - Crossover modulus, crossover frequency e parâmetro $R$ dos ligantes envelhecidos e rejuvenescidos

\begin{tabular}{ccccc}
\hline Ligante & Condição & $\mathbf{G}^{*} \mathbf{c}$ & $\boldsymbol{\omega}_{\mathbf{c}}$ & $\mathbf{R}$ \\
\hline \multirow{5}{*}{ CAP 50/70 } & RTFOT & $2.96 \mathrm{E}+07$ & 3.59 & 1.53 \\
& PAV 60h & $9.29 \mathrm{E}+06$ & 0.07 & 2.03 \\
& PAV 60h + 2\% AR & $8.03 \mathrm{E}+06$ & 0.16 & 2.10 \\
& PAV 60h + 4\% AR & $9.06 \mathrm{E}+06$ & 2.94 & 2.04 \\
& PAV 60h + 6\% AR & - & - & - \\
& RTFOT & $2.23 \mathrm{E}+07$ & 2.58 & 1.65 \\
CAP 30/45 & PAV 60h + 2\% AR & $8.82 \mathrm{E}+06$ & 0.18 & 2.05 \\
& PAV 60h + 4\% AR & $9.08 \mathrm{E}+06$ & 0.98 & 2.04 \\
& PAV 60h + 6\% AR & $1.13 \mathrm{E}+07$ & 17.13 & 1.95 \\
\hline
\end{tabular}


Figura 55 - Comparação do crossover frequency $(\omega c)$ e do parâmetro R para os ligantes envelhecidos e rejuvenescidos.

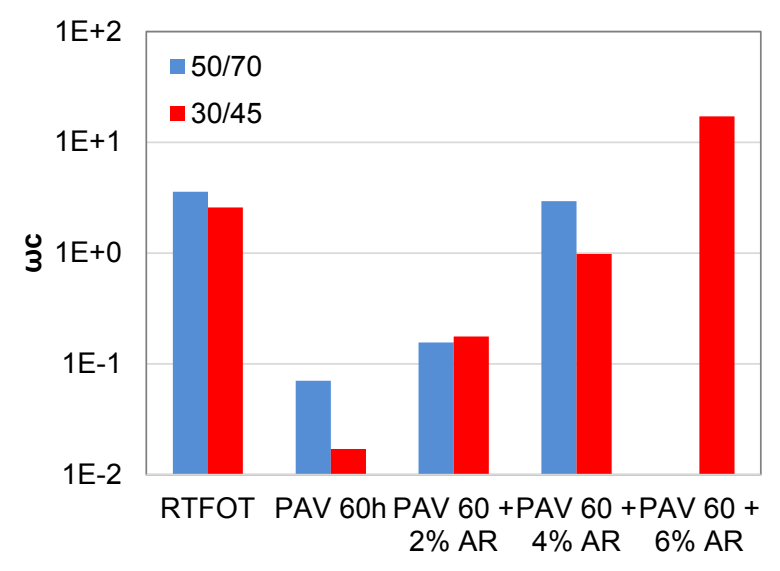

(a)

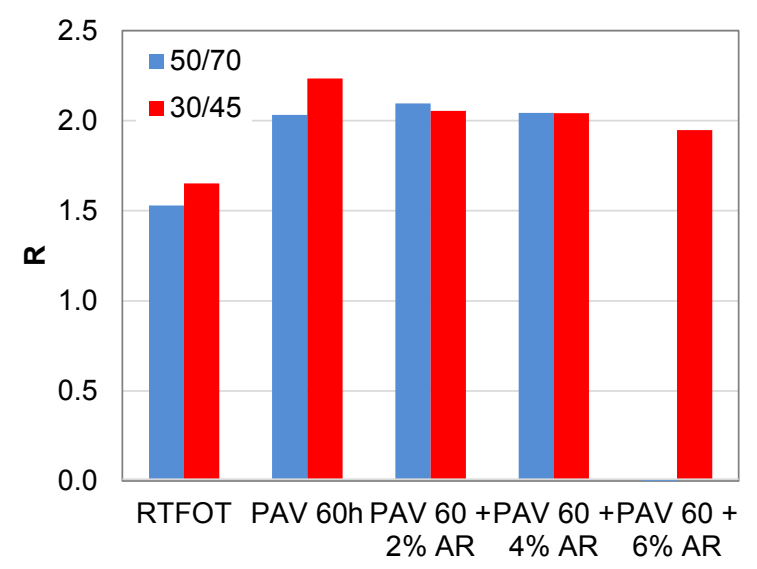

(b)

Fonte: Autora

\subsubsection{Parâmetro Glover-Rowe (GR)}

Os ligantes envelhecidos e rejuvenescidos foram avaliados pelo parâmetro GR calculado na temperatura de $15^{\circ} \mathrm{C}$ e frequência de $0,005 \mathrm{rad} / \mathrm{s}$. Os resultados são apresentados no Espaço Black (Figura 56).

O processo de rejuvenescimento permitiu a recuperação do parâmetro GR para níveis fora da zona de dano com teor de AR a partir de $2 \%$, em ambos os ligantes. Considerando desejável que o AR proporcione um rejuvenescimento até o nível do ligante envelhecido após o RTFOT, o teor de $4 \%$ de AR apresenta o resultado mais próximo para o CAP 50/70 e enquanto que para o CAP 30/45, o teor fica entre $4 \%$ e $6 \%$ de AR para este parâmetro. 
Figura 56 - Diagrama de Espaço Black dos ligantes envelhecimentos e rejuvenescidos. Em (a) CAP 50/70 e em (b) CAP 30/45.

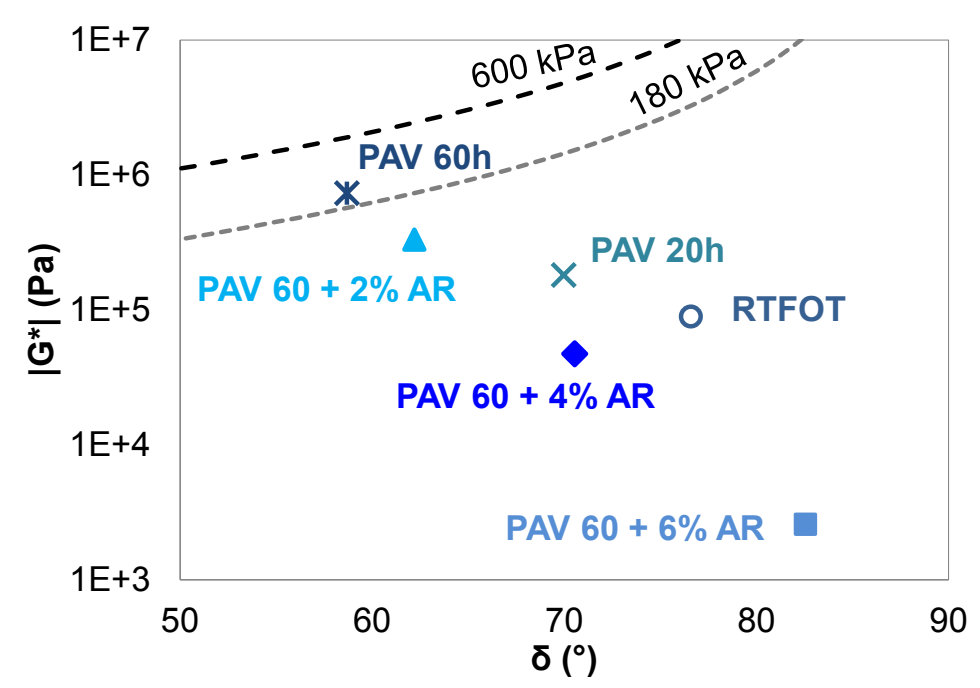

(a)

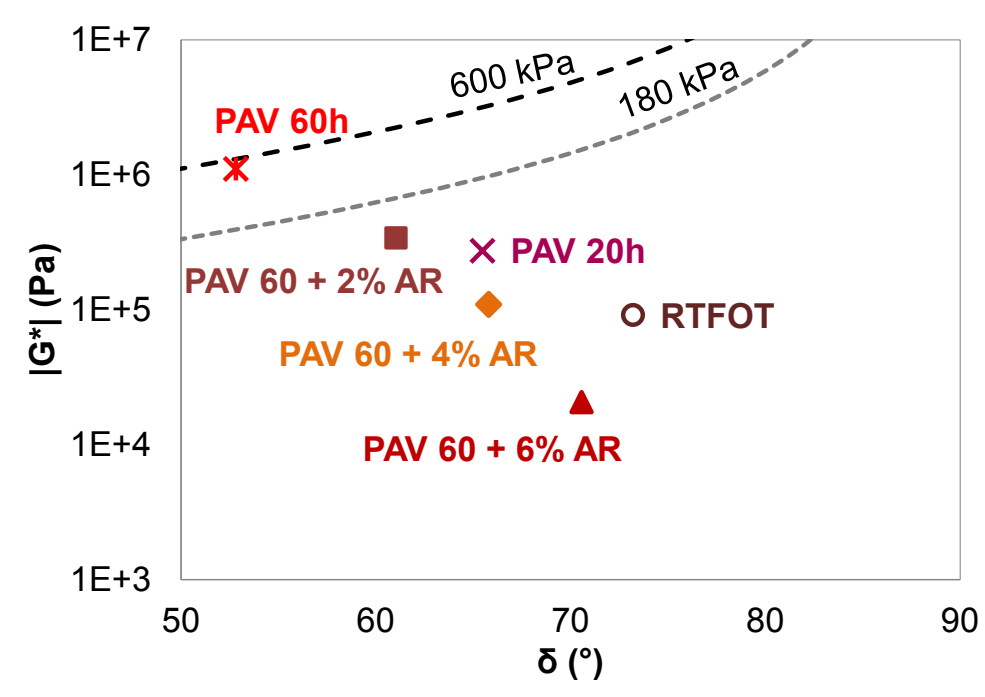

(b)

Fonte: Autora

Pela Figura 57 é possível observar que o processo de rejuvenescimento segue uma tendência diferente ao envelhecimento. Dessa forma, como também verificado pelas curvas mestras, o teor do AR não será facilmente dosado apenas pelas propriedades viscoelásticas lineares, visto que o $A R$ não altera apenas a rigidez do ligante envelhecido, mas também a tendência do seu comportamento quando solicitado. 
Figura 57 - Tendências observadas no Diagrama de Espaço Black dos ligantes envelhecimentos e rejuvenescidos. Em (a) CAP 50/70 e em (b) CAP 30/45.

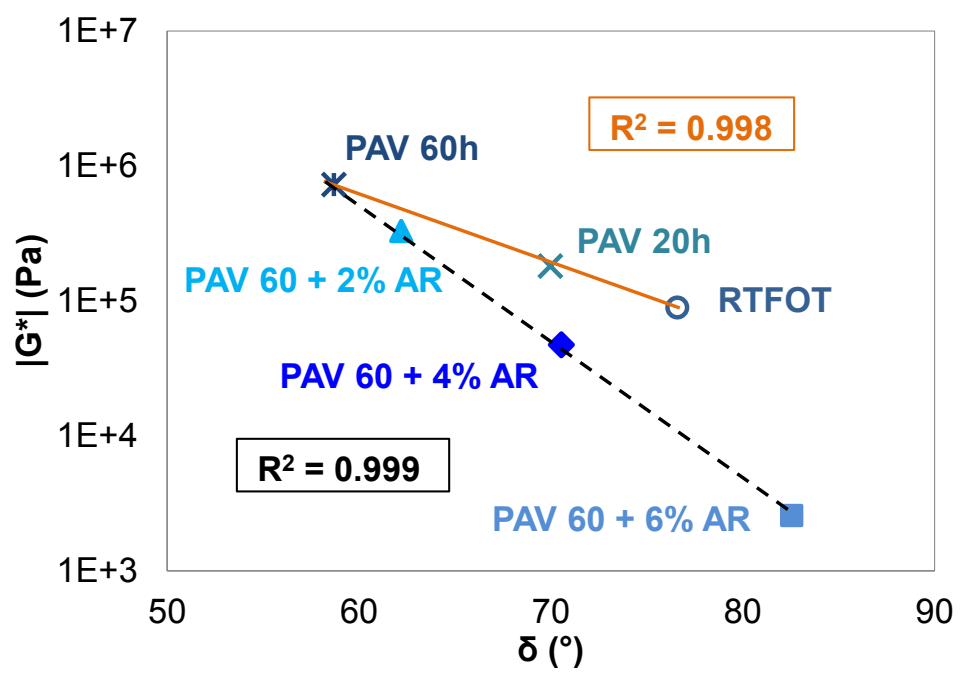

(a)

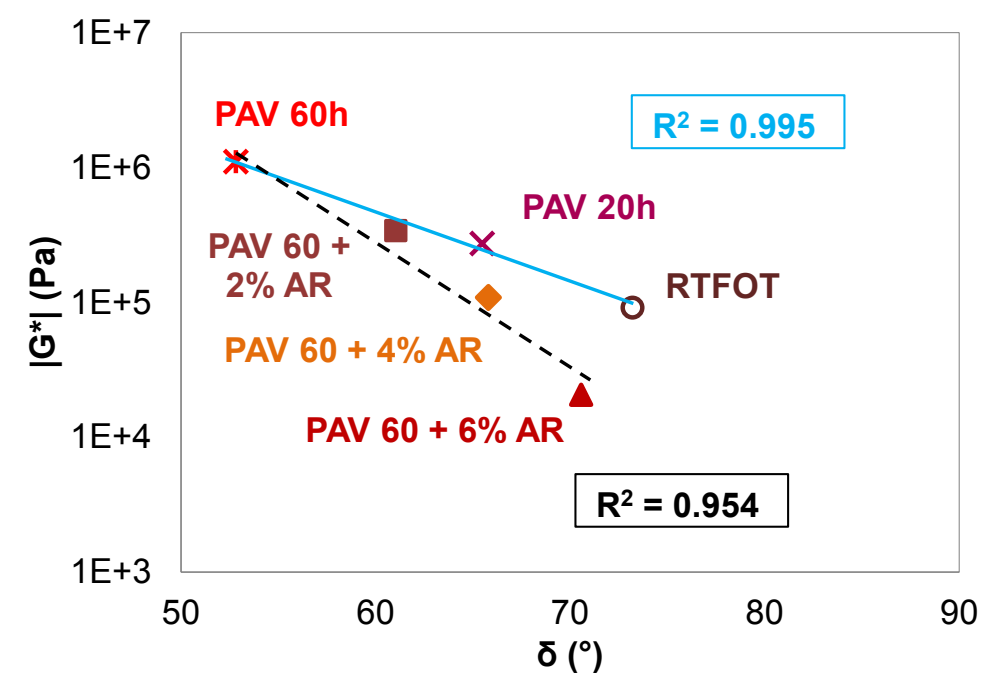

(b)

Fonte: Autora

\subsubsection{Ensaio MSCR}

Considerando apenas a deformação permanente, o uso de agente rejuvenescedor não seria necessário, visto que o envelhecimento do ligante asfáltico não impacta de forma negativa a resistência do ligante em relação a este defeito (MOGAWER et al., 2013). No entanto, conforme observado por Martins (2014), o envelhecimento provoca 
o enrijecimento do ligante asfáltico, reduzindo sua capacidade de relaxação de tensões, tornando-o mais suscetível à fadiga.

Dessa forma, para avaliar o impacto dos três teores de AR sobre a resistência à deformação permanente dos ligantes rejuvenescidos, o ensaio de MSCR foi realizado nos ligan tes envelhecidos e rejuvenescidos na temperatura de $64^{\circ} \mathrm{C}$, diferentemente dos capítulos anteriores, para evidenciar o efeito do agente rejuvenescedor. Os resultados de Jnr são apresentados na Figura 58a para a ten são de 100Pa e na Figura $58 \mathrm{~b}$ para a tensão de $3200 \mathrm{~Pa}$.

Figura 58 - Resultados de Jnr para os ligantes envelhecidos e rejuvenescidos. Em (a) tensão de 100Pa e em (b) tensão de $3200 \mathrm{~Pa}$.

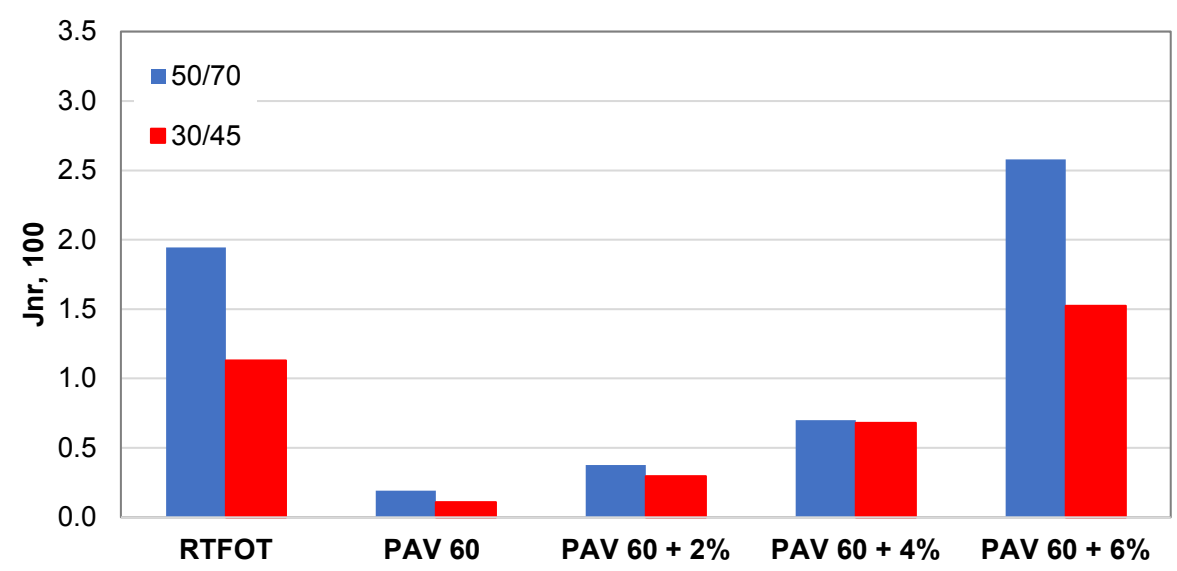

(a)

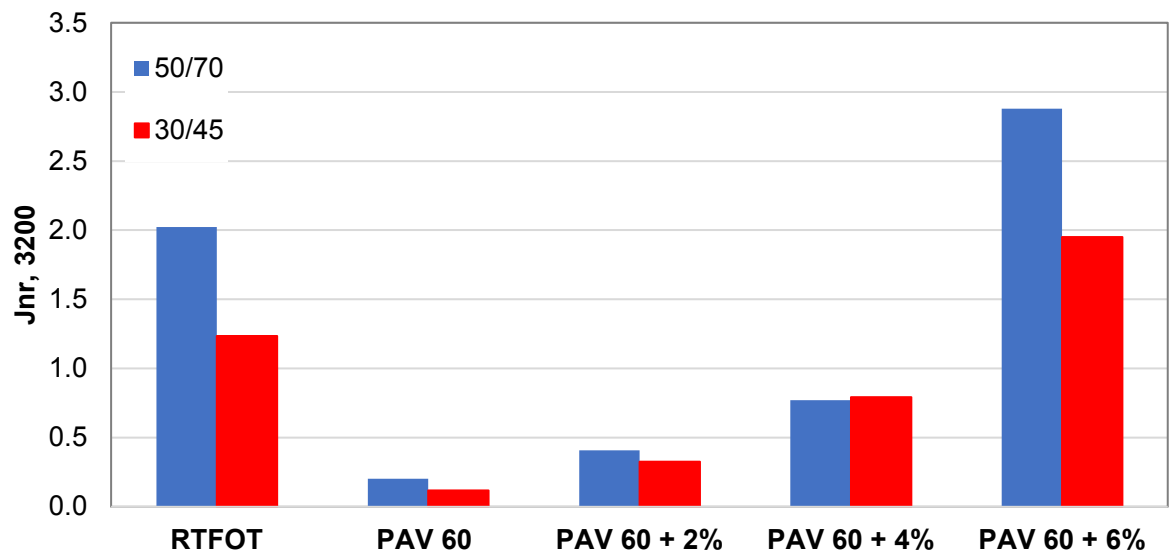

(b) 
A adição de AR torna os ligantes mais susceptíveis a deformação permanente, sendo que o teor de $6 \%$ de AR apresenta resultados bastante superior aos demais, com maior influência no CAP 50/70. Os resultados mostram que o teor de $4 \%$ de AR resulta em condições apropriadas, podendo ser utilizado para os ligantes estudados sem causar perda de resistência à deformação permanente quan do comparado ao RTFOT.

\subsubsection{Ensaio LAS}

Para complementar a análise e avaliar a resistência a fadiga dos ligantes rejuvenescidos, o ensaio LAS foi realizado nos ligantes, utilizando a temperatura de $20{ }^{\circ} \mathrm{C}$. Os resultados são apresentados na Figura 59 para o CAP 50/70 e na Figura 60 para o CAP $30 / 45$.

O emprego de agentes rejuvenescedores busca reverter o processo de envelhecimento de ligantes asfálticos a partir da restauração de algumas frações perdidas durante a vida de serviço do pavimento (OSMARI et al., 2017). Considerando ainda que o processo de rejuvenescimento torna o ligante menos rígido, a correta dosagem do AR é desejável para que a mistura reciclada seja resistente aos dois principais defeito de pavimentos asfálticos, a deformação permanente e o trincamento por fadiga. 
Figura 59 - Curva característica de dano (a) e curva de fadiga (b) do CAP 50/70 envelhecido e rejuvenescido

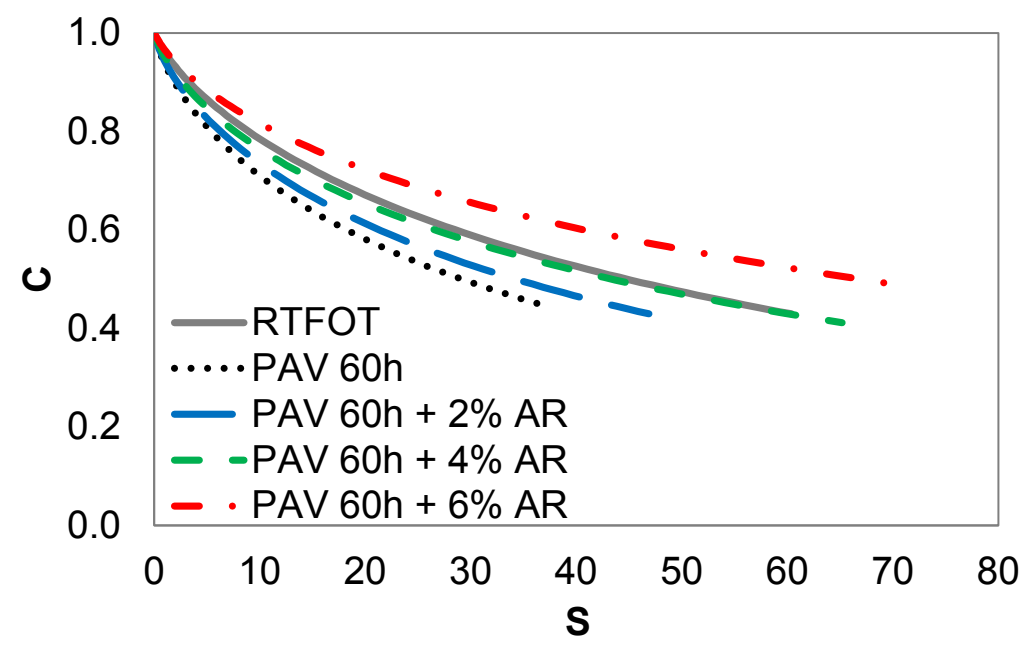

(a)

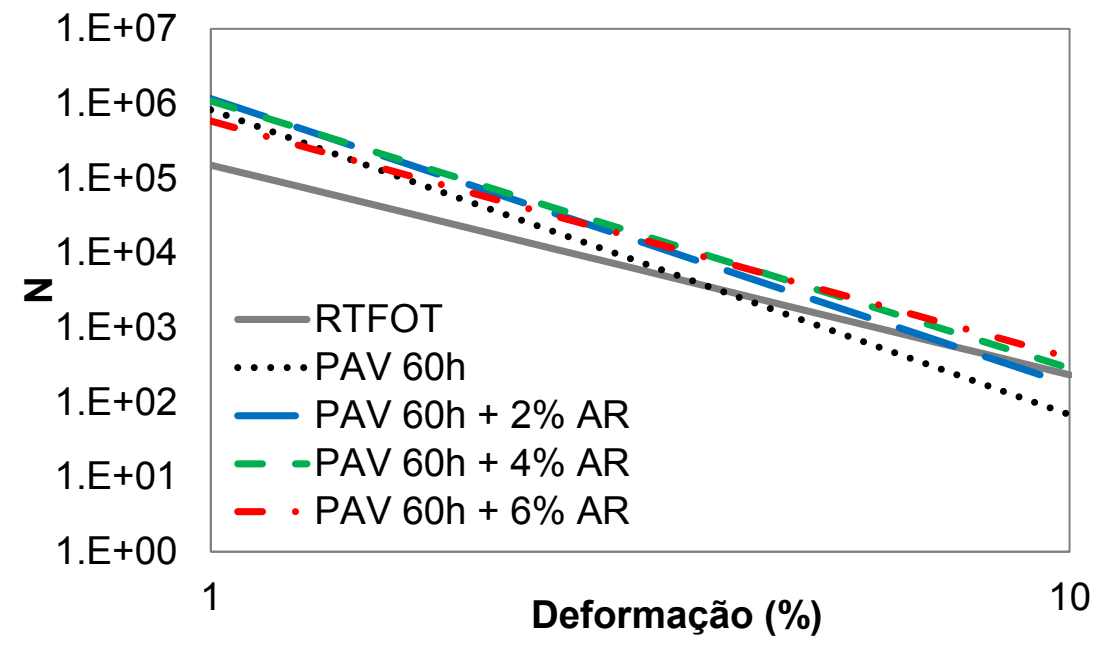

(b)

Fonte: Autora 
Figura 60 - Curva característica de dano (a) e curva de fadiga (b) do CAP 30/45 envelhecido e rejuvenescido

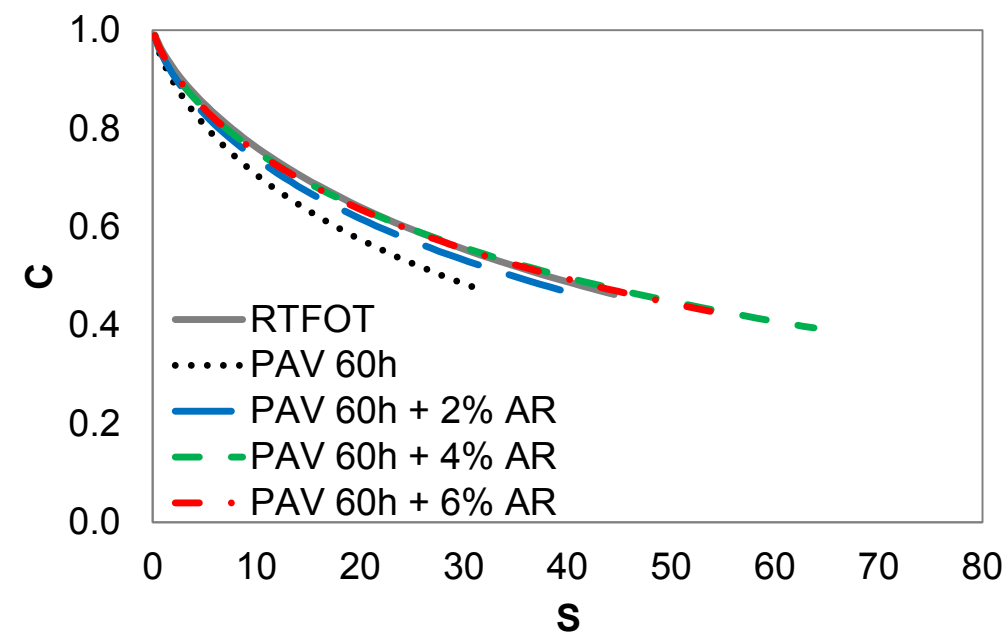

(a)

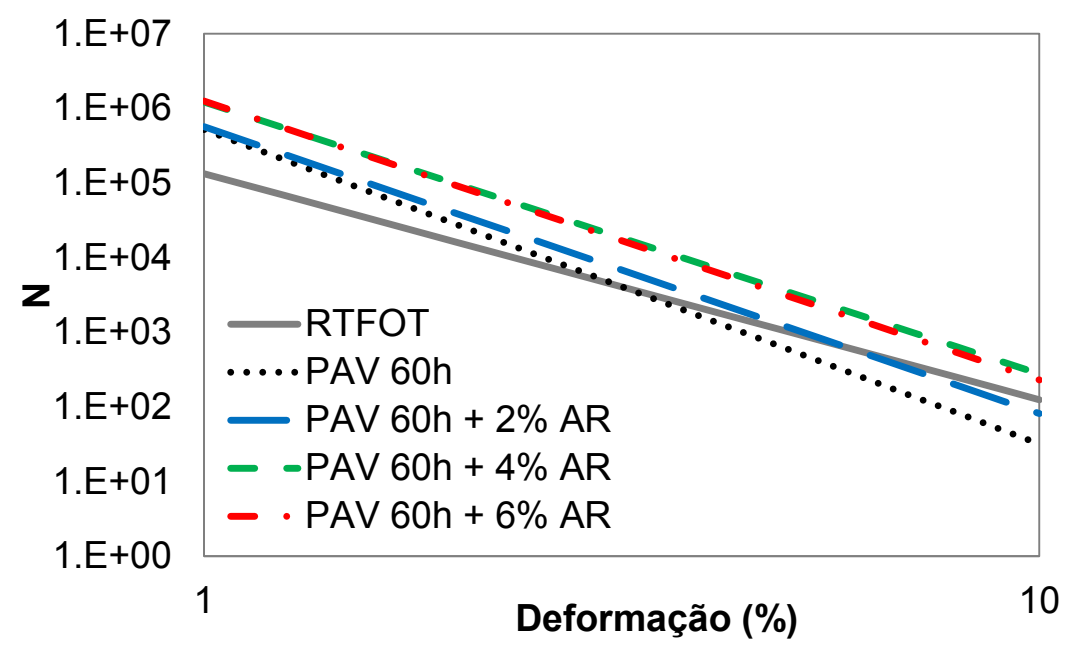

(b)

Fonte: Autora

Os resultados mostram que a adição do $A R$ favorece bastante a resistência à fadiga, mostrando que os ligantes rejuvenescidos com o teor de $4 \%$ de AR apresentam curva característica de dano muito similar ao RTFOT, porém resistindo a um dano mais elevado. Seguindo a tendência observada nos ou tros parâmetros avaliados, o agente rejuvenescedor utilizado no estudo apresenta maior influência sobre as propriedades do CAP 50/70. 


\subsubsection{Avaliação da dosagem de AR}

Como observado, os agentes rejuvenescedores são capazes de restaurar as propriedades reológicas dos ligantes asfálticos envelhecidos. No entanto, a quantidade de AR deve ser cuidadosamente escolhida, uma vez que o efeito desse AR pode afetar o desempenho das misturas asfálticas recicladas (MOGHADDAM; BAAJ, 2016; ARÁMBULA-MERCADO et al., 2018). Muitas vezes a dosagem é realizada de acordo com a recomendação do fornecedor. No entan to, a dosagem pode ser diferente dependendo das características do material fresado, principalmente no que diz respeito ao nível de envelhecimento (ARÁMBULA-MERCADO et al., 2018).

Dessa forma, uma análise de dosagem do AR foi realizada utilizando Blending Charts construídos a partir de dos resultados dos parâmetros de envelhecimento calculados a partir das propriedades viscoelásticas lineares e dos valores de Jnr, 3200 do ensaio MSCR. Os parâmetros utilizados foram:

a. $\left|G^{*}\right| / \operatorname{sen}\left(\delta\right.$, na temperatura de $60^{\circ} \mathrm{C}$, a $10 \mathrm{rad} / \mathrm{s}$;

b. $\left|G^{*}\right| \cdot \operatorname{sen} \delta$, na temperatura de $20^{\circ} \mathrm{C}$, a $10 \mathrm{rad} / \mathrm{s}$;

c. $\omega_{c}$, Crossover frequency;

d. $\left|G^{*}\right|-G R$, valor de $\left|G^{*}\right|$ do parâmetro Glover-Rowe;

e. $\delta$-GR, valor de $\delta$ do parâmetro Glover-Rowe;

f. Jnr,3200.

Não foi possível desenvolver os blending charts para alguns parâmetros devido à falta de resultados no caso do crossover do CAP 50/70 (PAV 60h + 6\% AR) ou pelo resultado do ligante na condição RTFOT estar bem distante da relação encontrada nos resultados de rejuvenescimento, como foi o caso do CAP 30/45 nos parâmetro $\left|G^{*}{ }^{*}\right|$ e valor de $\delta$ do parâmetro GR e do CAP 50/70 no parâmetro $\omega_{c}$. Os resultados para o CAP 50/70 são apresentados na Figura 61.

Os resultados mostram que o teor de AR para o CAP 50/70 varia entre 2,79\% a 5,41\% de AR. Observando os blending charts que resultaram nos menores teores de AR, é possível verificar que eles correspondem a parâmetros relacionados a fadiga e ao trincamento térmico. Como observado pelas análises de propriedades reológicas e do ensaio LAS, o agente rejuvenescedor apresenta grande influência sobre as 
propriedades do ligante em altas frequências (baixas temperaturas), dessa forma, esses parâmetros indicam o teor mínimo necessário de AR para que a resistência a fadiga ou trincamen to térmico seja similar ao RTFOT (ZAUMANIS; MALLICK; FRANK, 2014; ARÁMBULA-MERCADO et al., 2018).

Por outro lado, observa-se que para o parâmetro Glover-Rowe, os teores definidos por $\left|G^{*}\right|-G R$ e $\delta-G R$ são contraditórios. Esse resultado demonstra o que foi observado pela Figura 57, no qual mostra que o processo de rejuvenescimento segue uma ten dência diferente do envelhecimento, mostrando que AR atua de forma diferente sobre as propriedade viscoelásticas $\left(\left|G^{*}\right|\right.$ e $\left.\delta\right)$ dos ligantes envelhecidos.

Da mesma forma, a análise foi realizada para a CAP 30/45, os blending charts são apresentados na Figura 62. Os resultados mostram que o teor de AR para o CAP $30 / 45$ varia entre $2,91 \%$ a $5,32 \%$ de AR. Assim como para o CAP $50 / 70$ os menores teores são apresentados pelos parâmetros de relacionados a fadiga e ao trincamento térmico.

Entre os teores mais elevados os parâmetros que apresentam esses valores, tanto para o CAP 30/45 como para o CAP 50/70, são o $\left|G^{*}\right| / \operatorname{sen} \delta$ e o Jnr,3200. O teor de AR, para o CAP 30/45, determinado pelo parâmetro $\left|\mathrm{G}^{*}\right| / \operatorname{sen} \delta(5,32 \%)$ é superior ao determinado pelo $\mathrm{Jnr}, 3200$ (4,45\%), mostrando que a determinação do teor de AR apenas pelas propriedades viscoelásticas do ligante asfáltico pode não ser suficiente para garantir o desempenho final das misturas asfálticas recicladas. 
Figura 61 - Blending charts dos parâmetros avaliados para rejuvenescimento do CAP 50/70. Em

(a) $\left|G^{*}\right| /$ senס, em (b) $\left|G^{*}\right|$.senס, em (c) $\left|G^{*}\right|-G R$, em (d) $\delta-G R$ e em (d) Jnr,3200.

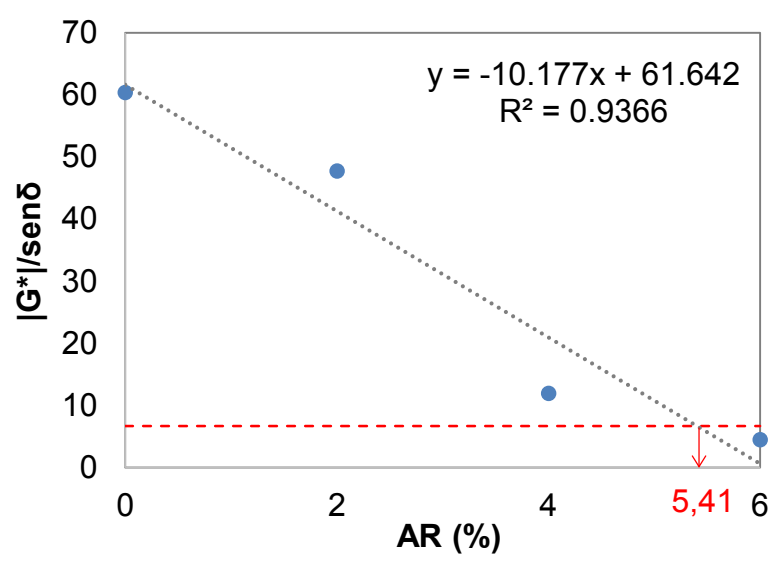

(a)

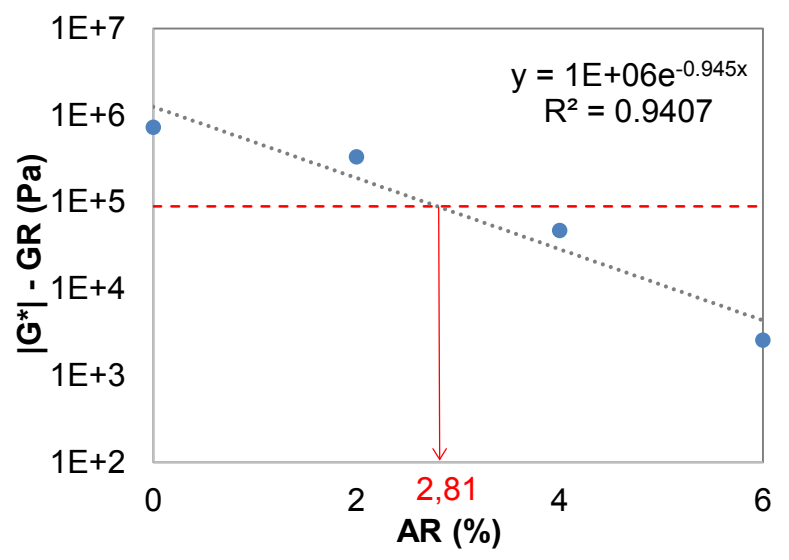

(c)

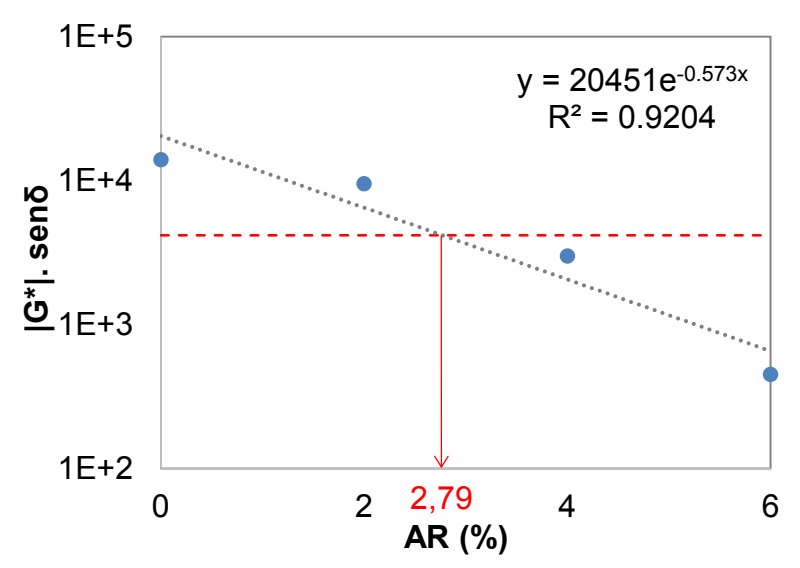

(b)

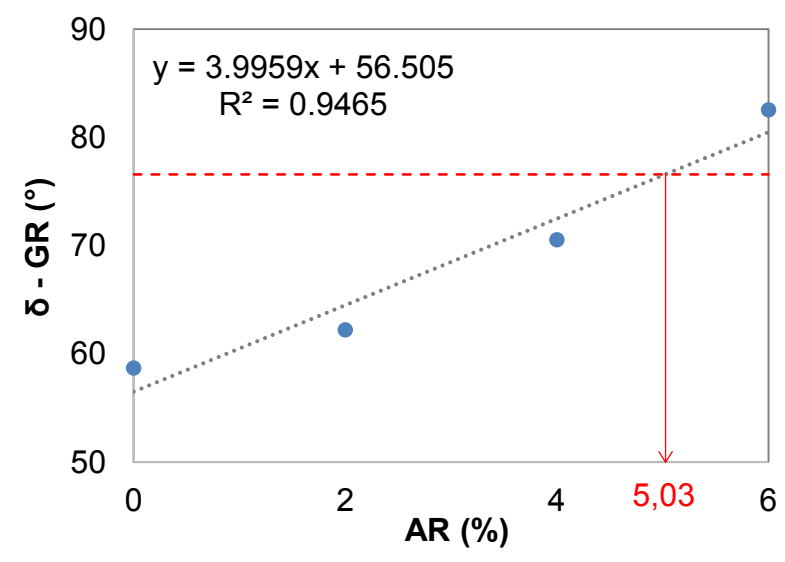

(d)

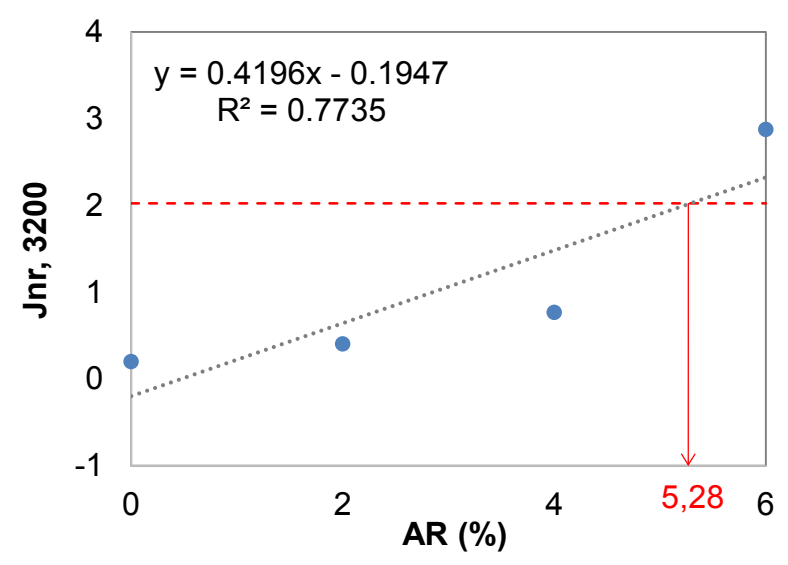

(e)

Fonte: Autora 
Figura 62 - Blending charts dos parâmetros avaliados para rejuvenescimento do CAP 30/45. Em (a) $\left|G^{*}\right| / \operatorname{sen} \delta$, em (b) $\left|G^{*}\right|$.sen $\delta$, em (c) $\omega_{c}$ e em (d) $\left|G^{*}\right|-G R$ e em (d) Jnr,3200.

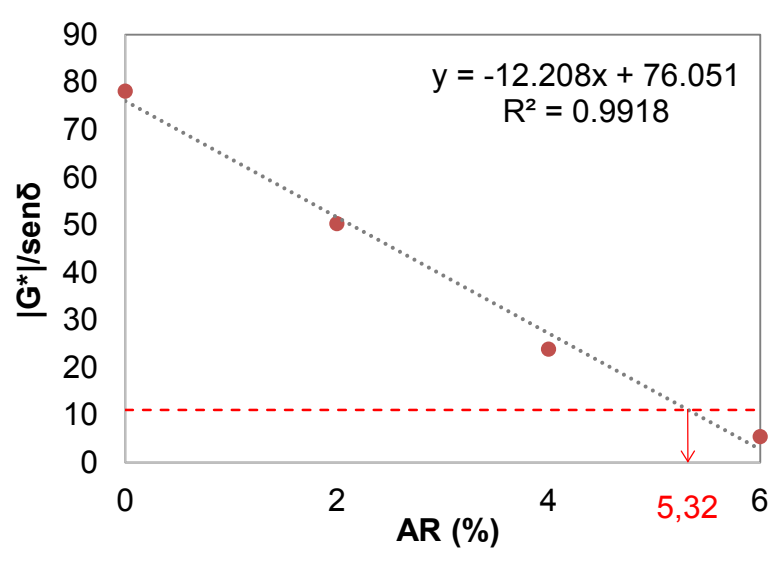

(a)

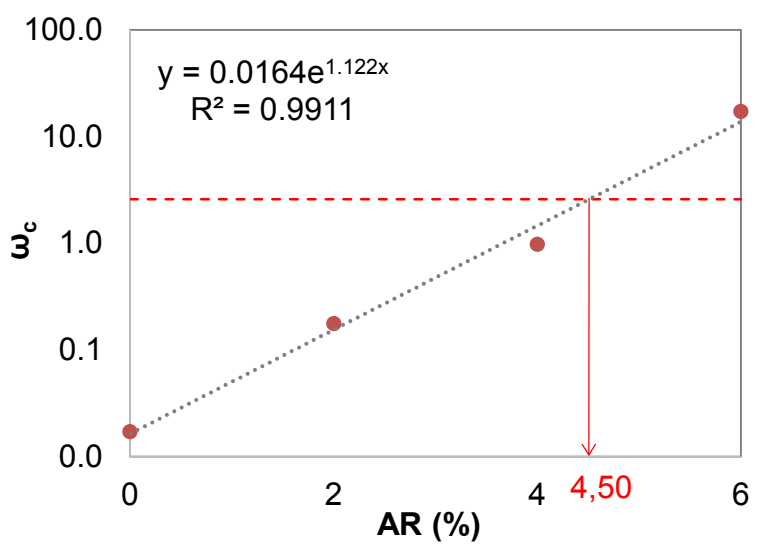

(c)

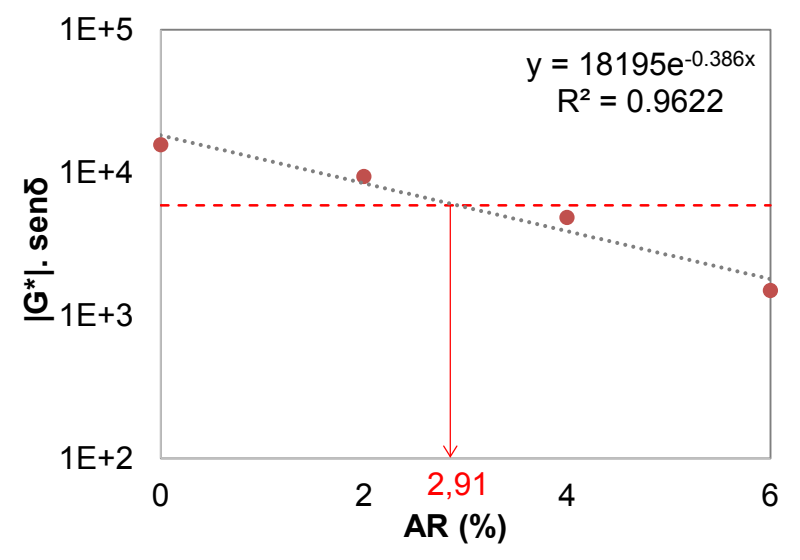

(b)

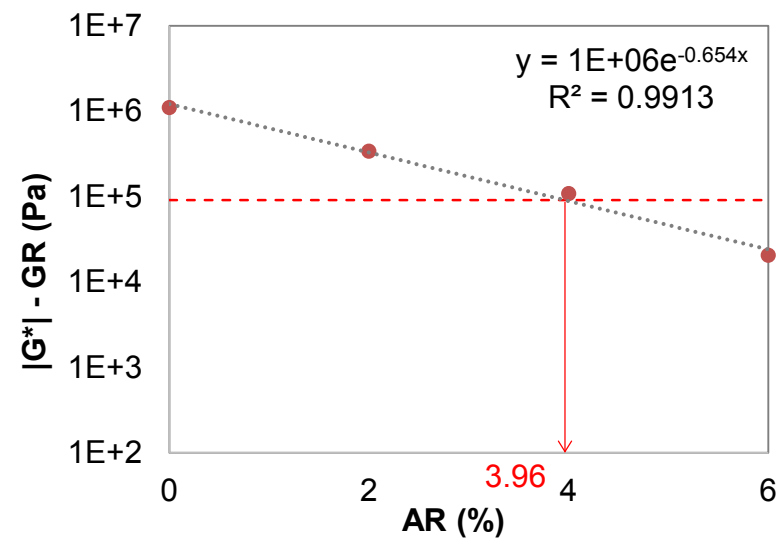

(d)

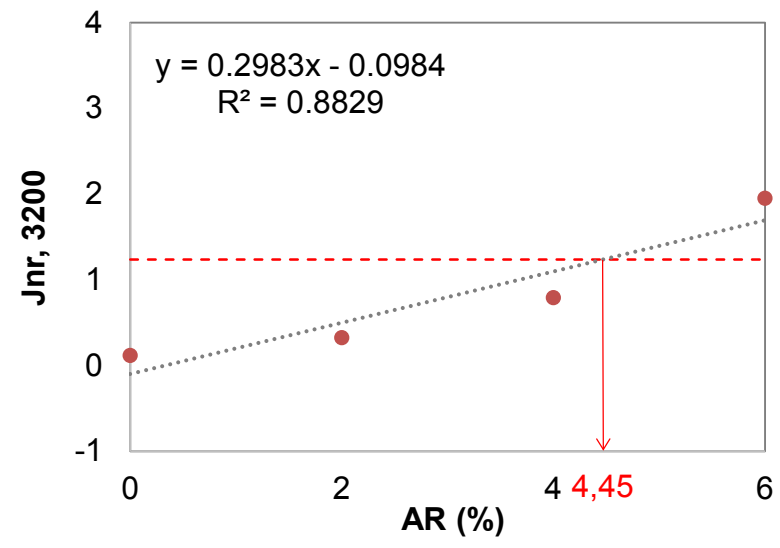

(e)

Fonte: Autora 


\section{CONSIDERAÇÕES FINAIS}

A técnica de reciclagem de misturas asfáltica tem se tornado uma alternativa sustentável para a construção e manutenção de pavimentos, com ganhos ambientais e econômicos. No entanto, a incorporação de altos teores de RAP levanta preocupações a respeito das propriedades do ligante envelhecido durante a vida de serviço do pavimento. Dessa forma, a compreensão dos processos de envelhecimento e rejuvenescimen to tornam-se importantes para melhorar o processo de reciclagem, possibilitan do a inclusão de maiores teores de RAP e prolongando a vida útil do pavimento. Neste estudo foram avaliados os envelhecimentos, em laboratório e em campo, de dois ligantes asfálticos convencionais e o rejuvenescimento dos mesmos ligantes após o envelhecimento a longo prazo em laboratório.

A partir do estudo do envelhecimento em laboratório foi possível avaliar comparativamente a influência dos envelhecimentos termo oxidativo e fotoquímico sobre as propriedades dos ligantes asfálticos. No envelhecimento termo oxidativo, o ensaio PAV com duração prolongada para 60 horas provocou um maior envelhecimento dos ligantes asfálticos. No entan to, o envelhecimento pelo SUNTEST foi o mais severo entre todos os métodos de envelhecimento de longo prazo avaliados, mostran do a importância da radiação UV no processo de envelhecimento dos ligantes asfálticos.

A análise química permitiu identificar, através dos ensaios SARA e FTIR, que o envelhecimento SUNTEST provoca reações químicas diferentes nos ligantes asfálticos, quando comparado ao envelhecimento termo oxidativo. Além disso, os resultados das frações SARA mostraram que o envelhecimento fotoquímico impacta de forma diferente as frações químicas dos ligantes avaliados.

A partir do estudo do envelhecimento em campo, foi possível verificar que os ligantes continuam envelhecendo ao longo do tempo, provocando alterações químicas e alterando o desempenho dos ligantes asfálticos. No entanto, foram verificadas inconsistências nos resultados que podem ser atribuídas aos processos que o material está exposto desde a construção do pavimento, até o processo de extração e recuperação dos ligantes asfálticos. Além disso, o fato de o ligante ter sido extraído 
de corpos de prova de $4 \mathrm{~cm}$ de espessura, pode ter colaborado para a variação dos resultados, visto que o envelhecimento da superfície, que fica exposta, é a mais severa como observado por outros pesquisadores.

Apesar do envelhecimento dos dois ligantes ser diferente, os resultados reológicos indicaram que eles podem apresentar desempenho similares após 36 meses em campo.

A comparação entre os envelhecimentos em laboratório e em campo mostrou que o envelhecimento em campo após 36 meses foi mais severo que o ensaio PAV 20h, normatizado, apresentando resultados mais próximos do PAV 60h, para ambos os ligantes.

O parâmetro GR, avaliado no Espaço Black, permitiu avaliar o envelhecimento e o rejuvenescimento dos ligantes asfálticos, a partir das propriedades viscoelásticas dos ligantes asfálticos, possibilitando visualizar inconsistências que não foram identificadas pelas curvas mestras de $\left|G^{*}\right|$ e $\delta$.

A análise química auxiliou na observação de alterações que foram quantificadas pelos ensaios reológicos, mostrando que a análise conjunta é essencial para melhor compreensão das alterações provocadas pelo envelhecimento. No entanto, os resultados químicos apresentaram grande sensibilidade, não apresentando uma ten dência específica e clara quanto ao aumento do nível de envelhecimento, exceto o índice de carbonila. Dentre os métodos utilizados para a avaliação, a técnica de RMN foi a que apresentou maior dificuldade de interpretação, devido a maior sensibilidade do ensaio. Apesar disso, ela se mostra uma técnica promissora para investigação das diferentes reações químicas decorrentes do processo de envelhecimento.

O estudo do rejuvenescimento mostra que o AR de base vegetal permitiu restaurar em grande parte as propriedades reológicas a níveis desejáveis, com a dosagem no teor de $4 \%$ de AR, favorecendo a resistência à fadiga. Porém, o processo de rejuvenescimento segue uma tendência diferente do envelhecimento e, portanto, a dosagem correta deve ser realizada para proporcionar um bom desempenho da mistura reciclada, tanto à deformação permanente, quanto à fadiga. 
Como sugestões para trabalhos futuros, têm-se:

- Avaliar os processos de envelhecimento e rejuvenescimento para ligantes asfálticos modificados, comparativamente aos convencionais;

- Avaliar o efeito da radiação UV com a profundidade do revestimento asfáltico;

- Diferenciação das reações químicas que ocorrem no envelhecimento termo oxidativo e no fotoquímico;

- Análise estatística dos resultados químicos, visto que esses parâmetros são muito sensíveis à composição do ligante asfáltico;

- Avaliar quimicamente o processo de rejuvenescimento, por meio de suas reações para diferentes agentes de reciclagem.

- Análise do envelhecimento e rejuvenescimento pelo parâmetro $\Delta T_{c}$.

- Análise do envelhecimento de campo utilizando a geometria de $4 \mathrm{~mm}$, sendo necessário menor quantidade de material para o estudo. 


\section{REFERÊNCIAS}

AGUIAR-MOYA, J. P.; SALAZAR-DELGADO, J.; BONILLA-MORA, V.; RODRÍGUEZCASTRO, E.; LEIVA-VILLACORTA, F.; LORÍA-SALAZAR, L. Morphological analysis of bitumen phases using atomic force microscopy. Road Materials and Pavement Design, 16(sup1), p. 138-152. 2015.

AGUIAR-MOYA, J. P.; SALAZAR-DELGADO, J.; GARCÍA, A.; BALDI-SEVILLA, A.; BONILLA-MORA, V.; LORÍA-SALAZAR, L. G. Effect of ageing on micromechanical properties of bitumen by means of atomic force microscopy. Road Materials and Pavement Design, p. 203-215, 2017.

AIREY, G. D. State of art report on ageing test methods for bituminous pavement materials. The International Journal of Pavement Engineering, 4, p. 165-176, 2003.

ALI, A. W.; MEHTA, Y. A.; NOLAN, A.; PURDY, C.; BENNERT, T. Investigation of the impacts of aging and RAP percentages on effectiveness of asphalt binder rejuvenators. Construction and Building Materials, 110, 211-217. 2016.

AL-QADI, I.L.; AURANGZEB, Q.; CARPENTER, S. H., PIN Morphological analysis of bitumen phases using atomic force microscopy E, W. J.; TREPANIER, J. Impact of High RAP Contents on Structural and Performance Properties of Asphalt Mixtures, Illinois Center for Transportation, Springfield. Report FHWA-ICT-12-002, 2012.

ARÁMBULA-MERCADO, E.; KASEER, F.; MARTIN, A. E.; YIN, F.; CUCALON, L. G. Evaluation of recycling agent dosage selection and incorporation methods for asphalt mixtures with high RAP and RAS contents. Construction and Building Materials, v. 158, p. 432-442, 2018.

ARRA - ASPHALT RECLAIMING AND RECYCLING ASSOCIATION. Basic Asphalt Recycling Manual, ARRA, 2001.

BAHIA, H. U.; ANDERSON, D. A. The Pressure Aging Vessel (PAV): a test to simulate rheological changes due to field aging. Physical properties of asphalt cement binders. ASTM International, 1995. 
BALDINO, N.; ROSSI, C. O.; LUPI, F. R.; GABRIELE, D. Rheological and structural properties at high and low temperature of bitumen for warm recycling technology. Colloids and Surfaces. A: Physicochemical and Engineering Aspects, v. 532, p. 592600, 2017.

BARTHOLOMEU, D. B.; CAIXETA FILHO, J. V. Impactos econômicos e ambientais decorrentes do estado de conservação das rodovias brasileiras: um estudo de caso. Revista de Economia e Sociologia Rural, v. 46, n. 3, p. 703-738, 2008.

BERNUCCI, L. B.; MOTTA, L. M. G.; CERATTI, J. A. P.; SOARES, J. B. Pavimentação asfáltica: Formação básica para engenheiros. Rio de Janeiro: PETROBRAS: ABEDA, 3a reimp., 2010.

BESAMUSCA, J.; VOLKERS, A.; VD WATER, J.; GAARKEUKEN, B. Simulating ageing of en $1259170 / 100$ bitumen at laboratory conditioning compared to porous asphalt. 5th Eurasphalt \& Eurobitume Congress, June, Istanbul, 2012.

BLOOMQUIST, D.; DIAMOND, G.; ODEN, M.; RUTH, B.; TIA, M. Engineering and environmental aspects of recycled materials for highway construction. Appendix 1. Final report, September 1992 - June 1993 (No. FHWA-RD-93-088). Western Research Institute, 1993.

BORGHI, A.; CARRIÓN; A. J. B.; LO PRESTI, D.; GIUSTOZZI, F. Effects of Laboratory Aging on Properties of Biorejuvenated Asphalt Binders. Journal of Materials in Civil Engeneering, 29(10), 04017149, 2017.

BOSSO, M.; VASCONCELOS, K. L.; BEJA, I. A.; BERNUCCI, L. L. B.; BITTENCOURT, T. Weigh-in-Motion System to Monitoring Overloading In a Brazilian Heavy Traffic Highway. 7th International Conference on Weigh-In-Motion (ICWIM7), Foz do Iguaçu, Novembro, p. 242-248, 2016.

BROSSEAUD, Y. Reciclagem de misturas asfálticas: Evolução após 20 anos e a situação atual na França. $3^{\circ}$ Salão de Inovação ABCR $-7^{\circ}$ Congresso Brasileiro de Rodovias e Concessões, Foz do Iguaçu, 2011.

BROWN, E. R.; KANDHAL, P. S.; ROBERTS, F. L.; KIM, Y. R.; LEE, D. Y.; KENNEDY, 
T. W. Hot mix asphalt materials, mixture design, and construction. NAPA Research and Education Foundation, 2009.

CAMARGO, F. F. Field and laboratory perfomance evaluation of a field-blemded rubber asphalt. 2016. 161 p. Tese de Doutorado (Engenharia) - Escola Politécnica, Universidade de São Paulo, São Paulo, 2016.

CAO, X.; WANG, H.; CAO, X.; SUN, W.; ZHU, H.; TANG, B. Investigation of rheological and chemical properties asphalt binder rejuvenated with waste vegetable oil. Construction and Building Materials, 180, p. 455-463, 2018.

CAVALLI, M. C.; ZAUMANIS, M.; MAZZA, E.; PARTL, M.N.; POULIKAKOS, L.D. Aging effect on rheology and cracking behavior of reclaimed binder with bio-based rejuvenators. Journal of Cleaner Production, 189, p. 88-97, 2018.

CHEN, J.; WANG C.; HUANG C. Engineering Properties of Bituminous Mixtures Blended with Second Reclaimed Asphalt Pavements (R2AP), Road Materials and Pavement Design, 10:sup1, 129-149, 2009.

CHEN, M.; XIAO, F.; PUTMAN, B.; LENG, B.; WU, S. High temperature properties of rejuvenating recovered binder with rejuvenator, waste cooking and cotton seed oils. Construction and Building Materials, v. 59, p. 10-16, 2014.

CHRISTENSEN, D. W.; ANDERSON, D. A.; ROWE, G. M. Relaxation spectra of asphalt binders and the Christensen-Anderson rheological model. Road Materials and Pavement Design, 18(sup1), p. 382-403, 2017.

CNT. Pesquisa CNT de Rodovias: Relatório Gerencial. Brasil: CNT, 236 p., 2019.

COSTA, C.; PINTO, S. O uso de reciclagem de pavimentos como alternativa para o desenvolvimento sustentável em obras rodoviárias no Brasil. São Paulo: Revista Engenharia, 602 ed, p. 96-102, 2011.

CRAVO, M. C. C. Efeitos do envelhecimento térmico e fotoquímico em ligantes asfálticos, mástique e matriz de agregados finos. Tese de Doutorado, COPPE, Universidade Federal do Rio de Janeiro, Rio de Janeiro, 2016. 
DAVID, D. Misturas asfálticas recicladas a frio: Estudo em laboratório utilizando emulsão e agente de reciclagem emulsionado. 2006. 117 P. Dissertação de Mestrado. Escola de Engenharia/UFRGS - Universidade Federal do Rio Grande do Sul, Porto Alegre, 2006.

DOMKE, C. H.; DAVISON, R. R.; GLOVER, C. J. Effect of Oxidation Pressure on Asphalt Hardening Susceptibility. Transportation Research Record, n. 99, p. 114$121,1999$.

DONDI, G.; MAZZOTTA, F.; SIMONE, A.; VIGNALI, V.; SANGIORGI, C.; LANTIERI, C. Evaluation of different short term aging procedures with neat, warm and modified binders. Construction and Building Materials, v 106, p. 282-289, 2016.

EL BEZE, L. Recyclage à chaud des agrégats d'enrobés bitumeux: identification de traceurs d'homogénéité du mélange entre bitume vieilli et bitume neuf d'apport. Thèse de Doctorat. Aix-Marseille 3, 2008.

ELKASHEF, M.; CHRISTOPHER WILLIAMS, R. Improving fatigue and low temperature performance of $100 \%$ RAP mixtures using a soybean-derived rejuvenator. Construction and Building Materials, 151, p. 345-352, 2017.

ELKASHEF, M.; CHRISTOPHER WILLIAMS, R.; COCHRAN, E. Investigation of fatigue and thermal cracking behavior of rejuvenated reclaimed asphalt pavement binders and mixtures. International Journal of Fatigue, 108, p. 90-95, 2018.

ERKENS, S.; POROT, L.; GLASER, R.; GLOVER, C. J. Review of asphalt (concrete) ageing tests in the US and Europe. 95th Annual Meeting of the Transportation Research Board. 2016.

ERSKINE, J.; HESP, S. A. M.; KAVEH, F. Anotherlook at accelerated aging of asphalt cements in the pressure aging vessel. 5th Eurasphalt and Eurobitumen Congress, Istanbul, Turkey. 2012.

FARRAR, M. J.; HARNSBERGER, P. M.; THOMAS, K. P.; WISER, W. Evaluation of oxidation in asphalt pavement test sections after four years of service. International Conference on Perpetual Pavement. Western Research Institute. 2006. 
FARRAR, M. J.; TURNER, T. F.; PLANCHE, J. P.; SCHABRON, J. F.; HARNSBERGER, P. M. Evolution of the crossover modulus with oxidative aging: method to estimate change in viscoelastic properties of asphalt binder with time and depth on the road. Transportation Research Record, v. 2370, n. 1, p. 76-83, 2013.

FENG, Z. G.; YU, J. Y.; ZHANG, H. L.; KUANG, D. L. Effect of ultraviolet aging on rheology, chemistry and morphology of ultraviolet absorber modified bitumen. Materials and Structures, 46, p. 1123-1132. 2013.

FERROTTI, G.; BAAJ, H.; BESAMUSCA, J.; BOCCI, M.; FALCHETTO, A. C.; GRENFELL, J.; HOFKO, B; POROT, L; POULIKAKOS, L. D.; YOU, Z.; YOU, Z. Comparison of Short Term Laboratory Ageing on Virgin and Recovered Binder from HMA/WMA Mixtures. RILEM 252-CMB-Symposium on Chemo Mechanical Characterization of Bituminous Materials. RILEM Bookseries. Springer, p. 21-26, 2018.

FREIRE, J.; GÓIS, T. S.; DOMINICINI, W. K.; LUTIF, J. O estado da arte sobre uso de reciclado de pavimento asfáltico na pavimentação no Brasil e no mundo. XXVIII ANPET Congresso da Associação Nacional de Pesquisa e Ensino em Transportes, Curitiba, 2014.

GADLER, F. Desempenho e propriedades mecânicas de misturas asfálticas mornas produzidas com revestimento asfáltico fresado e agregado de resíduo de concreto em substituição da fração graúda e miúda da granulometria. 164 p. Dissertação de Mestrado (Engenharia) - Universidade Federal do Paraná. Curitiba, 2018.

GANDHI, T. Effects of warm asphalt additives on asphalt binder and mixture properties. 144p. Doctoral thesis. Clemson University. South Carolina, 2008.

GARCIA CUCALON, L.; KASEER, F.; ARÁMBULA-MERCADO, E.; EPPS MARTIN, A.; MORIAN, N.; POURNOMAN, S.; HAJJ, E. The crossover temperature: significance and application towards engineering balanced recycled binderblends. Road Materials and Pavement Design, 20(6), p. 1391-1412, 2018.

GARCIA CUCALON, L.; KASEER, F.; ARÁMBULA-MERCADO, E.; EPPS MARTIN, 
A.; MORIAN, N.; POURNOMAN, S.; HAJJ, E. The crossover temperature: significance and application towards engineering balanced recycled binder blends. Road Materials and Pavement Design, p. 1-22, 2018.

GASPAR, M. S. Mecanismos de ativação e interação entre ligantes na reciclagem asfáltica a quente e morna. Dissertação de Mestrado (Engenharia) - Escola Politécnica, Universidade de São Paulo, São Paulo, 2019.

GenNesseauX, M. M. L. Avaliação da Durabilidade de Misturas Asfálticas a Quente e Mornas Contendo Material Asfáltico Fresado. 195 p. Tese de Doutorado (Engenharia) - Escola Politécnica, Universidade de São Paulo, São Paulo, 2015.

GLOVER, C. J.; DAVISON, R. R.; DOMKE, C. H.; RUAN, Y.; JURISTYARINI, P.; KNORR, D. B.; JUNG, S. H. Development of a new method for assessing asphalt binder durability with field validation. FHWA/TX-05/1872-2, Texas Tansportation Institute. 2005.

GONDIM, L. M. Investigação sobre a formulação de um bio-ligante à base da seiva de euphorbia tirucalli para emprego em pavimentação. 2017, 216 p. Tese de Doutorado (Engenharia) - Universidade Federal do Ceará, Fortaleza, 2017.

HAGHSHENAS, H. F.; KIM, Y. R.; KOMMIDI, S. R.; NGUYEN, D.; HAGHSHENAS, D. F.; MORTON, M. D. Evaluation of long-term effects of rejuven ation on reclaimed binder properties based on chemical-rheological tests and analyses. Materials and Structures, 51:134, 2018.

HALEY, G. A. Changes in chemical composition of a Kuwait short residue during air blowing. Analytical Chemistry, v. 47, n. 14, p. 2432-2437, 1975.

HASAN, M. U.; ALI, M. F.; BUKHARI, A. Structural characterization of Saudi Arabian heavy crude oil by NMR spectroscopy. Fuel, v. 62, 1983.

HESP, S. A.M.; SHURVELL, H. F. X-ray fluorescence detection of waste engine oil residue in asphalt and its effect on cracking in service. International Journal of Pavement Engineering, v. 11, n. 6, p. 541-553, 2010.

HOLLER, F. J.; SKOOG, D. A.; CROUCH, S. R. Princípios de análise instrumental. 
Bookman, 2009.

HUANG, S. C.; TURNER, T. F. Aging Characteristics of RAP Blend Binders: Rheological Properties. Journal of Materials in Civil Engeneering, 26(5), p. 966$973,2014$.

HUNTER, R. N.; SELF, A.; READ, J. The Shell Bitumen Handbook. 6a edition, London, England, ICE Publishing, 2015.

IM, S.; ZHOU, F.; LEE, R.; SCULLION, T. Impacts of Rejuvenators on Performance and Engineering Properties of Asphalt Mixtures Containing Recycled Materials. Construction and Building Materials, Vol. 53, No. 28, p. 596-603, 2014.

JENNINGS, P. W.; PRIBANIC, J. A.; DESANDO, M. A.; RAUB, M. F.; MOATS, R.; SMITH, J. A.; MENDES, T. M.; MCGRANE, M.; FANCONI, B.; VANDERHART, D. L.; MANDERS, W. F. Binder characterization and evaluation by nuclear magnetic resonance spectroscopy. Strategic Highway Research Program, SHRP-A-335, 1993.

JING, R.; VARVERI, A.; LIU, X.; SCARPAS, A.; ERKENS, S. Ageing effect on chemomechanics of bitumen, Road Materials and Pavement Design, 2019.

KASEER, F.; CUCALON, L. G.; ARÁMBULA-MERCADO, E.; MARTIN, A. E.; EPPS, J. Practical tools for optimizing recycled materials content and recycling agent dosage for improved short-and long-term performance of rejuvenated binder blends and mixtures. Journal of the Association of Asphalt Paving Technologists, v. 87, p. 513-550, 2018.

KENNEDY, T. W.; HUBER, G. A.; HARRIGAN, E. T.; COMINSKY, R. J.; HUGHES, C. S.; VON QUINTUS, H.; MOULTHROP, J. S. Superior performing asphalt pavements (Superpave): The product of the SHRP asphalt research program. 1994.

KIM, Y. Richard. Modeling of asphalt concrete. 2008.

KING, G.; ANDERSON, M.; HANSON, D.; BLANKENSHIP, P. Using black space diagrams to predict age-induced cracking. 7th RILEM international conference on 
cracking in pavements. Springer, Dordrecht, p. 453-463, 2012.

KOUDELKA, T; VARAUS, M; SPERKA, P. Influence of Aging on Oil Rejuvenated Binder. Key Engineering Materials. Trans Tech Publications, p. 528-534, 2017.

LEITE, L. F. M.; CRAVO, M. C. C.; DANTAS, L. N.; ARAUJO, M. F. Evaluation of the UV aging tests effect on asphalt binders using Glover Rowe parameter, 2018.

LEITE, L. F. M.; ODA, S.; NASCIMENTO, L. A. H.; CHACUR, M.; MOTTA, L. M. G. Estudo do envelhecimento do cimento asfáltico de petróleo: efeito dos parâmetros de dosagem da mistura asfáltica. XXIV ANPET Congresso de Pesquisa e Ensino em Transportes, Salvador, 2010.

LIMA, V. S. Avaliação da influência da temperatura de corte sobre as frações asfaltênicas. Dissertação de Mestrado. Programa de Pós-graduação em Tecnologia de processos Químicos e Bioquímicos, Escola de Química, Universidade Federal do Rio de Janeiro, Rio de Janeiro, 2008.

LIN, M. S.; DAVISON, R. R.; GLOVER, C. J.; BULLIN, J. A. The Effects of Asphaltenes on Asphalt Re-cycling and Aging. Transport Research Record, v 1507, p. 86-95. 1995.

LIU, G.; NIELSEN, E.; KOMACKA, J.; GREET, L.; VAN DE VEN, M. Rheological and chemical evaluation on the ageing properties of SBS polymer modified bitumen: From the laboratory to the field. Construction and Building Materials, 51, p. 244-248, 2014.

LU, X.; ISACSSON, U. Effect of ageing on bitumen chemistry and rheology. Construction and Building Materials 16(1), p. 15-22, 2002.

LU, X.; TALON, Y.; REDELIUS, P. Ageing of bituminous binders-laboratory tests and field data. 4th Eurasphalt \& Eurobitume Congress, Copenhagen, p. 21-23, 2008.

LUCENA, M. C. C.; SOARES, S. A.; SOARES, J. B. Estudo do envelhecimento de asfalto modificado por SBS através de RMN. $7^{\circ}$ Congresso Brasileiro de Polímeros. 2003. 
MA, L.; LI, Z.; HUANG, J. Investigation of chemistry by FTIR and NMR during the natural exposure aging of asphalt. Pavements and Materials, 2011.

MARTINS, A. T. Contribuição para a validação do ensaio de resistência ao dano por fadiga para ligantes asfálticos. Dissertação de Mestrado. Universidade Federal do Rio de Janeiro, Rio de Janeiro, 2014.

MASSON, J., LEBLOND, V., MARGESON, J. Bitumen morphologies by phasedetection atomic force microscopy. Journal of Microscopy, 221, p. 17-29, 2006.

MCLEOD, N. W. Asphalt cements: pen-vis number and its application to moduli of stiffness. Journal of Testing and Evaluation, v. 4, n. 4, p. 275-282, 1976.

MENAPACE, I.; CUCALON, L. G.; KASEER, F.; ARÁMBULA-MERCADO, E.; MARTIN, A. E.; MASAD, E.; KING, G. Effect of recycling agents in recycled asphalt binders observed with microstructural and rheological tests. Construction and Building Materials, v. 158, p. 61-74, 2018.

MERDRIGNAC, I.; ESPINAT, D. Physicochemical characterization of petroleum fractions: the state of the art. Oil \& Gas Science and Technology-Revue de l'IFP, v. 62, n. 1, p. 7-32, 2007.

MOGAWER, W. S.; BOOSHEHRIAN, A.; VAHIDI, S.; AUSTERMAN, A. J. Evaluating the effect of rejuvenators on the degree of blending and performance of high RAP, RAS, and RAP/RAS mixtures. Road Materials and Pavement Design, v. 14, n. sup2, p. 193-213, 2013.

MOGHADDAM, T. B.; BAAJ, $\mathrm{H}$. The use of rejuvenating agents in production of recycled hot mix asphalt: A systematic review. Construction and Building Materials, v. 114, p. 805-816, 2016.

MOHAMMADAFZALI, M.; ALI, H.; MUSSELMAN, J. A.; SHOLAR, G. A.; KIM, S.; $\mathrm{NASH}, \mathrm{T}$. M. Study on long-term aging of recycled binders using performance-grade tests with extended aging time. 94th TRB Annual Meeting. Transportation Research Board, Washington, DC, 2015.

MORIAN, N.; ZHU, C.; HAJJ, E. Y. Rheological Indexes Phenomenological Aspects of 
AsphaltBinder Aging Evaluations. Transportation Research Record, 2505, p. 32-40, 2015.

MULLINS, O. C. The modified yen model. Energy and Fuels, 24, p. 2179-2270, 2010.

NAHAR, S. N.; QIU, J.; SCHMETS, A. J. M.; SCHLANGEN, E.; SHIRAZI, M.; VAN DE VEN, M. F. C.; SCARPAS, A. Turning back time: rheological and microstructural assessment of rejuvenated bitumen. Transportation Research Record, v. 2444, n. 1, p. 52-62, 2014.

NAYAK, P; SAHOO, U. C. Rheological, chemical and thermal investigations on an aged binder rejuvenated with two non-edible oils. Road Materials and Pavement Design, v. 18, n. 3, p. 612-629, 2017.

ONGEL, A.; HUGENER, M. Impact of rejuvenators on aging properties of bitumen. Construction and Building Materials, 94, 467-474. 2015.

OSMARI, P. H. Caracterização química, reológica e de morfologia superficial de ligantes asfálticos modificados por diferentes agentes rejuvenescedores. Instituto Alberto Luiz Coimbra de Pós-Graduação e Pesquisa de Engenharia (COPPE). Universidade Federal do Rio de Janeiro, Brasil, 2016.

OSMARI, P. H.; ARAGÃO, F. T. S.; LEITE, L. F. M.; SIMÃO, R. A.; MOTTA, L. M. G.; KIM, Y. R. Chemical, Microstructural, and Rheological Characterizations of Binders to Evaluate Aging and Rejuvenation. Transport Research Record, v 2632, p.14-24. 2017.

OSMARI, P. H.; LEITE, L. F. M.; ARAGÃO, F. T. S.; CRAVO, M. C. C; DANTAS, L. N.; MACEDO, T. F. Cracking resistance evaluation of asphalt binders subjected to differents laboratory and field aging conditions, Road Materials and Pavement Design, 20:sup2, S663-S677, 2019.

PETERSEN, C. J. Chemical composition of asphalt as related to asphalt durability: state of the art. Transportation Research Record, 999, p13-30, 1984.

PIRES, G. M.; DEL BARCO CARRIÓN, A. J.; AIREY, G. D.; PRESTI, D. L. Maximizing asphalt recycling in road surface courses: The importance of a preliminary binder 
design. Bearing Capacity of Roads, Railways and Airfields: 10th International Conference on the Bearing Capacity of Roads, Railways and Airfields (BCRRA 2017), Athens, Greece, June 28-30, p. 1225-1233, 2017.

POROT, L.; BROERE, D.; WISTUBA, M.; GRÖNNIGER J. Asphalt and binder evaluation of asphalt mix with $70 \%$ reclaimed asphalt. Road Materials and Pavement Design, v. 18, sup2, p. 66-75, 2017.

POROT, L.; EDUARD, P. Addressing asphalt binder aging through the viscous to elastic transition. ISAP Symposium. Jackson Hole, Wyoming, 2016a.

POROT, L.; EDUARD, P. Laboratory evaluation of half warm recycling with bio-based additive. 6th Eurasphalt \& Eurobitume Congress, June, Prague, Czech Republic, $2016 \mathrm{~b}$.

POROT, L.; SCOTT, D.; GAUDEFROY, V. Laboratory evaluation of emissions from asphalt binder and mixes using a bio-rejuvenating agente. 6th Eurasphalt \& Eurobitume Congress, June, Prague, Czech Republic, 2016.

POROT, L.; SEVERANCE, R.; FELIPO, J.; LÓPEZ, J. Empleo de rejuvenecedores en reciclado de mezclas bituminosas. Asfalto Y Pavimentación, n. 14, v. 4, p. 39-49, 2014.

POROT, L; GRADY, W. Effectiveness of a bio-based additive to restore properties of aged asphalt binder. ISAP Symposium, Jackson Hole, Wyoming. 2016.

QIN. Q; SCHABRON, J.F; BOYSEN, R.B; FARRAR, M.J. Field aging effect on chemistry and rheology of asphalt binders and rheological predictions for field aging. Fuel, 121, p. 86-94, 2014.

RAUL, C. M. Avaliação a nível de ligantes da aplicabilidade de material fresado na execução de misturas asfálticas antirrefleção de trincas. Dissertação de Mestrado (Engenharia) - Escola Politécnica, Universidade de São Paulo, São Paulo, 2019.

ROBERTS, F. L.; KANDHAL, P. S.; BROWN, E. R.; LEE, D. Y.; KENNEDY, T. W. Hot mix asphalt materials, mixture design, and construction. NAPA Research and 
Education Foundation, 2009.

ROWE, G. M.; KING, G.; ANDERSON, M. The influence of binder rheology on the cracking of asphalt mixes in airport and highway projects. Journal of Testing and Evaluation, v. 42, n. 5, p. 1063-1072, 2014.

ROWE, G. Some thoughts on the historical development. Expert Task Group Asphalt mix \& Asphalt binder, 2016.

SADEK, H.; RAHAMAN, M. Z.; LEMKE, Z.; BAHIA, H. U.; SWIERTZ, D. Effect of lowtemperature modifiers on HMA mixture aging and cracking resistance. Construction and Building Materials, v. 237, p. 117456, 2020.

SHEN, J; AMIRKHANIAN, S; AUNE MILLER, J. Effects of rejuvenating agents on superpave mixtures containing reclaimed asphalt pavement. Journal of Materials in Civil Engineering, v. 19, n. 5, p. 376-384, 2007a.

SHEN, J; AMIRKHANIAN, S; TANG, B. Effects of rejuvenator on performance-based properties of rejuvenated asphalt binder and mixtures. Construction and Building Materials, v. 21, n. 5, p. 958-964, 2007b.

SIDDIQUI, M. N. NMR Fingerprinting of Chemical Changes in Asphalt Fractions on Oxidation. Petroleum Science and Technology, 28:4, 401-411, 2010.

SIDDIQUI, M. N.; ALI, M F. Investigation of chemical transformations by NMR and GPC during the laboratory aging of Arabian asphalt. Fuel, v. 78, n. 12, p. 1407-1416, 1999a.

SIDDIQUI, M. N.; ALI, M F. Studies on the aging behavior of the Arabian asphalts. Fuel, 78, p. 1005-1015, 1999b.

SILVA, L. S.; CAMARGO FORTE, M. M.; BARTOLOMEO, P.; FARCAS, F.; DURRIEU, F. Envelhecimento UV de ligantes asfálticos. TRANSPORTES, v13, n. 2, 2005.

SMITH, B. T.; HOWARD, I. L.; JORDAN III, W. S.; DARANGA, C.; BAUMGARDNER, G. L. Comparing Pressure Aging Vessel Time to Field Aging of Binder as a Function of Pavement Depth and Time. Transportation Research Record, 2018. 
TAKAHASHI, M. M.; VASCONCELOS, K. L.; BERNUCCI, L. L. B.; DONY, A.; COLIN, J.; BROSSEAUD, Y. Simulação do Envelhecimento de Curto Prazo Sofrido pelo Ligante Asfáltico Durante a Produção de Mistura Asfáltica Morna e Mistura Asfáltica a Quente. 21 ${ }^{\circ}$ Encontro de Asfalto, Rio de Janeiro. 2014.

TARSI, G.; VARVERI, A.; LANTIERI, C.; SCARPAS, A.; SANGIORGI, C. Effects of DifferentAging Methods on Chemical and Rheological Properties of Bitumen . Journal of Materials in Civil Engineering, 30(3), 04018009. 2018.

TAZIANI, E. A.; TORALDO, E.; CRISPINO, M.; GIUSTOZZI, F. Application of rejuvenators and virgin bitumen to restore physical and rheological properties of RAP binder. Australian Journal of Civil Engineering, v. 15, n. 2, p. 73-79, 2017.

TURNER, P; TAYLOR, A; TRAN, P. N. Laboratory evaluation of SYLVAROADTM RP 1000 rejuvenator. Final Report. National Center for Asphalt Technology. Aubum University. No NCAT, 2015.

USIRF, RGRA. Les enrobes bitumineux 1. 2001.

VILLEGAS-VILLEGAS, R. E.; BALDI-SEVILLA, A.; AGUIAR-MOYA, J. P.; LORIASALAZAR, L. Analysis of asphalt oxidation by means of accelerated testing and environmental conditions. Transportation Research Record, 0361198118777630. 2018.

WILLIS, R.; TRAN, N.H. Bringing Life Back to Aging Asphalt Binder, Asphalt Pavement Magazine, Vol. 20, No. 4, pp. 36-41, 2015.

WU, S.; PANG, L.; LIU, G.; ZHU, J. Laboratory study on ultraviolet radiation aging of bitumen. Journal of Materials in Civil Engineering, 22(8), p. 767-772, 2010.

WU, S.; PANG, L.; MO, L.; QIU, J.; ZHU, G.; XIAO, Y. UV and thermal aging of pure bitumen comparison between laboratory simulation and natural exposure aging. Road Materials and Pavement Design, p. 103-113. 2008.

WU, S.; ZHAO, Z.; XIAO, Y.; YI, M.; CHEN, Z.; LI, M. Evaluation of mechanical properties and aging index of 10 -year field aged asphalt materials. Construction and Building Materials, 155, p. 1158-1167, 2017. 
YAN, C.; HUANG, W.; TANG, N. Evaluation of the temperature effect on Rolling Thin Film Oven aging for polymer modified asphalt. Construction and Building Materials, v. 137, p. 485-493, 2017.

YU, X.; ZAUMANIS, M.; DOS SANTOS, S.; POULIKAKOS, L. D. Rheological, microscopic, and chemical characterization of the rejuvenating effect on asphalt binders. Fuel, v. 135, p. 162-171, 2014.

ZAUMANIS, M.; MALLICK, R. B.; FRANK, R. 100\% hot mix asphalt recycling: challenges and benefits. Transportation Research Procedia, 14, p. 3493-3502, 2016.

ZAUMANIS, M.; MALLICK, R. B.; FRANK, R. Evaluation of different recycling agents for restoring aged asphalt binder and performance of $100 \%$ recycled asphalt. Materials and Structures, v. 48, n. 8, p. 2475-2488, 2015.

ZAUMANIS, M.; MALLICK, R. B.; FRANK, R. Evaluation of rejuvenator's effectiveness with conventional mix testing for 100\% RAP mixtures. 92nd Annual Meeting of the Transportation of Research Board, Washington, D. C., USA, January, p. 13-17, 2013.

ZAUMANIS, M.; MALLICK, R. B.; POULIKAKOS, L.; FRANK, R. Influence of six rejuvenators on the performance properties of Reclaimed Asphalt Pavement (RAP) binder and $100 \%$ recycled asphalt mixtures. Construction and Building Materials, v. 71 , p. $538-550,2014$ a.

ZAUMANIS, M; MALLICK, R. B.; FRANK, R. Determining optimum rejuvenator dose for asphalt recycling based on Superpave performance grade specifications. Construction and Building Materials, v. 69, p. 159-166, 2014.

ZENG, W; WU, S; PANG, L; CHEN, H; HU, J; SUN, Y; CHEN, Z Research on Ultra Violet (UV) aging depth of asphalts. Construction and Building Materials, v 160, p. 620-627, 2018.

ZHANG, H.; CHEN, Z.; XU, G.; SHI, C. Evaluation of aging behaviors of asphalt binders through different rheological indices. Fuel, 221, p. 78-88, 2018. 
ZHANG, H.; XU, G.; CHEN, X.; WANG, R.; SHEN, K. Effect of long-term laboratory aging on rheological properties and cracking resistance of polymer-modified asphalt binders at intermediate and low temperature range. Construction and Building Materials, v. 226, p. 767-777, 2019.

ZHAO, K.; WANG, Y.; LI, F. Influence of ageing conditions on the chemical property changes of asphalt binders. Road Materials and Pavement Design, 2019. 